\title{
Analysis of CERK1 ectodomain shedding and the role of XLG2 in cerk1-4 cell death execution
}

\author{
Dissertation \\ zur Erlangung des mathematisch-naturwissenschaftlichen Doktorgrades \\ "Doctor rerum naturalium" \\ der Georg-August-Universität Göttingen \\ im Promotionsprogramm Biologie \\ der Georg-August University School of Science (GAUSS)
}

vorgelegt von

Christopher Meusel

aus Ankum

Göttingen, 2016 
Betreuungsausschuss

Prof. Dr. Volker Lipka

Zellbiologie der Pflanze

Albrecht-von-Haller Institut für Pflanzenwissenschaften

PD. Dr. Thomas Teichmann

Zellbiologie der Pflanze

Albrecht-von-Haller Institut für Pflanzenwissenschaften

Dr. Elena K. Petutschnig

Zellbiologie der Pflanze

Albrecht-von-Haller Institut für Pflanzenwissenschaften

Mitglieder der Prüfungskommission

Referent: Prof. Dr. Volker Lipka

Zellbiologie der Pflanze

Albrecht-von-Haller Institut für Pflanzenwissenschaften

Korreferent: PD. Dr. Thomas Teichmann

Zellbiologie der Pflanze

Albrecht-von-Haller Institut für Pflanzenwissenschaften

Weitere Mitglieder der Prüfungskommission:

Prof. Dr. Ivo Feußner

Biochemie der Pflanze,

Albrecht-von-Haller Institut für Pflanzenwissenschaften

PD Dr. Martin Fulda

Biochemie der Pflanze,

Albrecht-von-Haller Institut für Pflanzenwissenschaften

Prof. Dr. Christiane Gatz

Molekularbiologie und Physiologie der Pflanze,

Albrecht-von-Haller Institut für Pflanzenwissenschaften

Prof. Dr. Andrea Polle

Forstbotanik und Baumphysiologie,

Fakultät für Forstwissenschaften und Waldökologie

Tag der mündlichen Prüfung: 18.04.2016 



\section{Promovierenden-Erklärung der Georg-August-Universität Göttingen}

1. Die Gelegenheit zum vorliegenden Promotionsvorhaben ist mir nicht kommerziell vermittelt worden. Insbesondere habe ich keine Organisation eingeschaltet, die gegen Entgelt Betreuerinnen und Betreuer für die Anfertigung von Dissertationen sucht oder die mir obliegenden Pflichten hinsichtlich der Prüfungsleistungen für mich ganz oder teilweise erledigt.

2. Hilfe Dritter wurde bis jetzt und wird auch künftig nur in wissenschaftlich vertretbarem und prüfungsrechtlich zulässigem Ausmaß in Anspruch genommen. Insbesondere werden alle Teile der Dissertation selbst angefertigt; unzulässige fremde Hilfe habe ich dazu weder unentgeltlich noch entgeltlich entgegengenommen und werde dies auch zukünftig so halten.

3. Die Ordnung zur Sicherung der guten wissenschaftlichen Praxis an der Universität Göttingen wurde von mir beachtet.

4. Eine entsprechende Promotion wurde an keiner anderen Hochschule im In- oder Ausland beantragt; die eingereichte Dissertation oder Teile von ihr wurden nicht für ein anderes Promotionsvorhaben verwendet.

Mir ist bekannt, dass unrichtige Angaben die Zulassung zur Promotion ausschließen bzw. später zum Verfahrensabbruch oder zur Rücknahme des erlangten Grades führen. 



\section{Abstract}

Conserved microbial signatures are perceived via plasma membrane localized pattern recognition receptors (PRRs). In Arabidopsis, perception of the fungal cell wall component chitin requires the LysM receptor-like kinase CERK1. CERK1 is post-translationally modified to release a soluble ectodomain derivative into the apoplast. The ectodomain fragment is likely to be generated by a proteolytic mechanism called ectodomain shedding. Ectodomain shedding is well documented in animals, where it fulfils diverse regulatory functions on a range of different proteins. In plants, ectodomain shedding has so far only been reported for CERK1 and the function of CERK1 ectodomain shedding is unknown. Some evidence for a role in cell death control comes from cerk1-4, a CERK1 mutant that lacks the soluble ectodomain fragment and is characterized by enhanced cell death upon pathogen attack and in senescence.

The first part of the present study focused on the analysis of CERK1 ectodomain shedding and its function in the development of the cerk1-4 phenotype. Arabidopsis accessions were found to vary regarding the abundance of the shed CERK1 ectodomain. The presence of prolines within the extracellular stalk of CERK1 positively correlated with ectodomain abundance. CERK1 variants lacking specific proline residues showed reduced ectodomain abundance, but did not suppress the development of the cerk1-4 phenotype. Point mutations targeting possible protease recognition motifs or variations in extracellular stalk length did not abolish CERK1 ectodomain shedding. Similarly, replacement of the CERK1 transmembrane domain and extracellular stalk with corresponding regions from the flagellin receptor FLS2 had little impact on ectodomain shedding. In mass spectrometry analyses of cell culture supernatants and apoplastic wash fluids, peptides corresponding to extracellular domains of numerous RLKs were identified. The peptides probably derived from ectodomain which were proteolytically released into the apoplast. These results indicate that ectodomain shedding might be a common post-translational modification in plants.

The second part of this study focused on the identification of signal transduction components which are essential for development of the cerk1-4 phenotype. A novel mutant fully suppressing the cerk1-4 phenotype was isolated from a genetic screen. The underlying mutation was mapped to the extra-large G-protein 2 (XLG2), which has recently been proposed to act as a G-protein $\alpha$-subunit. In the suppressor mutant, a highly conserved glutamic acid was substituted by lysine in the N-terminal part of XLG2. Complementation studies showed that XLG2 fusions with an $\mathrm{N}$-terminal fluorescence protein tag are functional, 
while C-terminal fusions are not. Confocal microscopy of stably transformed Arabidopsis plants expressing Venus-XLG2 revealed localization to the cell periphery. A subpopulation of Venus-XLG2 accumulates in the nucleus upon diverse stimuli such as water and PAMP infiltration, wounding or pathogen attack. XLG2 has recently been shown to physically interact with canonical heterotrimeric G-protein $\beta y$-dimers. Also, G-protein $\beta$ - and $y$-subunits were shown to be required for full development of the cerk1-4 phenotype. Interestingly, in the G-protein $\beta$-subunit mutant agb1, a subpopulation of Venus-XLG2 was localized to the nucleus already in untreated cells. These results suggest that XLG2 subcellular localization is modulated by interaction with G-protein $\beta \gamma$-subunits, which in turn affects its action on downstream targets. 


\section{Zusammenfassung}

Konservierte mikrobielle Strukturen werden von Plasmamembran lokalisierten Rezeptoren erkannt. In Arabidopsis erfordert die Wahrnehmung der Pilzzellwand-Komponente Chitin die LysM Rezeptor-ähnliche Kinase CERK1. CERK1 wird post-translational modifiziert was die Freisetzung seiner Ektodomäne in den Apoplasten zur Folge hat. Die Freisetzung der Ektodomäne erfolgt wahrscheinlich durch so genanntes Ektodomänen-Shedding. Ektodomänen-Shedding ist ein in Tieren gut dokumentierter Mechanismus, wo es diverse regulatorische Funktionen für eine Reihe von verschiedenen Proteinen erfüllt. In Pflanzen wurde Ektodomänen-Shedding bisher nur für CERK1 beschrieben, wobei die Funktion unbekannt ist. Anzeichen für eine Rolle der CERK1 Ektodomäne in Zelltodkontrolle kommen von cerk1-4, einer CERK1 Mutante der das lösliche Ektodomänen Fragment fehlt.

Der erste Teil der vorliegenden Arbeit konzentrierte sich auf die Analyse von CERK1 Ektodomänen-Shedding und dessen Funktion in der Entwicklung des cerk1-4 Phänotyps. Die Abundanz der löslichen CERK1 Ektodomäne zwischen Arabidopsis Ökotypen variiert. Die Anwesenheit von Prolinen innerhalb des so genannten extrazellulären Stiels von CERK1 konnte positiv mit der Abundanz der Ektodomäne korreliert werden. CERK1 Varianten denen spezifische Proline fehlten zeigten reduzierte Ektodomänen Abundanz, konnten die Entwicklung des cerk1-4 Phänotyps jedoch nicht unterdrücken. Punktmutationen möglicher Protease-Erkennungsmotive oder Längenveriationen des extrazellulären Stiels konnten das Ektodomänen-Shedding nicht supprimieren. In ähnlicher Weise hatten der Austausch der CERK1 Transmembran-Domäne und des extrazellulären Stiels mit korrespondierenden Regionen des Flagellin-Rezeptors FLS2 nur geringe Auswirkungen auf das EktodomänenShedding von CERK1. Bei der massenspektrometrischen Analyse von Zellkulturen und apoplastischen Waschflüssigkeiten konnten Peptide identifiziert werden, die mit der extrazellulären Domäne zahlreicher Rezeptor-ähnlicher Kinasen korrespondierten. Die Peptide stammen wahrscheinlich von Ektodänen, die proteolytisch in den Apoplasten entlassen wurden. Diese Ergebnisse deuten an, dass Ektodomänen-Shedding eine verbreitete post-translationale Modifikation in Pflanzen sein könnte.

Der zweite Teil der Arbeit konzentrierte sich auf die Identifizierung von Signalübertragungskomponenten, die für die Entwicklung des cerk1-4 Phänotyps erforderlich sind. Eine neue Mutante, die den cerk1-4 Phänotypen vollständig unterdrückt wurde aus einem genetischen Screen isoliert. Die zugrunde liegende Mutation wurde in dem extra großen G-Protein 2 (XLG2) lokalisiert, das vor kurzem als G-Protein a-Untereinheit vorgeschlagen wurde. In der Suppressor-Mutante wurde eine hoch konservierte Glutaminsäure durch Lysin in dem N-terminalen Teil von XLG2 ersetzt. 
Komplementationsstudien zeigten, dass XLG2 Fusionen mit einem N-terminalen Fluoreszenz Protein-Tag funktionell sind, wohingegen C-terminale Fusionen es nicht sind. Konfokale Mikroskopie von stabil mit Venus-XLG2 transformierten Arabidopsis Pflanzen zeigten Lokalisierung an der Zellperipherie. Eine Subpopulation von Venus-XLG2 akkumuliert im Zellkern auf diverse Reize wie Wasser und PAMP Infiltration, Verletzung oder Pathogenbefall. Für XLG2 wurde vor kurzem die physische Interaktion mit kanonischen heterotrimeren G-Protein- $\beta$ y Dimeren nachgewiesen. Auch $\beta$ und y G-Proteinuntereinheiten wurden als erforderlich für die vollständige Entwicklung des cerk1-4 Phänotyps gezeigt. Interessanterweise war in der G-Protein $\beta$ Mutante agb1 eine Subpopulation von VenusXLG2 bereits in unbehandelten Zellen im Zellkern lokalisiert. Diese Ergebnisse legen nahe, dass die subzelluläre Lokalisierung von XLG2 durch Wechselwirkung mit G-Protein $\beta \gamma$ Untereinheiten moduliert wird, was wiederum seine Wirkung auf nachgeschaltete Ziele betrifft. 


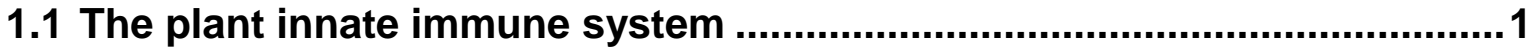

1.1.1 Pattern recognition receptors perceive conserved microbial structures ........... 3

1.1.1.1 Peptide ligands are perceived by LRR-proteins ............................ 4

1.1.1.2 LysM-proteins mediate perception of GlcNAc-containing oligosaccharides ............................................................... 5

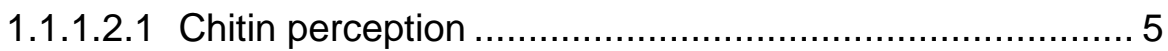

1.1.1.2.2 Peptidoglycan perception .......................................... 8

1.1.2 Heterotrimeric G-proteins act as molecular switches ................................. 9

1.1.2.1 The role of heterotrimeric G-proteins in plant immunity and cell death....................................................................... 11

1.1.2.2 Arabidopsis Extra-large G-Proteins (XLGs) are alternative $\mathrm{Ga}$ subunits.

\subsection{Ectodomain shedding and related proteolytic processes in}

metazoans

1.2.1 Well studied examples of ectodomain shedding in metazoans .................... 17

1.2.2 Ectodomain shedding of metazoan receptor kinases and their ligands.......... 20

1.2.3 Ectodomain shedding of plant receptor-like kinases.................................... 22

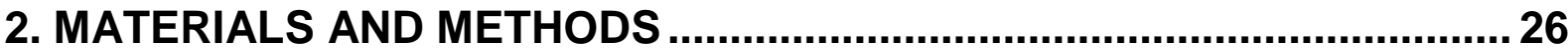

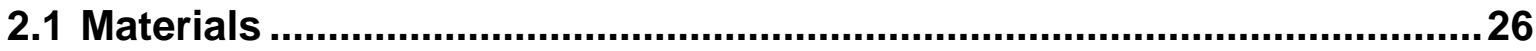

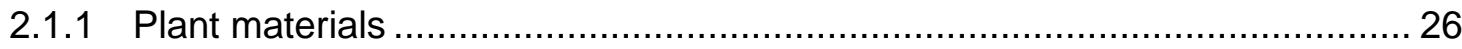

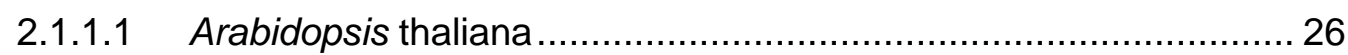

2.1.1.1 Nicotiana benthamiana............................................................ 29

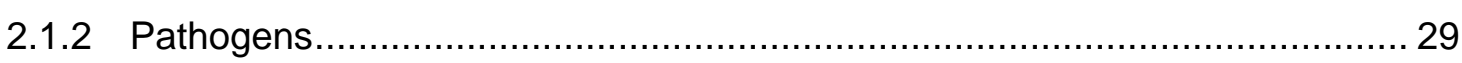

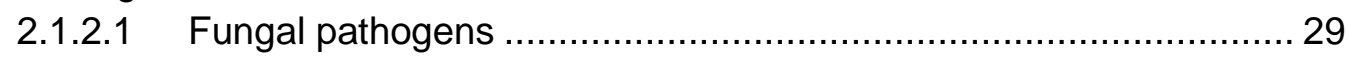

2.1.2.1.1 Powdery mildews ................................................... 29

2.1.3 Bacterial strains used for cloning and transformation ................................. 29

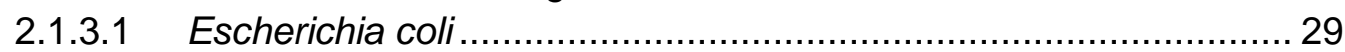

2.1.3.2 Agrobacterium tumefaciens................................................. 29

2.1.4 Yeast strains used for cloning and transformation ....................................... 29

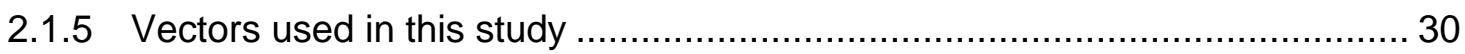




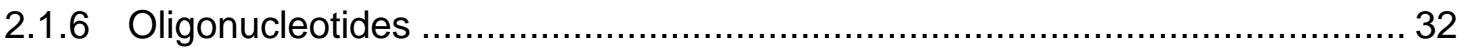

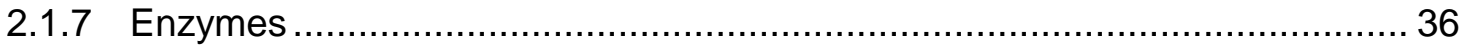

2.1.7.1 Restriction endonucleases ................................................. 36

2.1.7.2 Nucleic acid modifying enzymes ........................................... 36

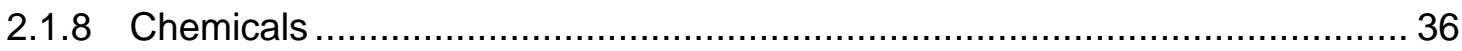

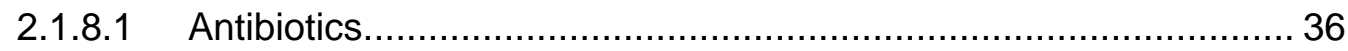

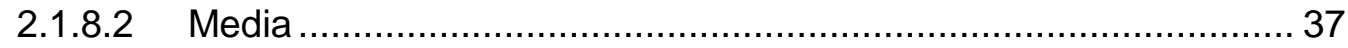

2.1.8.3 Buffers and solutions......................................................... 38

2.1.8.4 Antibodies .............................................................. 41

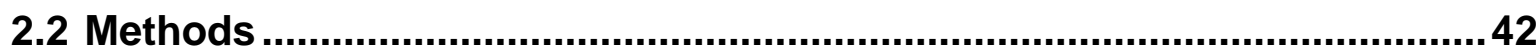

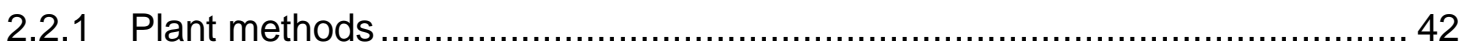

2.2.1.1 Plant cultivation .................................................................... 42

2.2.1.2 Crossing of Arabidopsis thaliana plants..................................... 43

2.2.1.3 Stable transformation of Arabidopsis thaliana (floral dip) .............. 43

2.2.1.4 Transient transformation of Nicotiana benthamiana ..................... 43

2.2.1.5 Selection of transgenic Arabidopsis plants on soil ........................ 44

2.2.1.6 In-vitro selection of transgenic Arabidopsis plants ....................... 44

2.2.1.7 Chitin treatment of Arabidopsis plants ......................................... 44

2.2.1.8 Cultivation and inoculation of Blumeria graminis f.sp. hordei........ 44

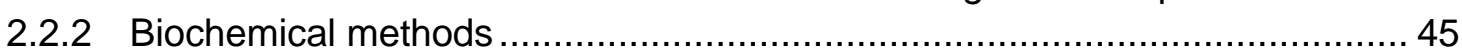

2.2.2.1 Protein extraction .............................................................. 45

2.2.2.1.1 Standard preparation of total protein extracts ............... 45

2.2.2.1.2 Preparation of total protein extracts with SDS .............. 45

2.2.2.2 Chitin pull-down................................................................ 46

2.2.2.3 Microsomal preparation ...................................................... 46

2.2.2.4 Determination of protein concentration by the Bradford method .... 47

2.2.2.5 SDS-polyacrylamide gel electrophoresis (SDS-PAGE) ................. 47

2.2.2.6 Immunoblotting............................................................ 47

2.2.2.7 Coomassie staining of PVDF membranes ................................ 48

2.2.2.8 Mass spectrometry analysis ............................................... 49

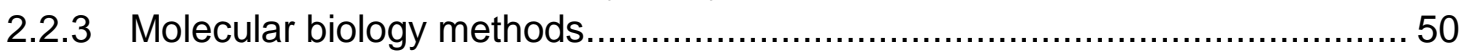

2.2.3.1 Preparation of genomic DNA from Arabidopsis leaves ................. 50

2.2.3.2 Preparation of total RNA from Arabidopsis leaves ....................... 51

2.2.3.3 Plasmid preparation from E.coli............................................... 51

2.2.3.4 Plasmid preparation from S. cerevisiae .................................... 51

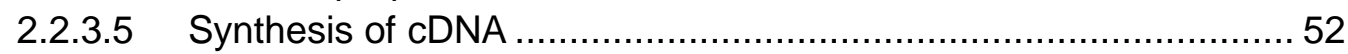

2.2.3.6 Polymerase chain reaction (PCR) .......................................... 52

2.2.3.7 Semi-quantitive reverse transcription-polymerase chain reaction

(RT-PCR) ................................................................. 53

2.2.3.8 Agarose gel electrophoresis ................................................. 53

2.2.3.9 DNA purification from agarose gels .......................................... 53

2.2.3.10 Measurement of DNA and RNA concentration .......................... 53

2.2.3.11 Restriction endonuclease digestion of DNA ............................... 54

2.2.3.12 Ligation of DNA fragments .................................................. 54

2.2.3.13 Cloning by homologous recombination in S. cerevisae................. 54

2.2.3.14 DNA sequencing and analysis................................................ 55 
2.2.3.15 Preparation of chemically competent E.coli cells ......................... 55

2.2.3.16 Transformation of chemically competent E.coli cells .................... 55

2.2.3.17 Preparation of electro-competent $A$. tumefaciens cells ................. 56

2.2.3.18 Transformation of electro-competent $A$. tumefaciens cells ............ 56

2.2.3.19 Preparation of chemically competent $S$. cerevisiae cells .............. 56

2.2.3.20 Transformation of chemically competent $S$. cerevisiae cells ..........57

2.2.4 Confocal laser scanning microscopy (CLSM) ......................................... 57

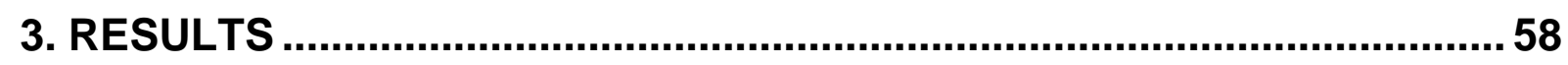

3.1 Analysis of CERK1 ectodomain shedding............................................59

3.1.1 Investigation of CERK1 ectodomain shedding in Arabidopsis thaliana

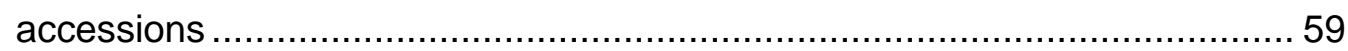

3.1.2 Mutational analysis of potential CERK1 protease cleavage motifs ................62 62

3.1.3 The cvg1 mutation does not suppress the cerk1-4 phenotype .......................66

3.1.4 Variation of the CERK1 extracellular stalk length ...................................... 71

3.1.5 CERK1-FLS2 domain swap experiments .............................................. 73

3.1.6 CERK1 and FLS2 extracellular stalk harbor a KS motif...............................76

3.1.7 The extracellular domains of many receptor-like kinases can be found in supernatants of cell cultures................................................................ 78

3.1.8 CERK1 ectodomain shedding is not altered in sphingolipid mutants ............. 84

\subsection{Extra-Large G-protein 2 (XLG2) plays a key role in cerk1-4 cell death} execution

3.2.2 Characterization of cerk1-4 suppressor mutants ..................................... 86

3.2.3 A single amino acid exchange in XLG2 (E293K) suppresses the cerk1-4

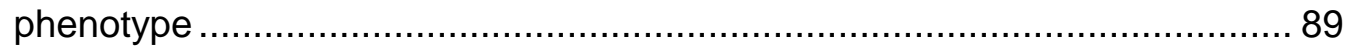

3.2.4 Localization studies with XLG2-GFP fusion protein ................................. 93

3.2.4.1 XLG2-GFP and xlg2-E293K-GFP are located to the nucleus and cell periphery in $\mathrm{N}$. benthamiana ............................................ 93

3.2.4.2 XLG2-GFP localizes to the cell periphery in unchallenged Arabidopsis plants and accumulates in the nucleus upon stress ... 94

3.2.4.3 C-terminal XLG2-GFP fusions are not functional ....................... 96

3.2.5 Localization studies with Venus-XLG2 .................................................. 97

3.2.5.1 Venus-XLG2 localizes to the nucleus, cytoplasm and plasma membrane in Nicotiana benthamiana.

3.2.5.2 N-terminal XLG2 fusions are functional and restore the cerk1-4 phenotype in nole1-1 plants

3.2.5.3 Venus-XLG2 localises to the cell periphery in unchallenged Arabidopsis plants and accumulates in the nucleus upon stress 100

3.2.5.4 XLG2 is localized to the nucleus in Bgh attacked and surrounding cells 108 
4.1 Analysis of CERK1 ectodomain shedding

4.1.1 Prolines within the extracellular stalk of CERK1 modulate the abundance of the CERK1 ectodomain fragment

4.1.2 Reduced abundance of the CERK1 ectodomain cannot suppress the cerk1-4 phenotype

4.1.3 CERK1 ectodomain shedding cannot be suppressed by mutating potential protease cleavage motifs

4.1.4 Reduction of extracellular stalk length cannot suppress CERK1 ectodomain shedding

4.1.5 The CERK1 extracellular stalk and transmembrane domain are not critical for ectodomain shedding

4.1.6 The extracellular domain of many RLKs is proteolytically processed........... 117

4.1.7 Possible function of CERK1 ectodomain shedding ................................... 119

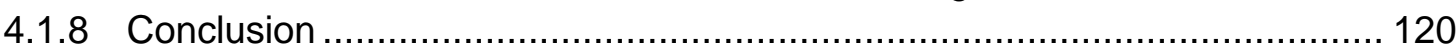

4.1 .9 Outlook ..................................................................................... 120

4.2 Analysis of nole1-2 and XLG2 subcellular localization ..........................121

4.2.1 XLG2 is a key regulator of cerk1-4 cell death execution ............................ 121

4.2.2 XLG2 localization is stimulus dependent .............................................. 122

4.2.3 XLG2 localization in Bgh-infected cerk1-4 plants does not differ from wild

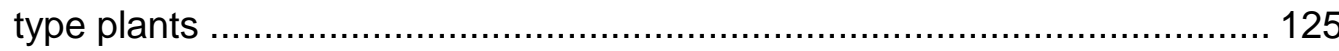

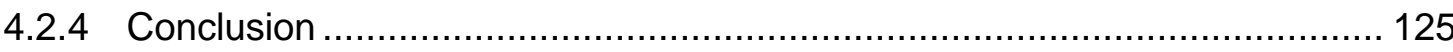

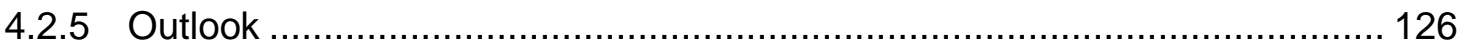

5. REFERENCES …........................................................................ 128

6. SUPPLEMENTAL MATERIAL .......................................................... 149

LIST OF TABLES.................................................................................. 157

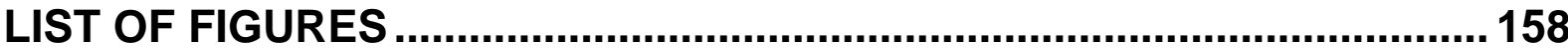

LIST OF SUPPLEMENTAL TABLES ..................................................... 161

LIST OF SUPPLEMENTAL FIGURES .................................................... 162

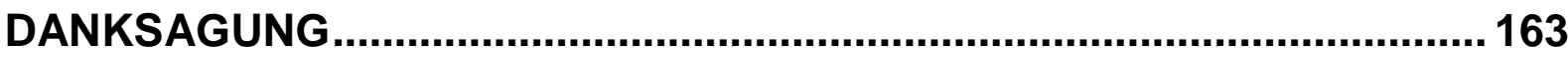

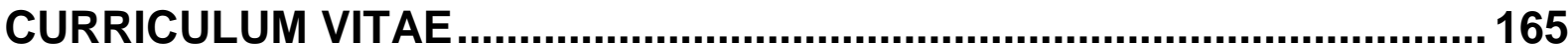




\section{Table of abbreviations}

$$
::
$$

7TM

ADAM

AGB1

AGG

AP

APP

A. thaliana

A. tumefaciens

APS

AWF

BAK1

$B g h$

BIK1

BKK1

BRI1

bp

${ }^{\circ} \mathrm{C}$

$\mathrm{C}$

cDNA

CEBiP

CERK1

CLSM

CPD

d

dCAPS

ddH2O

DAMP

DMSO

DNA

dNTP

DSL

DTT

E. coli

EDTA

EFR

EF-Tu

EGF

EGFR fused to (gene fusions)

seven transmembrane

A DESINTEGRIN AND

METALLOPROTEINASE

ARABIDOPSIS G-PROTEIN

BETA-SUBUNIT 1

ARABIDOPSIS G-PROTEIN

GAMMA-SUBUNIT

Alkaline phosphatase

AMYLOID PRECURSOR

PROTEIN

Arabidopsis thaliana

Agrobacterium tumefaciens

ammoniumpersulfat

apoplastic wash fluid

BRASSINOSTEROID

INSENSITIVE1-ASSOCIATED

RECEPTOR KINASE1

Blumeria graminis forma

specialis hordei

BOTRYTIS-INDUCED

KINASE1

BAK1-LIKE 1

BRASSINOSTEROID

INSENSITIVE1

base pair(s)

degree Celsius

carboxy terminal

complementary DNA

CHITIN ELICITOR-BINDING

PROTEIN

CHITIN ELICITOR

RECEPTOR KINASE1

confocal laser

scanning microscopy

chitin pull-down

days

derived cleaved amplified

polymorphic sequence

double deionised water

damage-associated

molecular pattern

dimethylsulfoxide

deoxyribonucleic acid

deoxynucleosidetriphosphate

Delta/Serrate/LAG-2

dithiothreitol

Escherichia coli

ethylenediaminetetraacetic

acid

EF-TU RECEPTOR

ELONGATION FACTOR

THERMO UNSTABLE

EPIDERMAL GROWTH

FACTOR

EPIDERMAL GROWTH

FACTOR RECEPTOR
Eph

ES

et al.

ETI

$\mathrm{EtOH}$

ETS

FLS2

$\mathrm{g}$

$\mathrm{xg}$

GAP

gDNA

GDP

GEF

GTP

GFP

GPA1

GPI

GPCR

h

HB-EGF

iCLIP

ICD

$\mathrm{kb}$

$\mathrm{kDa}$

I

LD

LRR

LysM

$M$

MAMP

MLD

MMP

$\mu$

$\min$

$\mathrm{mM}$

$\mathrm{N}$

$\mathrm{NADPH}$

$N$. benthamiana

NES

NLS

PAMP

PCR

PAGE

PDF1.2 erythropoietin-producing

hepatoma

extracellular stalk

Et alii; and others

effector triggered immunity

ethanol

effector triggered

susceptibility

FLAGELLIN SENSING 2

gram

times gravity

GTPase activating protein

genomic DNA

guanosine diphosphate

guanine nucleotide

exchange factor

guanosine triphosphate

green fluorescent protein

ARABIDOPSIS G-PROTEIN

ALPHA SUBUNIT 1

glycosylphosphatidylinositol

G-PROTEIN COUPLED

RECEPTOR

hour(s)

heparin-binding EGF-like

growth factor

intramembrane-cleaving

protease

Intracellular domain

kilobase(s)

kiloDalton(s)

litre

long-day

leucine-rich repeats

lysin motif

molar (mol/L)

microbe-associated

molecular pattern

malectin-like domain

MATRIX

METALLOPROTEINASE

micro

minute(s)

millimolar

amino-terminal

nicotinamide adenine

dinucleotide phosphate

Nicotiana benthamiana

nuclear export signal

nuclear localization signal

pathogen-associated

molecular pattern

polymerase chain reaction

polyacrylamide gel-

electrophoresis

PLANT DEFENSIN 1.2 


\begin{tabular}{|c|c|c|c|}
\hline PDGF & platelet-derived growth factor & XLG & EXTRA-LARGE \\
\hline PGN & peptidoglycan & & G-PROTEIN \\
\hline $\mathrm{pH}$ & $\begin{array}{l}\text { negative decimal logarithm of } \\
\text { the } \mathrm{H}+\text { concentration }\end{array}$ & & \\
\hline PM & plasma membrane & & \\
\hline \multirow[t]{2}{*}{ PR1 } & PATHOGENESIS & & \\
\hline & RELATED 1 & & \\
\hline PRR & pattern recognition receptor & & \\
\hline PTI & PAMP-triggered immunity & & \\
\hline PVDF & polyvinylidene fluoride & & \\
\hline $\mathrm{R}$ & resistance & & \\
\hline \multirow[t]{2}{*}{ RGS } & REGULATOR OF G- & & \\
\hline & PROTEIN SIGNALING & & \\
\hline \multirow[t]{2}{*}{ RHOBD } & RESPIRATORY BURST & & \\
\hline & OXIDASE-D & & \\
\hline RIP & $\begin{array}{l}\text { regulated intramembrane } \\
\text { proteolysis }\end{array}$ & & \\
\hline \multirow[t]{2}{*}{ RLCK } & receptor-like cytoplasmic & & \\
\hline & kinase & & \\
\hline RLK & receptor-like kinase & & \\
\hline RLP & receptor-like protein & & \\
\hline RNA & ribonucleic acid & & \\
\hline ROS & reactive oxygen species & & \\
\hline rpm & rounds per minute & & \\
\hline RSK & receptor serine kinase & & \\
\hline RT & room temperature & & \\
\hline RTK & receptor tyrosine kinase & & \\
\hline RT-PCR & $\begin{array}{l}\text { reverse transcription- } \\
\text { polymerase chain reaction }\end{array}$ & & \\
\hline S & second $(s)$ & & \\
\hline SA & salicylic acid & & \\
\hline S. cerevisiae & Saccharomyces cerevisiae & & \\
\hline SD & short-day & & \\
\hline SDS & sodium dodecyl sulphate & & \\
\hline $\mathrm{sec}$ & second(s) & & \\
\hline \multirow[t]{2}{*}{ SNP } & single nucleotide & & \\
\hline & polymorphism & & \\
\hline SOBIR & SUPPRESSOR OF BIR1-1 & & \\
\hline SP & signal peptide & & \\
\hline \multirow[t]{2}{*}{ SYMRK } & SYMBIOSIS RECEPTOR- & & \\
\hline & LIKE KINASE & & \\
\hline TBS & Tris buffered saline & & \\
\hline $\mathrm{T} \beta \mathrm{R} I$ & $\begin{array}{l}\text { transforming growth factor } \\
\text { beta receptor type I }\end{array}$ & & \\
\hline T-DNA & transfer DNA & & \\
\hline \multirow[t]{2}{*}{ TEMED } & N,N,N',N'-tetramethylethane- & & \\
\hline & 1,2-diamine & & \\
\hline TE & total extract & & \\
\hline TGF & transforming growth factor & & \\
\hline TM & transmembrane domain & & \\
\hline TMK & TRANSMEMBRANE KINASE & & \\
\hline Tris & $\begin{array}{l}\text { Tris-(hydroxymethyl)- } \\
\text { aminomethane }\end{array}$ & & \\
\hline TTSS & type III secretion system & & \\
\hline U & unit & & \\
\hline $\mathrm{v} / \mathrm{v}$ & volume per volume & & \\
\hline WT & wild type & & \\
\hline$w / v$ & weight per volume & & \\
\hline \multirow[t]{2}{*}{ XA21 } & XANTHOMONAS & & \\
\hline & RESISTANCE 21 & & \\
\hline
\end{tabular}




\section{Introduction}

Plants are in a constant battle against a variety of abiotic and biotic stresses. As sessile organisms, they cannot simply evade unfavorable conditions, but have to respond to the continuously changing environmental cues they are confronted with. In contrast to animals, plants do not possess mobile immune cells which are activated upon pathogen attack. Instead, they have developed a multi-layered innate immune system. Every plant cell is equipped with a set of receptor and defense proteins to detect pathogens and initiate defense responses (Dodds \& Rathjen, 2010). This system is highly effective with disease being the exception and not the rule (Jones \& Dangl, 2006).

The first layer of defense responses is initiated upon perception of conserved pathogenassociated molecular patterns (PAMPs) by pattern recognition receptors (PRRs) on the cell surface (Zipfel, 2014). PAMPs are molecules that are conserved among a whole class of pathogens and often derived from structural or motility components, like the cell wall or flagella (Newman et al., 2013). The activation of PRRs leads to the induction of a wide range of signaling and defense responses which result in PAMP-triggered immunity (PTI). These defense responses together with preformed barriers are sufficient to stop the progression of a broad spectrum of non-adapted pathogens. This process is also known as non-host resistance (Nürnberger \& Lipka, 2005). Adapted pathogens developed specialized effector proteins which are able to suppress PTI leading to effector triggered susceptibility (ETS) (Jones \& Dangl, 2006). Plants in turn developed mechanisms to recognize these effectors, thereby mounting a second layer of defense, which is called effector triggered immunity (ETI) (Jones \& Dangl, 2006).

\subsection{The plant innate immune system}

Once a pathogen arrives on the plant surface, it is confronted with a variety of preformed obstacles, like the cell wall, anti-microbial substances and a waxy cuticle (Nürnberger \& Lipka, 2005). Pathogens which are able to overcome these barriers are then challenged by an efficient two-layered immune system (Dodds \& Rathjen, 2010). Perception of microbial signatures on the cell surface by pattern recognition receptors (PRRs) activates the first layer called PAMP-triggered immunity (PTI, Figure 1, step 1). Microbial signatures, also referred to as pathogen associated molecular pattern (PAMPs) are molecules which are highly conserved among a class of pathogens and are absent from the host. To date, many PAMPs 
of different classes of pathogens and their cognate receptors have been identified. Well studied examples in Arabidopsis thaliana include the perception of the bacterial PAMPs flagellin and elongation factor thermo unstable (EF-Tu) by the PRRs FLAGELLIN SENSING 2 (FLS2) and EF-Tu receptor (EFR), respectively (Gómez-Gómez \& Boller, 2000; Zipfel et al., 2006). The perception of chitin derived from fungal cell walls by the CHITIN ELICITOR RECEPTOR KINASE 1 (CERK1) is another well established example of PAMP perception (Miya et al., 2007). Plants also possess PRRs to perceive self-molecules, which are released from damaged plant structures (Boller \& Felix, 2009). These molecules are referred to as

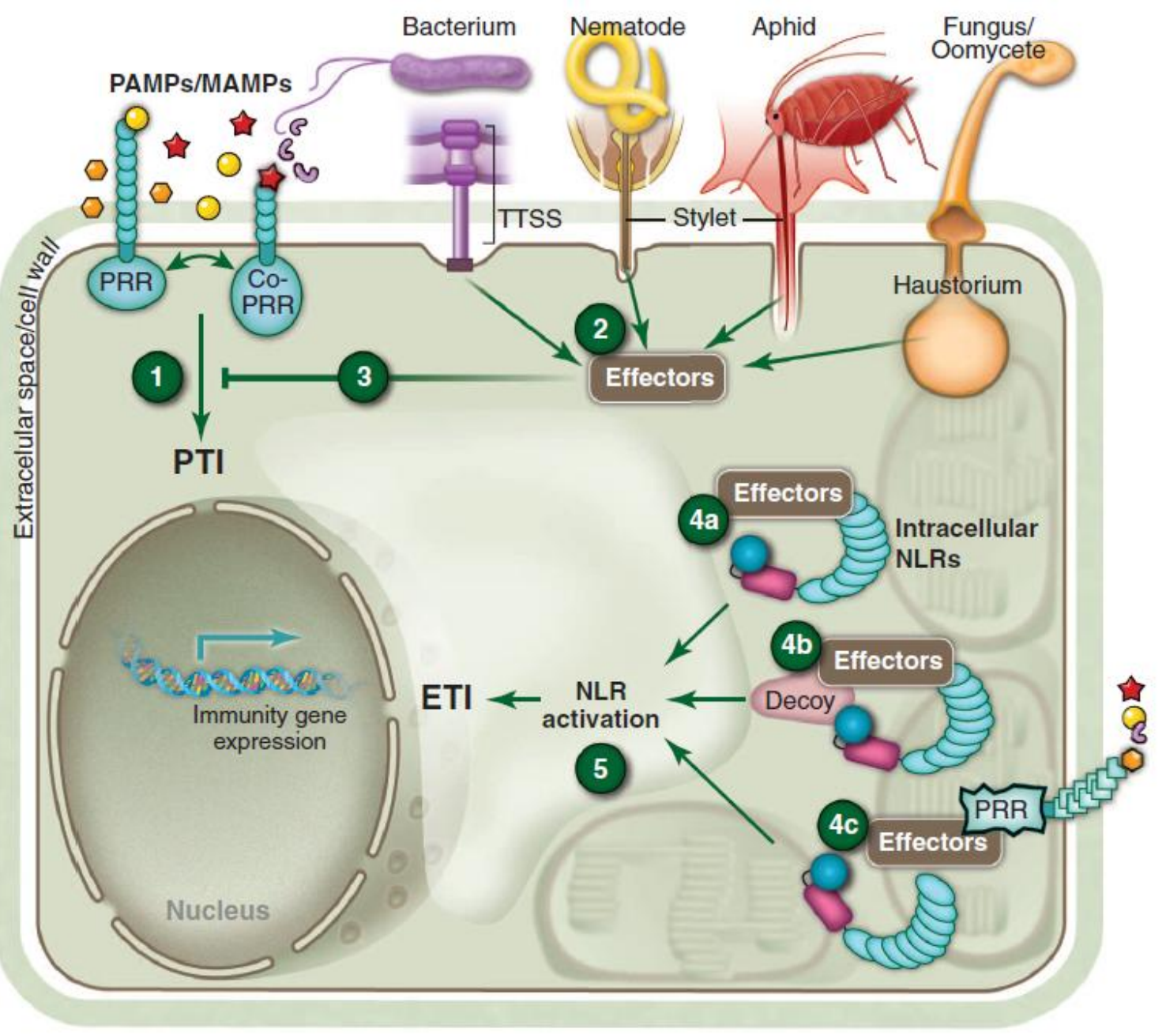

Figure 1. The plant immune system. Pathogen associated molecular patterns (PAMPs) are perceived by pattern recognition receptors at the cell surface. Signaling initiated by pattern recognition receptors leads to the onset of PAMP-triggered immunity (PTI) (1). Pathogens developed effector molecules (2) of which some are delivered into the cell to block PTI responses (3), leading to effector triggered susceptibility (ETS). Plants developed Resistance proteins (R-proteins) to cope with pathogen effector molecules. R-proteins either detect effectors by direct interaction with the effector molecules (4a) or sense the activity of effectors on other host proteins. This can be achieved by monitoring the integrity of a decoy protein, which resembles an effector target (4b) or by guarding the integrity of an effector target protein (4c). Perception of effector activity by an R-protein leads to the induction of effector triggered immunity (ETI) (5). Image from Dangl et al. (2013). 
damage-associated molecular patterns (DAMPs). Characteristic PAMP (and DAMP) responses involve generation of reactive oxygen species (ROS), activation of mitogen activated protein (MAP) kinase cascades and induction of defense related genes (Dodds \& Rathjen, 2010). The mechanisms of PTI are sufficient to establish resistance against most pathogens and, together with pre-formed physical barriers and toxins, are the basis of nonhost resistance (Nürnberger \& Lipka, 2005).

In order to establish a compatible interaction with the host plant, adapted pathogens developed effector molecules to prevent or inhibit PTI initiation (Jones \& Dangl, 2006). Fungal pathogens and oomycetes secrete effector proteins into the apoplast (not shown) or deliver them into the host cell by a not yet identified mechanism (Lo Presti et al., 2015), while bacterial pathogens use a type III secretion system (TTSS) to transport effector proteins into the host cell (Figure 1, step 2) (Hueck, 1998; Lo Presti et al., 2015). Effector proteins can suppress PTI responses or prevent recognition of the pathogen by the host, resulting in effector-triggered susceptibility (ETS) (Figure 1, step 3). To detect effector protein activity and halt further pathogen ingress, plants have developed intracellular Resistance (R) proteins. Most R-proteins are NB-LRR proteins and contain a nucleotide-binding site (NB) and a leucine-rich repeat (LRR) domain. They may recognize the activity of intracellular effectors either directly or indirectly (Figure 1, step 4) (Spoel \& Dong, 2012). Direct recognition occurs via binding of an effector to an R-protein, but is a rather uncommon mechanism. Indirect recognition is explained by the guard model, where R-proteins monitor the integrity of effector target proteins (van der Hoorn \& Kamoun, 2008). Detection of target protein modifications, like phosphorylation or degradation, leads to the activation of the Rprotein, resulting in effector triggered immunity (ETI) within the host plant (Axtell \& Staskawicz, 2003; Liu et al., 2011) (Figure 1, step 5). ETI is a strong defense response which typically results in a hypersensitive response leading to cell death of the infected tissue (Spoel \& Dong, 2012).

\subsubsection{Pattern recognition receptors perceive conserved microbial structures}

Recognition of conserved microbial structures (PAMPs) is mediated by PRRs and takes place at the cell surface. PRRs are membrane localized proteins and contain extracellular ligand-binding domains. There are two kinds of PRRs: Receptor-like kinases (RLKs) contain a transmembrane domain and an intracellular kinase domain (Trdá et al., 2015). Receptorlike proteins (RLPs) lack an intracellular kinase domain and are often linked to the extracellular leaflet of the plasma membrane via glycosylphosphatidylinositol (GPI) anchors (Zipfel, 2014). 
Perception of peptide-based PAMPs like bacterial flagellin or EF-Tu is mediated by PRRs containing leucine-rich repeats (LRRs) within their extracellular domain (Chinchilla et al., 2006; Zipfel et al., 2006). Carbohydrate PAMPs that contain $\mathrm{N}$-acetylglucosamine moieties, such as fungal chitin or bacterial peptidoglycan, are perceived by lysin motif (LysM) containing receptors (Kaku et al., 2006; Kaku \& Shibuya, 2011; Miya et al., 2007; Willmann et al., 2011).

Plant PRRs are often organized in multiprotein complexes, which contain components in addition to the PRR, such as co-receptors and receptor-like cytoplasmic kinases (RLCKs) to ensure proper and specific signaling (Macho \& Zipfel, 2014).

\subsubsection{Peptide ligands are perceived by LRR-proteins}

LRR receptor-like kinases (LRR-RLKs) are the largest group of RLKs in Arabidopsis (Shiu \& Bleecker, 2001). Several of them have been identified as receptors of peptide ligands involved in growth, development or defence. One of the most prominent members of this group is FLAGELLIN-SENSITIVE 2 (FLS2) which was the first PRR identified in Arabidopsis (Chinchilla et al., 2006; Gómez-Gómez \& Boller, 2000; Zipfel et al., 2004). FLS2 harbors 28 extracellular leucine-rich repeats (LRRs) which can bind a conserved 22 amino-acid epitope (flg22) of flagellin, the building block of bacterial flagella (Chinchilla et al., 2006). Flagellin perception by FLS2 is an essential part of defense against bacterial pathogens, as fls2 mutants are severely impaired in resistance against avirulent and virulent Pseudomonas syringae pv. tomato strains (Zipfel et al., 2004). Orthologs of AtFLS2 can be found in genomes of many higher plants, such as tomato (Robatzek et al., 2007), Nicotiana benthamiana (Hann \& Rathjen, 2007) and rice (Takai et al., 2008).

Another well studied member of the group of LRR-RLKs is the Arabidopsis ELONGATION FACTOR-TU RECEPTOR (EFR). The extracellular domain of EFR containing 21 LRR motifs binds an 18 amino acid N-terminal peptide (elf18) of the bacterial elongation factor Tu (EFTu) (Kunze et al., 2004; Zipfel et al., 2006). Similar to FLS2, EFR is a crucial part of the defense system against bacterial pathogens, as efr plants are more susceptible to Agrobacterium transformation (Zipfel et al., 2006). Upon ligand binding, both FLS2 and EFR1 form a complex with the BRI1-ASSOCIATED RECEPTOR KINASE 1 (BAK1) which was shown to act as a co-receptor for a variety of LRR-RLKs and LRR-RLPs (Chinchilla et al., 2007; Heese et al., 2007; Liebrand et al., 2014; Roux et al., 2011; Schulze et al., 2010). BAK1, also known as SOMATIC EMBRYOGENIC RECEPTOR KINASE 3 (SERK3), is a LRR-RLK and was discovered as a positive regulator of Brassinosteroid signaling (Li et al., 2002). Heterodimerization of FLS2 or EFR with BAK1 followed by transphosphorylation 
events is a prerequisite for proper defense signaling and bak1 mutant plants exhibit severely reduced defense responses to flg22 and elf18 treatment (Chinchilla et al., 2007; Roux et al., 2011; Schwessinger et al., 2011). FLS2 and EFR do not only associate with BAK1, but also with receptor-like cytoplasmic kinases (RLCKs). RLCKs possess kinase domains similar to RLKs, but lack extracellular and transmembrane domains (Shiu \& Bleecker, 2001). Upon flg22 or elf18 perception, the RLCK BOTRYTIS-INDUCED KINASE1 (BIK1) is phosphorylated by BAK1 and subsequently phosphorylates BAK1 and FLS2 (Lu et al., 2010). BIK1 also mediates flg22- and elf18- triggered ROS production by phosphorylating the NADPH oxidase RHOBD (Kadota et al., 2014; Lu et al., 2010; Zhang et al., 2010). Apart from PAMP perception and signaling, BAK1 and the closely related RLK BKK1 were also shown to be negative regulators of cell death. Upon inoculation with different pathogens, bak1 plants exhibit enhanced cell death (Kemmerling et al., 2007). Double mutant bak1 bkk1 plants show an even more severe phenotype and do not survive seedling stage ( $\mathrm{He}$ et al., 2007).

\subsubsection{LysM-proteins mediate perception of GIcNAc-containing oligosaccharides}

Lysin motif (LysM) containing proteins can be found in almost all living organisms (Buist et al., 2008). The lysin motif was discovered in bacteriophage lysozymes that degrade bacterial cell walls during the lytic cycle (Garvey et al., 1986). In plants, LysM domain containing receptor-like kinases (LysM-RLKs) and receptor-like proteins (LysM-RLPs) mediate the perception of $\mathrm{N}$-acetyl-D-glucosamine (GlcNAc) containing carbohydrate molecules such as chitin and peptidglycan, as well as Nod- and Myc-factors. They play important roles in establishment of symbiosis and defense (Antolín-Llovera et al., 2012). The following part will focus on the roles of LysM-proteins in defense responses.

\subsection{Chitin perception}

Chitin is one of the main constituents of the fungal cell wall and the second most abundant naturally occurring biopolymer after cellulose. It is a polymer consisting of $\beta-1-4$ linked monomers of N-Acetyl-D-glucosamine (GlcNAc) (Muzzarelli, 1977). Plant-derived chitinases are able to degrade the fungal cell wall, thereby releasing chitin fragments (chitooligosaccharides) which can serve as a PAMP and be perceived by plants (Eckardt, 2008). Chitin perception and signaling has been the subject of extensive research in rice and Arabidopsis (Gust et al., 2012). In rice, two LysM motif containing proteins have been found 
to be indispensable for chitin signaling (Kaku et al., 2006; Shimizu et al., 2010). The LysMRLP CHITIN ELICITOR-BINDING PROTEIN (OsCEBiP) consists of three extracellular LysM domains, a transmembrane domain and was the first identified PRR to have chitin binding ability (Hayafune et al., 2014; Kaku et al., 2006). As OsCEBiP lacks an intracellular domain, it requires interaction with additional proteins for proper signal transduction. The LysM-RLK CHITIN ELICTITOR RECEPTOR-LIKE KINASE (OsCERK1) was found to form a heteromeric complex with OsCERK1 upon chitin perception (Shimizu et al., 2010). As OsCERK1 has no chitin binding ability, it seems to be functionally important for signal transduction via its intracellular kinase domain (Shinya et al., 2012). Knockout analyses confirmed that both, OsCEBIP and OsCERK1 are essential factors of rice chitin signaling and pathogen resistance. Chitin-induced generation of reactive oxygen species and transcriptional reprogramming are markedly impaired in oscebip and completely abolished in oscerk1 mutants. Furthermore, both mutants showed reduced resistance against the rice blast fungus Magnaporthe oryzae (Kouzai et al., 2014b; Kouzai et al., 2014a).

The ectodomains of OsCEBIP and OsCERK1 are believed to form a sandwich-like tetrameric receptor complex for chitin perception and signaling (Hayafune et al., 2014; Shimizu et al., 2010). In this model, two OsCEBIP proteins bind opposing $\mathrm{N}$-acetyl moieties of a chitin oligosaccharide, forming a homodimer, thereby inducing the dimerization of closely associated OsCERK1 (Figure 2a) (Hayafune et al., 2014).

In addition to OsCEBIP, the two LysM-RLPs LYP4 and LYP6 were found to contribute to chitin perception in rice (Liu et al., 2012a). They were reported to heterodimerize with OsCERK1 upon chitin binding and induce defense responses (Ao et al., 2014). In agreement with that, knock-down of either LYP4 or LYP6 resulted in impaired chitin-induced defense gene expression and ROS production and enhanced susceptibility against bacterial and fungal pathogens (Liu et al., 2012a). Interestingly, LYM2, the Arabidopsis homolog of OsCEBiP, has also chitin binding ability, but is not involved in canonical chitin signaling (Shinya et al., 2012; Wan et al., 2012). However, it was shown to regulate changes in plasmodesmata flux upon chitin treatment (Faulkner et al., 2013; Shinya et al., 2012; Wan et al., 2012).

In Arabidopsis, CHITIN ELECITOR RECEPTOR-LIKE KINASE (AtCERK1/AtLysMRLK1/AtLYK1), an ortholog of OsCERK1, was identified as an essential component of chitin signaling (Kaku et al., 2006; Miya et al., 2007). CERK1 T-DNA knockout mutants such as cerk1-2, are completely insensitive to chitin (Miya et al., 2007; Wan et al., 2008). Upon chitin treatment, cerk1-2 plants do not generate reactive oxygen species, activate MAP kinase cascades or show induction of chitin responsive genes. In contrast to OsCERK1, direct chitin binding activity was shown for CERK1, pointing to possible differences between the chitin 


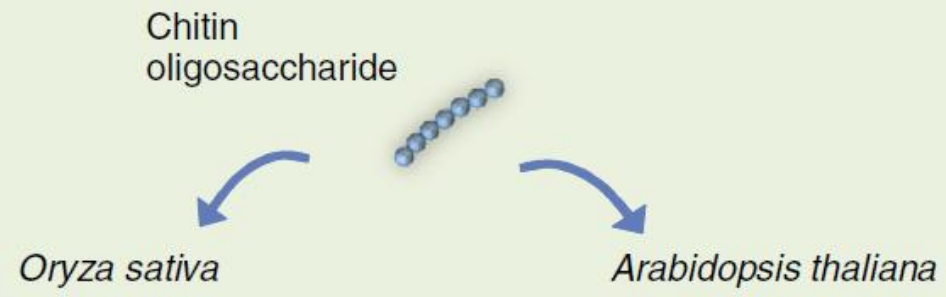

(a)

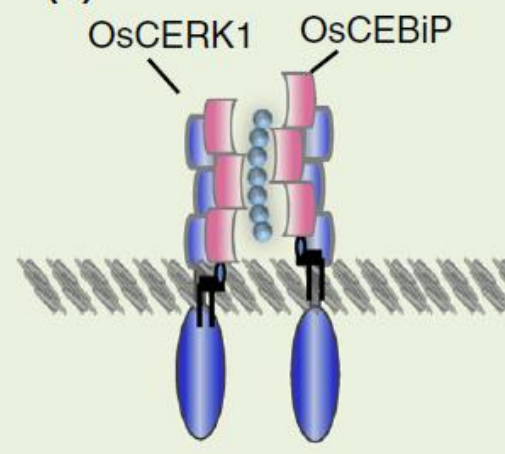

(b)

AtCERK1

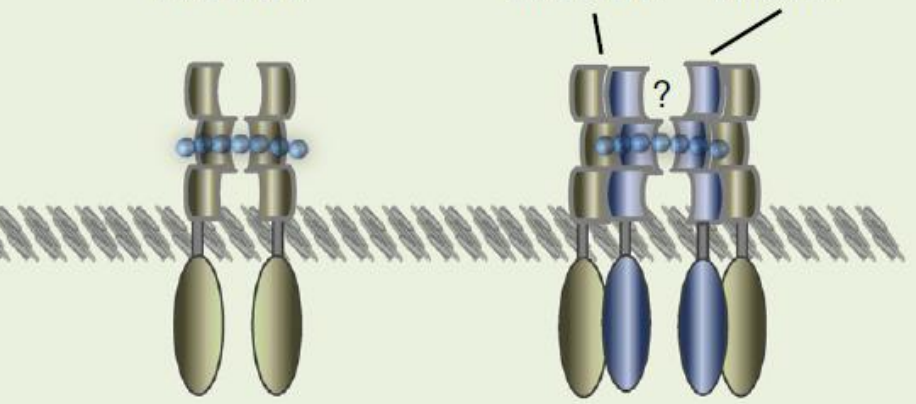

(c) AtCERK1 AtLYK5

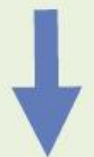

\section{Defense}

Figure 2. Chitin perception in plants. a) Chitin perception in rice. Homodimers of OsCEBIP bind chitin and recruit OsCERK1 to form a heteromeric complex. b) Model of chitin perception in Arabidopsis through AtCERK1 only. Upon chitin binding, AtCERK1 homodimerizes and is thereby activated. c) Model of chitin perception through a receptor complex. Chitin binding of AtLYK5 homodimers recruits AtCERK1 to form an active receptor complex. Image from Shinya et al. (2015).

perception systems of Arabidopsis and rice (lizasa et al., 2010; Liu et al., 2012b; Petutschnig et al., 2010). Chitin binding of CERK1 is mediated via its extracellular domain and transmitted into the cell via its intracellular kinase domain. Similar to rice OsCEBiP (Hayafune et al., 2014), CERK1 forms homodimers through binding of chitooligosaccharides (Figure 2b) (Hayafune et al., 2014; Liu et al., 2012b). Homodimerization is a crucial step in receptor activation and leads to phosphorylation events at the intracellular juxtamembrane and kinase domains (Liu et al., 2012b; Petutschnig et al., 2010). Chitin-induced CERK1 phosphorylation is required for downstream signaling and results in an electrophoretic mobility shift of CERK1, which can be detected in immunoblot experiments (Petutschnig et al., 2010). CERK1 kinase activity is crucial for both receptor phosphorylation and defense processes, as kinase dead (cerk1-LOF) variants of CERK1 are unable to complement cerk12 knockout mutants (Petutschnig et al., 2010). 
Arabidopsis contains four more LysM-RLKs in addition to CERK1. Of these, the LysM-RLK LYK4 was shown to play a minor role in chitin perception, as lyk4 mutant plants show reduced expression of chitin responsive genes and a moderately reduced calcium influx after chitin treatment (Wan et al., 2012). As LYK4 appears to be an inactive kinase, it might act as a co-receptor and depend on CERK1 for signal transduction. The LysM-RLK LYK5 was also shown to be involved in chitin signaling, as chitin treatment leads to CERK1 dependent LYK5 endocytosis and phospyhorylation (Erwig et al., unpublished). Furthermore, LYK5 was shown to be phosphorylated by CERK1 in vivo and in vitro. The current model for chitin perception in Arabidopsis considers CERK1 as an 'all-in-one' receptor, which is the main protein responsible for direct chitin binding, signal transduction and activation of downstream signaling responses (lizasa et al., 2010; Liu et al., 2012b; Miya et al., 2007; Petutschnig et al., 2010; Wan et al., 2012). Recent results however, call this model into question and propose the LysM-RLK LYK5 to be the main chitin receptor in Arabidopsis forming a complex with CERK1 (Figure 2c) (Cao et al., 2014). This new model is based on results revealing a higher chitin binding affinity for LYK5 than CERK1 and complete chitin insensitivity for lyk5-2 mutants. These results however, are contradictory to previous results, assigning a higher chitin binding affinity to CERK1 and wild type-like chitin signaling for lyk5-1 mutants (Cao et al., 2014; Liu et al., 2012b; Wan et al., 2012). Due to these contradicting results the contribution of different LysM-RLKs to chitin perception and signaling is not yet clear and it is still a matter of debate whether there is a "main" chitin receptor in Arabidopsis.

Similar to FLS2 and EFR, the receptor-like cytoplasmic kinase BIK1 was also shown to interact with CERK1 and to be involved in ROS generation after chitin treatment (Zhang et al., 2010). The related RLCK PBL27 mediates downstream responses like MAP kinase activation and induction of defense related genes. The importance of PBL27 for pathogen resistance is further corroborated by enhanced susceptibility of pbl27 mutant plants to bacterial and fungal pathogens (Shinya et al., 2014). Furthermore, the RLCK CLR1 was shown to be phosphorylated by CERK1 in vivo and vitro and to be involved in chitin induced ROS production, MAPK activation and induction of defense genes (Ziegler, 2015).

\subsection{Peptidoglycan perception}

The cell wall of gram-negative and gram-positive bacteria contains peptidoglycan (PGN), a polymer of $\mathrm{N}$-acetyl-D-glucosamine (GlcNAc) and $\mathrm{N}$-acteylmuramic acid (MurNAc) that is crosslinked with peptide chains (Lovering et al., 2012). PGN represents a classical PAMP and PRRs involved in PGN perception have been described in plants (Gust, 2015). The LysM-RLPs OsLYP4 and OsLYP6, homologs of OsCEBIP, were shown to be critical 
components for PGN perception in rice (Liu et al., 2012a). Similar to the rice chitin receptor OsCEBIP, OsLYP4 and OsLYP6 lack an intracellular kinase domain and depend on OsCERK1 for signal transduction (Ao et al., 2014). The importance of OsLYP4 and OsLYP6 in PGN signaling is supported by knockdown and overexpression analyses. Knockdown of OsLYP4 and OsLYP6 led to enhanced susceptibility to bacterial pathogens, while the overexpression of both proteins resulted in enhanced resistance (Liu et al., 2012a).

The Arabidopsis thaliana genome harbors three LysM-RLPs (LYM1-3). While LYM2 binds chitin (Petutschnig et al., 2010; Shinya et al., 2012), LYM1 and LYM3 were shown to physically bind to PGN (Willmann et al., 2011). lym1 and lym3 mutants showed enhanced susceptibility to bacterial pathogens and altered defense gene expression upon PGN treatment (Willmann et al., 2011). Interestingly, cerk1 mutant plants were similarly altered in PGN perception. As LYM1 and LYM3 lack an intracellular kinase domain, complex formation of LYM1, LYM3 and CERK1 for proper PGN signaling was proposed (Willmann et al., 2011). CERK1 is a target of the bacterial effector AvrPtoB, which mediates its degradation (Gimenez-lbanez et al., 2009). This provides further evidence for a role of CERK1 in perception of PGN and possibly other bacterial PAMPs.

\subsubsection{Heterotrimeric G-proteins act as molecular switches}

In order to adapt to constantly changing environmental conditions, eukaryotic cells need to transduce extracellular stimuli into intracellular signals through receptor proteins. In animals, G-protein coupled receptors (GPCRs) are an important class of receptors. These seventransmembrane (7TM) containing proteins harbor an extracellular ligand binding site and are in complex with heterotrimeric G-proteins at the intracellular site of the plasma membrane (Urano \& Jones, 2014). Heterotrimeric G-proteins consist of a Ga-subunit, which can bind and hydrolyze GTP, as well as a G $\beta$ - and Gy- subunit which form an obligate dimer. In animals, GPCRs act as guanine nucleotide exchange factors (GEFs) after ligand binding and promote GDP dissociation and GTP binding on Ga (Figure 3a). The activated Ga-subunit

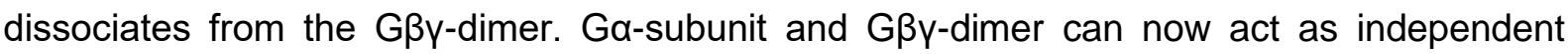
signaling units and regulate the activity of downstream targets (Urano et al., 2013). The GTPase activity of Ga terminates signaling by hydrolyzing GTP to GDP. This leads to the reassociation of $\mathrm{Ga}$ with the Gßy-dimer, thereby returning the complex to its assembled and inactive state (Ross \& Wilkie, 2000). GTP hydrolysis can be promoted by a group of GTPase activating proteins (GAPs) termed regulators of G-protein signaling (RGSs). Animals possess large numbers of GPCRs. The human genome, for example, encodes for over $800 \mathrm{GCPRs}$ (Jones \& Assmann, 2004). In plants however, the 

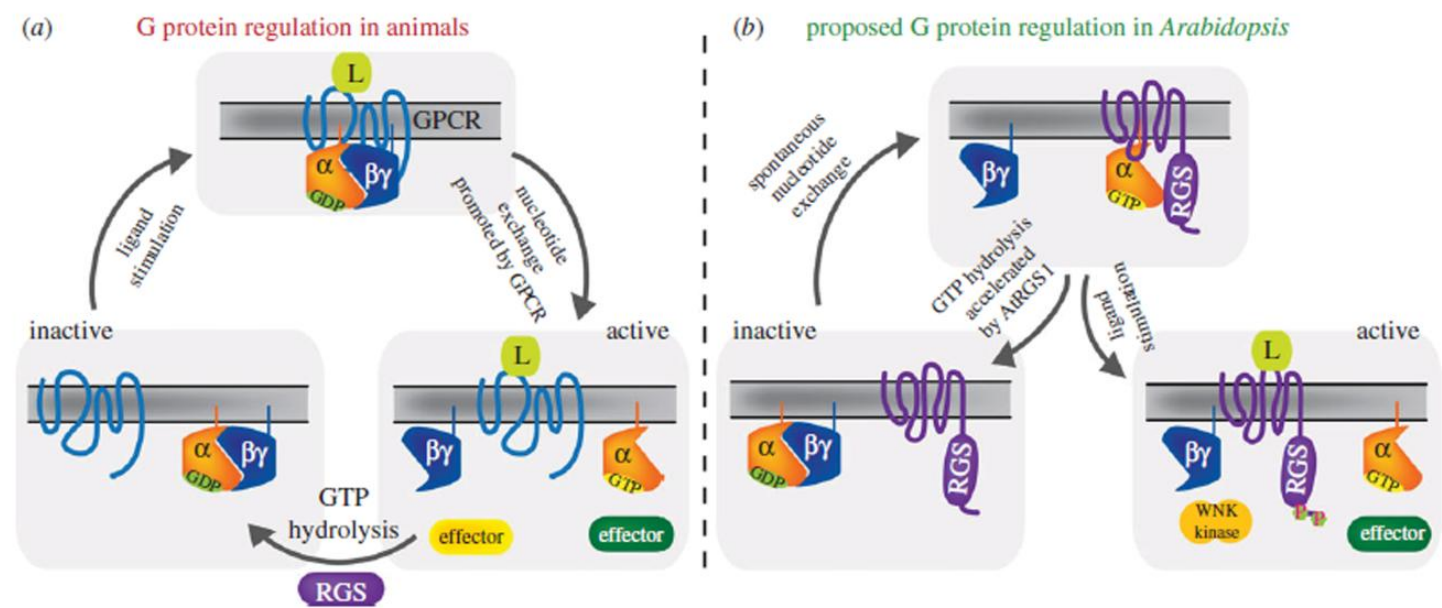

Figure 3. Cycle of heterotrimeric G-protein activation in animals and in Arabidopsis. a) G-protein activation in animals. Ligand binding leads to G-protein coupled receptor (GPCR) activation and nucleotide exchange at the Ga-subunit. The GTP-bound Ga-subunit dissociates from the G $\beta y$-dimer, which can now independently interact with downstream targets (effectors). GTP hydrolysis at the Ga-subunit is promoted by regulators of G-protein signaling (RGS) leading to inactivation and reformation of the heterotrimeric complex. b) G-protein activation in Arabidopsis. Spontaneous release of GDP and binding of GTP leads to activation of the Ga-subunit. The low intrinsic GTPase activity of the Ga-subunit is enhanced by RGS, resulting in an inactive and assembled heterotrimeric complex. Ligand binding of RGS leads to its endocytosis, thereby preventing Ga inactivation. Ga and $G \beta y$ can now interact with downstream targets. Image from Urano et al. (2013).

situation is different. A number of proteins have been proposed as GPCRs, but whether GPCRs really exist in plants is still under debate (Urano et al., 2013). In vitro analyses and structural studies suggest that the Arabidopsis Ga-subunit AtGPA1 does not need a GPCR for activation. It spontaneously releases GDP and binds GTP in vitro (Johnston et al., 2007; Urano et al., 2012a). The rate of GTP hydrolysis in AtGPA1 is slower than the rate of nucleotide exchange, resulting in a permanently GTP-bound state. This has led to a model of G-protein signaling in plants, where the G-proteins are active by default and regulated by deactivation through GAPs that enhance the intrinsic GTPase acitivity of $\alpha$-subunits (Figure 3b). To date, only one GAP targeting AtGPA1 has been identified. AtRGS1 is a membrane localized protein with a 7TM and an RGS domain (Chen et al., 2003) and has therefore been proposed to act as a hybrid G-protein coupled receptor GAP. AtRGS1 acts in sugar sensing and based on genetic evidence, glucose has been put forward as its ligand. AtRGS1mediated GTP hydrolysis leads to the formation of the inactive Gaßy heterotrimer (Figure 3b). Ligand binding of AtRGS1 triggers its phosphorylation and subsequent endocytosis, physically decoupling it from AtGPA1 (Urano et al., 2012b). AtGPA1 and the Gßy-dimer are now able to relay signals to downstream targets (Figure $3 b$ ) (Urano et al., 2013). The Arabidopsis genome encodes one Ga-subunit (GPA1), one Gß-subunit (AGB1) and three Gy-subunits (AGG1-3) (Jones \& Assmann, 2004; Thung et al., 2012). AGG1 and AGG2 are 
highly similar, while AGG3 is a much larger protein and shares little sequence homology with the other two Gy-subunits (Chakravorty et al., 2011).

Knockout mutants of Arabidopsis thaliana heterotrimeric G-proteins have been subject of intensive research and have revealed many processes in which G-proteins play important roles including defense against fungal and bacterial pathogens, cell death, hormone signaling, oxidative stress, as well as seedling and root development (Chen et al., 2006; Joo et al., 2005; Liu et al., 2013a; Nitta et al., 2015; Trusov et al., 2006).

Since Arabidopsis contains only one AtRGS1-like protein, it is not clear how heterotrimeric G-proteins are regulated in these pathways and how specificity is achieved. AtRGS1 might associate with RLKs, since AtRGS1 interacts with some RLKs in yeast (Klopffleisch et al., 2011). RLK mediated phosporylation of AtRGS1 might trigger endocytosis, thereby activating G-protein signaling (Urano et al., 2013). However, cereals lack RGS1-like proteins, so alternative mechanisms for regulation of heterotrimeric G-proteins must be present in at least some plants (Urano et al., 2012a).

\subsubsection{The role of heterotrimeric G-proteins in plant immunity and cell death}

Heterotrimeric G-proteins are involved in nearly all aspects of life. Research on plant Gproteins however, has mainly focused on their roles in immunity and functions for most Gproteins herein have been described (Liu et al., 2013a; Llorente et al., 2005; Trusov et al., 2006; Trusov et al., 2007). Furthermore, G-proteins have been found to be important regulators of cell death signaling in plants (Liu et al., 2013a). The following section will focus on the roles that G-proteins play in these two pathways.

GPA1 and AGB1 were shown to be regulators of resistance against fungal pathogens. gpa1 mutant plants exhibited enhanced resistance, while agb1 plants were more susceptible to the necrotrophic fungal pathogens Plectosphaerella cucumerina (Llorente et al., 2005), Fusarium oxysporum (Trusov et al., 2006) and Alternaria brassicola (Trusov et al., 2006). Studies about the role of GPA1 and AGB1 in resistance against bacterial pathogens are contradictory. Trusov and colleagues (2006) reported that resistance against Pseudomonas syringae pv. tomato DC3000 is independent of heterotrimeric G-proteins. Torres et al. (2013) however, found agb1 mutant plants to be more susceptible to Pseudomonas syringae pv. tomato DC3000, while resistance against this pathogen is unaffected in gpa1 plants. The situation is further complicated by reports that gpa1 and agb1 as well as gpa1 agb1 double mutants showed similarly impaired resistance against virulent and avirulent Pseudomonas syringae pv. maculicola and pv. tabaci strains (Lee et al., 2013a).

Several studies have reported partly redundant functions of the Gy-subunits AGG1 and 
AGG2 in disease resistance (Lee et al., 2013a; Liu et al., 2013a). Arabidopsis plants lacking either AGG1 or AGG2 showed wild type-like resistance when inoculated with virulent or avirulent Pseudomonas syringae strains, while double knockout agg1 agg2 plants were more susceptible (Lee et al., 2013a). But not all defense responses are redundantly mediated by AGG1 and AGG2. Resistance against the necrotrophic fungal pathogen Fusarium oxysporum was impaired in agg1 single and agg1 agg2 double mutants, while agg2 plants exhibited wild type-like resistance (Trusov et al., 2007). To date, no defense related role has been postulated for AGG3.

AGB1, AGG1 and AGG2 have been found to be involved in PAMP triggered defense responses, while GPA1 seems not to play a role in these pathways (Liu et al., 2013a). ROS production was reduced in agb1 single and agg1 agg2 double mutants upon flg22, elf18 and chitin treatment. Interestingly, ROS production in agg1 plants was only reduced after elf18 treatment and wild type-like for flg22, elf18 and chitin treatment in agg2 plants, pointing to partly redundant functions of $A G G 1$ and $A G G 2$ in PAMP responses. Furthermore, AGB1, AGG1 and AGG2 were required for activation of the MAPK4, but dispensable for MAPK3 and 6 activation (Liu et al., 2013a).

Heterotrimeric G-proteins were also reported to play a role in cell death regulation (Liu et al., 2013a). Knockout mutants of the BAK1 interacting kinase BIR1 (bir1-1) are characterized by constitutive activation of defense responses which result in cell death and stunted growth (Gao et al., 2009). This phenotype could be suppressed by agb1 single and agg1 agg2 double knockout mutants, but not by gpa1, agg1 or agg2 single mutants (Liu et al., 2013a). A mutant of the LRR-RLK SUPPRESSOR OF BIR1-1 (SOBIR1) was found to suppress the cell death phenotype of bir1-1 and act as a positive regulator of cell death (Gao et al., 2009). Overexpression of SOBIR1 resulted in a cell death phenotype similar to bir1-1 (Gao et al., 2009), which could be suppressed by agb1 knockout, indicating that they act in the same pathway (Liu et al., 2013a).

Given the fact that heterotrimeric G-proteins are involved in PAMP-triggered responses and cell death suggest that RLKs like FLS2, EFR, CERK1 and SOBIR1 might act upstream of Gproteins. Heterotrimeric G-proteins might act as converging point for these RLKs activating a common signaling pathway leading to the induction of PTI or cell death.

\subsubsection{Arabidopsis Extra-large G-Proteins (XLGs) are alternative Ga subunits}

In addition to the canonical Ga-subunit GPA1, the Arabidopsis genome encodes for so called extra-large G-proteins (XLGs), which are nearly twice the size of conventional Ga-subunits 
(Ding et al., 2008; Lee \& Assmann, 1999). The first extra-large G-protein was identified in 1999 and was named XLG1 (Lee \& Assmann, 1999). Further research led to the discovery of two additional Arabidopsis XLGs (XLG2 and 3) (Ding et al., 2008).

Extra large G-proteins contain a C-terminal domain which is homologous to GPA1 and mammalian Gas as well as an N-terminal domain of unkown function (Ding et al., 2008; Lee \& Assmann, 1999). In comparison to GPA1, the Ga domains of XLGs lack several conserved amino acids which are involved in GTP binding and hydrolysis (Temple \& Jones, 2007). Nevertheless, GTPase activity was confirmed for all Arabidopsis extra-large G-proteins in vitro (Heo et al., 2012). In contrast to AtGPA1 and other canonical Gas which need $\mathrm{Mg}^{2+}$ as a cofactor, GTPase activity of XLG proteins depends on the presence of $\mathrm{Ca}^{2+}$ (Heo et al., 2012). The $\mathrm{N}$-terminal part of XLGs harbours a cysteine-rich region with four perfect $\mathrm{CxxC}$ motifs which is followed by a region that is highly conserved among all extra large G-proteins (Ding et al., 2008; Lee \& Assmann, 1999). The regularly spaced cysteines have been speculated to form a DNA binding domain, since they resemble elements found in DNA binding zinc finger domains (Ding et al., 2008). Overall, the region containing the CxxC motifs does not match any known zinc-finger-like patterns and their function remains unknown.

Localization studies concerning extra-large G-proteins are contradictory. Ding et al. (2008) reported localization of GFP-XLG1/2/3 fusion proteins in nuclei when heterologously expressed in Vicia faba leaves. Due to the predicted nuclear localization signals in each of the XLG proteins, this was not unexpected. However, Maruta et al. (2015) reported GFPXLG1 to be localized at the plasma membrane, and GFP-XLG2 and GFP-XLG3 to be localized to both, the plasma membrane and the nucleus when stably overexpressed in Arabidopsis or transiently in $N$. benthamiana. As the XLG-GFP fusion constructs in both these studies were overexpressed under control of the strong $35 \mathrm{~S}$ promoter, Chakravorty et al. (2015) sought to investigate XLG localization using the weaker UBIQUITIN10 promoter for 'enhanced temporal resolution'. These localization studies were performed via transient expression in $N$. benthamiana and essentially confirmed the results of Maruta et al. (2015). Nevertheless, the reported XLG localization patterns might be the result of mild to strong overexpression and/or transient heterologous expression and may therefore not necessarily display the localization of the endogenous XLG proteins. A nuclear localization signal (NLS) was predicted in the $\mathrm{N}$-terminal part of all three XLGs. Their functionality was confirmed by fusion of the N-terminal part of each XLG to GFP and heterologues expression in Vicia faba (Ding et al., 2008). However, re-evaluation of nuclear localization signals of XLGs confirmed a classical NLS only for XLG3, while XLG2 harbors a non-canonical NLS. The functionality of the XLG2 NLS was confirmed by fusion to XLG1, which changed its localization pattern from 
primarily extra-nuclear to mainly nuclear (Chakravorty et al., 2015). No NLS could be identified for XLG1 in this study, which is expected according to localization studies. XLG3 contains an additional, non-canonical NES, whose functionality was confirmed by mutational analysis (Chakravorty et al., 2015).

XLG knockout mutant analyses revealed functions of XLG proteins in root development, hormone signaling, pathogen resistance and cell death (Ding et al., 2008; Maruta et al., 2015; Pandey et al., 2008; Zhu et al., 2009) of which the latter two will be the focus of the following part. All three XLGs act as negative regulators of root growth, as indicated by $x / g$ triple mutant seedlings grown in darkness. XLG3 has additional functions in the regulation of root-waving and root-skewing (Pandey et al., 2008). xlg triple mutants were further found to be hypersensitive to osmotic stress and abscisic acid (Ding et al., 2008).

XLG2 was found to be involved in resistance against bacterial pathogens (Maruta et al., 2015; Zhu et al., 2009). Inoculation of xlg2 plants with virulent and avirulent Pseudomonas syringae pv. tomato strains led to enhanced bacterial growth in comparison to Col-0 wild type plants (Zhu et al., 2009). The analysis of double $(x \lg 2 x \lg 3)$ and triple $(x \lg 1 x \lg 2 x \lg 3)$ mutants revealed no additive effect in susceptibility, indicating that XLG1 and XLG3 do not participate in resistance against Pseudomonas syringae (Maruta et al., 2015). Transcription of XLG2 and XLG3 is induced upon Pseudomonas infection, even though only XLG2 contributes to resistance (Zhu et al., 2009). XLG2 and XLG3 were shown to exhibit functions in resistance against fungal pathogens. Inoculation of $x \lg 2$ mutants with the incompatible biotrophic pathogen Erysiphe pisi led to enhanced cell penetration in comparison to wild type plants (Humphry et al., 2010). Resistance against the hemibiotrophic fungal pathogen Fusarium oxysporum is impaired in $x \lg 2$ and $x \lg 3$ single and even more impaired in $x \lg 2 x \lg 3$ double mutants, indicating that XLG2 and XLG3 have redundant functions in resistance against this pathogen (Maruta et al., 2015). Similar to experiments with Pseudomonas, xlg2 mutants showed enhanced susceptibility to the necrotrophic pathogen Alternaria brassicola but there was no additive effect regarding Alternaria susceptibility in $x \lg 2 x \lg 3$ double or $x \lg$ triple mutants (Maruta et al., 2015). Interestingly, agb1 mutants were similarly impaired in resistance against $P$. syringae, F. oxysporum and $A$. brassicola as $x \lg 2$ single and/or $x \lg 2$ $x \lg 3$ double mutants, indicating that they are involved in the same defense signalling pathway. Another hint for XLG2 and AGB1 acting in the same signalling pathways came from experiments showing that the bir1-1 cell death phenotype not only depends on AGB1, but also on XLG2 (Liu et al., 2013a; Maruta et al., 2015).

For a long time it was thought that there are only 3 possible heterotrimeric complexes in Arabidopsis consisting of GPA1/AGB1 and one of the three Gy-subunits AGG1-3. Interaction of XLGs with AGB1/AGG was deemed unlikely because of considerable sequence 
divergence between extra-large G-proteins and conventional Ga-subunits, particularly in regions thought to mediate GPA1-AGB1 interaction (Temple \& Jones, 2007). This view was supported by the fact that in contrast to GPA1 (Klopffleisch et al., 2011), XLG2 did not interact with AGB1 in yeast (Zhu et al., 2009).

The situation changed recently, when XLGs were reported to bind G $\beta Y$-dimers in yeast and upon transient transformation of Arabidopsis protoplasts or Nicotiana benthamiana leaves (Chakravorty et al., 2015; Maruta et al., 2015). XLG proteins were shown to interact with AGB1 in yeast, when one of the AGG proteins was also expressed. Interaction in plants occurs at the plasma membrane and also depends on the presence of at least one of the Gysubunits (Chakravorty et al., 2015; Maruta et al., 2015). One possible explanation is that the Gy-subunits are required for stabilization of AGB1. This is consistent with recent results showing that AGB1 abundance is decreased in agg1 agg2 double mutants and barely detectable in agg1 agg2 agg3 triple mutants (Wolfenstetter et al., 2015). Alternatively, XLG proteins could directly bind the $G_{\gamma}$-subunits. However, contradicting results were reported about the direct interaction of XLGs with the Gy-subunits in absence of AGB1. Maruta et al. (2015) could detect XLG2 interaction with each Gy-subunit in agb1 protoplasts in bimolecular fluorescence experiments. These results could not be confirmed by Chakravorty et al. (2015), who could detect XLG - AGG1/2/3 interaction only in the presence of AGB1. It therefore remains unclear, if direct interaction between XLGs and Gy-subunits alone is possible. Also, the interaction specificity between the three XLG proteins and the three possible G $\beta y$-dimers is not yet entirely clear. While Maruta et al. (2015) reported that XLG2 equally interacted with all Gßy-dimers, Chakravorty et al. (2015) found that XLG1 and XLG2 preferentially interact with Gßy-dimers containing either AGG1 or AGG2, whereas XLG3 bound strongly to all three possible GBy-dimers (AGB1 + AGG1/2/3). In this study, GPA1 interacted preferentially with Gßy-dimers containing AGG3.

Taken together, these recent findings (Chakravorty et al., 2015; Maruta et al., 2015) confirmed XLG proteins as components of heterotrimeric G-protein complexes, expanding the Ga family in Arabidopsis from one to four members: GPA1, XLG1, XLG2 and XLG3. This increases the number of potential heterotrimeric G-protein complexes from three to twelve. The involvement of extra-large G-proteins and their possible direct interaction with $G_{y}$ subunits is an uncommon theme in G-protein signaling and clearly distinguishes plant heterotrimeric G-protein signalling from its animal counterpart. 


\subsection{Ectodomain shedding and related proteolytic processes in metazoans}

The proteolytic cleavage of transmembrane proteins to release the extracellular domain is referred to as ectodomain shedding (Figure 4) (Arribas \& Borroto, 2002). In animals, it acts as a regulatory mechanism in a wide range of proteins, such as growth factors, cytokines, cell adhesion molecules and receptors (Hayashida et al., 2010). Ectodomain shedding leads to the release of a soluble ectodomain into the extracellular space which may then act as a signaling module in paracrine signaling (Blobel, 2005). Cells can also use ectodomain shedding as a regulatory mechanism to control the abundance or function of proteins on the cellular surface and it may also be a prerequisite for further proteolytic processing steps. Basal ectodomain shedding takes place in unstimulated cells, but it can also be induced by different stimuli such as protein kinase $\mathrm{C}$ activating chemicals or ligand binding (Hayashida et al., 2010).

For most vertebrate proteins, proteolytic processing of the extracellular domain depends on the catalytic activity of metalloproteases belonging either to the A Desintegrin and Metalloproteinase (ADAM) or Matrix Metalloproteinases (MMPs) family (Hayashida et al., 2010). In addition to the catalytic metalloprotease domain, MMPs and ADAMs share an $\mathrm{N}$-terminal pro-domain, which is cleaved off to activate the protein. ADAMs contain additional disintegrin and EGF-like domains (Khokha et al., 2013). Members of the ADAM and MMP family are either soluble or membrane bound by transmembrane domains (MMPs + ADAMs) or GPI anchors (MMPs). Despite their involvement in distinct cellular processes, many different proteins may be cleaved by the same sheddase and many sheddases may be involved in the cleavage of one substrate (Hayashida et al., 2010). The activity of a sheddase on a certain substrate is thought to also depend on spatio-temporal expression of protease and substrate and on the presence of activators (Chow \& Fernandez-Patron, 2007).

Proteolytic cleavage of the extracellular domain is often followed by cleavage within the transmembrane domain (Figure 4). This mechanism is referred to as regulated intramembrane proteolysis (RIP) and is a common mechanism to release the intracellular domain, which can serve as signaling molecule or is subject to degradation (Lichtenthaler et al., 2011). Intramembrane proteolysis is carried out by intramembrane-cleaving proteases (iCLIPs), which are either aspartyl proteases (presenilin, signal peptide peptidase and related proteases), metallo proteases (Membrane-bound transcription factor site-2 protease) or serine proteases (Rhomboids) (Kopan \& Ilagan, 2004; Lal \& Caplan, 2011). The protease type most frequently reported to perform RIP after ectodomain shedding is presenilin, which interacts with additional proteins to form the $y$-secretase complex. Ectodomain shedding is a 
prerequisite for intramembrane cleavage by most iCLIPs. Rhomboid proteases are an exception to this rule, since they are able to cleave substrates containing long ectodomains (Freeman, 2009).

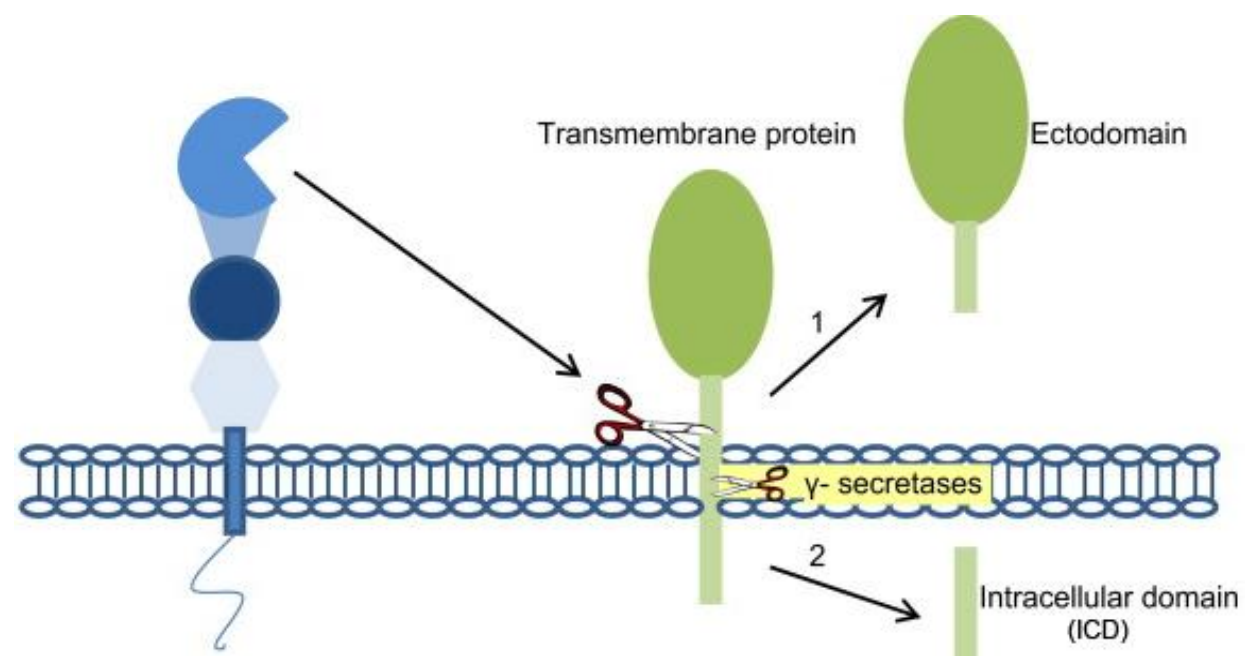

Figure 4. Ectodomain shedding and RIP of integral membrane proteins. An integral transmembrane protein is cleaved in close vicinity to the plasma membrane. The cleaved ectodomain is released into the extracellular space and can act as signaling module. The remaining membrane bound fragment is then subject to iCLIP mediated cleavage (for example by $\mathrm{y}$-secretease). This leads to release of the intracellular domain (ICD) which can now function as a cytosolic or nuclear effector. Image from herrlichlab.org (modified).

\subsubsection{Well studied examples of ectodomain shedding in metazoans}

Many different signaling pathways in animals are regulated via proteolytic processing of extracellular domains. Tight regulation of this process is of great importance and dysregulation often results in disease (Saftig \& Reiss, 2011). The Notch signaling pathway is a well-documented pathway which is regulated by ectodomain shedding. Notch receptors are a family of transmembrane proteins and are important regulators of cell to cell communication (Kopan \& llagan, 2009). Notch is conserved in metazoans with homologs in Drosophila, Caenorhabditis and mammals (Chillakuri et al., 2012; Kopan \& llagan, 2009). Notch receptors are constitutively cleaved in the trans-Golgi resulting in an N-terminal ligand binding part and a C-terminal transmembrane domain containing part (Guruharsha et al., 2012). Noncovalent heterodimerization of both parts constitutes the mature receptor. Notch receptors are activated upon binding of DSL (Delta/Serrate/LAG-2) ligands on opposing cell surfaces (Chillakuri et al., 2012). Ligand binding leads to structural changes, rendering the Notch ectodomain accessible for proteolytic cleavage by either ADAM10 or ADAM17/TACE (Bozkulak \& Weinmaster, 2009). Subsequent to ectodomain shedding, the transmembrane domain of Notch is cleaved by the $\mathrm{y}$-secretase complex to release the intracellular domain, 
which translocates into the nucleus, where it can interact with transcription factors (Guruharsha et al., 2012). Amino acid substitutions and insertions resulting in reduced heterodimer stability or ligand-independent ectodomain shedding lead to inappropriate activation of the Notch receptor and are frequently associated with leukemia (Aster et al., 2008).

The amyloid precursor protein (APP) is a type I transmembrane protein which has drawn much attention because of its involvement in the development and progression of Alzheimer's disease and can be found in mammalian and non-mammalian cells (Dawkins \& Small, 2014). Intriguingly, the molecular function of APP is still elusive, but it has been proposed as a regulator of growth and maturation of many cells in the nervous system (Dawkins \& Small, 2014). The amyloid plaques associated with Alzheimer's disease are caused by production and accumulation of a proteolytic cleavage product of APP (Murphy \& LeVine, 2010). Post-translational processing of APP can occur in two different ways (Haass et al., 2012). The enzymes involved in the so-called anti-amyloidogenic pathway are similar to those of Notch ectodomain shedding. APP is first cleaved by ADAM10, which leads to the release of the extracellular APPsa fragment (Figure 5A) (Postina et al., 2004). The remaining membrane bound part of APP is then cleaved by the $\mathrm{y}$-secretase complex, leading to generation of the p3 peptide.

The second possible processing mechanism is the amyloidogenic pathway, which involves proteolytic cleavage of APP near the transmembrane domain by the aspartic protease betasecretase 1 (BACE1). This leads to the release of a large part of the APP ectodomain (APPs $\beta$, Figure 5B) (Seubert et al., 1993). A second cleavage of the remaining membranebound fragment of APP mediated by the $\mathrm{Y}$-secretase complex results in generation of $A \beta$ (Haass et al., 1993). The $A \beta$ peptide accumulates and aggregates in the brain, forming senile plaques, which is characteristic for Alzheimers disease (Selkoe, 2001).

The anti-amyloidogenic and the amyloidogenic pathways are in competition with each other. Postina et al. (2004) showed that overexpression of ADAM10 leads to enhanced generation of the APPs $\alpha$ fragment and reduced the formation of $A B$. A C-terminal intracellular fragment (ICD) is released in both pathways, which is believed to engage in nuclear signaling thereby inducing its own expression to restore full length APP (Rotz et al., 2004). L-selectin is a celladhesion molecule that is expressed on most leukocytes. It consists of a large extracellular domain and a small cytoplasmic tail (Smalley \& Ley, 2005). L-selectin is involved in adhesion of leukocytes to the endothelium, the initial step of leukocyte recruitment to sites of 


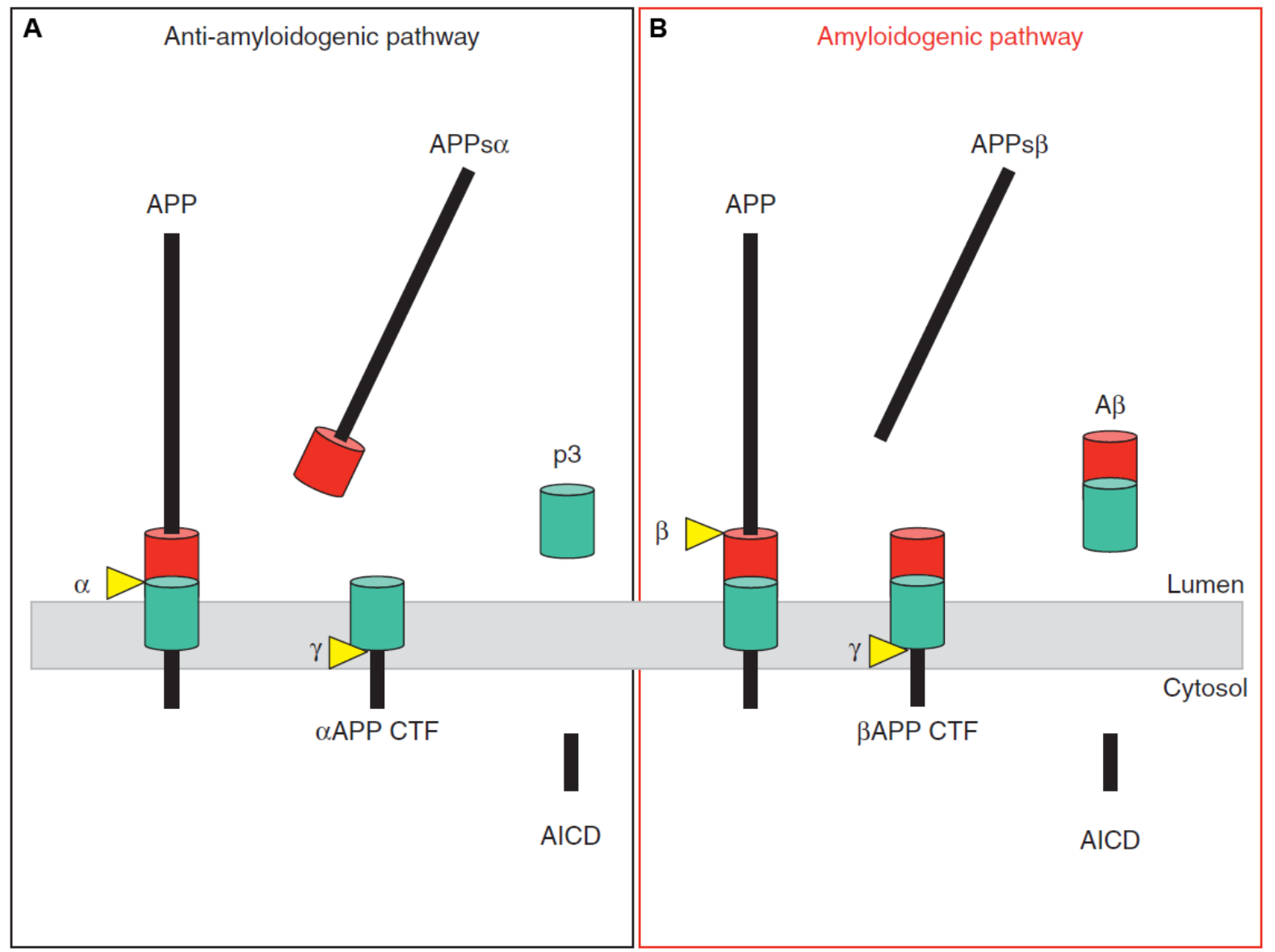

Figure 5. Proteolytic processing of amyloid precursor protein. A) In the anti-amyloidogenic pathway, APP is cleaved by ADAM10 ( $\alpha$-secretase) close to the transmembrane domain to release the extracellular APPs $\alpha$ fragment. Subsequent cleavage of the remaining truncated $C$-terminal fragment ( $\alpha$ APP CTF) by a $\gamma$-secretase releases an extracellular peptide (p3) and the intracellular domain (AICD). B) In the amyloidogenic pathway, cleavage by BACE ( $\beta$-secretase) releases the extracellular fragment APPs $\beta$. BACE cleavage occurs closer to the $\mathrm{N}$-terminus in comparison to ADAM10 cleavage. The remaining $\mathrm{C}$-terminal fragment ( $\beta A P P \mathrm{CTF}$ ) is subsequently cleaved to release the neurotoxic $A \beta$ peptide and the intracellular domain (AICD). Image from Haass et al. (2012).

inflammation (Raffler et al., 2005). The ectodomain of L-selectin is cleaved by ADAM17/TACE and other sheddases (Walcheck et al., 2003), which is important for directional migration of monocytes to sites of inflammation (Rzeniewicz et al., 2015).

An example for ectodomain shedding by MMPs is E-cadherin, a transmembrane glycoprotein that mediates cell to cell adhesion in a calcium dependent manner (van Roy \& Berx, 2008). The ectodomain of $\mathrm{E}$-cadherin consists of 5 cadherin domain repeats which mediate interactions between cadherin molecules on adjacent cells (David \& Rajasekaran, 2012). Cleavage of the extracellular part of E-cadherin by a number of different metalloproteinases releases the soluble ectodomain (sE-cad) into the extracellular space. One function of $s E$ cad is the disruption of cell-to-cell contacts, probably by interacting with unshed E-cadherin molecules (Noe et al., 2001). sE-cad further acts as a paracrine/autocrine signaling molecule and was shown to activate receptor-like tyrosine kinases (David \& Rajasekaran, 2012). 


\subsubsection{Ectodomain shedding of metazoan receptor kinases and their ligands}

Receptor kinases are single-span transmembrane proteins with an extracellular ligand binding domain, and an intracellular kinase domain (Ganten et al., 2006). They share a common mechanism of activation, which involves ligand binding, receptor oligomerization and subsequent transphosphorylation events at the intracellular kinase domains (Ganten et al., 2006; Schlessinger, 2000). Based on the amino acids they phosphorylate, receptor kinases can be grouped into receptor serine/threonine kinases (RSKs) and receptor tyrosine kinases (RTKs). The human genome encodes 12 RSKs which serve as receptors for members of the transforming growth factor beta (TGF- $\beta$ ) superfamily of secreted peptides and are involved in many processes of metazoan life such as embryogenesis, tissue fibroses and cancer (Ganten et al., 2006; Josso \& Di Clemente, 1997). RTKs are a large gene family in humans with 58 members that fall into 20 families. Most of the ligands, which are perceived by RTKs are polypeptides including insulin, epidermal growth factor (EGF) and platelet-derived growth factor (PDGF) (Schlessinger, 2000). RTKs play key roles in metabolism, growth, differentiation and motility (Hubbard \& Miller, 2007; Schlessinger, 2000). An important regulatory step of receptor kinase mediated signaling is the availability of the ligand to the receptor. Ligands of RSKs are secreted, while many ligands of RTKs are synthesized as transmembrane ligand precursors (Singh \& Harris, 2005; Weiss \& Attisano, 2013). Ectodomain shedding of the precursor protein leads to release of the active ligand which can then participate in juxtacrine/paracrine signaling and activate RTKs. A particularly well-substantiated example is heparin-binding EGF-like growth factor (HB-EGF) which plays a role in cell proliferation and migration (Faull et al., 2001; Piepkorn et al., 1998). HB-EGF can be cleaved by members of the ADAMs family of proteases to release its $\mathrm{N}$-terminal domain which can then bind to epidermal growth factor receptors (EGFRs) (Singh et al., 2004). Both, mice expressing an uncleavable or a soluble form of HB-EGF suffered from heart problems indicating that regulated shedding is essential for normal development and health (Yamazaki et al., 2003).

The release of the extracellular domain of the EGF-like growth factor spitz in Drosophila is an example for rhomboid-mediated ectodomain shedding. Spitz is synthesized as an inactive transmembrane bound precursor (Rutledge et al., 1992). Proteolytic cleavage within the transmembrane domain by Rhomboid-1 releases the extracellular domain of spitz (Urban et al., 2001) which is then suggested to engage in paracrine signaling to activate EGFR signaling.

Not only ligands, but also receptor kinases themselves are subject to proteolytic cleavage of their extracellular domain. The transforming growth factor beta receptor type I (TRRI) is a 
RSK and part of the receptor complex that perceives transforming growth factor beta (TGF- $\beta$ ) ligands (Feng \& Derynck, 2005). T $\beta R I$ is subject to ADAM17/TACE-mediated proteolytic cleavage of its ectodomain, which is thought to downregulate its presence on the cellular surface (Liu et al., 2009). Downstream responses mediated by T $\beta R I$ include growth inhibition (Siegel \& Massagué, 2003). Enhanced ectodomain shedding of T $\beta R I$ might therefore be a strategy of cancer cells to inhibit tumor suppression (Liu et al., 2009; Siegel \& Massagué, 2003).

Ectodomain shedding is a fairly common process in RTKs. Out of the 20 RTK-subfamilies, 10 contain members for which ectodomain shedding has been reported. In the majority of these cases, ectodomain shedding is mediated by ADAM17/TACE or ADAM10 and often followed by intramembrane cleavage by $\gamma$-secretase (Chen \& Hung, 2015). The released intracellular domains are usually short lived (Carpenter \& Liao, 2009), but can be stabilized by posttranslational modifications or interaction with other proteins such as chaperones. This way they may be transported into various intracellular compartments. Most commonly translocation occurs into the nucleus, where RTK intracellular domains may interact with transcriptional regulators (Chen \& Hung, 2015).

Ectodomain shedding has been characterized well in the epidermal growth factor receptor (EGFR) sub-family of RTKs. In humans, the EGFR group consists of four members (erbB1erbB4). Ligand binding induces homo- or heterodimerization of erbBs, which are then able to activate signaling cascades within the cell, leading to cell proliferation, differentiation and migration (Higashiyama et al., 2011).

The erbB4 receptor occurs in two isoforms which are generated by alternative splicing and differ in their juxtamembrane amino acid composition (Elenius et al., 1997). Only the Jm-a isoform harbors the ADAM17/TACE cleavage site (Cheng et al, 2003) and is therefore subject to ectodomain shedding. erbB4 ectodomain shedding is constitutive, but can also be induced by ligand binding (Rio, 2000; Zhou \& Carpenter, 2000). After ectodomain shedding, $\mathrm{Y}$-secretase cleavage releases the erbB4 intracellular domain (ICD), which then translocates to the nucleus (Ni et al., 2001). High levels of erbB4 ectodomain can be found in breast cancer cells (Hollmén et al., 2009). Tumor growth can be stopped by inhibition of erbB4 ectodomain shedding underlining the importance of a tight regulation of this process (Hollmén et al., 2012).

erbB2 (Her2/neu2) is the only EGFR family receptor for which no direct ligand has been described so far. The erbB2 ectodomain was shown to be shed into the extracellular space by ADAM10 (Liu et al., 2006). Overexpression of erbB2 in breast cancer cells leads to frequent cleavage of the extracellular domain. This also generates a C-terminal fragment with constitutive, ligand-independent kinase activity (Gajria \& Chandarlapaty, 2011). This 
constitutive activation of growth factor signaling pathways by erbB2 serves as an oncognic driver in breast cancer.

Investigations of the erbB2 cleavage site led to the discovery of a signature motif within the extracellular juxtamembrane domain (Yuan et al., 2003). A five to seven amino acid stretch flanked by either a proline or a glycine $\left(P / G-X_{5-7}-P / G\right)$ was found to be conserved from human to chicken EGFRs and was therefore proposed as a common cleavage motif for the EGFR family.

There are also examples of RTK ectodomain shedding by MMPs. EphB2 belongs to the RTK subfamily of erythropoietin-producing hepatoma (Eph) receptors. Ephs are activated by binding membrane bound ligands (ephrins) on adjacent cells. Thereby, they regulate adhesion between neuronal cells which is critical for the development of the nervous system (Kullander \& Klein, 2002). EphB2 was reported to undergo ectodomain shedding driven by MMP-2 and MMP-9 upon ligand binding, which triggers repulsion between neurons (Lin et al., 2008). Similar to ectodomain shedding by ADAMs, proteolytic cleavage of the EphB extracellular domain by MMPs is a prerequisite for intramembrane cleavage by the $\mathrm{Y}$ secretase complex to release the intracellular domain (ICD) (Litterst et al., 2007).

\subsubsection{Ectodomain shedding of plant receptor-like kinases}

Plant receptor-like kinases (RLKs) are transmembrane proteins composed of an extracellular domain and an intracellular kinase domain and thus have a domain organization similar to animal RSKs and RTKs (Shiu \& Bleecker, 2001). They are involved in a plethora of developmental and stress responses including hormone signaling, defense and symbiosis (Tax \& Kemmerling, 2012). Despite the importance of ectodomain shedding for regulation of many animal RTKs, there are hardly any studies on this topic concerning plant RLKs. In recent years however, reports emerged indicating that ectodomain shedding or related processes might also be important regulatory mechanisms of receptor kinases in the plant kingdom.

A process that is similar to, but distinct from ectodomain shedding regulates the function of Lotus japonicus SYMBIOSIS RECEPTOR-LIKE KINASE (SYMRK). SYMRK is involved in the early stages of symbiosis establishment between plants and rhizobia or mycorrhizal fungi (Stracke et al., 2002). The ectodomain of SYMRK contains three LRRs and an N-terminal malectin-like domain (MLD). Recently, it was shown that the MLD of SYMRK is proteolitically released in absence of symbiotic stimulation (Antolín-Llovera et al., 2014). Cleavage occured at a GDPC motif that connects the MLD domain with the LRR domain (Antolín-Llovera et al., 2014) and can be found in many MLD-LRR-RLKs (Hok et al., 2011). Mutation of this motif 
abolished the release of the MLD domain (Antolín-Llovera et al., 2014). The release of the MLD domain is of striking physiological importance, as plants expressing SYMRK constructs unable to release MLD were severely impaired in the establishment of symbiotic interactions. Conversely, deletion of the entire SYMRK extracellular domain led to a massive induction of infection threads which points to important regulatory functions of the SYMRK ectodomain (Antolín-Llovera et al., 2014). This was confirmed by the finding that proteolytic cleavage of the SYMRK extracellular domain seemed to be a prerequisite for complex formation of SYMRK with Nod factor receptor 5 (NFR5) (Antolín-Llovera et al., 2014).

Evidence for proteolytic processing of plant RLKs also came from Xanthomonas resistance 21 (XA21), a rice LRR-RLK mediating resistance to the Gram-negative bacterium Xanthomonas oryzae pv. oryzae (Xoo) (Song et al., 1995). A sulfated, 17-amino acid peptide $\left(A x Y^{S} 22\right)$ derived from the $A \times 21$ protein of Xanthomonas was initially reported to induce XA21 mediated defense responses (Lee et al., 2009). These studies however were later retracted and a new ligand candidate was presented (Lee et al., 2013b; Pruitt et al., 2015). The newly proposed ligand, RaxX, is a Xanthomonas protein of unknown function. A 21-amino acid tyrosine-sulfated peptide derived from $\operatorname{RaxX}(\operatorname{Rax} X 21-s Y$ ) is sufficient to trigger Xa21-mediated defence responses in rice (Pruitt et al., 2015). Immunoblot analyses of transgenic rice plants expressing a labeled version of XA21 with a myc-tag inserted into the extracellular domain, revealed the presence of an XA21 $\mathrm{N}$-terminal cleavage product. This cleavage product was found in microsomal protein fractions and accumulated together with full length XA21 protein after infection with the Xoo strain PXO99Az (Park et al., 2010; Xu et al., 2006) or treatment with the now controversial ligand $A x Y^{S} 22$ (Lee et al., 2009). Interestingly, the intracellular juxtamembrane domain of XA21 harbors a P/G- $X_{5-7}-P / G$ motif similar to extracellular juxtamembrane domain of EGFRs. This signature was proposed as a cleavage site in XA21 and auto-phosphorylation of residues within this motif was positively correlated with protein stability and resistance (Xu et al., 2006). Park \& Ronald (2012) showed that XA21 accumulation upon $\mathrm{Xoo}$ or $\mathrm{AxY} \mathrm{S}^{\mathrm{S}} 22$ treatment is also associated with the release of a C-terminal fragment. The authors demonstrated the presence of XA21-GFP at the plasma membrane and in the endoplasmatic reticulum in unstimulated protoplasts. Upon $A x Y^{S} 22$ treatment, the C-terminal XA21-GFP fragment translocated to the nucleus. The nuclear translocation of the XA21-GFP C-terminus was shown to be critical for $X A 21$-mediated immunity. However, since the role of $A x Y^{S} 22$ as a $X A 21$ ligand is questionable, the significance of this report (Park \& Ronald, 2012) is not clear.

Another hint for the existence of ectodomain shedding in plants comes from BRI1. BRI1 is an LRR-receptor-like kinase and the Arabidopsis brassinosteroid receptor (Wang et al., 2001). Immunoblots on plant extracts using an N-terminal BRI1 antibody revealed the presence of 
an N-terminal fragment in addition to the full-length receptor (Wang et al., 2001). Since the BRI1 gene consists of only one exon, this fragment is likely generated by proteolytic cleavage. The presence of a soluble, N-terminal BRI1 fragment was confirmed in our laboratory (Elena Petutschnig, unpublished data).

Ectodomain shedding similar to animal receptor kinases was reported for CERK1 (Petutschnig et al., 2014). In addition to full-length CERK1, an N-terminal fragment can be detected in immunoblots using an N-terminal CERK1 antibody. This fragment lacks the CERK1 transmembrane domain, as it can be found in soluble fractions of microsomal preparations and in apoplastic wash fluids. Therefore, it represents the free CERK1 ectodomain. The abundance of the CERK1 ectodomain fragment increases in older plants and after inoculation with the non-adapted pathogen Blumeria graminis f. sp. hordei $(B g h)$ (Petutschnig et al., 2014).

A CERK1 mutant (cerk1-4) lacking the $\mathrm{N}$-terminal cleavage product was identified (Petutschnig et al., 2014). cerk1-4 plants harbor a leucine to phenylalanine (L->F) exchange within the second LysM domain of CERK1. These plants exhibit normal chitin signaling but are characterized by an enhanced salicylic acid-dependent cell death phenotype upon inoculation with Bgh. This phenotype is independent of CERK1 kinase activity and does not require the intracellular domain of CERK1. CERK1-GFP and cerk1-4-GFP fusion proteins revealed the presence of a C-terminal fragment in both cases. This suggests that the ectodomain fragment is missing in cerk1-4 plants because of the instability of the released cerk1-4 ectodomain, rather than shedding deficiency of the full length cerk1-4 protein. However, the mechanism of CERK1 ectodomain shedding and its role in cell death regulation remain unclear (Petutschnig et al., 2014).

The proteases acting on plant RLKs are currently not known. While ADAMs, one of the main actors in ectodomain shedding in vertebrates, do not exist in the plant kingdom (Seals \& Courtneidge, 2003) there are five homologs of the vertebrate family of MMPs in Arabidopsis thaliana (At1-MMP - At5-MMP) (Maidment et al., 1999; Seals \& Courtneidge, 2003). All five At-MMPs were shown to have protease activity in vitro and (with the exception of At5-MMP) showed similar cleavage site specificity to human MMPs (Marino et al., 2014).

Of these five MMPs, only At2-MMP was functionally characterized in plants. At2-MMP knockout mutants showed early senescence, smaller growth and early flowering (Golldack et al., 2002). A tomato MMP was recently reptorted to mediate resistance against fungal as well as bacterial pathogens ( $\mathrm{Li}$ et al., 2015).

Rhomboids are another family of proteases which are engaged in animal ectodomain shedding and can be found in plants. 13 rhomboid homologs can be found in Arabidopsis (Koonin et al., 2003), but studies on plant rhomboids are scarce. Rhomboid activity and 
specificity were demonstrated in vitro for heterologously expressed AtRBL2 (Kanaoka et al., 2005). Also, the subcellular localization has been investigated for several Arabidopsis RBLs and ranges from golgi apparatus to chloroplasts and mitochondria (Kmiec-Wisniewska et al., 2008). However, the information on the function of RBLs in Arabidopsis is very limited. Mutants of AtRBL8 were reported to show defects in floral development, but no substrates were identified (Adam, 2013; Thompson et al., 2012). The examples about proteolytic processing and ectodomain shedding of plant RLKs presented in this section might just be the beginning of many more studies to come. Results from this study (compare section 3.1.7) suggest that ectodomain shedding may be a common process in plant RLKs. Future work may elucidate the function of RLK ectodomain shedding and the proteases involved in it. 


\section{Materials and Methods}

\subsection{Materials}

\subsubsection{Plant materials}

\subsubsection{Arabidopsis thaliana}

Arabidopsis accessions, mutant and transgenic lines used in this work are listed in Table 1, Table 2 and Table 3.

Table 1. Arabidopsis accessions used in this study.

\begin{tabular}{lll}
\hline Accession & Abbr. & Source / NASC Stock number \\
\hline Columbia-0 & Col-0 & J. Dangl, University of North Carolina, USA. \\
\hline Columbia-3 & Col-3 & N908 \\
\hline Argentat & Ag-0 & N901 \\
\hline Barcelona-Tibidabo & Bar-1 & N77689 \\
\hline Bensheim & Be-0 & N964 \\
\hline Landsberg erecta & Ler-0 & N77020 \\
\hline Lipowiec & Lip-0 & N1336 \\
\hline Mühlen & Mh-1 & N1368 \\
\hline Moscow & Ms-0 & N905 \\
\hline N & N14 & N22492 \\
\hline N & N6 & N22484 \\
\hline N & N7 & N22485 \\
\hline Nossen & No-0 & N77128 \\
\hline Oberursel & Ob-0 & N1418 \\
\hline Pitztal & Pi-0 & N1454 \\
\hline Poppelsdorf & Po-0 & N1470 \\
\hline Richmond & Ri-0 & N1492 \\
\hline Rschew & Rsch-4 & N1494 \\
\hline Slavice & Sav-0 & N1514 \\
\hline Shakdara & Shakdara & N929 \\
\hline Sorbo & Sorbo & N931 \\
\hline Spandau & Sp-0 & N1530
\end{tabular}


Table 1 (continued).

\begin{tabular}{lll}
\hline San Feliu & Sf-0 & N1510 \\
\hline Stobowal & Stw-0 & N1538 \\
\hline Wilna & Wil-2 & N1596 \\
\hline Wietze & Wt-5 & N1612 \\
\hline
\end{tabular}

Table 2. Mutant Arabidopsis lines used in this study.

\begin{tabular}{|c|c|c|c|c|}
\hline $\begin{array}{l}\text { Genotype / } \\
\text { Name }\end{array}$ & $\begin{array}{l}\text { AGI locus } \\
\text { identifier }\end{array}$ & Accession & $\begin{array}{l}\text { T-DNA / } \\
\text { mutagen }\end{array}$ & Reference / source \\
\hline Col-3 gl1 & AT3G27920 & Col-3 & EMS & Volker Lipka \\
\hline cerk1-2 & AT3G21630 & Col-0 & T-DNA insertion & Miya et al. (2007) \\
\hline cerk1-4 & AT3G21630 & Col-3 gl1 & EMS & Petutschnig et al. (2014) \\
\hline fah1 fah2 & $\begin{array}{l}\text { AT2G34770 } \\
\text { AT4G20870 }\end{array}$ & Col-0 & T-DNA & König et al. (2012) \\
\hline fah1 fah2 loh1 & $\begin{array}{l}\text { AT2G34770 } \\
\text { AT4G20870 } \\
\text { AT3G25540 }\end{array}$ & Col-0 & T-DNA & Prof. Dr. Ivo Feussner \\
\hline fah1 fah2 loh2 & $\begin{array}{l}\text { AT2G34770 } \\
\text { AT4G20870 } \\
\text { AT3G19260 }\end{array}$ & Col-0 & T-DNA & Prof. Dr. Ivo Feussner \\
\hline fah1 fah2 loh3 & $\begin{array}{l}\text { AT2G34770 } \\
\text { AT4G20870 } \\
\text { AT1G13580 }\end{array}$ & Col-0 & T-DNA & Prof. Dr. Ivo Feussner \\
\hline pad4-1 & AT3G52430 & Col-0 & EMS & Glazebrook et al. (1996) \\
\hline sid2-2 & AT1G74710 & Col-0 & EMS & Dewdney et al. (2000) \\
\hline$a g b 1-2$ & AT4G34460 & Col-0 & T-DNA insertion & Ullah et al. (2003) \\
\hline nole1-1 & $\begin{array}{l}\text { AT3G21630 } \\
\text { AT4G34390 }\end{array}$ & Col-3 gl1 & EMS & Marnie Stolze \\
\hline nole1-2 & $\begin{array}{l}\text { AT3G21630 } \\
\text { AT4G34390 }\end{array}$ & Col-3 gl1 & EMS & This work \\
\hline nole2/7 & unknown & Col-3 gl1 & EMS & This work \\
\hline nole3/4 & unknown & Col-3 gl1 & EMS & This work \\
\hline nole3/8 & unknown & Col-3 gl1 & EMS & This work \\
\hline
\end{tabular}


Table 3. Transgenic Arabidopsis lines used in this study.

\begin{tabular}{|c|c|c|c|}
\hline Background & Construct & Resistance & Reference \\
\hline cerk1-2 & $\begin{array}{l}\text { pGreenll0229-PREP- } \\
\text { pCERK1::CERK1 }\end{array}$ & Basta & This work \\
\hline cerk1-2 & $\begin{array}{l}\text { pGreenll0229-PREP- } \\
\text { pCERK1::cerk1 cvg1 }\end{array}$ & Basta & This work \\
\hline cerk1-2 & $\begin{array}{l}\text { pGreenlI0229-PREP- } \\
\text { pCERK1::cerk1-4 cvg1 }\end{array}$ & Basta & This work \\
\hline cerk1-2 & $\begin{array}{l}\text { pGreenlI0229-PREP- } \\
\text { pCERK1::cerk1 cvg2 }\end{array}$ & Basta & This work \\
\hline cerk1-2 & $\begin{array}{l}\text { pGreenll0229-PREP- } \\
\text { pCERK1::cerk1 cvg3 }\end{array}$ & Basta & This work \\
\hline cerk1-2 & $\begin{array}{l}\text { pGreenll0229-PREP- } \\
\text { pCERK1::cerk1 clx }\end{array}$ & Basta & This work \\
\hline cerk1-2 & $\begin{array}{l}\text { pGreenlI0229-PREP- } \\
\text { pCERK1::cerk1 Del1 }\end{array}$ & Basta & This work \\
\hline cerk1-2 & $\begin{array}{l}\text { pGreenlI0229-PREP- } \\
\text { pCERK1::cerk1 Del2 }\end{array}$ & Basta & This work \\
\hline cerk1-2 & $\begin{array}{l}\text { pGreenll0229-PREP- } \\
\text { pCERK1::cerk1 cerk1 fls2tm }\end{array}$ & Basta & This work \\
\hline cerk1-2 & $\begin{array}{l}\text { pGreenll0229-PREP- } \\
\text { pCERK1::cerk1 fls2tmex1 }\end{array}$ & Basta & This work \\
\hline cerk1-2 & $\begin{array}{l}\text { pGreenll0229-PREP- } \\
\text { pCERK1::cerk1 fls2tmex2 }\end{array}$ & Basta & This work \\
\hline cerk1-2 & $\begin{array}{l}\text { pGreenlI0229-PREP- } \\
\text { pCERK1::cerk1 fls2tmex3 }\end{array}$ & Basta & This work \\
\hline cerk1-2 & $\begin{array}{l}\text { pGreenll0229-PREP- } \\
\text { pCERK1::cerk1 -ks }\end{array}$ & Basta & This work \\
\hline cerk1-2 & $\begin{array}{l}\text { pGreenll0229-PREP- } \\
\text { pCERK1::cerk1 ks->aa }\end{array}$ & Basta & This work \\
\hline cerk1-2 & $\begin{array}{l}\text { pGreenll0229-PREP- } \\
\text { pCERK1::cerk1 -ks }\end{array}$ & Basta & This work \\
\hline nole1-2 cerk1-4 & $\begin{array}{l}\text { pGreenll0229-PREP- } \\
\text { pXLG2::XLG2 }\end{array}$ & Basta & This work \\
\hline $\begin{array}{l}\text { Col-3 gl1, nole1-2 } \\
\text { cerk1-4 }\end{array}$ & pGWB604-pXLG2::XLG2-GFP & Basta & This work \\
\hline Col-3 gl1 & $\begin{array}{l}\text { pGWB604-pXLG2::xlg2 } \\
\text { E293K-GFP }\end{array}$ & Basta & This work \\
\hline $\begin{array}{l}\text { Col-0, cerk1-2, } \\
\text { Col-3 gl1, cerk1-4 }\end{array}$ & $\begin{array}{l}\text { pGreenll0229-PREP - } \\
\text { pXLG2::Venus-XLG2 }\end{array}$ & Basta & This work \\
\hline
\end{tabular}




\subsubsection{Nicotiana benthamiana}

$N$. benthamiana seeds were originally provided by $\mathrm{T}$. Romeis (Biochemistry of Plants, Institute of Biology, Freie Universität Berlin). N. benthamiana plants were used for transient expression mediated by Agrobacterium tumefaciens.

\subsubsection{Pathogens}

\subsubsection{Fungal pathogens}

\subsection{Powdery mildews}

The non-adapted filamentous powdery mildew Blumeria graminis f.sp. hordei (Lipka et al., 2005) was used for inoculation experiments of Arabidopsis plants.

\subsubsection{Bacterial strains used for cloning and transformation}

\subsubsection{Escherichia coli}

Chemically competent $E$. coli TOP10 (F- mcrA $\Delta$ (mrr-hsdRMS-mcrBC) Ф80lacZ $\Delta \mathrm{M} 15$ $\Delta$ lacX74 deoR recA1 araD139 $\Delta$ (ara-leu)7697 galU galK rpsL (StrR) endA1 nupG) cells (Thermo Scientific ${ }^{\mathrm{TM}}$, Waltham, USA) were used for cloning and transformation.

\subsubsection{Agrobacterium tumefaciens}

Electro-competent Agrobacterium tumefaciens GV3101 were used in this study containing resistance against rifampicin and gentamycin (Koncz \& Schell, 1986). Agrobacteria contained the additional helper plamsmid pSoup conferring tetracycline resistance (Hellens et al., 2000).

\subsubsection{Yeast strains used for cloning and transformation}

For transformation and cloning by drag and drop the Saccharomyces cerevisae strain S288c

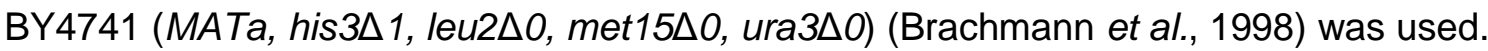




\subsubsection{Vectors used in this study}

Table 4 lists the vectors used or generated in this study.

Table 4. Vectors used in this study.

\begin{tabular}{|c|c|c|c|}
\hline Name & Description & Resistance & Reference \\
\hline $\begin{array}{l}\text { pGreenll0229PREP- } \\
\text { pCERK1::CERK1 }\end{array}$ & & $\begin{array}{l}\text { Bacterial resistance: Kan } \\
\text { Plant resistance: Basta }\end{array}$ & This work \\
\hline $\begin{array}{l}\text { pGreenll0229PREP- } \\
\text { pCERK1::cerk1 cvg1 }\end{array}$ & $\begin{array}{l}\text { Synthesized by } \\
\text { GeneWiz (South } \\
\text { Plainfield) and } \\
\text { subcloned into } \\
\text { pGreenll0229- } \\
\text { PREP }\end{array}$ & $\begin{array}{l}\text { Bacterial resistance: Kan } \\
\text { Plant resistance: Basta }\end{array}$ & This work \\
\hline $\begin{array}{l}\text { pGreenll0229PREP- } \\
\text { pCERK1::cerk1-4 } \\
\text { cvg1 }\end{array}$ & $\begin{array}{l}\text { Synthesized by } \\
\text { GeneWiz (South } \\
\text { Plainfield) and } \\
\text { subcloned into } \\
\text { pGreenll0229PREP }\end{array}$ & $\begin{array}{l}\text { Bacterial resistance: Kan } \\
\text { Plant resistance: Basta }\end{array}$ & This work \\
\hline $\begin{array}{l}\text { pGreenll0229PREP- } \\
\text { pCERK1::cerk1 cvg2 }\end{array}$ & $\begin{array}{l}\text { Synthesized by } \\
\text { GeneWiz (South } \\
\text { Plainfield) and } \\
\text { subcloned into } \\
\text { pGreenll0229PREP }\end{array}$ & $\begin{array}{l}\text { Bacterial resistance: Kan } \\
\text { Plant resistance: Basta }\end{array}$ & This work \\
\hline $\begin{array}{l}\text { pGreenlI0229PREP- } \\
\text { pCERK1::cerk1 cvg3 }\end{array}$ & $\begin{array}{l}\text { Synthesized by } \\
\text { GeneWiz (South } \\
\text { Plainfield) and } \\
\text { subcloned into } \\
\text { pGreenll0229PREP }\end{array}$ & $\begin{array}{l}\text { Bacterial resistance: Kan } \\
\text { Plant resistance: Basta }\end{array}$ & This work \\
\hline $\begin{array}{l}\text { pGreenll0229PREP- } \\
\text { pCERK1::cerk1 clx }\end{array}$ & $\begin{array}{l}\text { Synthesized by } \\
\text { GeneWiz (South } \\
\text { Plainfield) and } \\
\text { subcloned into } \\
\text { pGreenll0229PREP }\end{array}$ & $\begin{array}{l}\text { Bacterial resistance: Kan } \\
\text { Plant resistance: Basta }\end{array}$ & This work \\
\hline $\begin{array}{l}\text { pGreenll0229PREP- } \\
\text { pCERK1::cerk1 Del1 }\end{array}$ & & $\begin{array}{l}\text { Bacterial resistance: Kan } \\
\text { Plant resistance: Basta }\end{array}$ & This work \\
\hline $\begin{array}{l}\text { pGreenll0229PREP- } \\
\text { pCERK1::cerk1 Del2 }\end{array}$ & & $\begin{array}{l}\text { Bacterial resistance: Kan } \\
\text { Plant resistance: Basta }\end{array}$ & This work \\
\hline $\begin{array}{l}\text { pGreenll0229PREP- } \\
\text { pCERK1::cerk1 } \\
\text { cerk1 fls2tm }\end{array}$ & & $\begin{array}{l}\text { Bacterial resistance: Kan } \\
\text { Plant resistance: Basta }\end{array}$ & This work \\
\hline
\end{tabular}


Table 4 (continued).

\begin{tabular}{|c|c|c|}
\hline $\begin{array}{l}\text { pGreenll0229PREP- } \\
\text { pCERK1::cerk1 } \\
\text { fls2tmex1 }\end{array}$ & $\begin{array}{l}\text { Bacterial resistance: Kan } \\
\text { Plant resistance: Basta }\end{array}$ & This work \\
\hline $\begin{array}{l}\text { pGreenlI0229PREP- } \\
\text { pCERK1::cerk1 } \\
\text { fls2tmex2 }\end{array}$ & $\begin{array}{l}\text { Bacterial resistance: Kan } \\
\text { Plant resistance: Basta }\end{array}$ & This work \\
\hline $\begin{array}{l}\text { pGreenll0229PREP- } \\
\text { pCERK1::cerk1 } \\
\text { fls2tmex3 }\end{array}$ & $\begin{array}{l}\text { Bacterial resistance: Kan } \\
\text { Plant resistance: Basta }\end{array}$ & This work \\
\hline $\begin{array}{l}\text { pGreenll0229PREP- } \\
\text { pCERK1::cerk1 -ks }\end{array}$ & $\begin{array}{l}\text { Bacterial resistance: Kan } \\
\text { Plant resistance: Basta }\end{array}$ & This work \\
\hline $\begin{array}{l}\text { pGreenll0229PREP- } \\
\text { pCERK1::cerk1 ks- } \\
>\text { aa }\end{array}$ & $\begin{array}{l}\text { Bacterial resistance: Kan } \\
\text { Plant resistance: Basta }\end{array}$ & This work \\
\hline $\begin{array}{l}\text { pGreenll0229PREP- } \\
\text { pCERK1::cerk1 -ks }\end{array}$ & $\begin{array}{l}\text { Bacterial resistance: Kan } \\
\text { Plant resistance: Basta }\end{array}$ & This work \\
\hline $\begin{array}{l}\text { pGreenll0229PREP- } \\
\text { pXLG2::XLG2 }\end{array}$ & $\begin{array}{l}\text { Bacterial resistance: Kan } \\
\text { Plant resistance: Basta }\end{array}$ & $\begin{array}{l}\text { Elena } \\
\text { Petutschnig } \\
\text { (unpublished) }\end{array}$ \\
\hline $\mathrm{pENTR}^{\mathrm{TM}} / \mathrm{D}-\mathrm{TOPO}{ }^{\mathrm{B}}$ & Kan & Inivitrogen $^{\top \mathrm{M}}$ \\
\hline $\begin{array}{l}\text { pGWB604; no } \\
\text { promoter, C-sGFP }\end{array}$ & $\begin{array}{l}\text { Bacterial resistance: Spc } \\
\text { Plant resistance: Basta }\end{array}$ & $\begin{array}{l}\text { Nakamura et al. } \\
\text { (2010) }\end{array}$ \\
\hline $\begin{array}{l}\text { pGWB604+ } \\
\text { pXLG2::XLG2-GFP }\end{array}$ & $\begin{array}{l}\text { Bacterial resistance: Spc } \\
\text { Plant resistance: Basta }\end{array}$ & This work \\
\hline $\begin{array}{l}\text { pGWB604- } \\
\text { pXLG2::xlg2 E293K- } \\
\text { GFP }\end{array}$ & $\begin{array}{l}\text { Bacterial resistance: Spc } \\
\text { Plant resistance: Basta }\end{array}$ & This work \\
\hline $\begin{array}{l}\text { pGreenlI0229PREP } \\
\text { - } \\
\text { pXLG2::Venus- } \\
\text { XLG2 }\end{array}$ & $\begin{array}{l}\text { Bacterial resistance: Kan } \\
\text { Plant resistance: Basta }\end{array}$ & This work \\
\hline $\begin{array}{l}\text { pGreenlI0229-JE - } \\
\text { pLYK5::LYK5-mKate }\end{array}$ & $\begin{array}{l}\text { Bacterial resistance: Kan } \\
\text { Plant resistance: Basta }\end{array}$ & Jan Erwig \\
\hline $\begin{array}{l}\text { pHG34 + p35S- } \\
\text { mCherry }\end{array}$ & $\begin{array}{l}\text { Bacterial resistance: Amp } \\
\text { Plant resistance: Basta }\end{array}$ & $\begin{array}{l}\text { Hassan } \\
\text { Ghareeb }\end{array}$ \\
\hline $\begin{array}{l}\text { pHG77p-H2B- } \\
\text { TagRFP-T-TQ2- } \\
\text { LTI6b }\end{array}$ & $\begin{array}{l}\text { Bacterial resistance: Kan } \\
\text { Plant resistance: Hyg }\end{array}$ & $\begin{array}{l}\text { Hassan } \\
\text { Ghareeb }\end{array}$ \\
\hline pGreenll-0229 & $\begin{array}{l}\text { Bacterial resistance: Kan } \\
\text { Plant resistance: Basta }\end{array}$ & $\begin{array}{l}\text { Hellens et al. } \\
(2000)\end{array}$ \\
\hline pRS426 & $\begin{array}{l}\text { Bacterial resistance: Amp } \\
\text { Yeast marker: Uracil }\end{array}$ & $\begin{array}{l}\text { Christianson et } \\
\text { al. (1992) }\end{array}$ \\
\hline
\end{tabular}




\subsubsection{Oligonucleotides}

Oligonucleotides used in this study are given in Table 5.

Table 5. Primer used in this study.

\begin{tabular}{|c|c|c|}
\hline Name & Sequence $5^{\prime}$-> 3' & Description \\
\hline \multicolumn{3}{|c|}{ Primer used for cloning } \\
\hline CM1 & $\begin{array}{l}\text { GTAACGCCAGGGTTTTCCCAGTCACGACAA } \\
\text { GCTTCAAAATGAAGCTAAAGATTTCTCTAATC }\end{array}$ & $\begin{array}{l}\text { Forward primer for } \\
\text { amplification of CERK1 with } \\
\text { additional HindlII restriction } \\
\text { site and pRS426 overhang }\end{array}$ \\
\hline $\mathrm{CM} 2$ & ACCAACACCATCTTGTTTACTTG & $\begin{array}{l}\text { Reverse primer for amplifying } \\
\text { CERK1 without } \\
\text { transmembrane domain }\end{array}$ \\
\hline CM3 & $\begin{array}{l}\text { TTCAAATCAAGTAAACAAGATGGTGTTGGTG } \\
\text { TCATCCTGATTATTCTTGGATCAGCCGC }\end{array}$ & $\begin{array}{l}\text { Forward primer for } \\
\text { amplification of FLS2 } \\
\text { transmembrane domain with } \\
\text { overhang homologues to } \\
\text { CERK1 }\end{array}$ \\
\hline CM4 & $\begin{array}{l}\text { CTTCGACTTATTCTTCCGGTAAGCATAATATA } \\
\text { GAATCAGAACAAGAAGCAGGACAAGAAG }\end{array}$ & $\begin{array}{l}\text { Reverse primer for } \\
\text { amplification of FLS2 } \\
\text { transmembrane domain with } \\
\text { overhang homologues to } \\
\text { CERK1 }\end{array}$ \\
\hline CM5 & TATTATGCTTACCGGAAGAATAAGTCG & $\begin{array}{l}\text { Forward primer for amplifying } \\
\text { CERK1 without } \\
\text { transmembrane domain }\end{array}$ \\
\hline CM7 & $\begin{array}{l}\text { CTATACCAGCAATAACTCCAGCACCAACACC } \\
\text { TCCAGGCACATAAACGATTCCATTCCCGG }\end{array}$ & $\begin{array}{l}\text { Reverse primer for } \\
\text { amplification of CERK1 for } \\
\text { deletion of } 16 \text { amino acids }\end{array}$ \\
\hline CM8 & GGTGTTGGTGCTGGAGTTATTGCTGGTATAG & $\begin{array}{ll}\text { Forward } & \text { primer for } \\
\text { amplification of CERK1 for } \\
\text { deletion of } 16 \text { amino acids }\end{array}$ \\
\hline CM9 & $\begin{array}{l}\text { GCGGATAACAATTTCACACAGGAAACAGCTG } \\
\text { GATCCCCCGGGCTGCAGGAATTCTAC }\end{array}$ & $\begin{array}{l}\text { Reverse primer for } \\
\text { amplification of CERK1 with } \\
\text { additional Smal restriction } \\
\text { site and pRS426 overhang }\end{array}$ \\
\hline CM12 & $\begin{array}{l}\text { AACTCCAGCACCAACTGATTTGAATGGTGGA } \\
\text { AATGCACC }\end{array}$ & $\begin{array}{l}\text { Reverse primer for deletion of } \\
5 \text { amino acids within the } \\
\text { CERK1 extracellular stalk }\end{array}$ \\
\hline CM13 & $\begin{array}{l}\text { CCACCATTCAAATCAGTTGGTGCTGGAGTTA } \\
\text { TTGCTGGT }\end{array}$ & $\begin{array}{l}\text { Forward primer for deletion of } \\
5 \text { amino acids within the } \\
\text { CERK1 extracellular stalk }\end{array}$ \\
\hline
\end{tabular}


Table 5 (continued).

\begin{tabular}{|c|c|c|}
\hline CM33 & $\begin{array}{l}\text { GATCCAAATGGTGCATTTCCACCATTCAAAA } \\
\text { TCAACGCCTCTGATCTAATGGGAAAC }\end{array}$ & $\begin{array}{lcr}\text { Forward } & \text { primer } & \text { for } \\
\text { amplification } & \text { of } & \text { FLS2 } \\
\text { extracellular } & \text { stalk } & \text { with } \\
\text { overhang } & \text { homologues } & \text { to } \\
\text { CERK1 } & & \end{array}$ \\
\hline CM34 & TTTGAATGGTGGAAATGCACC & $\begin{array}{l}\text { Reverse Primer } r \text { for } \\
\text { amplification of CERK1 } \\
\text { ectodomain for }\end{array}$ \\
\hline CM35 & $\begin{array}{l}\text { GATCCAAATGGTGCATTTCCACCATTCAAAA } \\
\text { GCCACTTCTCGAAGAGAACCAGAGTC }\end{array}$ & $\begin{array}{lrr}\text { Forward } & \text { primer } & \text { for } \\
\text { amplification } & \text { of } & \text { FLS2 } \\
\text { extracellular } & \text { stalk } & \text { and } \\
\text { transmembrane } & \text { domain } & \text { with } \\
\text { overhang homologues } & \text { to } \\
\text { CERK1 } & & \end{array}$ \\
\hline CM36 & AGGCACATAAACGATTCCATTCCCGG & $\begin{array}{lcr}\text { Reverse } & \text { Primer } & \text { for } \\
\text { amplification } & \text { of } & \text { CERK1 } \\
\text { ectodomain for } & \text { FLS2 fusion }\end{array}$ \\
\hline CM37 & $\begin{array}{l}\text { AACTCCGGGAATGGAATCGTTTATGTGCCTA } \\
\text { TCAACGCCTCTGATCTAATGGGAAAC }\end{array}$ & $\begin{array}{lrr}\text { Forward } & \text { primer } & \text { for } \\
\text { amplification } & \text { of } & \text { FLS2 } \\
\text { extracellular } & \text { stalk } & \text { and } \\
\text { transmembrane domain } & \text { with } \\
\text { overhang homologues } & \text { to } \\
\text { CERK1 } & & \end{array}$ \\
\hline CM55 & $\begin{array}{l}\text { TGGTGCATTTCCACCATTCGCAGCAAGTAAA } \\
\text { CAAGATGGTGTTG }\end{array}$ & $\begin{array}{lll}\text { Forward } & \text { primer } & \text { for } \\
\text { replacement } & \text { of } \text { CERK1 } & \text { KS } \\
\text { with AA } & & \\
\end{array}$ \\
\hline CM56 & $\begin{array}{l}\text { CAACACCATCTTGTTTACTTGCTGCGAATGG } \\
\text { TGGAAATGCACCA }\end{array}$ & $\begin{array}{lll}\text { Reverse } & \text { primer } & \text { for } \\
\text { replacement } & \text { of } \text { CERK1 } & \mathrm{KS} \\
\text { with AA } & & \\
\end{array}$ \\
\hline CM57 & GAATGGTGGAAATGCACCATTTGG & $\begin{array}{l}\text { Reverse primer for CERK1 } \\
\text { KS deletion }\end{array}$ \\
\hline CM58 & $\begin{array}{l}\text { AGAGATCCAAATGGTGCATTTCCACCATTCA } \\
\text { GTAAACAAGATGGTGTTGGTGCTGGAGTTAT } \\
\text { TG }\end{array}$ & $\begin{array}{l}\text { Forward primer for CERK1 } \\
\text { KS deletion }\end{array}$ \\
\hline CM82 & $\begin{array}{l}\text { GTAACGCCAGGGTTTTCCCAGTCACGACGG } \\
\text { GCGCGCCCCTGGAGGAGCATAGTGTGATTA } \\
\text { TTTACGAGAGTG }\end{array}$ & $\begin{array}{l}\text { Forward primer for } \\
\text { amplification of the XLG2 } \\
\text { promoter with additional } \\
\text { pRS426 homology and Ascl } \\
\text { site }\end{array}$ \\
\hline CM83 & $\begin{array}{l}\text { GCGGATAACAATTTCACACAGGAAACAGCG } \\
\text { GATCCTCAAGAGGACGAGCTGGCCTCTATG } \\
\text { CTAGTAG }\end{array}$ & $\begin{array}{l}\text { Reverse primer for } \\
\text { amplification of XLG2 with } \\
\text { additional pRS426 homology } \\
\text { and BamHI site }\end{array}$ \\
\hline
\end{tabular}


Table 5 (continued).

\begin{tabular}{|c|c|c|}
\hline CM92 & $\begin{array}{l}\text { GGTGAACAGCTCCTCGCCCTTGCTCACCAT } \\
\text { CTTCTTACCCAATCAAGCACACATACAAACC } \\
\text { C }\end{array}$ & $\begin{array}{l}\text { Reverse primer for } \\
\text { amplification of XLG2 } \\
\text { promoter with overhang } \\
\text { homologues to Venus }\end{array}$ \\
\hline CM93 & $\begin{array}{l}\text { AGGTAATAACTTTCTTATAACTGCAGCCATC } \\
\text { GCTCCAGCGCCCTTGTACAGCTCGTCCATG } \\
\text { CCGAGAGTGATCCC }\end{array}$ & $\begin{array}{l}\text { Reverse primer for } \\
\text { amplification of Venus } \text { with } \\
\text { homology to XLG2 with } \\
\text { additional YAGA linker }\end{array}$ \\
\hline CM94 & $\begin{array}{l}\text { ATGGCTGCAGTTATAAGAAAGTTATTACCTTT } \\
\text { C }\end{array}$ & $\begin{array}{l}\text { Forward primer for } X L G 2 \\
\text { amplification }\end{array}$ \\
\hline JE23 & ATGGTGAGCAAGGGCGAGGAGC & $\begin{array}{l}\text { Forward primer for Venus } \\
\text { amplification }\end{array}$ \\
\hline EP209 & $\begin{array}{l}\text { ACTGCAGGCGCGCCTGGAGGAGCATAGTGT } \\
\text { GATTATTTAC }\end{array}$ & 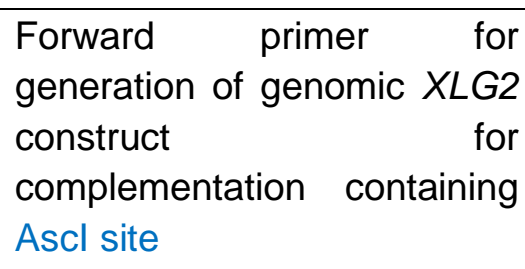 \\
\hline EP210 & $\begin{array}{l}\text { TGAGCTGGATCCTCAAGAGGACGAGCTGGC } \\
\text { CTCTATG }\end{array}$ & $\begin{array}{lr}\text { Reverse primer ror } \\
\text { generation of genomic } X L G 2 \\
\text { construct } & \text { for } \\
\text { complementation } & \text { containing } \\
\text { BamHI site } & \end{array}$ \\
\hline EP314 & caccTGGAGGAGCATAGTGTGATTATTTAC & $\begin{array}{l}\text { Forward primer for } \\
\text { generation of } X L G 2-G F P \text { and } \\
X L G 2 \text { E293K-GFP with cacc } \\
\text { gateway site }\end{array}$ \\
\hline EP315 & AGAGGACGAGCTGGCCTCTATGC & $\begin{array}{l}\text { Reverse primer for } \\
\text { generation of } X L G 2-G F P \text { and } \\
\text { xlg2 E293K-GFP without } \\
\text { XLG2 stop codon }\end{array}$ \\
\hline \multicolumn{3}{|c|}{ Primer used for sequencing } \\
\hline $\begin{array}{l}\text { 35S } \\
\text { GC359 }\end{array}$ & CTATAAGAACCCTAATTCССТTATCTG & $35 S$ terminator reverse \\
\hline CM73 & GATTCTGAACTTCGACAAGTCATGAATCTC & $\begin{array}{l}\text { Forward dCAPS primer } \\
\text { introducing containing a } \\
\text { partly Xhol restriction site for } \\
\text { genotyping } x \text { lg2 E293K }\end{array}$ \\
\hline CM75 & GTAGTTAAAAATCCTTCAAATTC & $A G B 1$ sequencing \\
\hline CM76 & CAATAAGACCAAACCTATATGTTG & $A G B 1$ sequencing \\
\hline CM77 & GTTCAGGTGATCAAACTTGTATCTTATGGG & $A G B 1$ sequencing \\
\hline CM78 & CTTGCTCGGATTTGAAAACCACTACC & $A G B 1$ sequencing \\
\hline CM74 & CCAATAGTGTCCGGGTTTTAGCTTCTTGG & $\begin{array}{l}\text { Reverse dCPAPs primer for } \\
\text { genotyping } x \text { lg2 E293K }\end{array}$ \\
\hline
\end{tabular}


Table 5 (continued).

\begin{tabular}{|c|c|c|}
\hline EP164 & GACTGGTGATTTTTGCGGACTC & $35 S$ terminator reverse \\
\hline CM81 & CATGAATGTATCTTCACACTAC & $X L G 2$ sequencing \\
\hline EP219 & CCTAACCCGCGTTGACGGCAAG & $X L G 2$ sequencing \\
\hline EP221 & CCGGGAAATAACCAAGCCAGAG & $X L G 2$ sequencing \\
\hline EP233 & AACTGGCAGAGAGAACACAGC & $X L G 2$ sequencing \\
\hline MS226 & GGCGCTTGAGCATTCTTGAACAC & $X L G 2$ sequencing \\
\hline JH15 & CCGGTAAGCATAATATACGATA & CERK1 sequencing \\
\hline MS122 & TCGAAACAGTTCTTGGCGGAAC & CERK1 sequencing \\
\hline MS148 & TGGACCTACCTTTCACAGCATTTC & $P A D 4$ sequencing \\
\hline MS149 & ACGGACGTGATGGCATACAAAC & $P A D 4$ sequencing \\
\hline MS150 & CCACCATTTGGAATATGTCATTG & $P A D 4$ sequencing \\
\hline MS151 & ACGCCACTTGTGTCATCGTTAGAG & $P A D 4$ sequencing \\
\hline MS152 & CACCGAGGAACATCAGAGGTACG & $P A D 4$ sequencing \\
\hline MS153 & ACATGAGAAACTCTTTGCACATTG & PAD4 sequencing \\
\hline MS154 & GCTACATCAGTCCCCTATTTATATC & SID2 sequencing \\
\hline MS155 & CCTTGCCTTTACAACAAATTGG & SID2 sequencing \\
\hline MS156 & TAGTGTGGCCATGCTAAG & SID2 sequencing \\
\hline MS157 & AAGACCTACCGTGTTTCC & SID2 sequencing \\
\hline MS158 & TGGCTAGCACAGTTACAG & SID2 sequencing \\
\hline MS159 & AGGTCCCGCATACATTCCTCTATC & SID2 sequencing \\
\hline MS160 & ATTGGCTGCTCTGCATCCAAC & SID2 sequencing \\
\hline MS161 & AAAGGCCCAAGCATTCTACGG & SID2 sequencing \\
\hline MS164 & GTCTCCAATAGCCAAAGAGTC & EDS1 sequencing \\
\hline MS165 & GCAAGAACATGAGGCAAAG & EDS1 sequencing \\
\hline MS166 & AATGGAGCCGGTTCTTTGTG & EDS1 sequencing \\
\hline MS167 & GCTCAACTAATCTGCGGTATCG & EDS1 sequencing \\
\hline MS168 & CGAGGTGCTTGGTTTAATG & EDS1 sequencing \\
\hline MS169 & TAGTGCTCCGTTTGGTTAG & EDS1 sequencing \\
\hline UL154 & TCTTCTTCCCCACAGAGCAACGACG & CERK1 sequencing \\
\hline UL166 & TTCCAGGCACATAAACGATTCC & CERK1 sequencing \\
\hline UL167 & TTACGTATCCGCTTCGTCCTGAAG & CERK1 sequencing \\
\hline
\end{tabular}

Primer used for semi-quantitative RT-PCR

\begin{tabular}{lll}
\hline EP13 & AGACTCATACACTCTGGTGGGCCTT & $P R 1 \mathrm{fw}$ \\
\hline EP14 & CGTCCTTTATGTACGTGTGTATGCA & $P R 1 \mathrm{rev}$ \\
\hline EP15 & TAATCATCATGGCTAAGTTTGCTTC & $P D F 1.2 \mathrm{fw}$ \\
\hline EP16 & GCATGTCATAAAGTTACTCATAGAGTG & $P D F 1.2 \mathrm{rev}$ \\
\hline Act fw & TGCGACAATGGAACTGGAATG & Actin fw \\
\hline Act rev & GGATAGCATGTGGAAGTGCATAC & Actin rev
\end{tabular}




\subsubsection{Enzymes}

\subsubsection{Restriction endonucleases}

Restriction endonucleases were obtained from New England BioLabs (Frankfurt/Main, Germany) or Thermo Scientific ${ }^{\mathrm{TM}}$ (Life Technologies $\mathrm{GmbH}$, Darmstadt, Germany) and were used according to the manufacturer's manual.

\subsubsection{Nucleic acid modifying enzymes}

Homemade Taq polymerase was used for colony and genotyping PCRs. For cloning, iProof High-Fidelity DNA Polymerase (BioRad, München, Germany) was used.

\subsubsection{Chemicals}

Chemicals were obtained from Bio-Rad (Munich, Germany), Difco (Heidelberg, Germany), Duchefa (Haarlem, Netherlands), Thermo Scientific ${ }^{\mathrm{TM}}$ (Waltham, USA), GE Healthcare (Munich, Germany), Macherey Nagel (Düren, Germany), Merck (Darmstadt, Germany), New England BioLabs (NEB) (Frankfurt/Main, Germany), Roche (Mannheim, Germany), Roth (Karlsruhe, Germany), Serva (Heidelberg, Germany), Sigma-Aldrich (Deisenhofen, Germany) or VWR ${ }^{\mathrm{TM}}$ (Darmstadt, Germany).

\subsubsection{Antibiotics}

The following antibiotic stock solutions were used. Stock solutions were filter sterilized and stored at $-20{ }^{\circ} \mathrm{C}$. For the final working concentration, stocks were used at a dilution of 1:1000.

Ampicillin

Gentamycin

Phosphinothricin

Rifampicin

Spectinomycin

Tetracyclin
$100 \mathrm{mg} / \mathrm{ml}$ in $\mathrm{dd}_{2} \mathrm{O}$

$15 \mathrm{mg} / \mathrm{ml}$ in $\mathrm{ddd}_{2} \mathrm{O}$

$25 \mathrm{mg} / \mathrm{ml}$ in $\mathrm{ddd}_{2} \mathrm{O}$

$20 \mathrm{mg} / \mathrm{ml}$ in methanol

$100 \mathrm{mg} / \mathrm{ml}$ in dd $\mathrm{H}_{2} \mathrm{O}$

$5 \mathrm{mg} / \mathrm{ml}$ in ethanol 


\subsubsection{Media}

Media were sterilized by autoclaving at $121^{\circ} \mathrm{C}$ for 20 minutes. Antibiotics were added after media were cooled down. The following media were used in this work:

\section{$\underline{1 / 2 \text { Murashige and Skoog (MS) medium }}$}

MS powder: $\quad 2.2 \mathrm{~g} / \mathrm{l}$

Sucrose: $\quad 0.5 \%$

The $\mathrm{pH}$ was adjusted to $\mathrm{pH} 5.7$ with $\mathrm{KOH}$. For $1 / 2 \mathrm{MS}$ plates, $4.5 \mathrm{~g} / \mathrm{l}$ plant agar were added. Phosphinothricin $(25 \mu \mathrm{g} / \mu \mathrm{l})$ was added for selection of transgenic plants expressing phosphinothricin acetyltransferase (PAT) conferring BASTA resistance.

\section{Lysogeny broth (LB) medium:}

$\begin{array}{lr}\text { Peptone: } & 10 \mathrm{~g} / \mathrm{l} \\ \text { Yeast extract: } & 5 \mathrm{~g} / \mathrm{l} \\ \mathrm{NaCl}: & 10 \mathrm{~g} / \mathrm{l}\end{array}$

For LB agar plates, $1.5 \%(\mathrm{w} / \mathrm{v})$ bacterial grade agar was added before autoclaving.

Yeast extract-peptone dextrose (YPD) medium:

Yeast extract: $\quad 10 \mathrm{~g} / \mathrm{l}$

Peptone: $\quad 20 \mathrm{~g} / \mathrm{l}$

Glucose $20 \mathrm{~g} / \mathrm{l}$

For YPD agar plates, $1.5 \%(\mathrm{w} / \mathrm{v})$ bacterial grad agar was added before autoclaving.

Synthetic complete (SC) medium (-Uracil, +Glucose):

Yeast nitrogen base (YNB)

w/o amino acids:

$13.4 \mathrm{~g} / \mathrm{l}(2 \mathrm{x})$

Amino acid drop-out mix (-Ura): $\quad 4.0 \mathrm{~g} / \mathrm{l}(2 \mathrm{x})$

Adjust to ph 5.6 with $\mathrm{NaOH}$

Agar:

$40.0 \mathrm{~g} / \mathrm{l}(2 \mathrm{x})$

Glucose:

$40.0 \mathrm{~g} / \mathrm{l}(2 \mathrm{x})$

Glucose was prepared and autoclaved separately from the remaining components. After autoclaving, the glucose solution and the medium prepared with the other components were mixed in a 1:1 ratio before pouring plates. 


\subsubsection{Buffers and solutions}

Buffers and solutions used in this work are listed in Table 6. Ultra-pure water was used for the preparation of all buffers and solutions. Sterilization was either carried out by autoclaving at $121^{\circ} \mathrm{C}$ for 20 minutes or by filter-sterilization.

Table 6. Buffers used in this study.

\begin{tabular}{|c|c|c|}
\hline \multicolumn{3}{|c|}{ Buffer for bacterial infiltration } \\
\hline Agrobacterium & $\mathrm{MgCl}_{2}$ & $10 \mathrm{mM}$ \\
\hline Infiltration medium & Acetosyringone & $150 \mu \mathrm{M}$ \\
\hline \multicolumn{3}{|c|}{ PCR and gel electrophoresis } \\
\hline \multirow[t]{3}{*}{ TAE (50x) } & Tris base & $242 \mathrm{~g} / \mathrm{l}$ \\
\hline & Glacial acetic acid & $51.1 \mathrm{ml} / \mathrm{l}$ \\
\hline & EDTA (0.5 M; pH 8.0) & $100 \mathrm{ml} / \mathrm{l}$ \\
\hline \multirow{5}{*}{$\begin{array}{l}\text { Homemade Taq buffer } \\
(10 x)\end{array}$} & Tris & $100 \mathrm{mM}$ \\
\hline & $\mathrm{KCl}$ & $500 \mathrm{mM}$ \\
\hline & $\mathrm{MgCl}_{2}$ & $15 \mathrm{mM}$ \\
\hline & Triton X-100 & $1 \%$ \\
\hline & Adjust to $\mathrm{pH} 9.0$ & \\
\hline \multirow[t]{2}{*}{ TE buffer } & Tris-HCl, ph 8.0 & $2 \mathrm{M}$ \\
\hline & EDTA & $1 \mathrm{mM}$ \\
\hline \multirow[t]{4}{*}{ DNA loading dye (6x) } & Sucrose & $4 \mathrm{~g}$ \\
\hline & $\operatorname{EDTA}(0.5 \mathrm{M})$ & $2 \mathrm{ml}$ \\
\hline & Bromophenol blue & $25 \mathrm{mg}$ \\
\hline & Add $\mathrm{dd} \mathrm{H}_{2} \mathrm{O}$ to $10 \mathrm{~mL}$ & \\
\hline \multicolumn{3}{|c|}{ Extraction of genomic DNA } \\
\hline \multirow[t]{4}{*}{ Extraction buffer } & Tris- $\mathrm{HCl}, \mathrm{pH} 7.5$ & $0.2 \mathrm{M}$ \\
\hline & $\mathrm{NaCl}$ & $1.25 \mathrm{M}$ \\
\hline & EDTA & $25 \mathrm{mM}$ \\
\hline & SDS & $0.5 \%$ \\
\hline \multicolumn{3}{|c|}{ Plasmid preparation (alkaline lysis) } \\
\hline \multirow[t]{4}{*}{ P1 buffer } & Tris- $\mathrm{HCl}, \mathrm{pH} 8.0$ & $50 \mathrm{mM}$ \\
\hline & EDTA, pH 8.0 & $10 \mathrm{mM}$ \\
\hline & RNase A (DNase free) & $100 \mu \mathrm{g} / \mu \mathrm{l}$ \\
\hline & Storage at $4 \%$ after RNase $A$ addition & \\
\hline \multirow[t]{2}{*}{ P2 buffer } & $\mathrm{NaOH}$ & $200 \mathrm{mM}$ \\
\hline & SDS & $1 \%$ \\
\hline \multirow[t]{2}{*}{ P3 buffer } & KOAc & \\
\hline & Acetic acid & $2 \mathrm{M}$ \\
\hline
\end{tabular}


Table 6 (continued).

\begin{tabular}{lll}
\hline \multicolumn{3}{l}{ Buffers for preparation of chemically competent E.coli cells } \\
\hline CCMB80 buffer & $\mathrm{KOAc} \mathrm{pH} \mathrm{7.0}$ & $10 \mathrm{mM}$ \\
& $\mathrm{CaCl}_{2}$ & $80 \mathrm{mM}$ \\
$\mathrm{MnCl}_{2}$ & $20 \mathrm{mM}$ \\
$\mathrm{MgCl}_{2}$ & $10 \mathrm{mM}$ \\
& Glycerol & $10 \%(\mathrm{v} / \mathrm{v})$ \\
& Adjust to $\mathrm{pH} 6.4$ & \\
& Filter sterilze before use
\end{tabular}

\section{Buffers for cloning by homologous recombination in yeast}

\begin{tabular}{|c|c|c|}
\hline Li-PEG buffer & $\begin{array}{l}\text { Lithium acetate } \\
\text { Tris- } \mathrm{HCl}, \mathrm{pH} 8.0 \\
\text { EDTA, } \mathrm{pH} 8.0 \\
\text { PEG } 4000 \\
\text { Autoclave before use }\end{array}$ & $\begin{array}{l}100 \mathrm{mM} \\
10 \mathrm{mM} \\
1 \mathrm{mM} \\
50 \%(\mathrm{w} / \mathrm{v})\end{array}$ \\
\hline SORB buffer & $\begin{array}{l}\text { Lithium acetate } \\
\text { Tris- } \mathrm{HCl}, \mathrm{pH} 8.0 \\
\text { EDTA, pH } 8.0 \\
\text { Sorbitol } \\
\text { Autoclave before use }\end{array}$ & $\begin{array}{l}100 \mathrm{mM} \\
10 \mathrm{mM} \\
1 \mathrm{mM} \\
1 \mathrm{M}\end{array}$ \\
\hline \multicolumn{3}{|c|}{ Solutions for mass spectrometry analysis } \\
\hline & Ammonium bicarbonate (ABC) & $100 \mathrm{mM}$ \\
\hline & lodoacetamide (IAA) & $500 \mathrm{mM}$ \\
\hline & D-1,4-dithiothreitol & $100 \mathrm{mM}$ \\
\hline ABC/DTT solution & mix 1 vol DTT with 4 vol of ABC & \\
\hline & $\mathrm{NaCl}$ & $625 \mathrm{mM}$ \\
\hline & Tris-HCl pH 8.0 & $100 \mathrm{mM}$ \\
\hline & Ammonium formate (AF) $\mathrm{pH} 10$ & $20 \mathrm{mM}$ \\
\hline Trypsin stock solution & $\begin{array}{l}\text { Trypsin } \\
\mathrm{HCl} \text { (MS grade, Promega, Madison, USA) }\end{array}$ & $\begin{array}{l}100 \mathrm{ng} / \mu \mathrm{l} \\
10 \mathrm{mM}\end{array}$ \\
\hline \multicolumn{3}{|c|}{ Protein extraction, SDS PAGE and Immunoblotting } \\
\hline CERK1 extraction buffer & $\begin{array}{l}\text { Sucrose } \\
\text { HEPES-KOH, pH } 7.5 \\
\text { Glycerol } \\
\mathrm{Na}_{4} \mathrm{P}_{2} \mathrm{O}_{7} \\
\mathrm{Na}_{2} \mathrm{MoO}_{4} \\
\mathrm{NaF} \\
\text { EDTA } \\
\text { DTT } \\
\text { Triton X-100 } \\
\text { Add PIC }(1: 100) \text { prior to use }\end{array}$ & $\begin{array}{l}250 \mathrm{mM} \\
100 \mathrm{mM} \\
5 \%(\mathrm{v} / \mathrm{v}) \\
50 \mathrm{mM} \\
1 \mathrm{mM} \\
25 \mathrm{mM} \\
10 \mathrm{mM} \\
1 \mathrm{mM} \\
0.5 \%(\mathrm{v} / \mathrm{v})\end{array}$ \\
\hline
\end{tabular}


Table 6 (continued).

\begin{tabular}{|c|c|c|}
\hline \multirow[t]{7}{*}{$\begin{array}{l}\text { Protease inhibitor } \\
\text { cocktail (PIC, 100x) }\end{array}$} & $\begin{array}{l}\text { 4-(2-aminoethyl)benzenesulfonyl fluoride } \\
\text { hydrochloride (AEBSF) }\end{array}$ & $1 \mathrm{~g}$ \\
\hline & Bestatin hydrochloride & $5 \mathrm{mg}$ \\
\hline & Pepstatin A & $10 \mathrm{mg}$ \\
\hline & Leupeptin hemisulfate & $100 \mathrm{mg}$ \\
\hline & $\begin{array}{l}\text { E-64 (trans-epoxysuccinyl-L-leucylamido- } \\
\text { (4-guanidino)butane) }\end{array}$ & $10 \mathrm{mg}$ \\
\hline & $\begin{array}{l}\text { Phenanthroline (1, 10-phenanthroline } \\
\text { monohydrate) }\end{array}$ & $10 \mathrm{~g}$ \\
\hline & DMSO & Ad $2 \mathrm{ml}$ \\
\hline \multirow{5}{*}{$\begin{array}{l}\text { SDS sample } \\
\text { Buffer }(4 \mathrm{x})\end{array}$} & Tris-HCl, $\mathrm{pH} 6.8$ & $200 \mathrm{mM}$ \\
\hline & DTT & $400 \mathrm{mM}$ \\
\hline & SDS & $8 \%$ \\
\hline & Glycerol & $40 \%$ \\
\hline & Bromophenol blue & $0.1 \%$ \\
\hline \multirow[t]{3}{*}{ Stacking gel } & Tris-HCl, $\mathrm{pH} 6.8$ & $125 \mathrm{mM}$ \\
\hline & SDS & $0.1 \%$ \\
\hline & acrylamide/bis-acrylamide, $37.5: 1$ & $5 \%$ \\
\hline \multirow{3}{*}{$\begin{array}{l}\text { Resolving gel } \\
(8 \%)\end{array}$} & Tris-HCl, $\mathrm{pH} 8.8$ & $375 \mathrm{mM}$ \\
\hline & SDS & $0.1 \%$ \\
\hline & acrylamide/bis-acryladmide, $37.5: 1$ & $8 \%$ \\
\hline \multirow{3}{*}{$\begin{array}{l}\text { Resolving gel } \\
(10 \%)\end{array}$} & Tris-HCl, pH 8.8 & $375 \mathrm{mM}$ \\
\hline & SDS & $0.1 \%$ \\
\hline & acrylamide/bis-acryladmide, $37.5: 1$ & $10 \%$ \\
\hline \multirow{2}{*}{$\begin{array}{l}\text { Stacking gel } \\
\text { buffer }\end{array}$} & Tris- $\mathrm{HCl}, \mathrm{pH} 6.8$ & $150 \mathrm{mM}$ \\
\hline & SDS & $0.12 \%$ \\
\hline \multirow{2}{*}{$\begin{array}{l}\text { Resolving gel } \\
\text { buffer (8 \%) }\end{array}$} & Tris-HCl, $\mathrm{pH} 8.8$ & $525 \mathrm{mM}$ \\
\hline & SDS & $0.14 \%$ \\
\hline \multirow{2}{*}{$\begin{array}{l}\text { Resolving gel } \\
\text { buffer (10 \%) }\end{array}$} & Tris-HCl, $\mathrm{pH} 8.8$ & $575 \mathrm{mM}$ \\
\hline & SDS & $0.15 \%$ \\
\hline \multicolumn{3}{|c|}{ Mixtures for frequent use in SDS-PAGE and Immunoblotting } \\
\hline \multirow{3}{*}{$\begin{array}{l}\text { Stacking gel } \\
\text { buffer }\end{array}$} & Tris-HCl, ph 6.8 & $125 \mathrm{mM}$ \\
\hline & $10 \%$ SDS & $3.06 \mathrm{ml}$ \\
\hline & $\mathrm{H}_{2} \mathrm{O}$ & $208.36 \mathrm{ml}$ \\
\hline \multirow{3}{*}{$\begin{array}{l}\text { Resolving gel } \\
\text { buffer (8 \%) }\end{array}$} & 1 M Tris, $\mathrm{pH} 8.8$ & $130.9 \mathrm{ml}$ \\
\hline & $10 \%$ SDS & $3.46 \mathrm{ml}$ \\
\hline & $\mathrm{H}_{2} \mathrm{O}$ & $115.64 \mathrm{ml}$ \\
\hline \multirow{3}{*}{$\begin{array}{l}\text { Resolving gel } \\
\text { buffer (10\%) }\end{array}$} & 1 M Tris, $\mathrm{pH} 8.8$ & $143.6 \mathrm{ml}$ \\
\hline & $10 \%$ SDS & $3.79 \mathrm{ml}$ \\
\hline & $\mathrm{H}_{2} \mathrm{O}$ & $102.53 \mathrm{ml}$ \\
\hline
\end{tabular}


Table 6 (continued).

\begin{tabular}{lll}
\hline Stacking gel & Stacking gel buffer & $4.08 \mathrm{ml}$ \\
(per gel) & $30 \%$ acrylamide/bis-acrylamide, $37.5: 1$ & $0.83 \mathrm{ml}$ \\
& TEMED & $0.025 \mathrm{ml}$ \\
& $10 \%$ APS & $0.0025 \mathrm{ml}$ \\
\hline Resolving gel (8\%) & Resolving gel buffer (8\%) & $7.2 \mathrm{ml}$ \\
(per gel) & $30 \%$ acrylamide/bis-acrylamide, $37.5: 1$ & $2.7 \mathrm{ml}$ \\
& TEMED & $0.1 \mathrm{ml}$ \\
& $10 \%$ APS & $0.006 \mathrm{ml}$ \\
\hline Resolving gel 10\% & Resolving gel buffer (10\%) & $6.6 \mathrm{ml}$ \\
(per gel) & $30 \%$ acrylamide/bis-acrylamide, $37.5: 1$ & $3.3 \mathrm{ml}$ \\
& TEMED & $0.1 \mathrm{ml}$ \\
& $10 \%$ APS & $0.004 \mathrm{ml}$
\end{tabular}

\begin{tabular}{lll}
\hline SDS running & Tris & $30.28 \mathrm{~g} / \mathrm{l}$ \\
Buffer (10x) & Glycine & $144.13 \mathrm{~g} / \mathrm{l}$ \\
& SDS & $10 \mathrm{~g} / \mathrm{l}$ \\
\hline Transfer buffer & Tris & $1 \mathrm{M}$ \\
$(20 \mathrm{x})$ & Boric acid & $1 \mathrm{M}$ \\
& Adjust pH to 8.3 & \\
\hline TBS-T (20x) & $\mathrm{NaCl}$ & $3 \mathrm{M}$ \\
& Tris-HCl, pH 8.0 & $200 \mathrm{mM}$ \\
& Tween-20 & $1 \%$ \\
\hline Alkaline phosphatase & Tris, pH 9.5 & $100 \mathrm{mM}$ \\
(AP) buffer & NaCl & $100 \mathrm{mM}$ \\
& MgCl 2 & $50 \mathrm{mM}$ \\
\hline Staining solution for & Methanol & $45 \%(\mathrm{v} / \mathrm{v})$ \\
PVDF membranes & Acetic acid & $10 \%(\mathrm{v} / \mathrm{v})$ \\
& Coomassie R250 & $0.05 \%(\mathrm{w} / \mathrm{v})$ \\
\hline Destaining solution for & Methanol & $45 \%(\mathrm{v} / \mathrm{v})$ \\
PVDF membranes & Acetic acid & $10 \%(\mathrm{v} / \mathrm{v})$ \\
& Add H2O & \\
\hline \multicolumn{2}{c}{ Buffer stocks were diluted to 1x with ddH $\mathrm{H}_{2} \mathrm{O}$ before use } \\
\hline
\end{tabular}

\subsubsection{Antibodies}

The following table lists the antibodies used in this work. Antibodies were aliquoted and stored at $-80^{\circ} \mathrm{C}$. Aliquots in use were stored at $4{ }^{\circ} \mathrm{C}$. Secondary antibodies are conjugated to alkaline phosphatase (AP). 
Table 7. Antibodies used in this study.

\begin{tabular}{llll}
\hline Antibody & Source & Dilution & Reference \\
\hline a-CERK1 & Rabbit, polyclonal & $1: 3000$ & $\begin{array}{l}\text { Eurogentec Deutschland } \\
\text { GmbH,Köln, Germany }\end{array}$ \\
\hline a-GFP & Rat, monoclonal & $1: 3000$ & $\begin{array}{l}\text { Chromotek GmbH, Planegg- } \\
\text { Martiensried, Germany }\end{array}$ \\
\hline a-FLS2 & Rabbit, polyclonal & $1: 10000$ & Agrisera, Vännäs, Sweden \\
\hline a-BRI1 & Rabbit, polyclonal & $1: 5000$ & Agrisera, Vännäs, Sweden \\
\hline $\begin{array}{l}\text { a-Rabbit } \\
\text { (AP conjugated) }\end{array}$ & Goat, polyclonal & $1: 5000$ & $\begin{array}{l}\text { Sigma-Aldrich Chemie GmbH, } \\
\text { Taufkirchen, Germany }\end{array}$ \\
\hline $\begin{array}{l}\text { a-Rat } \\
\text { (AP conjugated) }\end{array}$ & Rabbit, polyclonal & $1: 5000$ & $\begin{array}{l}\text { Sigma-Aldrich Chemie GmbH, } \\
\text { Taufkirchen, Germany }\end{array}$ \\
\hline
\end{tabular}

\subsection{Methods}

\subsubsection{Plant methods}

\subsubsection{Plant cultivation}

Seeds were frozen $\left(-20^{\circ} \mathrm{C}, 2-3\right.$ days) to eliminate potential pest contaminations before they were sown. The seeds were placed directly on damp soil (Frühstorfer Erde, Type T25, Str1, Archut) which was steam-sterilized before it was filled into plant pots. To promote germination, the pots were covered with a transparent lid and transferred to growth chambers (Johnson Controls, Milwaukee, WI, USA) with short day (SD) conditions (8 h light, $22{ }^{\circ} \mathrm{C}, 140 \mathrm{~mol} \mathrm{~m}^{-2} \mathrm{sec}^{-1}, 65 \%$ rel. humidity). After germination, lids were removed. To induce flowering, plants were transferred to long day (LD) conditions ( $16 \mathrm{~h}$ light, $22{ }^{\circ} \mathrm{C}, 140$ $160 \mu \mathrm{mol} \mathrm{m} \mathrm{mec}^{-1}, 65 \%$ rel. humidity).

Nicotiana benthamiana seeds were treated as described for Arabidopsis. However, Nicotiana seeds were immediately placed under LD conditions ( $16 \mathrm{~h}$ light, $26{ }^{\circ} \mathrm{C}, 200 \mu \mathrm{mol}$ $\mathrm{m}^{-2} \mathrm{sec}^{-1}, 65 \%$ rel. humidity) to ensure rapid growth.

For in-vitro cultivation of plants, Arabidopsis seeds were placed in reaction tubes and washed with $70 \%$ ethanol three times in a sterile hood. During these washing steps, reactions tubes were inverted several times to ensure proper washing of the seeds. Ethanol was removed between each washing step. After that, a final washing step with $96 \%$ ethanol was performed. Tubes were put on a tube rack to allow sinking of the seeds. Ethanol was 
removed and seeds were put on a Whatman ${ }^{\circledR}$ paper placed in a petri dish to allow evaporation of the ethanol.

\subsubsection{Crossing of Arabidopsis thaliana plants}

For crossing of Arabidopsis plants, carpels of closed buds were uncovered by removing all other parts of the flowers using magnifying glasses and fine tweezers. Stamina of the donor line (male parent) were collected and used to pollinate the stigmas of the receptor line (female parent). Crossings were performed both ways, with each of the parental lines being acceptor and donor to exclude effects of the respective parental genotypes.

\subsubsection{Stable transformation of Arabidopsis thaliana (floral dip)}

The generation of stably transformed Arabidopsis plants was performed by the 'floral dip' method (Clough \& Bent, 1998). To induce flowering, Arabidopsis plants were transferred from SD to LD conditions. To induce the growth of additional shoots, the first developed apical meristem was removed. Transformed Agrobacterium tumefaciens strains were grown $\left(28^{\circ} \mathrm{C}\right)$ in $5 \mathrm{ml}$ LB containing the appropriate antibiotics overnight. This culture was used to inoculate $300 \mathrm{ml}$ LB containing appropriate antibiotics which were incubated at $28{ }^{\circ} \mathrm{C}$ with shaking for 1-2 days until the culture reached an $\mathrm{OD}_{600}>1.6$. Agrobacterium cells were pelleted $(4000 \mathrm{xg}, 20 \mathrm{~min}, \mathrm{RT})$ and resuspended in $300 \mathrm{ml} 5 \%$ glucose containing $0.05 \%$ Silwet-77. Plants were then dipped into the Agrobacteria solution until the inflorescence was completely submerged. This was repeated 2 - 3 times. Plants were then transferred to a plastic bag to ensure high humidity and were kept in the laboratory over night. The next day, the plastic bag was removed and plants were transferred back to the growth chamber (LD conditions).

\subsubsection{Transient transformation of Nicotiana benthamiana}

Transformed Agrobacterium tumefaciens strains were used to inoculated $5 \mathrm{ml}$ LB containing the appropriate antibiotics and were grown at $28{ }^{\circ} \mathrm{C}$ overnight. Cells were pelleted $(4000 \mathrm{xg}$, $20 \mathrm{~min}, \mathrm{RT}$ ) and resuspended in $1 \mathrm{ml}$ infiltration buffer. $\mathrm{OD}_{600}$ was measured and cultures were diluted to an $\mathrm{OD}_{600}$ of 0.4 . Cultures were left on the bench for several hours before use. 4 week old Nicotiana benthamiana plants were watered several hours before use and placed on the bench covered by a lid to increase humidity. A $1 \mathrm{ml}$ needle-less syringe was used to infiltrate whole leaves and infiltrated areas were marked. Plants were transferred back to the 
growth chamber (LD conditions). After 2 - 3 days, samples for protein extraction were taken or leaves were analyzed by confocal laser scanning microscopy.

\subsubsection{Selection of transgenic Arabidopsis plants on soil}

Surface-sterilized T1 seeds were sown densely on damp soil and covered with a plastic lid. After germination, seedlings were sprayed with a 1:1000 diluted herbicide BASTA® $(200 \mathrm{~g} / \mathrm{l}$ glufosinate [phosphinothricin ammonium] solution, Bayer CropScience AG, Monheim, Germany) every two days for a total of three times. The surviving and therefore transformed plants were transferred into single pots.

\subsubsection{In-vitro selection of transgenic Arabidopsis plants}

To select or analyse the segregation pattern of transgenic Arabidopsis plants, ethanol sterilized seeds were spread sparsely on $1 / 2 \mathrm{MS}$ plates containing $25 \mu \mathrm{g} / \mathrm{ml}$ phosphinothricin. Plants were grown under SD conditions until a clear difference between resistant and nonresistant plants became visible. Resistant plants were transferred onto soil for further propagation.

\subsubsection{Chitin treatment of Arabidopsis plants}

For investigation of the chitin-induced band-shift of CERK1, 2-6 Arabidopsis leaves were collected and divided into two $15 \mathrm{ml}$ falcons, one half for mock treatment and the other half for chitin treatment. The leaves were fully covered with water. $10 \mathrm{mg}$ Polymeric chitin (shrimp shell chitin) were transferred to a $1 \mathrm{ml}$ reaction tube. $100 \mu \mathrm{l} \mathrm{H}_{2} \mathrm{O}$ were added and the mixture was ground until no chitin chunks were visible anymore. $900 \mu \mathrm{H}_{2} \mathrm{O}$ were added to reach a final stock concentration of $10 \mathrm{mg} / \mathrm{ml}$. Chitin was then added to one half of the samples to a final concentration of $100 \mu \mathrm{g} / \mathrm{ml}$. The falcons were then placed in a desiccator and a vacuum was applied for 5 minutes. Vacuum was released leading to leaf infiltration. Leaves were incubated for 12 minutes and then blotted on paper tissue for drying. The leaves were transferred to $1.5 \mathrm{ml}$ reaction tubes, frozen in liquid nitrogen and stored at $-80^{\circ} \mathrm{C}$.

\subsubsection{Cultivation and inoculation of Blumeria graminis f.sp. hordei}

Cultivation of the obligate biotrophic ascomycete Blumeria graminis f.sp. hordei (Bgh) was performed on barley plants (Hordeum vulgare cv. Golden Promise) under short day 
conditions (16 h light, $22{ }^{\circ} \mathrm{C}, 140-160 \mu \mathrm{mol} \mathrm{m} \mathrm{sec}^{-1}, 65 \%$ rel. humidity) in a growth cabinet (CLF Plant Climatics, Wertingen, Germany). 6 day old barley plants were inoculated with Bgh spores formed on older infected barley plants. After one week, they were ready to be used for inoculation of Arabidopsis plants. For phenotype investigation of cerk1-4 and cerk14 suppressor lines, 5 - 6 week old plants were placed in an inoculation tower and were inoculated evenly by shaking the infected barley plants over the tower. For macroscopical analysis, plants were photographed 7 days after infection.

\subsubsection{Biochemical methods}

\subsubsection{Protein extraction}

\subsection{Standard preparation of total protein extracts}

50 - $100 \mathrm{mg}$ plant material were harvested in a $1.5 \mathrm{ml}$ reaction tube and frozen in liquid nitrogen. A spatula of quartz sand and $300 \mu$ l CERK1 extraction buffer were added. A drill equipped with a glass pistel (IKA-Werke $\mathrm{GmbH} \&$ Co. KG, Staufen, Germany) fitting $1.5 \mathrm{ml}$ tubes was used to grind the plant material thoroughly. Afterwards, additional $700 \mu \mathrm{l}$ of CERK1 extraction buffer were added and samples were centrifuged to sediment cell debris (15 min, $17000 \mathrm{xg}, 4{ }^{\circ} \mathrm{C}$ ). The supernatants were transferred to new reaction tubes and kept on ice. Protein concentrations were measured by the Bradford method (2.2.2.4) and were adjusted to the concentration of the lowest sample using CERK1 extraction buffer. For immunoblotting, equalized samples were mixed with $4 x$ SDS loading dye and stored at $-20^{\circ} \mathrm{C}$ until use.

\subsection{Preparation of total protein extracts with SDS}

To extract proteins that are not sufficiently soluble in CERK1 extraction buffer and/or prevent any degradation processes during extraction, proteins were extracted with $2 x$ SDS loading dye. This method excludes determination of protein concentrations. Therefore, a defined amount of thoroughly ground plant material was transferred to a reaction tube. $200 \mu \mathrm{l} 2 \mathrm{x}$ SDS buffer were added per $100 \mathrm{mg}$ plant material. A spatula of quartz sand was added and samples were ground with a glass pistil. Samples were centrifuged (10 min, $17000 \mathrm{xg}, \mathrm{RT}$ ) and supernatants were transferred to new reaction tubes and stored at $-20{ }^{\circ} \mathrm{C}$ until use in immunoblots. 


\subsubsection{Chitin pull-down}

Chitin pull-downs were performed to enrich chitin-binding proteins from protein extracts. Therefore, chitin magnetic beads (NEB, Frankfurt/Main, Germany) were washed three times and finally resuspended in ultra-pure $\mathrm{H}_{2} \mathrm{O} .20 \mu \mathrm{l}$ chitin beads were added to protein extracts containing $1-1.5 \mathrm{mg}$ total protein. Samples were then incubated on a wheel for 45 minutes at $4{ }^{\circ} \mathrm{C}$. Reaction tubes were then transferred to a magnet rack to pellet chitin magnetic beads. The supernatants were discarded and the beads were washed with $1 \mathrm{ml}$ ice-cold TBS-T. This step was repeated twice. A last washing step was performed using ice-cold ultra-pure water. Samples were centrifuged $\left(1 \mathrm{~min}, 10000 \mathrm{xg}, 4^{\circ} \mathrm{C}\right)$ to collect residual water at the bottom of the reaction tubes. The reaction tubes were transferred to a magnet rack and water was removed using a pipette. $20 \mu \mathrm{l} 1.5 \mathrm{x}$ SDS sample buffer were added and samples were centrifuged to mix beads with SDS buffer. Samples were then stores at $-20^{\circ} \mathrm{C}$.

\subsubsection{Microsomal preparation}

As a first step, a protein extract was prepared with CERK1 extraction buffer without Triton X100. For small scale preparations, the extraction was performed with a glass pistil as described in Chapter 2.2.2.1.1. For larger scale microsomal preparations, the plant material was ground to a fine powder with mortar, pestle and quartz sand under liquid nitrogen. Then the CERK1 extraction buffer lacking Triton X-100 was added at 2-3 ml per g plant material. Sedimentation of cell debris was performed at $2000 \mathrm{~g}$ at $4{ }^{\circ} \mathrm{C}$ for 5 minutes. $60 \mu \mathrm{l}$ of supernatant were taken as total protein extract and mixed with $4 \times$ SDS buffer. The remaining supernatant was transferred to ultracentrifugation tubes (Eppendorf, Hamburg, Germany) and centrifuged at $100000 \mathrm{xg}$ in a Sorvall ultracentrifuge (Thermo Scientific ${ }^{\mathrm{TM}}$, Waltham, USA) for 1 hour at $4{ }^{\circ} \mathrm{C}$. The supernatant was collected. Soluble proteins can be found in this fraction. The remaining pellet was washed with CERK1 extraction buffer without Triton-X 100 and was centrifuged again $\left(1 \mathrm{~h}, 100000 \mathrm{xg}, 4{ }^{\circ} \mathrm{C}\right)$. The final pellet was resuspended with CERK1 extraction buffer containing Triton-X 100 to dissolve membrane bound proteins (microsomal fraction). The microsomal fraction was transferred to new $1.5 \mathrm{ml}$ reaction tubes. The protein concentration of microsomal and soluble fractions was determined by the Bradford method. The fractions were then either used for chitin pull downs or mixed with $4 x$ SDS loading dye and stored at $-20^{\circ} \mathrm{C}$ until further use. 


\subsubsection{Determination of protein concentration by the Bradford method}

In order to determine the protein concentration of extracts, a method based on (Bradford, 1976)) was used. A calibration curve using determined concentrations of bovine serum albinum (BSA) was generated. For this, $0 \mu \mathrm{l}, 3 \mu \mathrm{l}, 7 \mu \mathrm{l}, 10 \mu \mathrm{l}$ and $15 \mu \mathrm{l}$ of a $1 \mathrm{mg} / \mathrm{ml}$ BSA solution was pipetted into cuvettes. $1 \mathrm{ml}$ Bradford solution (Rotiß-Quant, Roth, Karlsruhe, Germany) (diluted 1:5 with $\mathrm{H}_{2} \mathrm{O}$ ) was added and incubated for 5 minutes at room temperature. Absorbance at $595 \mathrm{~nm}$ was measured using a WPA Biowave II photometer (Biochrom, Berlin, Germany). The absorption was plotted against the protein concentration to generate the calibration curve. Samples (typically $3 \mu \mathrm{l}$ ) were pipetted in duplicate into cuvettes, $1 \mathrm{ml}$ Bradford solution was added and after $5 \mathrm{~min}$ of incubation, absorption was measured at $595 \mathrm{~nm}$. The calibration curve was used to calculate the protein concentrations of each sample.

\subsubsection{SDS-polyacrylamide gel electrophoresis (SDS-PAGE)}

Proteins were separated according to their molecular mass by SDS-PAGE. The MiniPROTEAN 3 system (BioRad, Munich, Germany) was used for casting of discontinuous gels. The system was assembled according to manufacturer's instructions. Resolving gels containing $8 \%$ or $10 \%$ acryl amide were poured between two glass plates spaced $1.5 \mathrm{~mm}$ apart and overlaid with isopropanol to remove air bubbles. After polymerization, isopropanol was removed and the stacking gel was poured on top of the resolving gel and a comb for formation of samples pockets was inserted. After the gels were completely polymerized, they were either used directly or wrapped in damp paper tissue and stored in plastic bags at $4{ }^{\circ} \mathrm{C}$. Gels were placed in a PROTEAN 3 vertical gel chamber which was filled with $1 \times$ SDS running buffer. The comb was removed and gel pockets were rinsed with running buffer. Samples were mixed with SDS sample buffer and boiled at $95{ }^{\circ} \mathrm{C}$ for 3 minutes. Samples were then loaded in the sample pockets. PageRuler ${ }^{\mathrm{TM}}$ Prestained Protein Ladder Plus (Thermo Scientific ${ }^{\mathrm{TM}}$, Waltham, USA) was used as size standard. SDS PAGE was then performed at $30 \mathrm{~mA}$ until the desired separation was achieved. Gels were then used for immunoblot analysis (2.2.2.6).

\subsubsection{Immunoblotting}

For the transfer of proteins from a SDS-polyacrylamide gel to a PVDF membrane, the Mini Trans-Blot $^{\circledR}$ system (BioRad, Munich, Germany) or Trans-Blot ${ }^{\circledR}$ system (BioRad, Munich, 
Germany) was used, depending on the number of gels to be blotted. The glass plates containing the SDS-gel were disassembled and the stacking gel was removed. Next, sponges and Whatman paper were thoroughly soaked in blotting buffer and a "sandwich" was assembled on the the cathode side of the blotting cassette. First, a sponge was placed on the cassette, followed by layers of Whatman $\AA$ paper. The resolving gel was then placed on the Whatman® paper and a methanol-activated PVDF membrane was arranged on top of the gel. After adding another Whatman® paper and sponge, air bubbles were removed by rolling with a $50 \mathrm{ml}$ tube. Then the blotting cassette was closed and placed into the blotting tank (BioRad, Munich, Germany) which was then filled to the

top with $1 \mathrm{x}$ blotting buffer. Blotting was carried out at $75 \mathrm{~V}$ for 2 hours. The blotting cassettes were disassembled and PVDF membranes were incubated in 1x TBS-T containing $3 \%$ milk powder for 1 hour to block unspecific binding sites. After blocking, membranes were incubated with primary antibody solution (primary antibody diluted in 1x TBS-T containing 3 $\%$ milk powder) and were incubated over night at $4{ }^{\circ} \mathrm{C}$ with shaking. The next day, membranes were washed 5 times for at least 10 minutes with $1 x$ TBS-T containing $3 \%$ milk powder. Membranes were then incubated with secondary antibody (secondary antibody diluted in 1x TBS-T containing $3 \%$ milk powder) solution for 2 hours at room temperature. Membranes were washed 5 times for at least 10 minutes with 1x TBS-T. Afterwards, membranes were incubated for 10 minutes in AP buffer. Membranes were then incubated with Immun-Star ${ }^{\text {TM }}$ AP substrate (BioRad, Munich, Germany) for 5 minutes and then placed in a plastic bag, which was subsequently transferred to an exposure cassette. The membranes were then exposed to an X-ray Screen Film Blue Sensitive (CEA, Hamburg, Germany) to detected chemiluminescence.

To enhance signal intensity and reduce background signals of GFP-immunoblots, the SuperSignalTM Western Blot Enhancer (Thermo Scientific ${ }^{\text {TM }}$, Westham, USA) was used according to manufacturer's instructions.

\subsubsection{Coomassie staining of PVDF membranes}

For visualization of total protein content, PVDF membranes were stained with Coomassie Brilliant Blue. Membranes were placed in a plastic box and incubated with staining solution until they were fully stained. Staining solution was decanted and membranes were rinsed with water. To remove background staining membranes were incubated with destaining solution until only stained protein bands remained. The staining solution was removed, membranes were rinsed with water and placed on a paper tissue under a fume hood to dry. 


\subsubsection{Mass spectrometry analysis}

Mass spectrometry analysis (Sample preparation and LC-ESI-MS analysis) were performed by Dr. Andrzej Majcherczyk (Georg-August University of Göttingen) according to the following protocol (provided by Dr. Andrzej Majcherczyk). Data analysis was performed by Christopher Meusel.

\section{Sample preparation}

Samples from Arabidopsis cell culture supernatants and Arabidopsis apoplastic wash fluids in $15 \mathrm{ml}$ Falcon-tubes were frozen at $-80^{\circ} \mathrm{C}$ and freeze-dried for about 5 days at $-30^{\circ} \mathrm{C}$. Dry samples were re-dissolved in $80 \mu \mathrm{l}$ ABC/DTT, centrifuged at $2000 \mathrm{rpm}$ for 3 minutes and 75 $\mu \mathrm{l}$ liquid was transferred to a new $1.5 \mathrm{ml}$ reaction tube. $75 \mu \mathrm{l}$ of TFE were added to extract proteins and precipitate polysaccharides. Samples were shaken for 15 minutes, sonicated for 5 minutes, shaken for 15 minutes again and incubated for 30 minutes at $60{ }^{\circ} \mathrm{C}$. After centrifugation for 10 minutes $(16000 \mathrm{xg}), 100 \mu$ supernatant were carefully collected into a new $1.5 \mathrm{ml}$ LoBind tube (Eppendorf, Hamburg, Germany) Proteins were alkylated with IAA (5 $\mu$ I IAA stock solution) in dark for 30 minutes and thereafter diluted with $50 \mu$ l water.

Protein purification was performed by chloroform/methanol precipitation according to Wessel and Fluegge (1984). Protein precipitates were suspended in $50 \mu \mathrm{l}$ Tris- $\mathrm{HCl} \mathrm{pH} 8.0$ by careful sonication for about 3 minutes and $5 \mu$ trypsin stock solution were added to each sample (protein to trypsin ratio was about 1:100). Protein digestion was performed overnight at $37^{\circ} \mathrm{C}$ in a water bath.

Thereafter, the digestion was stopped by addition of $20 \mu$ of $20 \mathrm{mM} \mathrm{AF}(\mathrm{pH} 10)$ and samples were vortexed and centrifuged for 20 minutes at $16000 \mathrm{xg} .60 \mu \mathrm{l}$ of peptide solutions were immediately purified by StageTips (Rappsilber et al., 2007) prepared from 3 layers of 3MC18 filter (3M, Minnesota, USA). Purification was performed with $20 \mathrm{mM} \mathrm{AF} \mathrm{pH} 10$ and peptides eluted with $60 \%$ acetonitrile (Ultima LC-MS grade, Fisher Scientific, Schwerte, Germany) in 20 mM AF buffer. After drying for 10 minutes in vacuum, concentrated peptides were stored at $-20{ }^{\circ} \mathrm{C}$ or immediately dissolved in $2 \%$ acetonitrile in water with $0.1 \%$ formic acid (all solvents were Ultima LC-MS quality) and analyzed by LC-ESI-MS. Peptide concentration was measured by Micro-BCA (Thermo Scientific ${ }^{\mathrm{TM}}$, Waltham, USA) method using BSA-digest as calibration standard.

\section{LC-ESI-MS analysis}

Peptides were analyzed by trap \& elute mode (Eksigent 420, Sciex, Framingham, USA) using $2.5 \mathrm{~cm}(\varnothing 100 \mu \mathrm{m})$ pre-column packed with $5 \mu \mathrm{m}$ Reprosil-Pur C18-AQ (Dr. Maisch $\mathrm{GmbH}$, Ammerbuch, Germany) and $30 \mathrm{~cm}(\varnothing 50 \mu \mathrm{m})$ analytical column packed with $3 \mu \mathrm{m}$ 
Reprosil-Gold C18. Peptide samples $(5 \mu \mathrm{l}$ corresponding to $0.1-0.2 \mu \mathrm{g})$ were separated in a gradient mode at $260 \mathrm{nl} /$ minute solvent flow. Solvent $A$ consisted of $100 \%$ water with $0.1 \%$ formic acid and solvent B of $100 \%$ acetonitrile with $0.1 \%$ formic acid. Peptide elution from the analytical column was performed in a gradient of solvent B: initially $5 \%, 100$ minutes to $35 \%$, 20 minutes to $50 \%$ and 2 minutes to $95 \%$.

Mass spectrometry system consisted of Hybrid Quadrupole-TOF LC/MS/MS Mass Spectrometer TripleTOF 5600+ (Sciex, Framingham, USA), nano-spray source Nanospray III (Sciex, Framingham, USA) and Analyst 1.7 software (Sciex, Framingham, USA). MS spectra in a positive mode were detected in a range of 300 to $2000 \mathrm{Da}$ and 30 most intensive ions with charge 2+ to $5+$ were fragmented in a MS/MS mode. Analysis of MS spectra and protein identification was performed by ProteinPilot 5.0 (Sciex, Framingham, USA), and database consisted of Arabidopsis TAIR10 (https://phytozome.jgi.doe.gov) protein sequences combined with a common contaminants dataset (Sciex, Framingham, USA). Carbamidomethylation of cysteine and trypsin cleavage were set as fixed modifications and searches were performed in FDR mode with thorough settings including biological modifications and amino acid substitutions.

\section{Data analysis}

Data obtained by mass spectrometry was analyzed using ProteinPilot 5.0 (Sciex, Framingham, USA) and Microsoft Excel 2007 (Microsoft, Redmond, USA). Only proteins were considered of which at least 2 peptides were found and which had an unused score of at least 2.

\subsubsection{Molecular biology methods}

\subsubsection{Preparation of genomic DNA from Arabidopsis leaves}

One small Arabidopsis leaf was harvested and transferred to a $1.5 \mathrm{ml}$ reaction tube. $300 \mu \mathrm{l}$ warm extraction buffer were added and a plastic pistil driven by an IKA drill (IKA-Werke $\mathrm{GmbH} \&$ Co. KG, Staufen, Germany) was used to disrupt the plant tissue. The sample was centrifuged (5 min, $17000 \mathrm{xg}, \mathrm{RT}$ ) and the resulting supernatant was transferred to a new reaction tube which was filled with $300 \mu \mathrm{l}$ isopropanol. After mixing by pipetting up and down the sample was incubated for 5 minutes at room temperature. After an additional centrifugation step (5 min, $17000 \mathrm{xg}, \mathrm{RT}$ ) the supernatant was carefully and completely 
removed and the pellet was air-dried. The pellet was resuspended in $50 \mu \mathrm{l} \mathrm{H}_{2} \mathrm{O}$ and stored at $-20^{\circ} \mathrm{C}$.

\subsubsection{Preparation of total RNA from Arabidopsis leaves}

Arabidopsis leaf material was harvested and ground to a fine powder a TissueLyser LT (Qiagen, Hilden, Germany). 70 - 100 mg powder were transferred to a reaction tube. For extraction of total RNA, the innuPREP Plant RNA kit (Analytik Jena, Jena, Germany) was used according to the manufacturer's instructions. RNA extraction in the present study was performed using the lysis buffer RL. RNA quality was checked on a $1 \%$ agarose gel. Therefore, $3 \mu \mathrm{l}$ total RNA were mixed with $7 \mu \mathrm{H}_{2} \mathrm{O}$ and $2 \mu \mathrm{l} 6 \mathrm{x}$ loading dye. RNA concentration was then measured using the TECAN Infinite ${ }^{\circledR} 200$ PRO NanoQuant plate reader (2.2.3.10) and samples were then adjusted to the lowest RNA concentration using RNase free $\mathrm{H}_{2} \mathrm{O}$.

\subsubsection{Plasmid preparation from E.coli}

Plasmid preparation was performed according to the protocol of alkaline lysis (Birnboim \& Doly, 1979). Single E.coli colonies were inoculated in $3 \mathrm{ml}$ LB containing the appropriate antibiotics and grown overnight at $37^{\circ} \mathrm{C}$. Cells were pelleted by centrifugation $(1 \mathrm{~min}, 17000$ $\mathrm{xg}, \mathrm{RT})$. The supernatant was discarded and the pellet was resuspended in $200 \mu \mathrm{P} 1$ buffer. $200 \mu$ P2 buffer were added and mixed by inverting the tube. The preparation was incubated for 3 minutes. $200 \mu \mathrm{l}$ P3 buffer were added and the reaction was inverted several times until a white precipitate formed. After centrifugation (10 min, $17000 \mathrm{xg}, \mathrm{RT}$ ), the supernatant was transferred to a new reaction tube and mixed with $1 \mathrm{ml} 96 \%$ Ethanol. The mixture was centrifuged (10 min, $17000 \mathrm{xg}, \mathrm{RT}$ ) and the supernatant was discarded using a pipette. The remaining pellet was washed with $70 \%$ ethanol and a last centrifugation step was performed (5 min, $17000 \mathrm{xg}, \mathrm{RT}$ ). Residual ethanol was removed and the pellet was air dried. Subsequently, the pellet was resuspended in $30-50 \mu \mathrm{lddH_{2 }}$ O and stored at $-20^{\circ} \mathrm{C}$.

\subsubsection{Plasmid preparation from S. cerevisiae}

S.cerevisae colonies were washed from plates using $1 \mathrm{ml} \mathrm{H}_{2} \mathrm{O}$ and a pipette tip and were transferred to a reaction tube. Cells were pelleted by centrifugation ( $5 \mathrm{~min}, 4000 \mathrm{xg}, \mathrm{RT}$ ) and resuspended in $200 \mu \mathrm{l} \mathrm{P1}$ buffer from the QIAGEN® Plasmid Midi Kit (art.nr. 12145). $0.3 \mathrm{~g}$ glass beads (425 - 600 micron) were added and the mixture was shaken on a Vibrax VXR 
basic (1500 rpm, 15 min) (IKA-Werke GmbH \& Co. KG, Staufen, Germany). Subsequently, glass beads were pelleted by centrifugation ( $5 \mathrm{~min}, 4000 \mathrm{xg}, \mathrm{RT}$ ). The next steps were performed according to the manufacturers' manual of the QIAGEN® Plasmid Midi Kit.

\subsubsection{Synthesis of cDNA}

For expression analysis, cDNA was synthesized from RNA samples using the RevertAid ${ }^{\mathrm{TM}} \mathrm{H}$ Minus First Strand cDNA Synthesis kit (Thermo Scientific ${ }^{\mathrm{TM}}$, Westham, USA) according to manufacturer's instructions. 1 - $4 \mu \mathrm{g}$ total RNA were used and cDNA synthesis was performed at $42{ }^{\circ} \mathrm{C}$ for 60 minutes. The synthesis reaction was terminated by incubation at $70^{\circ} \mathrm{C}$ for 10 minutes. The generated cDNA was diluted (1:5) with water and directly used for RT-PCR (2.2.3.7) or stored at $-20^{\circ} \mathrm{C}$.

\subsubsection{Polymerase chain reaction (PCR)}

To amplify DNA fragments, polymerase chain reaction (PCR) was performed (Mullis et al., 1986). PCR for cloning was carried out using iProof ${ }^{\mathrm{TM}}$ High-Fidelity DNAPolymerase (BioRad, Munich, Germany) according to manufacturer's instructions. Genotyping, colony PCR and RT-PCR were carried out using homemade Taq polymerase. Standard reactions using homemade Taq polymerase $(20 \mu \mathrm{l})$ were prepared as followed:

$\begin{array}{lrl}\text { 10x Taq buffer: } & 2.0 & \mu \mathrm{l} \\ 10 \mathrm{mM} \text { dNTPs: } & 0.5 & \mu \mathrm{l} \\ 10 \mathrm{mM} \text { Primer 1: } & 1.0 & \mu \mathrm{l} \\ 10 \mathrm{mM} \text { Primer 2: } & 1.0 \mathrm{\mu l} \\ \text { Taq DNA polymerase: } & 0.5 \mathrm{\mu l} \\ \mathrm{H}_{2} \mathrm{O} \text { : } & 15.0 \mathrm{\mu l}\end{array}$

Template: $1 \mu \mathrm{I}$ DNA or bacterial colony

The following PCR program was used for homemade Taq polymerase:

$\begin{array}{lrcl}\text { 1. } & 95^{\circ} \mathrm{C} & 5 \mathrm{~min} & \text { (initial denaturation) } \\ \text { 2. } & 95^{\circ} \mathrm{C} & 30 \mathrm{~s} & \text { (denaturation) } \\ 3 . & 50-60^{\circ} \mathrm{C} & 30 \mathrm{~s} & \text { (annealing) } \\ 4 . & 72^{\circ} \mathrm{C} & 1 \mathrm{~min} / \mathrm{kb} & \text { (extension) } \\ 5 . & 72^{\circ} \mathrm{C} & 5-10 \mathrm{~min} & \text { (final extension) } \\ 6 . & 4^{\circ} \mathrm{C} & 10 \mathrm{~min} & \text { (cooling) }\end{array}$

Steps $2-4$ were repeated $29-35 x$ 
The annealing temperature was adjusted to the primers used and the extension time to the length of the fragment to be amplified.

\subsubsection{Semi-quantitive reverse transcription-polymerase chain reaction (RT- PCR)}

Semi-quantitive RT-PCR was performed according to the standard PCR method (2.2.3.6). The number of amplification cycles was adjusted to the gene of interest and the cDNA used.

\subsubsection{Agarose gel electrophoresis}

DNA fragments were separated according to their length on $1-3 \%$ agarose gels using horizontal Sub-Cell GT electrophoresis apparatuses (BioRad, Munich, Germany). The appropriate amount of agarose was mixed with $1 \times$ TAE buffer and boiled in a microwave until the agarose was dissolved. Subsequently, the mixture was cooled down to about $60{ }^{\circ} \mathrm{C}$ and ethidium bromide to a final concentration of $1-5 \mu \mathrm{g} / \mathrm{ml}$ was added. The solution was poured into a casting chamber. After the gel solidified it was placed in the Sub-Cell GT tank filled with $1 \mathrm{x}$ TAE buffer. Samples were mixed with 6x DNA loading dye and loaded into the prepared pockets. Generuler ${ }^{\mathrm{TM}}$ ladders (Thermo Scientific ${ }^{\mathrm{TM}}$ ) were used as size standards. The DNA fragments were then separated by applying a voltage from $90-120 \mathrm{~V}$ for $20-60$ minutes depending on the gel percentage and fragment size. The gel was exposed to UV light $(312 \mathrm{~nm})$ to visualize the DNA fragments. Pictures were taken using a gel documentation and analysis system (VWR, Lutterworth, UK).

\subsubsection{DNA purification from agarose gels}

Agarose gel electrophoresis was performed to separate DNA fragments (2.2.3.8). The fragments of interest were excised from the gel under UV-light (365 nm) and purified using the NucleoSpin ${ }^{\circledR}$ Gel and PCR Clean-up kit (Macherey-Nagel, Düren, Germany) according to the manufacturer's instructions.

\subsubsection{Measurement of DNA and RNA concentration}

Measurement of DNA and RNA concentration was performed using the TECAN Infinite $\AA 200$ PRO NanoQuant plate reader (Tecan Group Ltd, Männedorf, Switzerland). $1 \mu \mathrm{l}$ of sample 
was pipetted onto the NanoQuant Plate ${ }^{\mathrm{TM}}$. Absorbance was measured at $260 \mathrm{~nm}$ and 280 $\mathrm{nm}$. The ratio of absorbance at $260 \mathrm{~nm}$ and $280 \mathrm{~nm}$ indicates the purity of the sample. For DNA samples, the optimal ratio is about 1.8. For RNA samples the optimal ratio is about 2.0.

\subsubsection{Restriction endonuclease digestion of DNA}

Digestion of DNA was performed using restriction endonucleases from Thermo Scientific ${ }^{\mathrm{TM}}$ or New Englad Biolabs and the corresponding buffer systems. Buffer and enzyme concentration as well as incubation temperature were chosen according to manufacturer's instructions.

\subsubsection{Ligation of DNA fragments}

Covalent linkage of DNA fragments was performed using T4-DNA Ligase (Thermo Scientific ${ }^{\mathrm{TM}}$, Waltham, USA) For cloning an insert into a linearized plasmid, the following reaction mixture was used:

Linearized plasmid DNA:

Insert:

T4-DNA Ligase:

T4-DNA Ligase Buffer:

$\mathrm{H}_{2} \mathrm{O}$ fill up to
$50 \mathrm{ng}$ $150-500 \mathrm{ng}$

$0.5 \mathrm{U}$

$2 \mu \mathrm{l}$

$20 \mu \mathrm{l}$

The sample was incubated for 4 hours at room temperate or at $16{ }^{\circ} \mathrm{C}$ overnight and subsequently transformed into chemo-competent E.coli (2.2.3.16).

\subsubsection{Cloning by homologous recombination in S. cerevisae}

Constructs were cloned by homologous recombination using a modified version of the ,drag and drop' method (Colot et al., 2006). In this method the yeast is used to recombine DNAfragments with short regions of homology (about 29 base pairs) with high efficiency. This method is exemplified by the generation of cerk1 fls2tm, a construct where the CERK1 transmembrane domain was replaced by the FLS2 transmembrane domain. The N-terminal part of CERK1 up to the transmembrane domain was amplified by PCR. The forward primer was designed to harbor a $29 \mathrm{bp}$ homology region to the shuttle vector pRS426 at the 5' end (Fragment 1) followed by a HindIII restriction site. The C-terminal part of CERK1 beginning 
right after the transmembrane domain was also amplified. The reverse primer was designed to harbor a $29 \mathrm{bp}$ homology region to pRS426 at the 3' end (Fragment 2). The FLS2 transmembrane domain was amplified adding 30bp homology to fragment 1 at the 5 ' end and 30 bp homology to fragment 2 at the 3 ' end. The vector pRS426 was linearized by digestion with BamHI and Kpnl. For transformation of S. cerevisiae see 2.2.3.20. $500 \mathrm{ng}$ of each fragment and $200 \mathrm{ng}$ of the linearized vector were used. Recombined plasmids were purified (see 2.2.3.4) and transformed into E.coli (see 2.2.3.16) for further analysis.

\subsubsection{DNA sequencing and analysis}

DNA sequencing was performed by Seqlab (Göttingen, Germany). Samples were premixed with suitable primers according to Seqlab's sequencing instructions. Sequencing data was analyzed using the bioninformatics software Geneious 7.1.5 (Kearse et al., 2012).

\subsubsection{Preparation of chemically competent E.coli cells}

$25 \mathrm{ml}$ LB containing the appropriate antibiotics were inoculated with a single colony from a fresh E.coli TOP10 plate and grown overnight at $37^{\circ} \mathrm{C}$. The next day, the overnight culture was used to inoculate a main culture of $300 \mathrm{ml} L B$ to an $\mathrm{OD}_{600}$ of 0.2 . The main culture was grown at $37^{\circ} \mathrm{C}$ until it reached an $\mathrm{OD}_{600}$ of 0.6 . The cells were chilled on ice for 15 minutes and then centrifuged $\left(2500 \mathrm{xg}, 10 \mathrm{~min}, 4^{\circ} \mathrm{C}\right)$. The resulting cell pellet was then resuspended in $80 \mathrm{ml}$ ice-cold CCMB80 buffer and incubated on ice for 15 minutes. After an additional centrifugation step (2500 xg, $10 \mathrm{~min}, 4^{\circ} \mathrm{C}$ ), the cells were resuspended in $10 \mathrm{ml}$ ice-cold CCMB80 buffer and aliquots of $50 \mu \mathrm{l}$ were prepared. Aliquots were frozen in liquid nitrogen and stored at $-80^{\circ} \mathrm{C}$.

\subsubsection{Transformation of chemically competent E.coli cells}

For transformation of chemo-competent E.coli, up to $10 \mu \mathrm{l}$ of ligations or $200-700 \mathrm{ng}$ plasmid DNA were mixed with $50 \mu$ of competent cells and incubated on ice for 10 minutes. Subsequently, cells were heat shocked at $42^{\circ} \mathrm{C}$ for 1 minute and incubated on ice again for 2 minutes. $1 \mathrm{ml} \mathrm{LB}$ was added and cells were regenerated at $37^{\circ} \mathrm{C}$ and $180 \mathrm{rpm}$ for 1 hour. Next, the cells were centrifuged ( $1 \mathrm{~min}, 17000 \mathrm{xg}, \mathrm{RT})$, most of the supernatant was discarded and the pellet was resuspended in residual LB. The resuspended cells were then plated on LB-agar plates containing the appropriate antibiotics and incubated at $37{ }^{\circ} \mathrm{C}$ overnight. 


\subsubsection{Preparation of electro-competent $\boldsymbol{A}$. tumefaciens cells}

$2 \mathrm{ml}$ LB containing the appropriate antibiotics was inoculated with a single colony of A. tumefaciens GV3101 pSoup and grown overnight at $28^{\circ} \mathrm{C}$. This culture was used to inoculate $50 \mathrm{ml}$ LB containing the appropriate antibiotics, which was again grown over night at $28{ }^{\circ} \mathrm{C}$. This culture was then used to inoculate the main culture of $300 \mathrm{ml}$ LB without antibiotics to and OD of 0.3 . The main culture was incubated at $28{ }^{\circ} \mathrm{C}$ until the $\mathrm{OD}_{600}$ reached 0.6 and was chilled on ice for $15-30$ minutes. The culture was then centrifuged (15 min, $\left.6000 \mathrm{xg}, 4^{\circ} \mathrm{C}\right)$. The supernatant was discarded and the cells were resuspended in ice-cold $1 \mathrm{mM}$ HEPES, pH 7.0 and centrifuged again $\left(15 \mathrm{~min}, 6000 \mathrm{xg}, 4^{\circ} \mathrm{C}\right.$ ). This step was repeated twice. Pellets were then resuspended in $30 \mathrm{ml}$ ice-cold $10 \%$ glycerol and centrifuged (15 $\min , 6000 \mathrm{xg}, 4^{\circ} \mathrm{C}$ ). The supernatant was discarded and pellets were resuspended in $2 \mathrm{ml}$ ice-cold $10 \%$ glycerol. $50 \mu$ laliquots were frozen in liquid nitrogen and stores at $-80{ }^{\circ} \mathrm{C}$ until further use.

\subsubsection{Transformation of electro-competent $A$. tumefaciens cells}

Transformation of electro-competent $A$. tumefaciens GV3101 pSoup cells was perfomed by electroporation (Koncz \& Schell, 1986). An aliquot of competent cells was thawed on ice and gently mixed with $100 \mathrm{ng}$ plasmid DNA. The bacterial suspension was then transferred to a pre-chilled electroporation cuvette (0.1 electrode distance). For electroporation, the MicroPulser ${ }^{\mathrm{TM}}$ (Bio-Rad, Munich, Germany) was used (25 $\mu \mathrm{F}, 2.5 \mathrm{kV}$ and $400 \Omega$ ). $1 \mathrm{ml} \mathrm{LB}$ was then added and the bacteria were transferred to a reaction tube. Cells were then incubated at $28^{\circ} \mathrm{C}$ for 2 hours for regeneration. Cells were then centrifuged ( $1 \mathrm{~min}, 17000$ $\mathrm{xg}, \mathrm{RT}$ ) and most of the supernatant was discarded. The pellet was then resuspended in residual LB, plated on LB agar containing the appropriate antibiotics and incubated at $28{ }^{\circ} \mathrm{C}$ for 2 - 3 days.

\subsubsection{Preparation of chemically competent S. cerevisiae cells}

For the preparation of chemically competent cells, $3 \mathrm{ml}$ YPD were inoculated with $S$. cerevisae and grown overnight at $30^{\circ} \mathrm{C}$. This overnight culture was used to inoculate 20 $\mathrm{ml} \mathrm{YPD}$ to an $\mathrm{OD}_{600}$ of 0.1 , which was then grown at $30^{\circ} \mathrm{C}$ for 6 hours. Cells were pelleted by centrifugation ( $3 \mathrm{~min}, 3000 \mathrm{xg}, \mathrm{RT}$ ) and washed once with $10 \mathrm{ml}$ sterile $\mathrm{H}_{2} \mathrm{O}$ and once with 2 $\mathrm{ml}$ volumes SORB-buffer. Subsequently, the cells were resuspended in $180 \mu \mathrm{l}$ SORB-buffer 


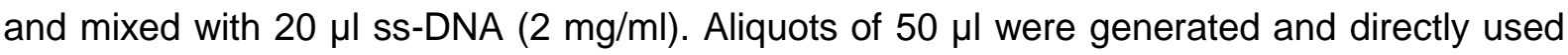
or stored at $-80^{\circ} \mathrm{C}$. It is important not to freeze the cells in liquid nitrogen.

\subsubsection{Transformation of chemically competent S. cerevisiae cells}

Chemically competent S. cerevisae cells were mixed with linearized pRS426 vector and each of the fragments to be recombined. $300 \mu \mathrm{Li}$-PEG were added and samples were incubated for 30 minutes on a wheel at room temperature. Subsequently, cells were heat-shocked at 42 ${ }^{\circ} \mathrm{C}$ for 15 minutes and then centrifuged ( $2 \mathrm{~min}, 3000 \mathrm{xg}, \mathrm{RT}$ ). Most of the supernatant was discarded and the cells were resuspended in residual liquid. The cell suspension was then plated on SC plates (-Ura +Gluc) and incubated at $28^{\circ} \mathrm{C}$ for $2-3$ days.

\subsubsection{Confocal laser scanning microscopy (CLSM)}

Confocal laser scanning microscopy was performed using a TCS SP5 DM6000 CS confocal laser scanning microscope (Leica, Wetzlar, Germany) equipped with an argon laser and HyD hybrid detectors as well as the appropriate software (LAS AF Leica Application Suite, Version 2.7.2). For microscopy, small leaf pieces cut and placed onto an object slide. A drop of water was placed in the middle and silicone to the corners of a cover glass. The cover glass was then placed onto the object slide with the water drop covering the leaf piece. For visualization of fungal structures in tissues, Fluorescent Brightener 28 (FB28, $10 \mu \mathrm{g} / \mathrm{ml}$ solution) (Sigma-Aldrich Deisenhofen, Germany) was used instead of water. Table 8 provides an overview of excitation and emission spectra for the fluorophores used in this study. Chloroplast autofluorescence was detected at $700-750 \mathrm{~nm}$. For co-localization studies sequential scanning was used.

Table 8. Settings for fluorophore detection

\begin{tabular}{lll}
\hline Fluorophore & Exitation & Emission \\
\hline Fluorescent Brightener 28 (FB28) & $405 \mathrm{~nm}$ & $420-460 \mathrm{~nm}$ \\
\hline GFP & $488 \mathrm{~nm}$ & $500-540 \mathrm{~nm}$ \\
\hline Venus & $514 \mathrm{~nm}$ & $525-560 \mathrm{~nm}$ \\
\hline TagRFP-T & $514 \mathrm{~nm}$ & $560-600 \mathrm{~nm}$ \\
\hline RFP & $561 \mathrm{~nm}$ & $580-620 \mathrm{~nm}$ \\
\hline mCherry & $561 \mathrm{~nm}$ & $590-630 \mathrm{~nm}$ \\
\hline mKate2 & $561 \mathrm{~nm}$ & $590-640 \mathrm{~nm}$ \\
\hline
\end{tabular}




\section{Results}

This work analyzed proteolytic processing of the LySM-RLK CERK1 as well as its role in cell death regulation. In immunoblot experiments, a specific CERK1 antibody that recognizes an epitope near the $\mathrm{N}$-terminus of CERK1 detects the full length CERK1 receptor protein and an additional band of lower molecular weight. Previous research showed that this smaller band corresponds to the soluble extracellular domain of CERK1, also called the CERK1 ectodomain (Petutschnig et al., 2014). A CERK1 mutant was identified that shows no ectodomain signals in immunoblots, likely due to reduced stability of the ectodomain fragment. This mutant, cerk1-4, exhibits an enhanced cell death phenotype upon inoculation with powdery mildews and during senescence (Petutschnig et al., 2014).

The results of this thesis are divided into two parts. The aim of the first part was to analyze CERK1 ectodomain shedding. In particular, possible functions of ectodomain shedding in the wild type CERK1 protein and its role in formation of the cerk1-4 phenotype should be investigated. To do so, CERK1 mutants should be generated that are defective in ectodomain shedding. Therefore, a CERK1 antibody is used, which detects an epitope within the ectodomain of CERK1. Bands detected in immunoblots are therefore either full length protein or N-terminal fragments. The non-shedding CERK1 variants should be analyzed with regard to their chitin signaling capacity, such as chitin binding and chitin-induced receptor phosphorylation. The mutant plants should then be used to analyze if CERK1 ectodomain shedding is a prerequisite for development of the cerk1-4 phenotype.

The second part of this thesis aimed at identification of signal transduction components required for cell death formation in cerk1-4. For this purpose, a cerk1-4 suppressor screen with an EMS mutagenized population was previously established. In this work, a novel mutant fully suppressing the cerk1-4 phenotype was identified and the underlying mutation was mapped to the extra-large G-protein 2 (XLG2). The analysis of this mutant and the investigation of the subcellular localization of XLG2 was the focus of the second part of this work. 


\subsection{Analysis of CERK1 ectodomain shedding}

\subsubsection{Investigation of CERK1 ectodomain shedding in Arabidopsis thaliana accessions}

Arabidopsis thaliana can be naturally found in different habitats throughout the northern hemisphere (Weigel \& Mott, 2009). Plants from different locations exhibit genetic and morphological variety in order to adapt to their environments. Arabidopsis accessions also vary with regard to their PRR- and NB-LRR-type immune receptors (Gomez-Gomez et al., 1999; Noel et al., 1999; Rose et al., 2004; Stahl et al., 1999). To investigate this, different Arabidopsis thaliana accessions were analyzed for CERK1 ectodomain shedding and variations in the CERK1 amino acid sequence. Immunoblot analysis of 24 Arabidopsis accessions using the specific N-terminal CERK1 antibody was carried out. The immunoblots were performed with total protein extracts as well as pull-downs with chitin magnetic beads that are enriched for chitin binding proteins such as CERK1 (Petutschnig et al., 2010). As expected, wild type Col- 0 and Col-3 g/1 controls showed a signal at $75 \mathrm{kDa}$ corresponding to full length CERK1 receptor protein, as well as a signal at $33 \mathrm{kDa}$ representing the soluble ectodomain (Figure 6A). As described previously (Petutschnig et al., 2014), the cerk1-4 mutant showed the $75 \mathrm{kDa}$ full length signal, but lacked the $33 \mathrm{kDa}$ band corresponding to the soluble ectodomain. After chitin pull-down, additional faint bands around $40 \mathrm{kDa}$ became apparent in Col-0, Col-3 g/1 and cerk1-4, which can be typically observed for CERK1 (Petutschnig, unpublished data). Occasionally, low levels of $33 \mathrm{kDa}$ and $40 \mathrm{kDa}$ fragment can be detected in the CERK1 knockout mutant cerk1-2. This is due to the localization of the T-DNA near the 3' end of the CERK1 gene which results in residual upstream transcript (Miya et al., 2007). However, no signal for any of these bands could be detected in the CERK1 knockout mutant cerk1-2, indicating that all described signals are CERK1-specific. In all tested Arabidopsis ecotypes, the $75 \mathrm{kDa}$ full length CERK1 signal could be observed at similar abundance levels. Also, most accessions showed the faint $40 \mathrm{kDa}$ band. The $33 \mathrm{kDa}$ CERK1 ectodomain shedding product was also visible in all tested lines, however its abundance appeared to be clearly reduced in Mh-1, Rsch-4, Shakdara, Sorbo and Wt-5 (Figure 6A). Furthermore, the soluble ectodomain of Rsch-4 had a lower molecular size in comparison to Col-0. This was expected as one N-glycosylation site in Rsch-4 is mutated (not shown). The CERK1 ectodomain fragment is soluble and thus does not contain a functional transmembrane domain (TM). The size of the fragment as well as proteomic analyses narrow the possible CERK1 cleavage site down to a region comprising 20 amino acids N-terminal of the TM and the TM itself (Petutschnig et al., 2014) (Figure 8A). This 
sequence overlaps with the extracellular stalk, which is defined as the region between transmembrane domain and third LysM domain. Interestingly, all accessions found to exhibit reduced CERK1 ectodomain shedding harbor amino acid substitutions within the extracellular stalk in comparison to Col-0 (Figure 6B).

A

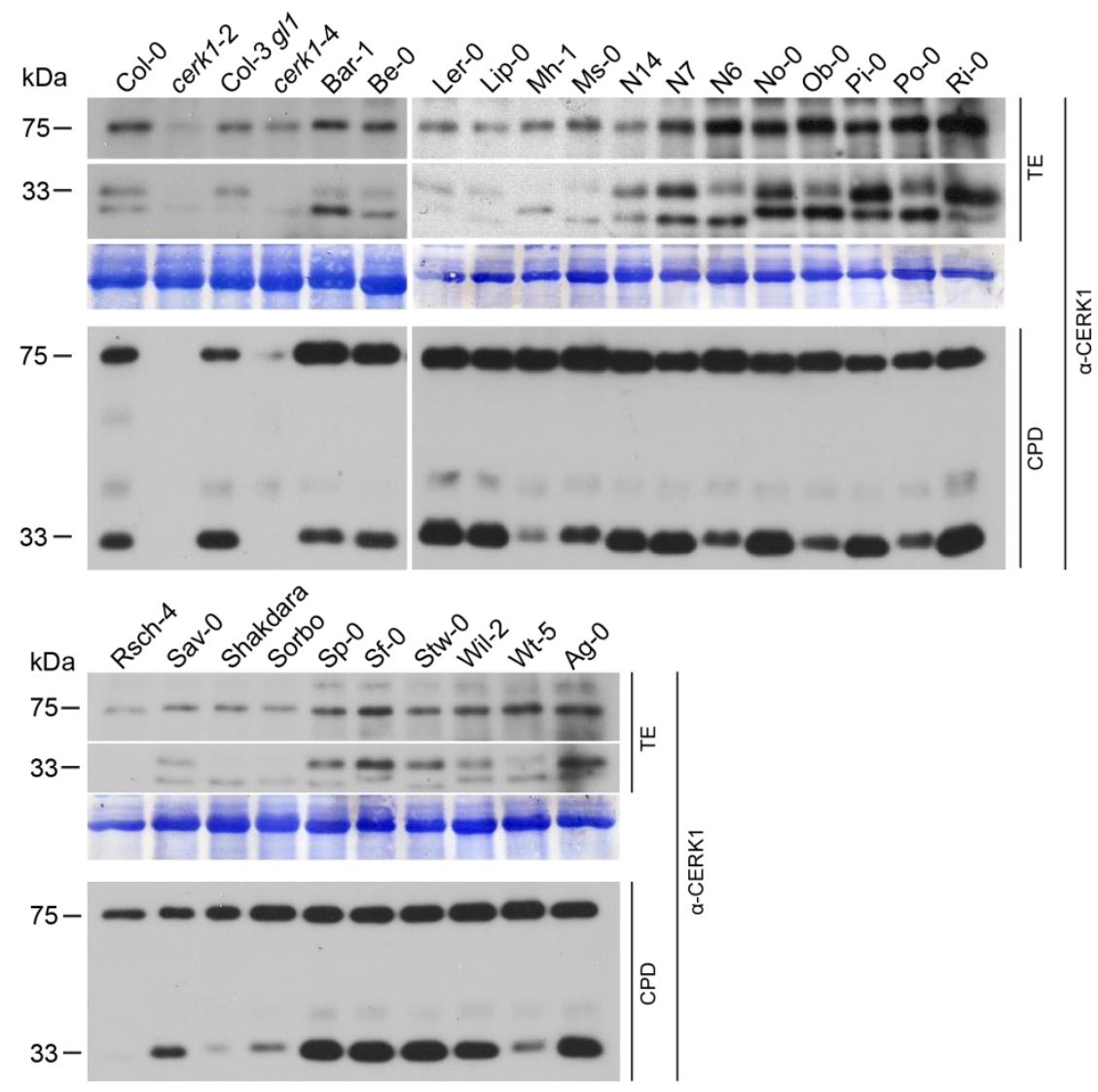

B

extracellular stalk

transmembrane domain

Col-0 207 I VYVPGRDPNGAFPPFKS SKQDGVGAG V I AG I VI GV I VALLL I LF I VYYAY

Sorbo $\quad 207$ I VYVPGRDPSGAFPAF KASKQGG I GAVVIAG I VVGVIVALLL ILF I I YYAY 257

Shakdara 207 I VYVPGRDPSGAFPAFKASKQGG I GAVVIAG IVVGVIVALLLILF I I YYAY 257

Wt-5 207 I VYVPGRDPSGAFPAFKASKQGG IGAVVIAG IVVGVIVALLLILF I IYYAY 257

Mh-1 207 I VYVPGRDPSGAFPAF KASKQGG IGAVVIAG IVVGVIVALLLILF I I Y I A 257

Rsch-4 207 I VYVPGRDPSGAFPAFKASKQGG IGAVVIAG IVVGVIVALLLILF I I Y $\quad 25 \%$

Figure 6. CERK1 ectodomain shedding is reduced in some Arabidopsis accessions. A) Anti-CERK1 immunoblot of different Arabidopsis accessions. Col-0, cerk1-2, Col-3 gl1 and cerk1-4 were used as controls. Upper panel, total extracts (TE). Lower panel, chitin pull-downs (CPD) prepared from total extracts shown in the upper panel. Full length CERK1 can be detected at $75 \mathrm{kDa}$ and CERK1 ectodomain at $33 \mathrm{kDa}$. CBB, Coomassie Brilliant Blue membrane (loading control). For Mh-1, Rsch-4, Sha Sorbo and Wt-5, reduced CERK1 ectodomain signal was observed in 3 independent experiments. B) Alignment of the extracellular stalk and transmembrane region of CERK1 from different Arabidopsis accessions with reduced CERK1 ectodomain shedding in comparison to $\mathrm{Col}-0$. 
It has to be noted that Sorbo, Shakdara, Wt-5, Mh-1 and Rsch-4 repeatedly showed decreased signals for the $33 \mathrm{kDa}$ CERK1 ectodomain fragment in several independent experiments, but in some blots they exhibited ectodomain shedding similar to Col-0. The abundance of the soluble ectodomain fragment increases with plant age and positively correlates with salicylic acid levels (Petutschnig et al., 2014). This raised the question whether the reduced abundance of the soluble ectodomain in Sorbo, Shakdara, Wt-5, Mh-1 and Rsch-4 is caused by differences in the developmental status of these lines, which in turn might be influenced by slightly variable growth conditions between experiments. To test if the reduction of CERK1 ectodomain shedding in these accessions is indeed caused by changes in the CERK1 amino acid sequence a construct containing the Wt-5 CERK1 coding sequence was generated and transformed into the CERK1 knockout cerk1-2, which is in the Col-0 background. Three independent transgenic cerk1-2 lines expressing Wt-5 CERK1 were tested in immunoblot analyses for CERK1 ectodomain shedding (Figure 7). A signal at $75 \mathrm{kDa}$ could be detected for all plants, except cerk1-2 and an ectodomain signal (33 kDa) could be observed for all plants except cerk1-2 and cerk1-4. Abundance of the ectodomain fragment in transgenic cerk1-2 plants expressing Wt-5 CERK1 was slightly reduced in comparison to Col-0, indicating that the amino acid sequence of CERK1 might play a role in ectodomain shedding. However, Wt-5 control plants exhibited CERK1 ectodomain shedding comparable to wild type in this experiment and the transgenic lines had lower overall abundance of the CERK1 protein compared to the controls, making interpretation of the data difficult.

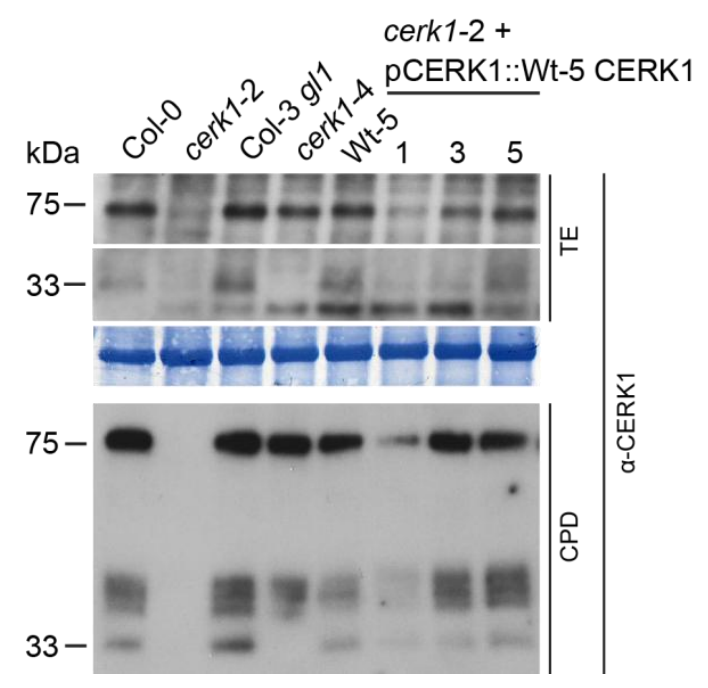

Figure 7. Wt-5 ectodomain shedding is also reduced in cerk1-2. Immunoblot of three independent transgenic lines expressing Wt-5 CERK1 using a specific CERK1 antibody. Col-0, cerk1-2, Col-3 g/1, cerk 1-4 and Wt-5 were sued as controls. Upper panel, total extracts (TE). Lower panel, chitin pull-down (CPD) using total extracts of the upper panel. CBB, Coomassie Brilliant Blue stained protein served as loading control. 


\subsubsection{Mutational analysis of potential CERK1 protease cleavage motifs}

Arabidopsis accessions with amino acid exchanges in the extracellular stalk region and TM show reduced abundance of the CERK1 ectodomain fragment in comparison to Col-0. The substitution from proline to alanine in position 221 is of special interest, as prolines are secondary structure disrupters (Vanhoof et al., 1995) which might be of importance for proper cleavage. Also, proline-containing motifs have been shown to be sites of ectodomain shedding in metazoan receptor kinases (Thorp et al., 2011; Yuan et al., 2003), which are structurally and functionally related to plant receptor-like kinases. In animals, ectodomain shedding of receptor kinases is performed by proteases belonging to two related families, $A$ Disintegrin And Metalloproteinases (ADAMs) and matrix metalloproteases (MMPs) (Hayashida et al., 2010). ADAM and MMP cleavage motifs are not clearly defined but cleavage sites of some receptor kinases are known. Yuan et al. (2003) analyzed ectodomain shedding of the human receptor tyrosine kinase Her2/neu/erbB2, a member of the epidermal growth factor receptor (EGFR) family and identified a short peptide signature within the extracellular stalk that is required for cleavage. This motif consists of two prolines or glycines flanking any five to seven amino acids (P/G- $\left.\mathrm{X}_{5-7}-\mathrm{P} / \mathrm{G}\right)$. Another member of the EGFR family, erbB4/Her4 is also subject to ectodomain shedding by ADAMs. Its cleavage site contains a $\mathrm{P}-\mathrm{X}_{7}-\mathrm{P}$ motif and a splice form that lacks this signature is not cleavable (Cheng et al., 2003). Proline-containing cleavage motifs have also been reported in RTKs outside the EGFR family. For example, ADAM-mediated ectodomain shedding of Mer tyrosine kinase (MerTK) is dependent on a $\mathrm{P}-\mathrm{X}_{5}-\mathrm{P}$ motif (Thorp et al., 2011). Moreover, many mammalian MMP cleavage motifs contain the $P / G-X_{5-7}-P / G$ signature (Turk et al., 2001).

Interestingly, the proline in position 221, which was found to be replaced by alanine in diverse accessions with reduced CERK1 ectodomain shedding (Figure 6B), is part of several potential EGFR cleavage motifs (Figure $8 \mathrm{~A}$ ), suggesting that this type of motif may also play a role in ectodomain shedding of CERK1. The neighboring amino acid in position 220 is also a proline, which is still present in the Arabidopsis accessions with reduced CERK1 ectodomain abundance. It may provide an alternative cleavage site and might explain why CERK1 ectodomain shedding is not completely abolished in these ecotypes. Thus, a construct was generated, where also the neighboring proline at position 220 was mutated to alanine. The mutation was denoted cerk1 cleavage1 (cvg1) (Figure 8B).

In addition to ADAMs and MMPs, Rhomboid proteases can mediate ectodomain shedding. They are intramembrane proteases which cleave their substrate within the transmembrane domain (Urban et al., 2001). Studies from Drosophila melanogaster revealed that Rhomboid-1 specifically recognizes a short amino acid sequence (ASIASGA) within the N- 
A

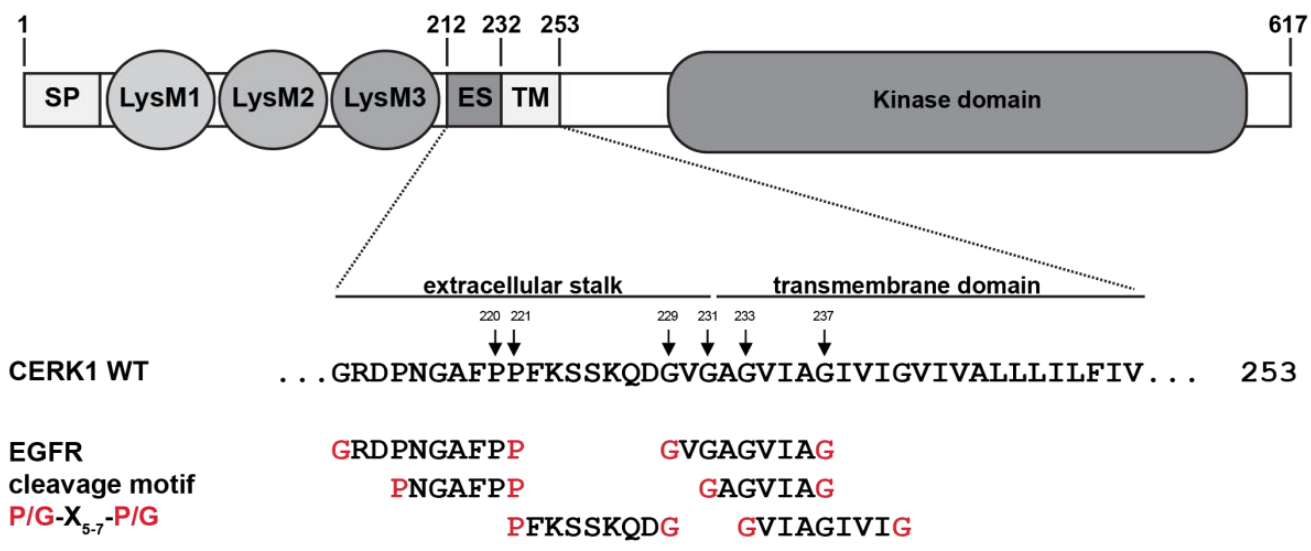

B

$\begin{array}{llll}\text { CERK1 WT } & \ldots \text { GRDPNGAFPPFKSSKQDGVGAGVIAGIVIGVIVALLLILFIV . . } & 253 \\ \text { cerk1 cvg1 } & \ldots \text { GRDPNGAFAAFKSSKQDGVGAGVIAGIVIGVIVALLLILFIV. . . } & 253 \\ \text { cerk1 cvg2 } & \ldots \text { GRDPNGAFPPFKSSKQDFVFAGVIAGIVIGVIVALLLILFIV. . } & 253 \\ \text { cerk1 cvg3 } & \ldots \text { GRDPNGAFPPFKSSKQDFVFAFVIAFIVIGVIVALLLILFIV. . . } & 253\end{array}$

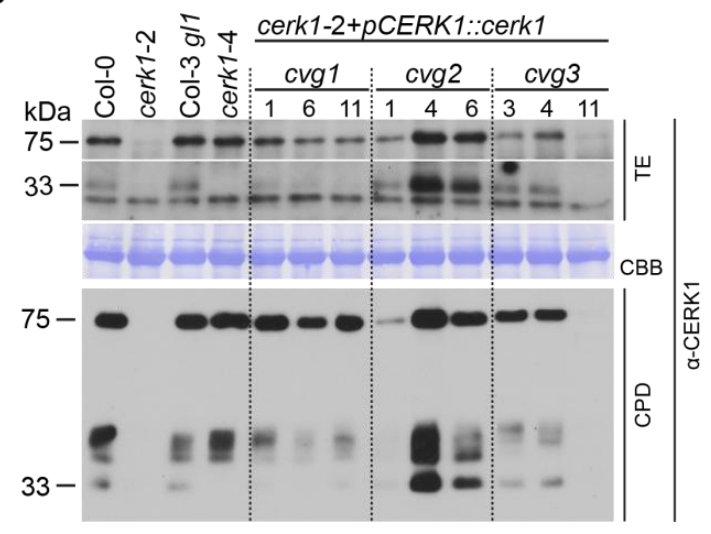

D

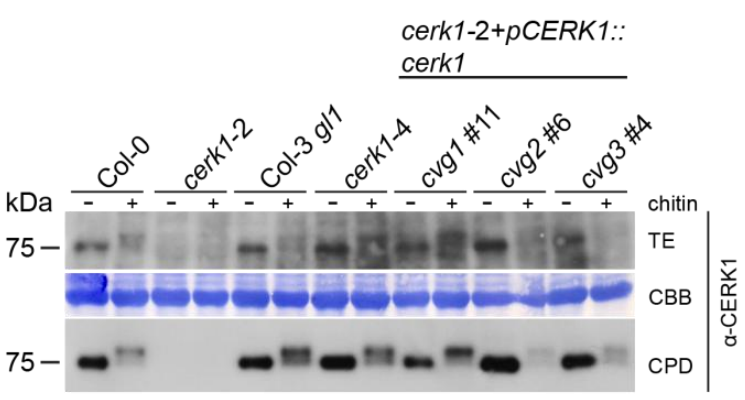

Figure 8. CERK1 cleavage motif mutants could not fully suppress CERK1 ectodomain shedding. A) Domain organization of CERK1 showing signal peptide (SP),lysin motifs (LysMs), extracellular stalk (ES), transmembrane domain (TM) and kinase domain. Positions of introduced mutations are indicated by arrows and numbers above arrows indicate amino acid positions. Potential EGFR-type cleavage motifs are aligned to the CERK1 extracellular stalk and transmembrane sequence and amino acids matching motifs are highlighted in red (CERK1 domain structure adapted from (Petutschnig et al., 2014). B) Alignment of CERK1 wild type sequence to protease cleavage mutants. Mutated amino acids are highlighted in red. C) Anti-CERK1 immunoblot of three independent cerk1-2 transgenic lines per cleavage construct expressed in cerk1-2. T2 transformants were selected for Basta ${ }^{\circledR}$ resistance and three whole rosettes per line were pooled and used for protein extraction. Samples from Col-0, cerk1-2, Col-3 g/1 and cerk1-4 were pooled the same way and served as controls. The upper panel shows total extracts (TE). To visualize both, the $75 \mathrm{kDa}$ full length fragment and the 33 kDaectodomain fragment optimally, different exposure times are shown. Lower panel, chitin pull-downs (CPD) prepared using total extracts shown inthe upper panel. CBB, Coomassie Brilliant Blue stained membrane (loading control). D) Band shift assay of CERK1 cleavage mutants. Plant leaves were vacuum-infiltrated with $100 \mu \mathrm{g} \mathrm{ml}$ shrimp shell chitin and were then incubated for 12 minutes. An anti-CERK1 Immunoblot of one chitin-treated transgenic line per CERK1 cleavage mutant is shown. Upper panel, total extracts of either mock-infiltrated (-) or chitin-infiltrated $(+)$ leaves. Lower panel, chitin pull-downs prepared from the total extracts shown in the upper panel. This experiment was repeated four times with similar results. 
terminal part of the transmembrane domain of its substrate, the TGFa homologue spitz (Urban \& Freeman, 2003). Detailed mutational analysis showed that the presence of the glycine residue in this motif is essential for cleavage and the adjacent alanine has an enhancing effect. Introduction of the GA motif turned synthetic transmembrane proteins into substrates for a number of different eukaryotic and prokaryotic rhomboid proteases. The small amino acids glycine and alanine were proposed to break the alpha helix and thereby increase the accessibility of the peptide backbone for rhomboid proteases (Urban \& Freeman, 2003). As rhomboid proteases are present in Arabidopsis (Koonin et al., 2003), it is possible that CERK1 might be a substrate of an Arabidopsis rhomboid protease.

The CERK1 transmembrane domain as well as the CERK1 extracellular stalk harbor several glycines, which might be part of potential Rhomboid cleavage motifs. Therefore, CERK1 mutants were generated where these glycines were mutated to the large hydrophobic amino acid phenylalanine. The mutants were designed in such a way, that also $P / G-X_{5-7}-P / G$ motifs overlapping with the transmembrane domain were mutated. In one mutant CERK1 variant, glycines at position 229 and 231 within the extracellular stalk were mutated (cerk1 cvg2, Figure 8B). In a second variant, additionally glycines in the transmembrane domain (position 233 and 237) were mutated to phenylalanine (cerk1 cvg3, Figure 8B) resulting in four glycine to phenylalanine substitutions. The cerk1 cvg1, cvg2 and cvg3 mutant variants were generated in the pGreenll-0229 vector containing the endogenous CERK1 promoter. The resulting constructs were transformed into the CERK1 knockout mutant cerk1-2 and transgenic plants were analyzed by immunoblotting using the specific CERK1 antibody. As expected, wild type Col-0, Col-3 g/1 and cerk1-4 controls showed a full length protein signal (75 kDa), whereas only Col-0 and Col-3 g/1 controls showed an ectodomain signal (33 kDa) (Figure $8 \mathrm{C}$ ). Additional bands at 40 kDa appeared in Col-0, Col-3 gl1 and cerk1-4 after chitin pull-down (Figure 8C). No CERK1 specific signal was detected in cerk1-2. Transgenic plants expressing the $\operatorname{cvg} 1, c v g 2$ or $c v g 3$ constructs showed both the full length CERK1 signal at 75 $\mathrm{kDa}$, as well as the $33 \mathrm{kDa}$ ectodomain band. The expression levels differed between individual lines, which would be expected for transgenic plants. Chitin binding ability was maintained in all tested CERK1 variants, as all of them could be pulled down by chitin magnetic beads at similar levels to the wild type controls (Figure $8 \mathrm{C}$ ). Comparison of signals intensities of the $75 \mathrm{kDa}$ and $33 \mathrm{kDa}$ bands in both total extracts and chitin pull-downs, suggested that ectodomain shedding was reduced in cerk $1 \mathrm{cvg} 1$ lines compared to Col-0 or Col-3 gl1. In contrast, ectodomain shedding in cerk1 cvg2 and cerk1 cvg3 seemed to be enhanced. CERK1 was reported to be phosphorylated after chitin treatment. This results in an electrophoretic mobility shift of phosphorylated CERK1 and can be detected in immunoblot experiments (Petutschnig et al., 2010). Each of the CERK1 variants showed the 
chitin-induced band shift in immunoblots, which was comparable to Col-0, Col-3 g/1 and cerk1-4, indicating functionality of the generated CERK1 variants (Figure 8D).

Several potential EGFR cleavage motifs can be found within an eleven amino acid stretch in the intracellular juxtamembrane domain of CERK1 (Figure 9A). Interestingly, this motif can also be found in the intracellular juxtamembrane domain of several rice RLKs (Ding et al., 2009) and autophosphorylation within this cleavage motif was suggested to prevent cleavage of the rice RLK XA21 (Xu et al., 2006). CERK1 cleavage within or near this motif would result in a fragment with a molecular weight of about $40 \mathrm{kDa}$. As already shown, fragments of this size can be detected in CERK1 immunoblots after chitin pull-down (see Figure 8C) and might represent precursors, which are subsequently cleaved to produce the soluble CERK1 ectodomain fragment. Therefore, a CERK1 variant was generated, where this amino acid stretch was deleted (cerk1 clx, Figure 9A). This construct was expressed in the CERK1 knockout mutant cerk1-2 under control of the endogenous CERK1 promoter. Immunoblot analysis of three independent transgenic cerk $1 \mathrm{cl} x$ expressing lines was performed using the specific CERK1 antibody (Figure 9B). Full length CERK1 protein at $75 \mathrm{kDa}$ and CERK1 ectodomain at $33 \mathrm{kDa}$ could be detected for Col-3 g/1 and Col-0. As expected, only full length protein and no ectodomain could be detected for cerk1-4. Full length protein and ectodomain were missing in cerk1-2, confirming the specificity of the described bands. cerk1 clx full length protein and ectodomain could be detected for all tested transgenic lines, albeit at lower molecular weights as their wild type counterparts. Lower molecular weight was expected and is caused by deletion of eleven amino acids. cerk $1 \mathrm{clx}$ maintained the ability to bind chitin, as for all tested transgenic lines full length protein and ectodomain could be pulled down with chitin magnetic beads. The abundance of full length CERK1, but not the ectodomain shedding product, is lower in cerk1 clx expressing lines than in the wild type controls, which can be observed in total extracts as well as chitin pull-downs. This led to the conclusion that ectodomain shedding in cerk $1 \mathrm{clx}$ is actually enhanced in comparison to wild type. Multiple bands around $40 \mathrm{kDa}$ were detected in chitin pull-downs of Col-0, Col-3 g/1 and cerk1-4, but not in cerk1-2. This is frequently observed, but the exact identity of these CERK1 signals is not known. The approximately $40 \mathrm{kDa}$ signals also occurred in the cerk1 $c l x$ expressing plants, indicating that the deleted amino acid stretch in the intracellular juxtamembrane domain is not critical for their generation. Thus CERK1 is probably not cleaved within the deleted sequence. The apparent molecular weight of the $40 \mathrm{kDa}$ bands was altered in the cerk $1 \mathrm{clx}$ expressing plants, which suggests that the cleavage site(s) might be shifted C-terminally of the $c / x$ deletion (Figure 9B). cerk1 $c l x$ is still able to autophosphorylate, as indicated by an electrophoretic mobility shift after chitin treatment, suggesting functionality of the construct (Figure 9C). 
A

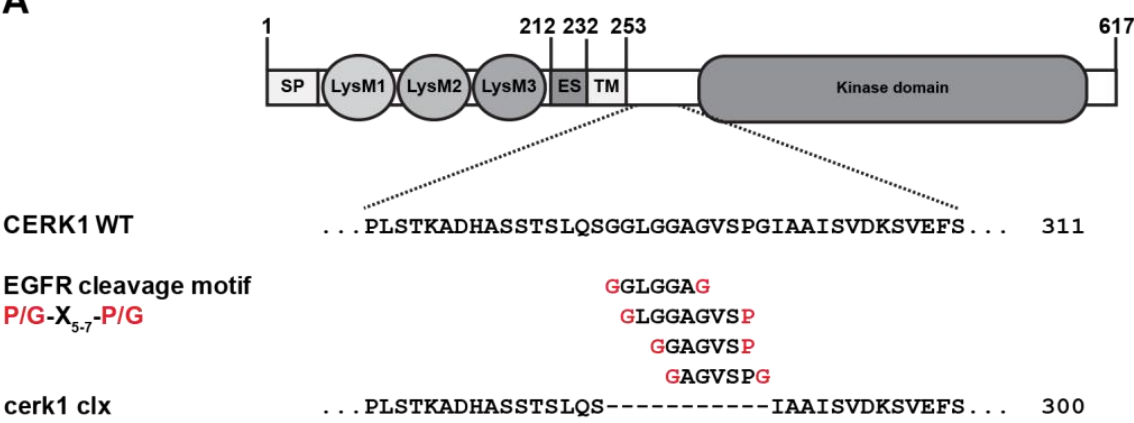

B

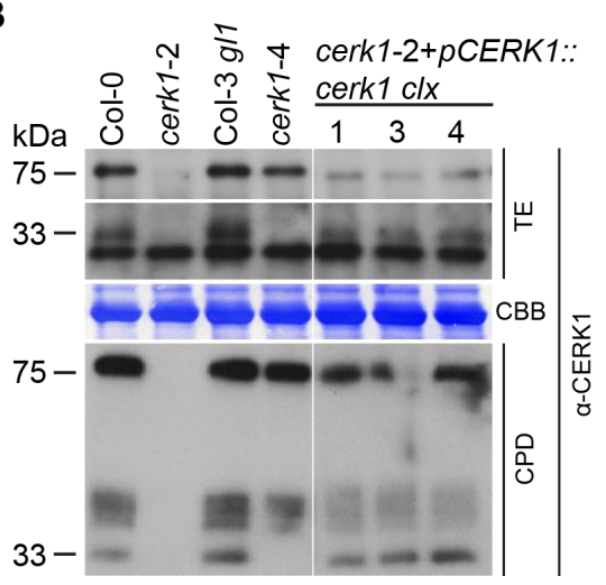

C

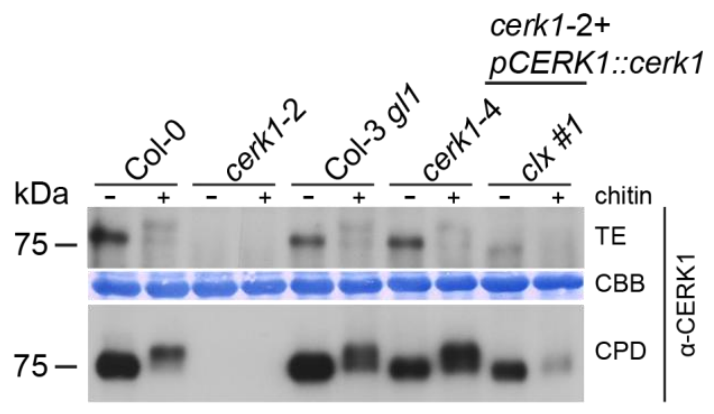

Figure 9. Deletion of potential intracellular cleavage motifs could not suppress CERK1 ectodomain shedding. Domain organization of CERK1 illustrating signal peptide (SP), lysin motifs (LysMs), extracellular stalk $(E S)$, transmembrane domain (TM) and kinase domain. Deleted amino acids in cerk1 clx are indicated by dashes. EGFR-type cleavage motifs are aligned to the CERK1 intracellular juxtamembrane domain. Amino acids of EGFR-type cleavage motifs matching the CERK1 sequence are highlighted in red (CERK1 domain structure adapted from (Petutschnig et al., 2014). B) Immunoblot of three individual transgenic cerk1-2 lines expressing cerk1 $c / x$ using the specific CERK1 antibody is shown. T2 transformants were selected for Basta $\Theta$ resistance and three whole rosettes per line were pooled and used for protein extraction. Col-0, cerk1-2, Col-3 gl1 and cerk1-4 plants were harvested the same way and served as controls. Upper panel shows total extracts (TE). To visualize both, the $75 \mathrm{kDa}$ full length fragment and the $33 \mathrm{kDa}$ ectodomain fragment optimally, different exposure times are shown. Lower panel shows chitin pull-downs (CPD) using total extracts shown in the upper panel. C) Band shift assay of cerk1 clx. Leaves were vacuum-infiltrated with $100 \mathrm{mg} \mathrm{ml}^{-1}$ shrimp shell chitin and incubated for 12 minutes. Immunoblot of one transgenic cer1-2 line expressing cerk1 $\mathrm{clx}$ using the specific CERK1 antibody is shown. Upper panel, total extracts of either mock-infiltrated (-) or chitin-infiltrated (+) leaves. Lower panel, chitin pull-down prepared of total extracts shown in upper panel. CBB, Coomassie Brilliant Blue stained membrane (loading control). This experiment was repeated three times with similar results

\subsubsection{The cvg1 mutation does not suppress the cerk1-4 phenotype}

Mutational analysis of CERK1 potential proteolytic cleavage sites led to the identification of a CERK1 mutant (cerk1 cvg1) with reduced ectodomain shedding. This mutant was used to investigate if reduced ectodomain shedding can suppress the development of the cerk 1-4 phenotype. Therefore, the cerk1-4 mutation was introduced into the vector pGreenll0229PREP harbouring cerk1 cvg1. The resulting construct (cerk1-4 cvg1) was transformed 
into the CERK1 knockout mutant cerk1-2 and expressed under the control of the endogenous promoter. The resulting transgenic lines were assessed for cerk1-4 phenoype development after pathogen inoculation (Figure 10) and of senescent plants (Figure 11). Five independent transgenic lines either expressing cerk1-4 cvg1 or cerk1 cvg1 were inoculated with Blumeria graminis f.sp hordei (Figure 10A). The controls Col-0, cerk1-2 and Col-3 gl1 did not show any macroscopically visible phenotype. As expected, cerk1-4 plants exhibited cell death and chlorosis, particularly on lower leaves. A similar phenotype was shown by four out of five transgenic plant lines expressing cerk1-4 cvg1, indicating that reduced ectodomain shedding cannot suppress the cerk1-4 phenotype. cerk1 cvg1 expressing plants looked like wild type, confirming that the cell death phenotype of cerk1-4 cvg1 plants is caused by the cerk 1-4 and not by the cvg1 mutation.

Immunoblot analysis of Bgh inoculated plants was performed to check for CERK1 protein levels and CERK1 band pattern in the transgenic plant lines (Figure 10B). Full length protein (75 kDa) could be observed for Col-0, Col-3 gl1 and cerk1-4 and an ectodomain fragment (33 kDa) for Col-0 and Col-3 g/1. No CERK1-specific bands were detected for cerk1-2. As expected, ectodomain abundance in cerk $1 \mathrm{cvg} 1$ expressing plants was reduced compared to wild type. However, it has to be noted that none of the cerk1 cvg1 lines tested in this experiment reached the overall CERK1 protein levels of the controls. Surprisingly, in plants expressing the double mutant cerk $1-4 \mathrm{cvg} 1$ version, only very low levels of full length cerk 1 protein could be detected compared to wild type. In spite of the low abundance of cerk1-4 cvg1, the protein amount was apparently still sufficient to trigger the cerk1-4 phenotype. Also, the cerk1-4 cvg1 protein maintained the ability to bind chitin, as indicated by pulldown experiments with chitin magnetic beads (Figure 10B). Interestingly, an ectodomain fragment could be detected in chitin pull-downs after long exposure for cerk1-4 cvg1 expressing plants, which is not present in cerk1-4 plants. 
A

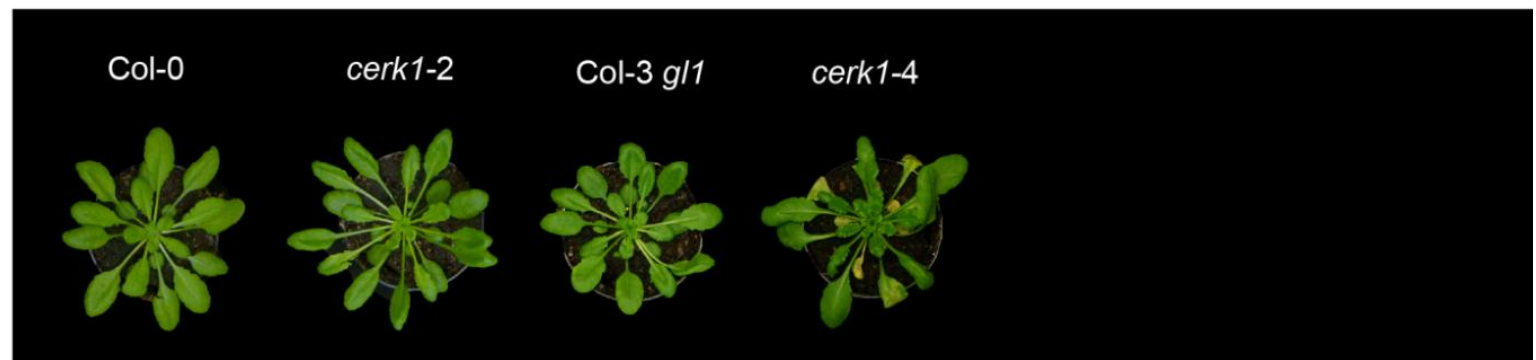

cerk1-2+pCERK1:.:cerk1 cvg1

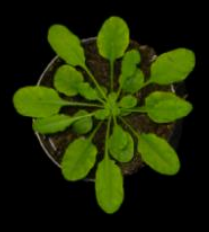

2

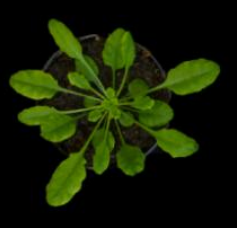

7

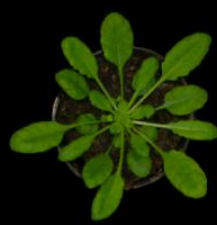

8

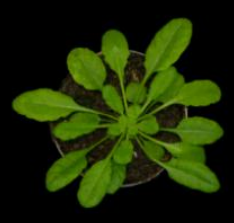

9

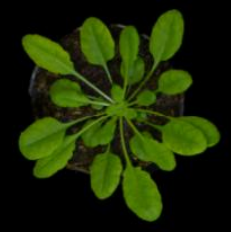

10

cerk1-2+pCERK1::cerk1-4 cvg1

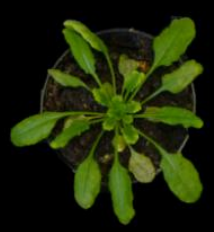

5

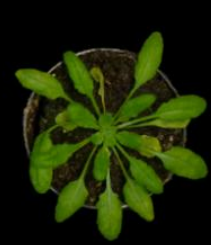

8

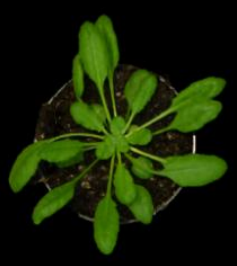

9

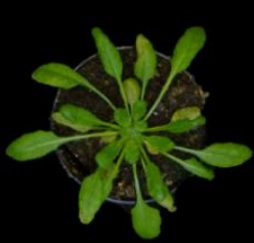

15

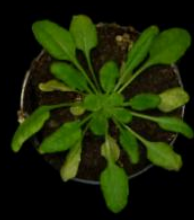

18

B

พ के cerk1-2 + pCERK1::

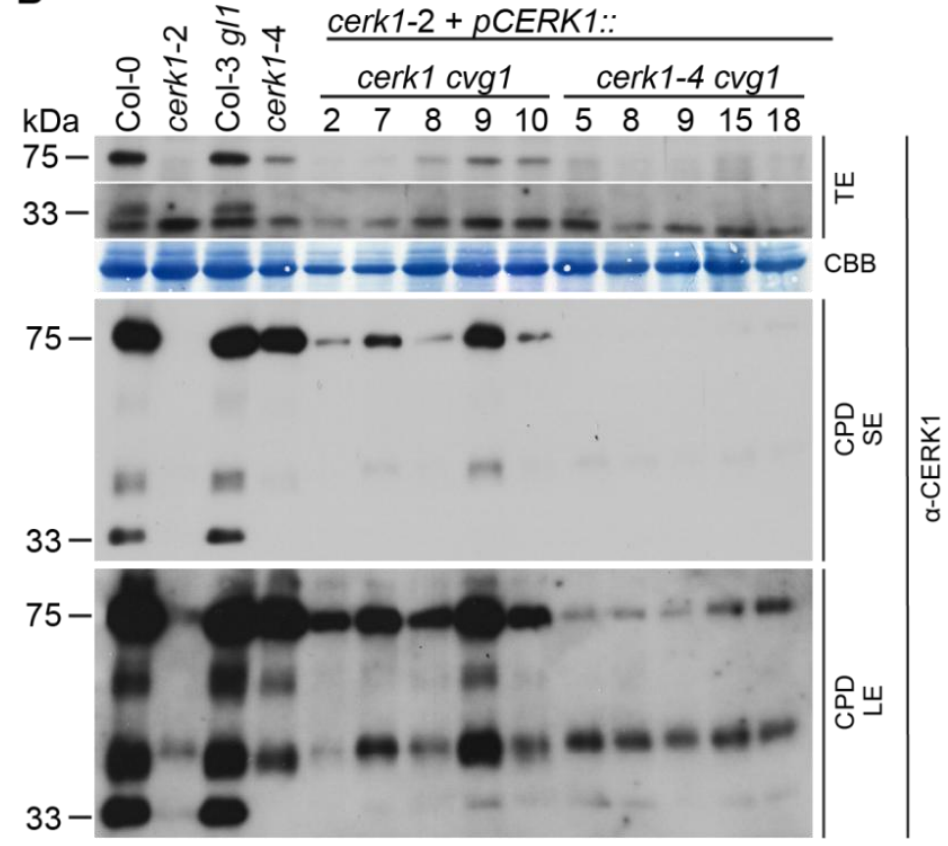


Figure 10 on page 68 . The $c v g 1$ mutation cannot suppress the Bgh-induced cerk1-4 phenotype. Five independent transgenic lines either expressing cerk1 cvg1 or cerk1-4 cvg1 under control of the CERK1 promoter as well as control plants were inoculated with Blumeria graminis f.sp. hordei (Bgh). T1 plants were selected for Basta ${ }^{\circledR}$ resistance and Col-0, cerk1-2, Col-3 g/1 and cerk1-4 served as controls. A) The macroscopical phenotype was assessed seven days after inoculation and pictures were taken. This experiment was repeated twice with similar results. B) Anti-CERK1 immunoblot using protein samples prepared from plants shown in A). 2 -3 leaves were harvested from each plant. Col-0, cerk1-2, Col-3 g/1 and cerk1-4 plants were harvested the same way. The upper panel shows total protein extracts (TE). To visualize both, the $75 \mathrm{kDa}$ full length fragment and the $33 \mathrm{kDa}$ ectodomain fragment optimally, different exposure times are shown. Lower panel shows chitin pulldowns (CPD) using total extracts shown in the upper panel. Two exposure times are shown to optimally visualize the ectodomain of cerk1-4 cvg1 expressing plants. CBB, Coommasie Brilliant blue staining (loading control); SE, short exposure; LE, long exposure. This experiment was repeated twice with similar results.

In addition to the exaggerated cell death phenotype upon inoculation with Bgh, cerk 1-4 plants also exhibit a typical phenotype during senescence, which is characterised by a reduced rosette size and enhanced cell death on older leaves (Petutschnig et al., 2014). To test if the cvg1 mutation could suppress the cerk1-4 senescence phenotype, five independent transgenic plants expressing cerk1-4 cvg1 or cerk1 cvg1 were assessed after five and ten weeks of growth, respectively (Figure 11A). At the age of five weeks, all plants, including the cerk1-4 control, looked like wild type with no macroscopically visible cell death. At ten weeks, cerk1-4 and all tested cerk1-4 cvg1 expressing plants showed the characteristic cerk1-4 senescence phenotype (Figure 11A). cerk1 cvg1 expressing plants looked like wild type plants, confirming that the senescence phenotype is caused by cerk 1-4 and not the cvg1 mutation. Immunoblot analysis was performed to asses CERK1 expression and band pattern (Figure 11B). The control plants Col-0, cerk1-2, Col-3 g/1 and cerk1-4 showed the expected band pattern. The transgenic lines expressing cerk1 cvg1 showed CERK1 full length signals $(75 \mathrm{kDa})$ that where comparable to wild type or weaker. In agreement with earlier results, the soluble ectodomain fragment was hardly visible in these lines. For cerk1-4 cvg1 expressing plants, only a weak $75 \mathrm{kDa}$ signal corresponding to full length protein could be detected, which is very similar to the results obtained with Bgh infected cerk1-4 cvg1 expressing plants. Taken together, the immunoblot data suggest that the cvg1 mutation has a destabilizing effect on CERK1 which predominantly affects the soluble CERK1 ectodomain fragment as a single mutation. In combination with the cerk1-4 mutation, the effect seems to become more severe and to also destabilize the full length CERK1 protein. The results of the phenotypic analyses suggest that the cvg 1 mutation could neither suppress the enhanced cell death phenotype after pathogen challenge nor the characteristic cerk1-4 senescence phenotype. 
A

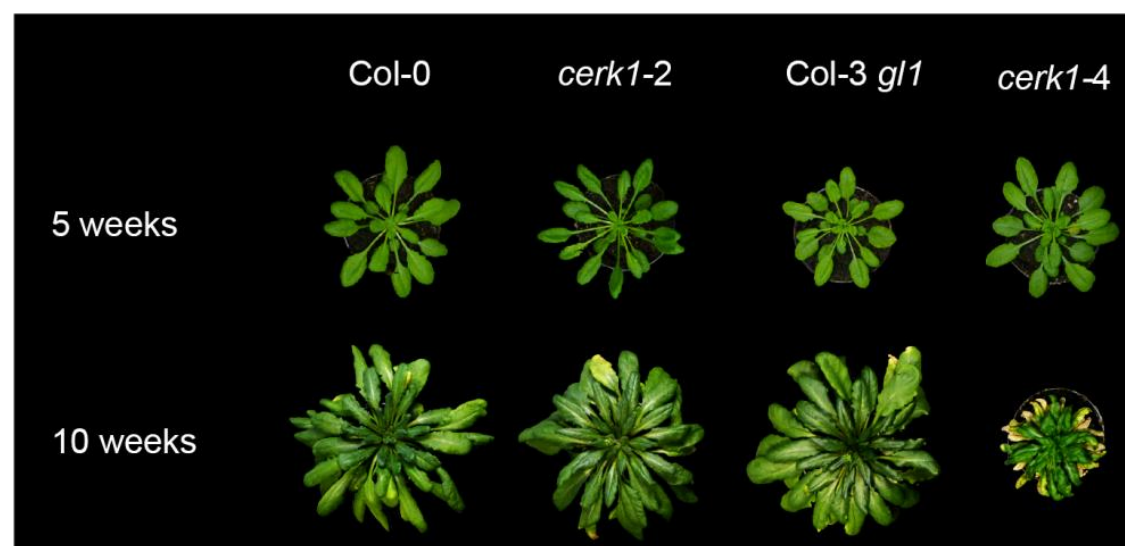

cerk1-2+pCERK1::cerk1 cvg1

5 weeks
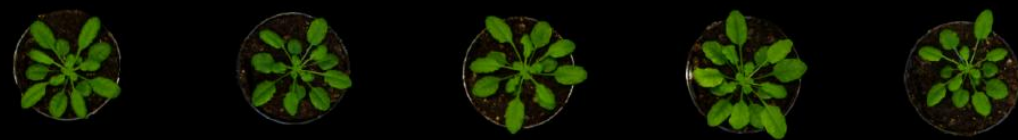

10 weeks

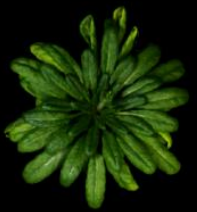

19

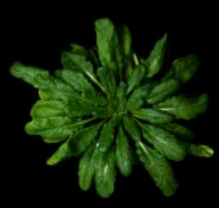

20

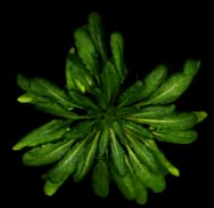

23

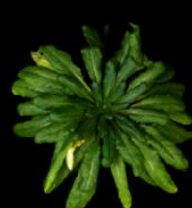

24

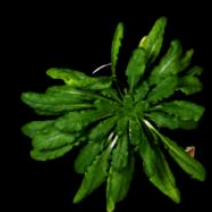

26

cerk1-2+pCERK1::cerk1-4 cvg1

5 weeks
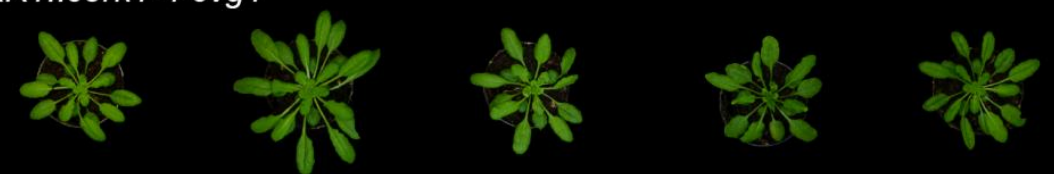

10 weeks
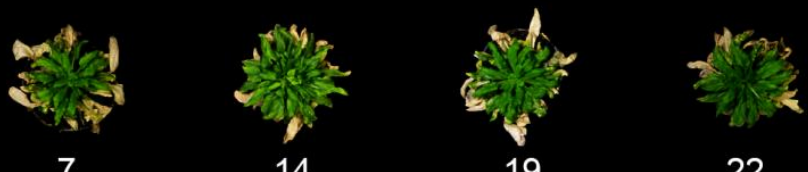

22

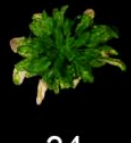

B

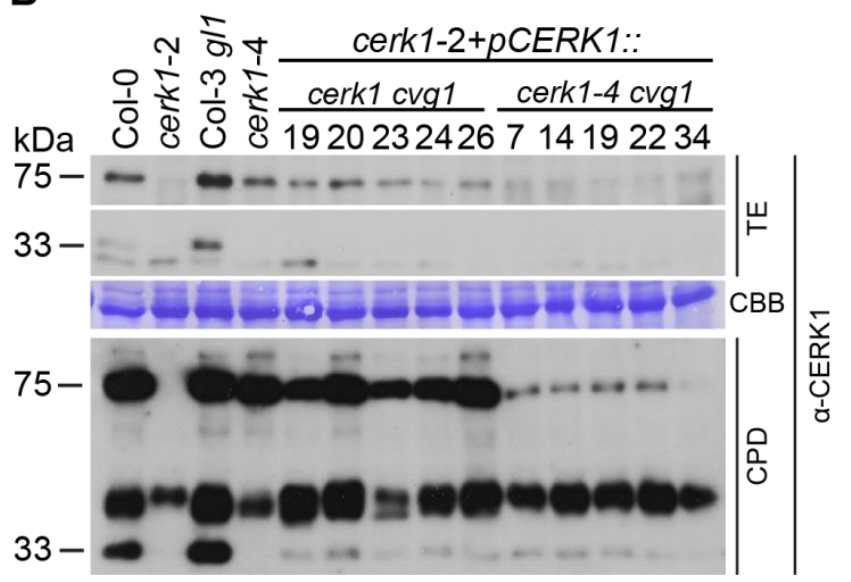


Figure 11 on page 70 . The cvg1 mutation cannot suppress the cerk1-4 senescence phenotype. Five independent transgenic lines expressing either cerk1 cvg1 or cerk1-4 cvg1 in the cerk1-2 background under control of the endogenous CERK1 promoter were grown under short day conditions. T1 plants were selected for Basta ${ }^{\circledR}$ resistance and Col-0, cerk1-2, Col-3 g/1 and cerk1-4 served as controls. A) Phenotype was macroscopically assessed after 5 and 10 weeks of growth and pictures were taken. B) Immunoblot analysis using the specific CERK1 antibody. Total extracts (TE) were prepared plants shown in A). $2-3$ leaves were harvested from each plant including controls. The upper panel shows total protein extracts (TE). To visualize both, the 75 $\mathrm{kDa}$ full length fragment and the $33 \mathrm{kDa}$ ectodomain fragment optimally, different exposure times are shown. Lower panel shows chitin pull-down which was performed using the total extracts shown in the upper panel. CBB, Coommasie Brilliant blue. This experiment was repeated twice with similar results.

\subsubsection{Variation of the CERK1 extracellular stalk length}

Point mutations targeting potential cleavage motifs in the extracellular juxtamembrane domain (extracellular stalk) of CERK1 did not fully suppress its ectodomain shedding. Furthermore, deletion of a potential cleavage motif within the intracellular juxtamembrane domain had no effect on the CERK1 band pattern. Therefore, other factors than the amino acid sequence might be of importance for proteolytic processing of the extracellular domain. Migaki et al. (1995) showed that cleavage of the leukocyte adhesion molecule L-selectin could be inhibited by reduction of the extracellular stalk length. Deletion of five amino acids within the extracellular stalk could suppress cleavage of the L-selectin extracellular domain completely, even if the native cleavage site of L-selectin was maintained. Similar effects were reported for other transmembrane proteins that undergo ectodomain shedding such as the interleukin 6-receptor (Baran et al., 2013) or the p75 neurotrophin receptor (Weskamp et al., 2004). This raised the idea that proteolytic cleavage of the CERK1 ectodomain might also depend on the length of the extracellular stalk. Therefore, CERK1 mutants were generated, where amino acids of the extracellular stalk were deleted (Figure 12A). In one mutant construct, five amino acids close to the transmembrane domain were deleted (cerk1 del1). In a second construct a deletion of 11 amino acids within the extracellular stalk was generated (cerk1 del2). In this construct, only a short amino acid stretch of the extracellular stalk was left as a linker between the third LysM domain and the transmembrane domain. Both mutant cerk1 variants were cloned into the pGreenII-0229PREP vector containing the native CERK1 promoter and expressed in the CERK1 knockout mutant background cerk1-2. Three independent transgenic plants expressing cerk1 del1 were analyzed in immunoblot experiments together with control lines (Figure 12B). 
A

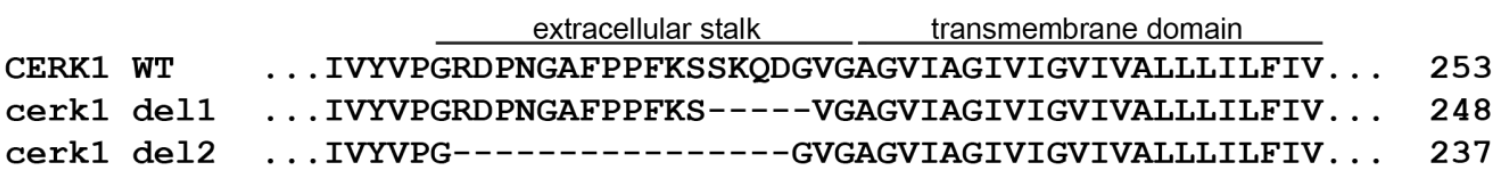

B

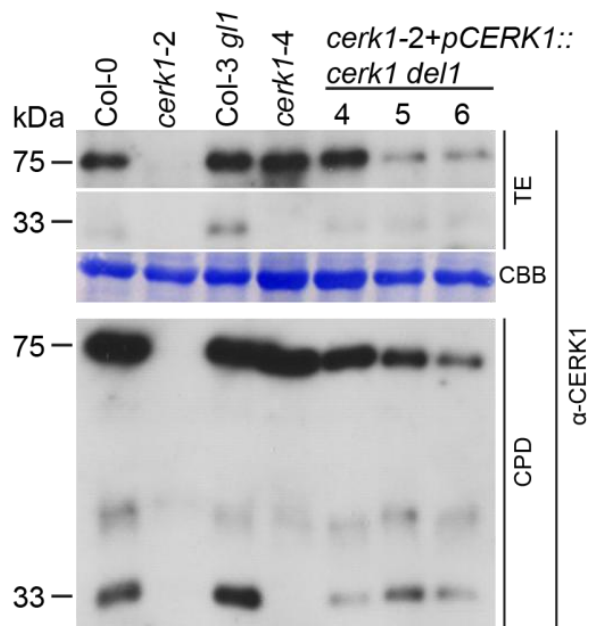

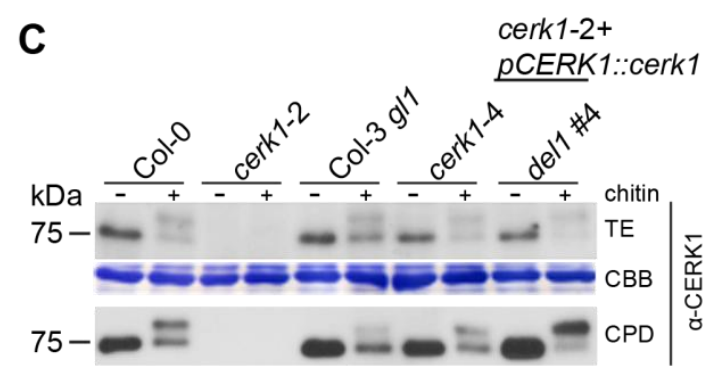

Figure 12. Deletion within the extracellular stalk did not suppress CERK1 ectodomain shedding. A) Alignment of generated CERK1 deletion mutants to wild type CERK1. Deleted amino acids are indicated by dashes. B) Anti-CERK1 immunoblot of three transgenic lines expressing cerk1 del1 in the CERK1 knockout background cerk1-2 under control of the native CERK1 promoter. Col-0, cerk1-2, Col-3 gl1 and cerk1-4 were used as controls. Upper panel, total extracts (TE). Lower panel, chitin pull-down (CPD) using total extracts shown in the upper panel. CBB, Coomassie Brilliant Blue stained membrane (loading control). C) Band shift assay. Leaves of one transgenic line expressing cerk1 del1 and control plants were vacuum infiltrated with 100 $\mu \mathrm{g} \mathrm{ml}^{-1}$ shrimp shell chitin and were then incubated for 12 minutes. An immunoblot using the specific CERK1 antibody is shown. Upper panel, total extract of either mock-infiltrated (-) or chitin-infiltrated (+) plants. Lower panel, chitin pull-down performed with total extracts shown in upper panel. Immunoblot analysis was repeated 3 times, band shift assay was repeated 2 times.

The expected band pattern could be detected for the control plants. For all three plants lines expressing cerk1 del1, a $75 \mathrm{kDa}$ signal corresponding to the full length protein and a $33 \mathrm{kDa}$ ectodomain fragment could be detected (Figure 12B) even though the overall CERK1 abundance between the transgenic lines was variable. Full length protein and ectodomain fragment of cerk 1 del1 could be pulled down using magnetic chitin beads demonstrating chitin binding capacity (Figure 12B). In addition to chitin binding, functionality of cerk1 del1 is further indicated by chitin-induced receptor phosphorylation, which appears as a characteristic band shift in immunoblot experiments (Figure 12C).

In transgenic plants expressing cerk1 del2 neither full length protein nor ectodomain fragment could be detected (not shown), even though 17 independent transformants were analyzed. Deletion of 16 amino acids within the CERK1 extracellular stalk did probably cause structural instability of the protein. 


\subsubsection{CERK1-FLS2 domain swap experiments}

CERK1 cleavage motif and short deletion mutants were not successful to suppress CERK1 ectodomain shedding. Longer deletions affected the stability of the CERK1 protein and thus the position of CERK1 proteolytic cleavage remains unknown. To generate shedding deficient CERK1 variants and/or to narrow down the area where CERK1 ectodomain shedding occurs, domain swap constructs with FLS2 were generated. FLS2 is the Arabidopsis flagellin receptor (Chinchilla et al., 2006) and one of the best characterized plant RLKs. To date there are no reports of any proteolytic modification of FLS2, suggesting that FLS2 may not be subject to ectodomain shedding. By replacing the CERK1 transmembrane domain and parts of the CERK1 extracellular stalk with the respective parts of FLS2, chimeric CERK1 FLS2 mutants were generated (Figure 13A). CERK1 FLS2 chimeras lacking the CERK1 sequences critical for ectodomain shedding should not generate any soluble ectodomain fragments and possibly extend our knowledge about the CERK1 cleavage site.

A series of chimeric CERK1-FLS2 constructs were generated. In cerk1 fls2tm, the CERK1 transmembrane domain was replaced by the FLS2 transmembrane domain (cerk1 fls2tm). In a second variant, the amino acid sequence of the CERK1 extracellular stalk beginning with serine at position 224 was replaced by the entire extracellular stalk of FLS2 including the FLS2 transmembrane domain (cerk1 fls2tmex1). In cerk1 fls2tmex2, the CERK1 transmembrane domain and eight amino acids $\mathrm{N}$-terminal of the transmembrane domain were replaced with the respective sequences of FLS2. A fourth domain swap construct was generated where the entire extracellular stalk and the transmembrane domain of CERK1 were replaced by the entire extracellular stalk and transmembrane domain of FLS2 (cerk1 fls2tmex3). The chimeric CERK1-FLS2 constructs were cloned into the vector pGreenII0229PREP and heterologously expressed in Nicotiana benthamiana under control of the endogenous CERK1 promoter. A CERK1 wild type construct was transformed as control. To confirm specificity of the observed bands, a sample of a non-transformed $N$. benthamiana leaf was included. Immunoblot analysis using the specific CERK1 antibody revealed expression of all constructs in $N$. benthamiana (Figure 13B). A signal at $75 \mathrm{kDa}$ corresponding to the full length CERK1 protein and a $33 \mathrm{kDa}$ fragment corresponding to the soluble ectodomain could be detected for wild type CERK1. Full length protein at $75 \mathrm{kDa}$ and an ectodomain fragment at $33 \mathrm{kDa}$ could also be observed for cerk1 fls2tm and cerk1 fls2tmex2. Leaves expressing cerk1 fls2tmex 1 and cerk1 fls2tmex3 showed a full length signal with a higher molecular weight than wild type CERK1. This was expected due to the insertion of the FLS2 extracellular stalk, which is longer than the CERK1 extracellular stalk. Interestingly, even though cerk 1 fls2tmex3 full 
A

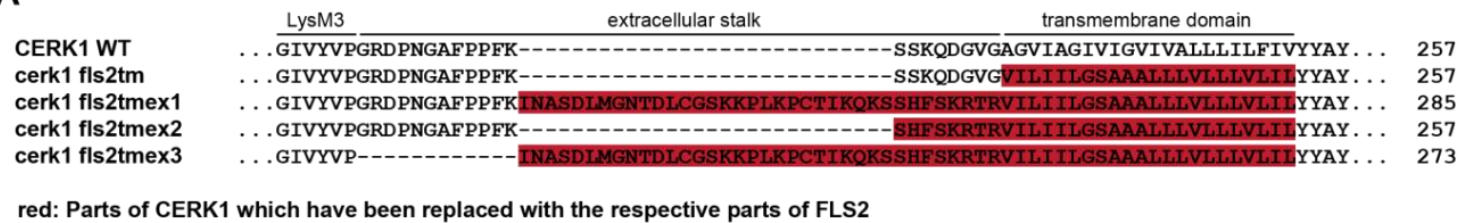

B

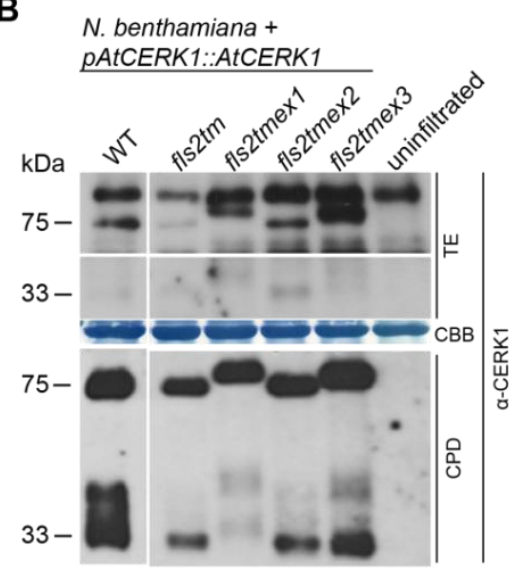

C

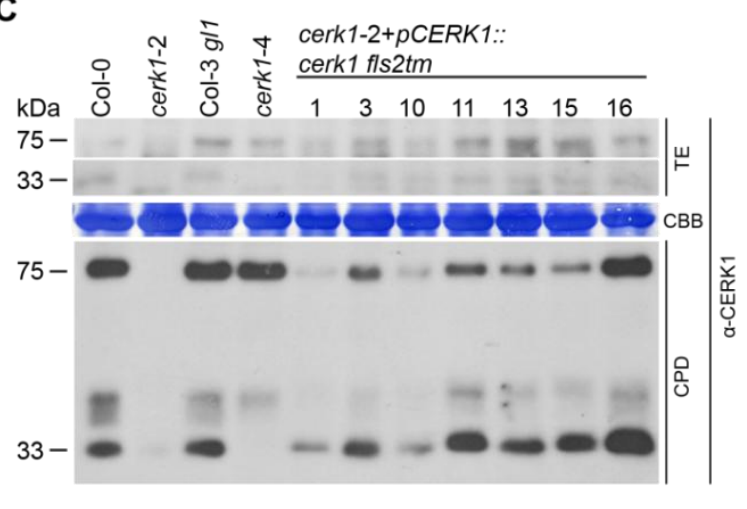

E

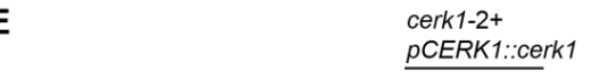

D

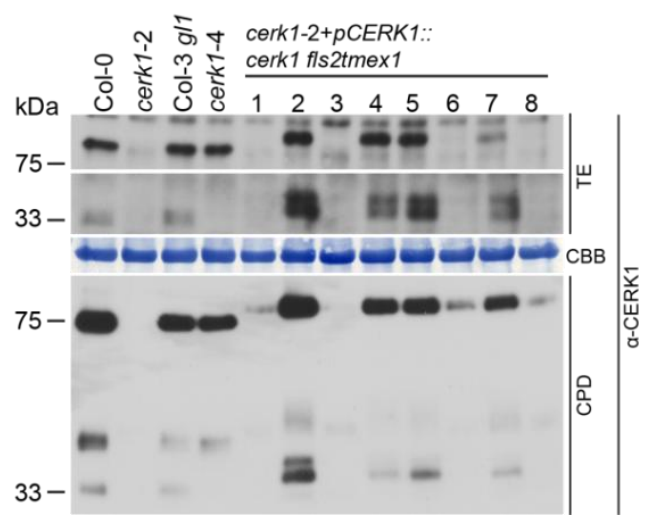

pCERK1::cerk1

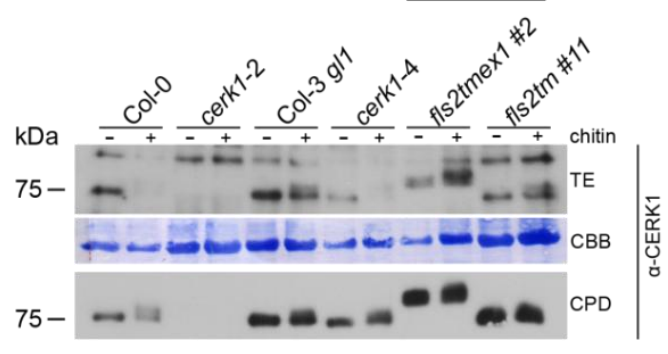

Figure 13. Replacement of the CERK1 extracellular stalk and transmembrane domain could not suppress CERK1 ectodomain shedding. A) Alignment of generated CERK1-FLS2 domain-swap mutants to the wild type CERK1 sequence. Sequences highlighted in red derive from FLS2 and have been used to replace the respective parts of CERK1. B) Anti-CERK1 immunoblot of CERK1-FLS2 domain swap proteins expressed transiently under control of the native CERK1 promoter in Nicotiana benthamiana. Wild type CERK1 was expressed as a control protein and uninfiltrated Nicotiana benthamiana leaves served as a negative control. Samples were harvested 3 days after infiltration. Upper panel, immunoblot with total protein extracts (TE). Lower panel, immunoblot with chitin pull-downs (CPD) of total extracts shown in upper panel. CBB, Coomassie Brilliant Blue stained membrane (loading control). C) Anti-CERK1 immunoblot of seven individual transgenic lines expressing cerk1 fls2tm under control of the native CERK1 promoter in the cerk1-2 background. Col-0, cerk1-2, Col-3 gl1 and cerk1-4 were used as controls. Upper panel, total extracts. Lower panel, chitin pull-down of total extracts. D) Anti-CERK1 immunoblots of eight individual transgenic lines expressing cerk1 fls2tmex 1 under control of the native CERK1 promoter in cerk1-2. Col-0, cerk1-2, Col-3 gl1 and cerk1-4 were used as controls. Upper panel, total extracts showing two different exposure times to visualize both, the full length protein and the ectodomain. Lower panel, chitin pulldown of total extracts. E) Band shift assay. Leaves of transgenic lines expressing cerk1 fls2tmex1 and cerk1 fls2tm as well as control plants were vacuum infiltrated with $100 \mathrm{\mu g} \mathrm{ml}^{-1}$ shrimp shell chitin and were then incubated for 12 minutes. Immunoblots using the specific CERK1 antibody is shown. Upper panel, total extracts of mock-infiltrated (-) or chitin-infiltrated (+) samples. Lower panel, chitin pull-downs of total extracts shown inupper panel. This experiment was repeated three times with similar results. 
length protein had a higher apparent molecular weight than wild type CERK1, it showed an ectodomain fragment that was very similar in size to the wild type variant. In contrast, the $\mathrm{N}$ terminal fragment of cerk1 fls2tmex1 ectodomain had a higher apparent molecular weight and gave only a very weak signal. All CERK1-FLS2 domain swap constructs retained chitin binding ability, as full length protein and ectodomain could be detected for all domain swap constructs after chitin pulldown (Figure 13B).

cerk1 fls2tm and cerk1 fls2tmex1 were also stably transformed into the CERK1 knockout mutant cerk1-2. Seven independent transgenic lines expressing cerk1 fls2tm were tested for ectodomain shedding in immunoblot experiments using the CERK1 specific antibody (Figure 13C). All controls (Col-0, Col-3 gl1, cerk1-4 and cerk1-2) showed the expected CERK1 band pattern. Confirming the results obtained by transient expression in $N$. benthamiana, full length cerk1 fls2tm protein ( $75 \mathrm{kDa})$ and ectodomain (33 $\mathrm{kDa}$ ) could be detected for all tested transgenic cerk1 fls2tm lines. These results indicate that CERK1 ectodomain shedding does not depend on the CERK1 transmembrane domain. Full length cerk $1 \mathrm{fls} 2 \mathrm{tm}$ as well as cerk1 fls2tm ectodomain could be detected after pulldown with chitin magnetic beads indicating that chitin binding ability of this CERK1 variant is not disturbed in Arabidopsis.

Eight transgenic cerk1 fls2tmex1 expressing lines were analyzed for CERK1 ectodomain shedding in immunoblot experiments (Figure 13D). As expected, full length CERK1 signal (75 kDa) could be detected for Col-0, Col-3 g/1 and cerk1-4, while an ectodomain fragment (33 kDa) could only be detected in Col-0 and Col-3 gl1 and was missing in cerk1-4. As already observed in heterologous expression experiments in $N$. benthiamana, full length cerk1 fls2tmex1 had a bigger apparent molecular weight than its wild type CERK1 counterpart. While cerk1 fls2tmex1 had shown a very weak $\mathrm{N}$-terminal fragment signal in $N$. benthamiana, the signal was quite strong in several cerk1 fls2tmex 1 expressing Arabidopsis plants. The putative fls2tmex1 ectodomain signal appeared as a double band at a size clearly larger than the wild type CERK1 soluble ectodomain (Figure 13D). cerk1 fls2tmex1 maintained chitin binding ability, as for all tested transgenic lines full length protein and $\mathrm{N}$ terminal fragments could be detected after pull-down with chitin magnetic beads. While the two putative ectodomain fragment bands were of similar intensity in blots performed with total extracts, the lower band was predominant after chitin pull-down. This suggests that the upper band might be cleaved in vitro.

One cerk1 fls2tm and one cerk1 fls2tmex1 expressing line were chosen to be tested for receptor phosphorylation after chitin treatment (Figure 13E). Both tested lines showed an electrophoretic mobility shift, which was comparable to Col-0, Col-3 gl1 and cerk1-4. This suggests that signaling initiated by ligand binding to the extracellular chitin binding domain 
can still be transmitted into the cell via the FLS2 extracellular stalk and the FLS2 transmembrane domain.

\subsubsection{CERK1 and FLS2 extracellular stalk harbor a KS motif}

Based on the results of the cleavage motif, deletion and domain swap mutants, it remained unclear which amino acids or structural characteristics are critical for CERK1 ectodomain shedding. In particular, the N-terminal fragments of the cerk1 fls2tmex1 and cerk1 fls2tmex3 protein variants were puzzling. The putative ectdodomain fragment of fls2tmex1 appeared as a double band and the ectodomain fragment of cerk1 fls2tmex3 was the same size as in wild type CERK1, although the full length protein was larger. A closer look at the amino acid sequences of the extracellular stalk of CERK1 and the generated domain swap constructs revealed the presence of a lysine followed by a serine (KS) within the extracellular stalk (Figure 14). This motif is also present in the tested protease cleavage motif and deletion mutants.

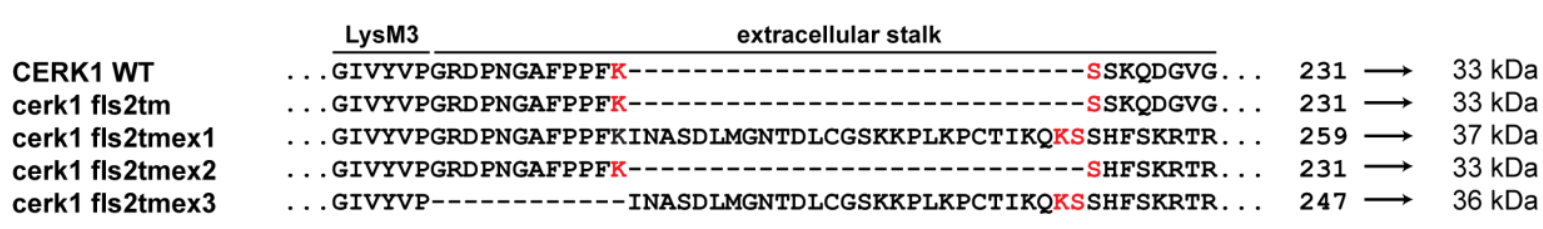

Figure 14. CERK1 and FLS2 extracellular stalk share a lysine-serine (KS) motif. Alignment of CERK1 extracellular stalk amino acid sequence with the generated CERK1 FLS2 domain swap constructs. The shared lysine-serine (KS) motif is indicated in red letters. Molecular masses were calculated based on the $\mathrm{N}$-terminal part of each CERK1 FLS2 domain swap construct up to the marked serine. $10 \mathrm{kDa}$ were added for 5 glycosylation sites present in the CERK1 ectodomain.

Figure 14 shows the calculated masses of the ectodomain for CERK1 wild type and the CERK1 FLS2 domain swap constructs if cleavage of the CERK1 ectodomain would occur at or near the KS motif. This would explain the size differences of the ectodomains between cerk1 fls2tmex 1 and wild type CERK1 after transient expression in Nicotiana benthamiana (Figure 13B). The double band of cerk1 fls2tmex 1 ectodomain fragment and the wild typelike size of the cerk 1 fls2tmex 3 ectodomain signal could then be explained by an additional genuine cleavage site within the FLS2 extracellular stalk. 
A $\begin{array}{llll}\text { CERK1 WT } & \ldots \frac{\text { extracellular stalk }}{\text { GRDPNGAFPPFKSSKQDGVGAGVIAGIVIGVIVALLLILFIVYYAY } \ldots} & 257 \\ \text { cerk1 -ks } & \ldots \text { GRDPNGAFPPF--SKQDGVGAGVIAGIVIGVIVALLLILFIVYYAY . . } & 255 \\ \text { cerk1 ks->aa } & \ldots \text { GRDPNGAFPPFAASKQDGVGAGVIAGIVIGVIVALLLILFIVYYAY . . } & 257\end{array}$

B

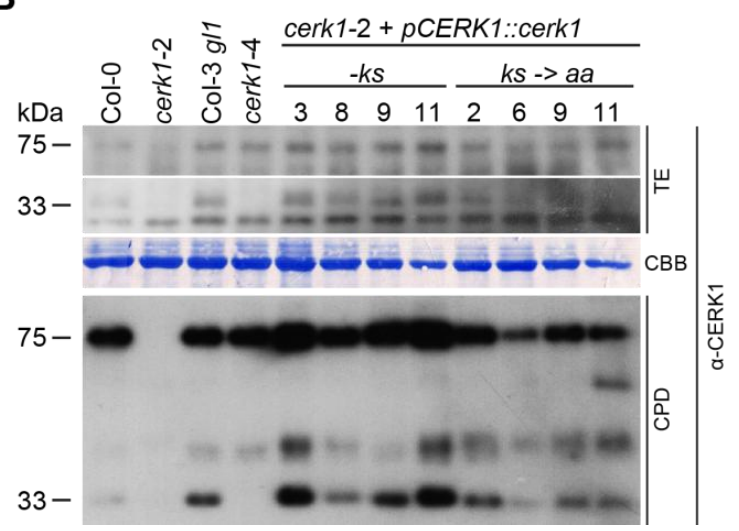

C

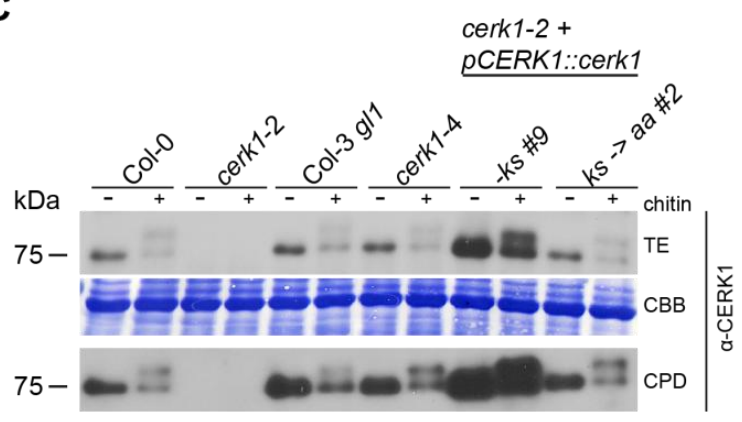

Figure 15. The KS motif within the FLS2 and CERK1 extracellular stalk is most likely not a cleavage motif. A) Alignment of KS motif mutants to the wild type CERK1 sequence. Deleted amino acids are indicated with dashes, while replaced amino acids are shown in red letters. B) CERK1 immunoblots of three individual transgenic plants lines either expressing cerk1-ks or cerk1 ks->aa under control of the native CERK1 promoter in cerk1-2. Col-0, cerk1-2, Col-3 gl1 and cerk1-4 were used as controls. Upper panel, total extracts (TE); lower panel, chitin pull-downs (CPD) prepared from the total extracts shown in upper panel. CBB, Coomassie Brilliant Blue stained membrane (loading control). C) Band shift assay using one transgenic line per KS motif mutant construct. Leaves were vacuum infiltrated with $100 \mathrm{\mu g} \mathrm{ml}^{-1}$ shrimp shell chitin and incubated for 12 minutes. Immunoblot using the specific CERK1 antibody is shown. Upper panel, total extracts of mock-infiltrated (-) or chitin-infiltrated $(+)$ samples. Lower panel, chitin pull-downs of total extracts shown in upper panel. Ectodomain shedding immunoblot was repeated 3 times with similar results and band shift assay was repeated twice with similar results.

To explore the hypothesis explained above, additional CERK1 variants were generated by either deleting the KS (cerk1 -ks) motif or replacing it by two alanines (cerk1 ks->aa) (Figure $15 \mathrm{~A})$. These variants were cloned into the vector pGreenll-0229PREP including the endogenous CERK1 promoter and the resulting constructs were used to generate transgenic lines in the CERK1 knockout mutant cerk1-2. Ectodomain shedding of four independent transgenic lines per construct was tested by immunoblotting with the specific CERK1 antibody (Figure 15B). Col-0, Col-3 gl1 and cerk1-4 showed a full length CERK1 signal (75 $\mathrm{kDa}$ ). An ectodomain fragment could be detected for Col-0 and Col-3 g/1, but was missing in cerk1-4 plants. No CERK1 signal was detected for cerk1-2. For each of the tested transgenic lines, a signal at $75 \mathrm{kDa}$ corresponding to full length protein and a signal at $33 \mathrm{kDa}$ corresponding to the soluble ectodomain could be observed (Figure 15B). The abundance of full length protein and ectodomain fragment seemed to be enhanced in plants expressing cerk1 -ks. Full length protein as well as ectodomain fragments could be detected for all transgenic lines after chitin pulldown, indicating chitin binding ability of both, cerk 1 -ks and cerk1 ks->aa. 
One transgenic line per construct was tested for chitin induced autophosphorylation of CERK1 (Figure 15C). Both lines showed a characteristic band shift after chitin treatment comparable to Col-0 and Col-3 g/1, indicating functionality of both CERK1 variants.

\subsubsection{The extracellular domains of many receptor-like kinases can be found in supernatants of cell cultures}

The extensive mutational studies described above failed to generate a shedding deficient CERK1-variant and also could not pinpoint the CERK1 cleavage motif. This raised the idea that ectodomain shedding may not require any specific motifs and might be a common phenomenon in plant receptor-like kinases (RLKs). To investigate this theory, supernatants of Arabidopsis Col-0 cell cultures were collected and analyzed by mass spectrometry. These supernatants were expected to be enriched in apoplastic proteins and might contain shed extracellular domains of receptor-like kinases and possibly also receptor-like proteins. Thus, this approach could reveal additional RLKs which are subject to ectodomain shedding. The collected cell culture supernatant was filtered and concentrated by protein precipitation. Subsequent mass spectrometric analyses identified 588 proteins. The subcellular localization of these proteins was then predicted by SUBA3 (Tanz et al., 2013) and results are summarized in Table 9. Proteins predicted to be localized to the extracellular space represented more than one third of all proteins found and half of all peptides in the sample and were thus the biggest fraction of all identified proteins. Cytosolic proteins accounted for $23.8 \%$ of all proteins and $19.5 \%$ of all peptides.

Table 9. Predicted localization of proteins from cell culture supernatants. SUBA3 localization prediction of proteins found in supernatants of Arabidopsis cell cultures.

\begin{tabular}{ccccc}
\hline Predicted localization & Proteins & $\%$ & Peptides & $\%$ \\
\hline Extracellular & 201 & 34.2 & 3678 & 50 \\
Cytosol & 140 & 23.8 & 1432 & 19.5 \\
Plasma membrane & 79 & 13.4 & 772 & 10.5 \\
Plastid & 60 & 10.2 & 497 & 6.8 \\
Mitochondrion & 42 & 7.1 & 334 & 4.5 \\
Vacuole & 29 & 4.9 & 472 & 6.4 \\
Peroxisome & 11 & 1.9 & 48 & 0.7 \\
ER & 10 & 1.8 & 64 & 0.9 \\
Nucleus & 16 & 2.7 & 58 & 0.7 \\
Total & 588 & 100 & 7355 & 100
\end{tabular}


The majority of detected cytosolic, plastid and mitochondrial proteins are highly abundant proteins involved in primary metabolism (Supplemental file 2) and are therefore likely contaminants. Furthermore, $13.4 \%$ of all identified proteins (corresponding to $10.5 \%$ of all peptides) were predicted to be localized to the plasma membrane. Apoplastic and plasma membrane (PM)-localized proteins were probably underestimated in this study, because they are typically glycosylated and glycosylated peptides cannot be identified by the method used.

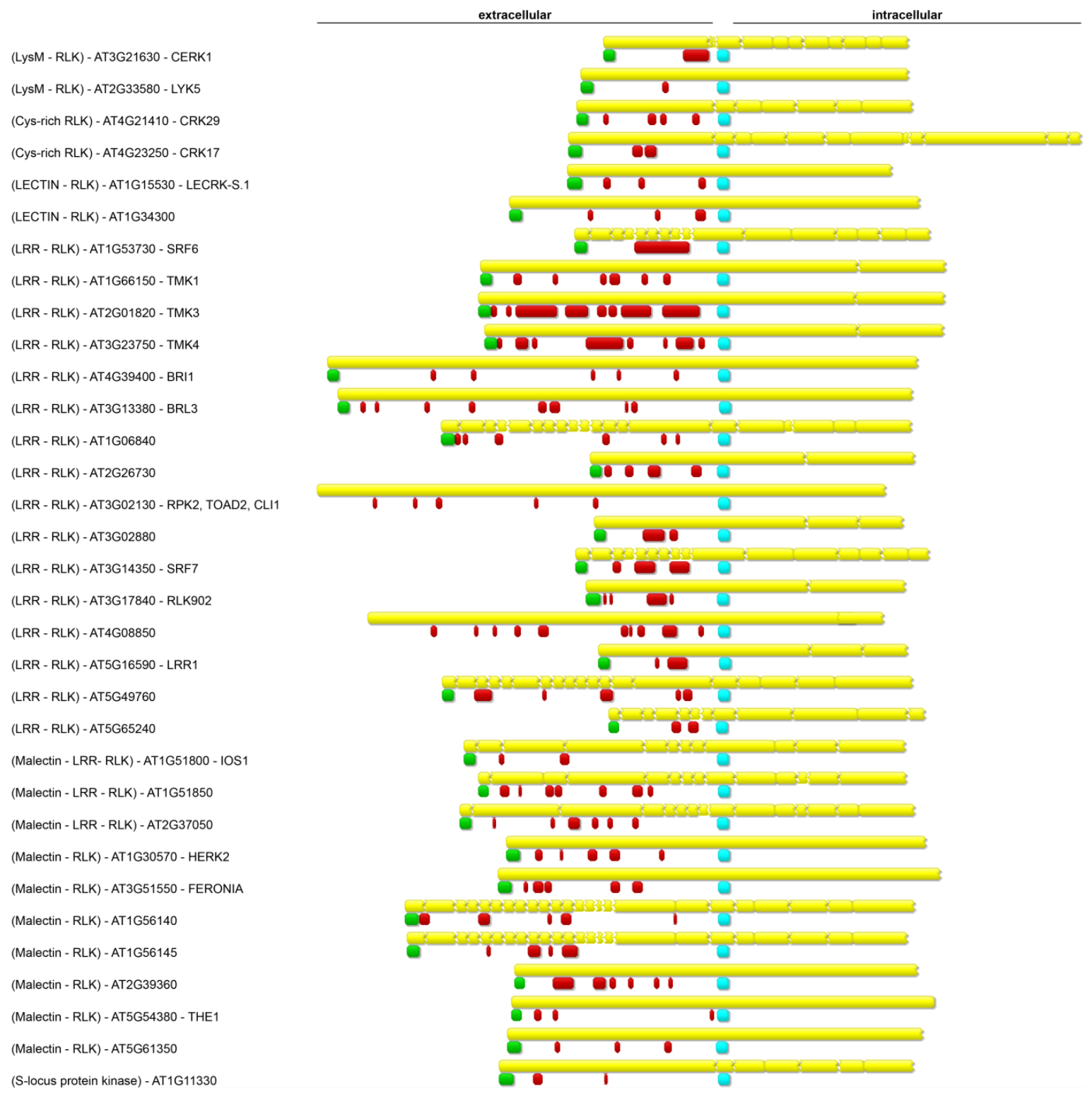

Figure 16. Receptor-like kinases found in Col-0 cell culture supernatants. The coding sequence of the proteins is shown as a yellow bar and breaks indicate the positions of introns. Identified peptides were mapped to the amino acid sequence of the respective RLK and peptide coverage is shown in red. The transmembrane domains are shown in light blue and predicted signal peptides are given in green. For easier comparison, the RLKs were aligned by their transmembrane domains. 
Among the 588 identified proteins, 33 were found to be receptor-like kinases and 4 receptorlike proteins. Thus RLKs and RLPs account for $46.8 \%$ of all identified PM proteins. Most of the identified receptor-like kinases were LRR-RLKs, but cysteine-rich RLKs, Lectin-RLKs, CrRLKs and the LysM-RLKs CERK1 and LYK5 were also found. Peptides corresponding to the identified receptor-like kinases were then aligned to their full length amino acid sequences (Figure 16). Interestingly, only peptides corresponding to extracellular parts of the receptor-like kinases could be found in supernatants of cell cultures. Despite the presence of cytosolic and plasma membrane localized proteins in the sample, peptides corresponding to intracellular parts of receptor-like kinases were not detected. Therefore, the peptides corresponding to extracellular domains of receptor-like kinases might derive from ectodomains released by shedding or a similar mechanism. Peptides corresponding to all 3 members of the TRANSMEMBRANE KINASE (TMK) group of LRR-RLKs (comprising a total of 4 members) which are expressed in leaves (Winter et al., 2007) were found. The ectodomain of TMKs consists of LRR-motifs which are separated by a non-LRR domain (Liu et al., 2013b). To test whether the non-LRR domain is the cleavage site for release of the $\mathrm{N}$ terminal fragment, the mapping positions of peptides found in the supernatant of cell cultures were compared to the domain organization of the TMK proteins (Figure 17A). Peptides Nand C-terminal of the non-LRR domain could be found indicating that the non-LRR domain is not the site where the soluble extracellular derivative of the TMK proteins is generated. AT1G51800 (IOS1), AT1G51850 and AT2G37050 are Malectin-LRR-RLKs and resemble members of the symbiosis receptor-like kinase family (Hok et al., 2011). They contain a malectin-like domain and short LRR motif stretches. The $L$. japonicus symbiosis receptor-like kinase
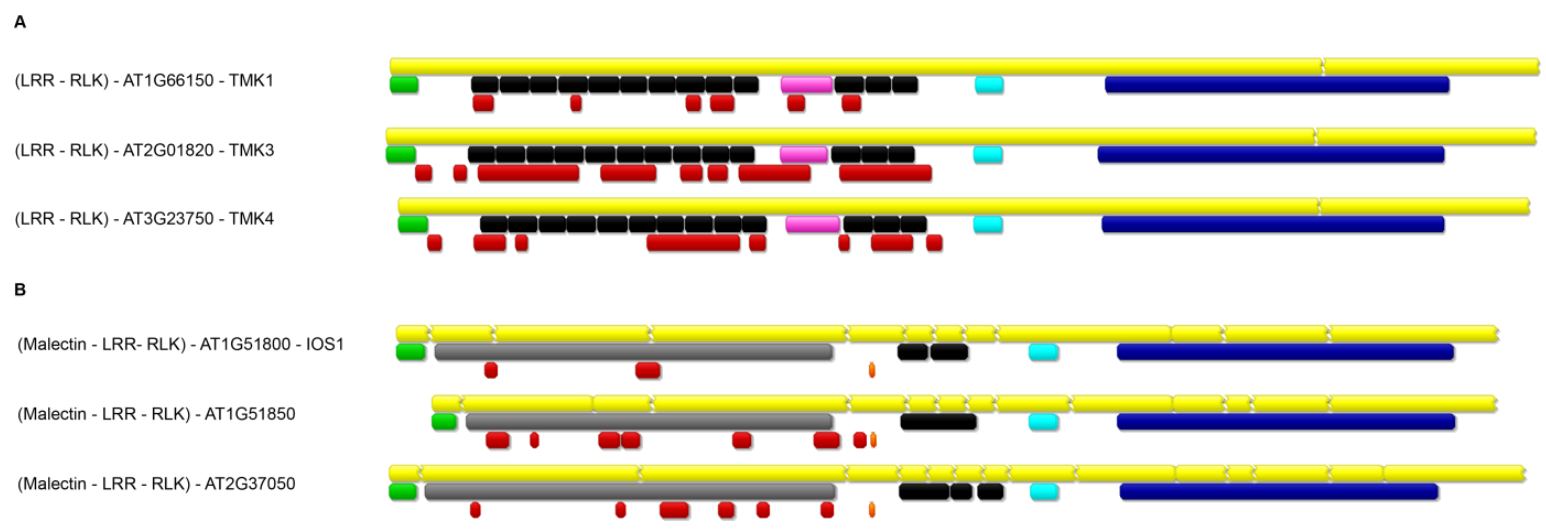

Figure 17. Detailed analysis of TMK1-3 and Malectin-LRR-RLKs. Domain organization of TMK1, TMK3 and TMK4. B) Domain organization of Malectin - LRR - RLKs. The coding sequence of the proteins is given as yellow bar with breaks indicating introns. As in Figure 16 peptides are aligned to the amino acid sequence and peptide coverage is shown in red. Green: Signal peptide; Black: LRR-repeats; Pink: non-LRR domain; light blue: transmembrane domain; blue: kinase domain; gray: malectin-like domain; orange: GDPC motif. 
SYMRK was reported to be proteolitcally processed to release its malectin-like domain (Antolín-Llovera et al., 2014). A GDPC motif connecting the malectin-like domain and LRRs was found to be critical for this process. The three Malectin-LRR-RLKs found in this study also harbored a GDPC motif and only peptides N-terminal of this motif were found (Figure 17B). This points to a SYMRK-like release of the malectin-like domain in Arabidopsis. In addition to receptor-like kinases, peptides corresponding to four receptor-like proteins were found (Figure 18). These are either anchored to the outer leaflet of the plasma membrane via GPI anchor (LYM1-3) or via a transmembrane domain (RLP51). GPI anchors are known to be cleaved by lipases, such as phospholipase D (Paulick \& Bertozzi, 2008), while the release of the RLP51 N-terminal domain probably occurs via ectodomain shedding or a related process. This experiment was performed with two different Arabidopsis cell culture lines (Ath-1, Ath-2) after one week or two weeks of subculturing (4 samples in total). The sample shown here (Sample02) yielded the highest number of RLKs and RLPs and the best peptide coverages, but overall the other three samples gave similar results (Table S1, Table S2, Table S3, Table S4, Table S5, Figure S1, Figure S2, Figure S3).
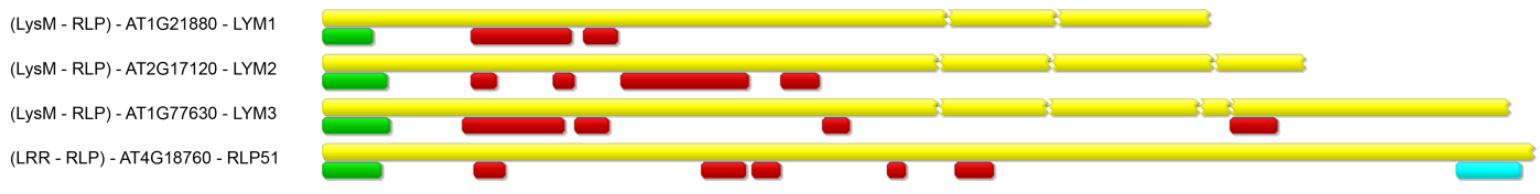

Figure 18. Receptor like proteins found in Col-0 cell culture supernatant.The exon structure of receptor-like proteins found in supernatants of Col-0 cell culture is shown in yellow. Identified peptides were aligned to the amino acid sequence and peptide coverage is shown in red. Predicted signal peptides are given in green and transmembrane domains are shown in light blue.

To validate the quality of the supernatant samples, total protein extracts from the cultured cells were prepared (Figure 19) and compared by immunoblotting to the supernatant samples analyzed by mass spectrometry. The proteomic analysis suggested ectodomain shedding of CERK1 and BRI1. For both receptor kinases, N-terminal antibodies are available that can detect ectodomain fragments. An immunoblot with a C-terminal antibody against FLS2 was included as a control. The full length receptor proteins could be detected for CERK1 (75 kDa), BRI1 (140 kDa) and FLS2 (175 kDa) in total extracts (lane A+B), but not in supernatants. Ectodomain fragments could be detected for CERK1 (33 kDa) and BRI1 (95 $\mathrm{kDa}$ ) in total extracts and were enriched in most of the supernatants (lane $\mathrm{C}$ ). As a Cterminal FLS2 antibody was used, no fragments corresponding to extracellular domains were detectable. 


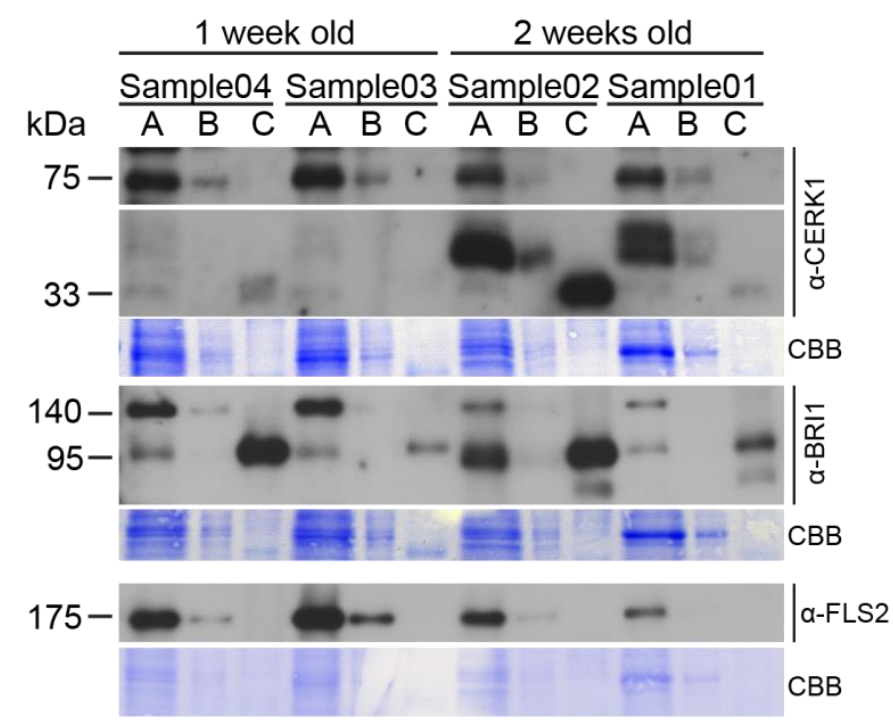

Figure 19. Only soluble ectodomain can be found in cell culture supernatants. Protein samples were prepared from one or two week old subcultured Arabidopsis cell culture lines. Total extracts of each cell culture sample were prepared and either $15 \mu \mathrm{g}(\mathrm{A})$ or $3 \mu \mathrm{g}$ (B) protein were loaded. Supernatants were collected and $3 \mu \mathrm{g}$ of precipitated proteins was used (C). Anti-CERK1, anti-BRI1 and anti-FLS2 immunoblots are shown. CBB, Coomassie Brilliant Blue membranes (loading control).

The absence of full length proteins from supernatants indicated good quality of the samples. To confirm the data of cell culture supernatants, apoplastic wash fluids (AWF) of Arabidopsis thaliana Col-3 gl1 leaves were prepared. Col-3 gl1 was chosen as a starting material to avoid contamination caused by broken trichomes. The AWF was subjected to analysis by mass spectrometry and 1005 proteins were identified (Table 10). AWFs are more difficult to harvest than cell culture supernatants. Even though great care was taken not to injure the leaves during the process, the quality of the AWF sample was lower than the cell culture supernatant preparation. In contrast to cell culture supernatants, the proportion of extracellular proteins was much lower. Only $15.9 \%$ of the identified proteins (corresponding to $20.5 \%$ of all peptides) were predicted to be localized to the apoplast (Table 10).

Table 10. Predicted localization of proteins from apoplastic wash fluids. SUBA3 localization prediction of proteins found in apoplastic wash fluids of Arabidopsis thaliana Col-0 leaves.

\begin{tabular}{ccccc}
\hline Predicted localization & Proteins & $\%$ & Peptides & $\%$ \\
\hline Extracellular & 160 & 15.9 & 2519 & 20.5 \\
Cytosol & 338 & 33.6 & 3200 & 26 \\
Plasma membrane & 51 & 5.1 & 442 & 3.6 \\
Plastid & 275 & 27.4 & 4085 & 33.1 \\
Mitochondrion & 76 & 7.6 & 946 & 7.7 \\
Vacuole & 23 & 2.3 & 384 & 3.1 \\
Peroxisome & 51 & 5.1 & 553 & 4.5 \\
ER & 13 & 1.3 & 112 & 0.9 \\
Nucleus & 18 & 1.7 & 72 & 0.6 \\
Total & 1005 & 100 & 12313 & 100
\end{tabular}



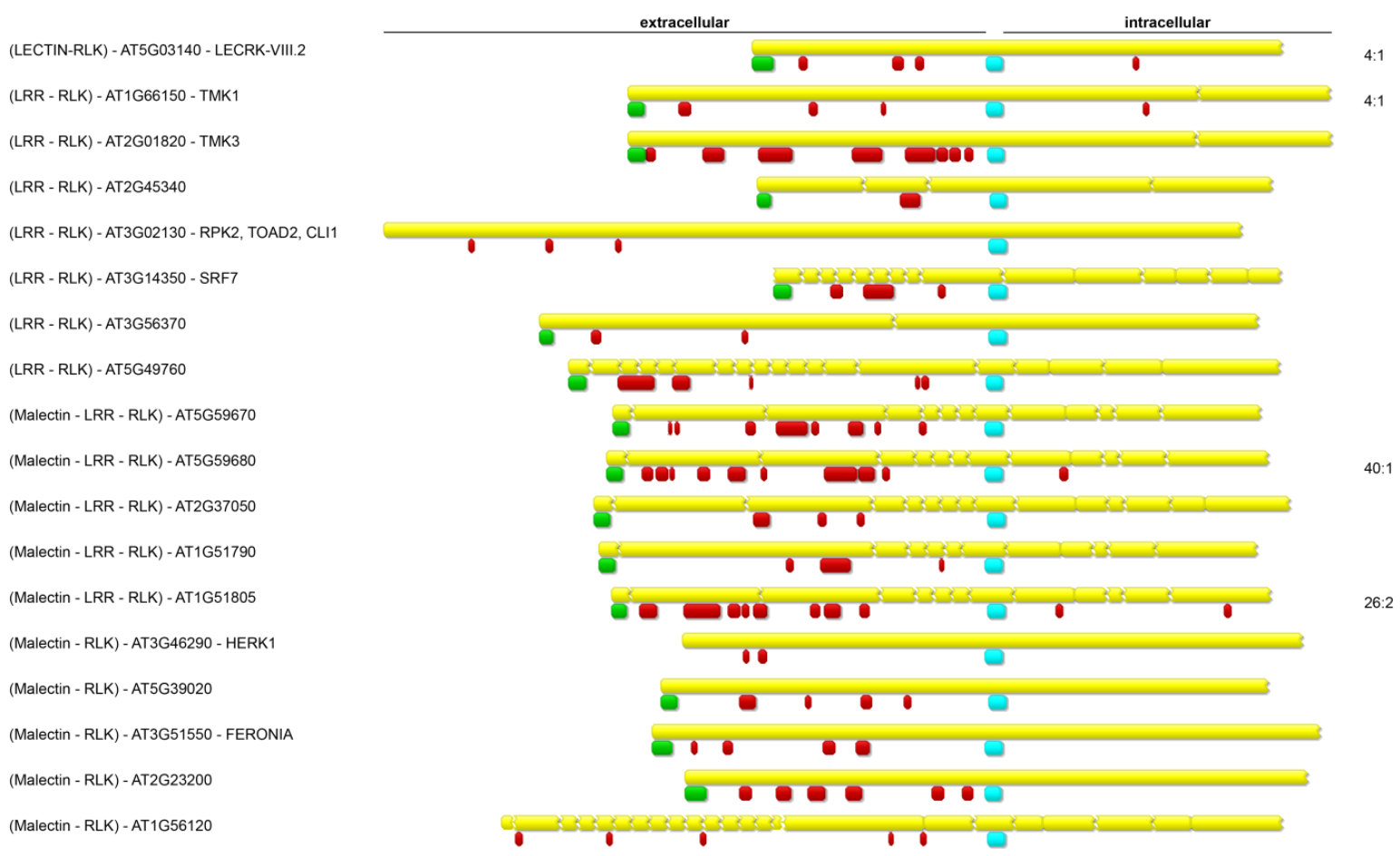

Figure 20. Receptor-like kinases found in apoplastic wash fluids of Col-3 gl1 leaves. The exon structure of receptor-like kinases which were found in apoplastic wash fluids is shown in yellow. Peptides were aligned to amino acid sequence and peptide coverage is shown in red. Proteins were arranged by the transmembrane domain for easier comparison. Transmembrane domain is shown in light blue. Predicted signal peptides are given in green. Numbers indicate ratio of extracellular to intracellular peptides.

Cytosolic proteins and corresponding peptides accounted for over one third of the total proteins and over one fourth of the peptides found. Plasma membrane localized proteins accounted for $5.1 \%$ of the identified proteins and $3.6 \%$ of the identified peptides. In contrast to cell cultures, leaves are fully autotrophic which is in agreement with a higher number of plastid proteins $(27.4 \%)$ in the AWFs. Despite the higher number of proteins detected in Arabidopsis apoplastic wash fluids, in comparison to cell culture supernatant, fewer RLKs were identified. 18 RLKs were found that belonged to the classes of LRR-RLKs, MalectinLRR-RLKs, Malectin-RLKs and LECTIN-RLKs. 9 out of these had also been detected in the cell culture supernatant. The matching peptides were aligned to the RLK amino acid sequences (Figure 20). Similar to cell culture supernatants, the vast majority of peptides mapped to the extracellular domains of the RLKs.

However, a few peptides aligned to intracellular kinase domains: 1 out of 4 peptides (25\%) for AT5G03140, 2 of 26 peptides of AT1G51805 (7.7\%), 1 out of 4 peptides for AT1G66150 (25\%) and 1 of 40 peptides of AT5G59680 (2.5\%). A higher number (5) of Malectin-LRRRLKs were found in AWFs than in cell culture supernatant. Most of them also harbored a GPDC motif connecting the malectin with the LRR domain. Almost all peptides matching these Malectin-LRR-RLKs mapped to the area N-terminal to the GPDC motif. However, in 
one case, one peptide each was found that mapped to an area C-terminal of the GDPC motif. Peptides corresponding to intracellular domains and LRR-domains in Malectin-LRRRLKs are most likely an artefact caused by the high levels of intracellular contamination. However, additional experiments will be necessary to confirm this. In addition to RLKs, LYM2 (AT2G17120) was the only RLP which could be found in Arabidopsis apoplastic wash fluids (Figure 21).

(LysM - RLP) - AT2G17120 - LYM2

Figure 21. Receptor-like proteins found in Col-3 gl1 apoplastic wash fluids. The exon structure of receptorlike proteins found in apoplastic wash fluids is shown in yellow. Peptides were aligned to the amino acid sequence and peptide coverage is shown in red. Predicted signal peptides are given in green.

\subsubsection{CERK1 ectodomain shedding is not altered in sphingolipid mutants}

Lipid rafts are microdomains within plasma membranes, where sterols and sphingolipids are enriched (Cacas et al., 2012). Receptor-like kinases were reported to localise to these lipid rafts in Medicago truncatula (Lefebvre et al., 2007) and Nicotiana tabacum (Morel et al., 2006) and it seems conceivable that CERK1 may also localize to lipid rafts. Localization to lipid rafts can be critical for ectodomain shedding in animals (Wakatsuki et al., 2004); (Zimina et al., 2005). CERK1 ectodomain shedding might also occur in lipid rafts and changes of lipid raft composition might lead to alterations in CERK1 ectodomain shedding. Double mutants of sphingolipid fatty acid hydroxylases (fah1 fah2) and single mutants of three Arabidopsis ceramide synthases (loh1, loh2, loh3) show alterations in sphingolipid composition (König et al., 2012; Ternes et al., 2011).

Interestingly, later in development fah1 fah2 and loh1 mutants exhibit a growth phenotype which resembles cerk1-4. Therefore, double mutants defective in sphingolipid fatty acid hydroxylation (fah1 fah2) (König et al., 2012) or triple mutants where fah1 fah2 was combined with mutants of each of the Arabidopsis ceramide synthases (Ternes et al., 2011) were tested for CERK1 ectodomain shedding. The respective mutant lines were provided by Prof. Ivo Feussner (Georg-August University of Göttingen). At ten weeks of age, double mutant plants (fah1 fah2) as well as each of the triple mutant plants (fah1 fah2 loh1/2/3) exhibited a growth phenotype characterized by smaller crinkly leaves and the development of cell death (Figure 22A). This phenotype looked similar, but not identical to cerk1-4 plants of the same age. 
A

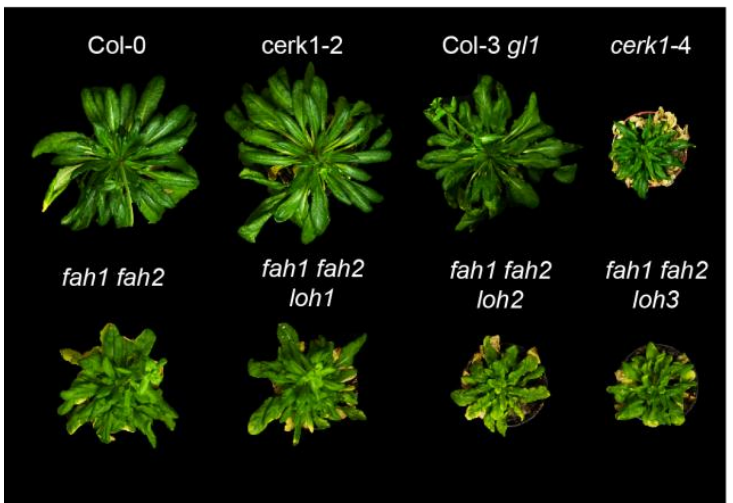

B

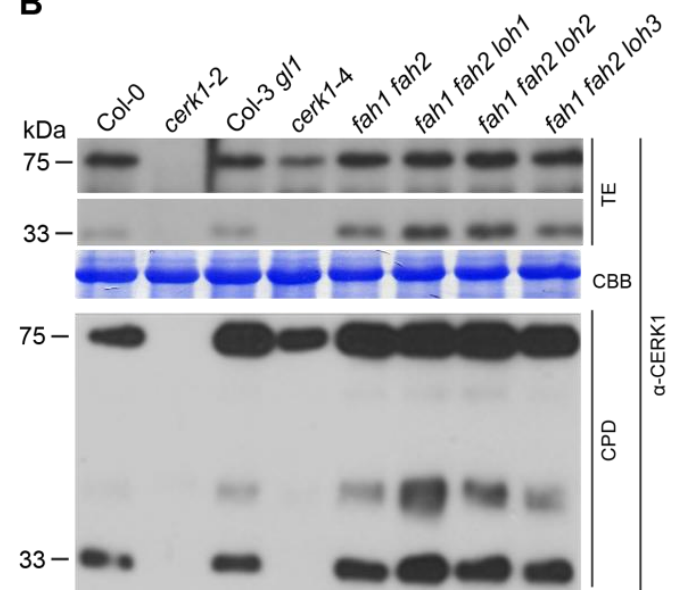

Figure 22. Sphingolipid mutants show enhanced CERK1 ectodomain shedding. A) Plants of the indicated genotypes were grown under short day conditions and pictures were taken after 10 weeks of growth. B) CERK1 immunoblots of the plant lines shown in A). Leaves of three plants per genotype were pooled and to prepare total protein extracts (TE, upper panel). Total extracts were used to prepare chitin pull-downs (CPD, lower panel). CBB, Coomassie Brilliant Blue stained membranes (loading control).

Immunoblot analysis of ten-week-old plants was performed (Figure 22B). Full length CERK1 protein $(75 \mathrm{kDa})$ could be detected in all tested lines, except cerk1-2. Furthermore, a CERK1 ectodomain fragment (33 kDa) was observed for all tested plant lines, except cerk1-2 and cerk1-4. The abundance of ectodomain fragments seemed to be slightly enhanced in all of the tested sphingolipid mutant lines. CERK1 ectodomain shedding is enhanced by high levels of salicylic acid (Petutschnig et al., 2014); unpublished data). Since fah1 fah2 mutants contain higher levels of salicylic acid (König et al., 2012), this could be the cause of the enhanced CERK1 ectodomain fragment abundance in these lines.

\subsection{Extra-Large G-protein 2 (XLG2) plays a key role in cerk1-4 cell death execution}

To identify components which are involved in cerk1-4 cell death execution, a forward genetic screen was initiated (Marnie Stolze, unpublished). cerk1-4 seeds were mutagenized with EMS and screened in the F2 generation for plants that had lost the cerk1-4 phenotype. The first cerk1-4 suppressor mutant isolated from the screen was named nole1-1 (no lesions 1-1). nole1-1 suppressed cerk1-4-mediated cell death formation upon Bgh inoculation and during senescence. It also restored susceptibility to Golovinomyces orontii and reduced pathogen induced elevation of SA levels to wild type levels. The underlying mutation was mapped to the lower arm of chromosome 4 by a new next generation sequencing approach (Hartwig et al., 2012). Analysis of single nucleotide polymorphisms (SNPs) in this region revealed the 
introduction of a stop codon into the gene encoding Extra-Large G-protein 2 (XLG2, AT4G34390). Complementation analysis using the genomic sequence of XLG2 expressed under the native XLG2 promoter in nole1-1 plants confirmed that suppression of the cerk1-4 phenotype is caused by the premature stop codon within $X L G 2$.

\subsubsection{Characterization of cerk1-4 suppressor mutants}

In addition to nole1-1, the cerk1-4 EMS mutagenesis screen yielded several other potential cerk1-4 suppressing mutants (Marnie Stolze, not published), which were named noce2/4 to noce4/6 (no cerk1-4). The first digit of the mutant designation indicates the batch number and the second refers to the plant number. These suppressor mutant candidates were analyzed in more detail and re-evaluated for full suppression of the cerk1-4 phenotype. For each of these mutant lines, M3 plants were inoculated with $B g h$ and their phenotype was assessed seven days after infection (Figure 23A).

All mutants except noce2/7 suppressed macroscopically visible lesions after Bgh infection. The rosettes of noce2/4 and noce3/4 plants appeared smaller compared to wild type plants. Next, the noce mutants were analyzed on the molecular level. Since knock-out of CERK1 would suppress the cerk1-4 phenotype, CERK1 immunoblots were performed.

The controls showed the expected CERK1 band patterns with full length CERK1 and ectodomain fragment in Col-0 and Col-3 g/1, only full length protein in cerk1-4 and no CERK1-specific signal (or just very weak $40 \mathrm{kDa}$ and $33 \mathrm{kDa}$ bands) in cerk1-2 and in all tested mutant lines. All noce mutants showed a CERK1 band pattern that matched cerk 1-4 (Figure 23B). This was expected, since all mutants were derived from EMS-mutagenized cerk1-4 seeds. In all noce mutants, the cerk1-4 protein could be pulled down by chitin magnetic beads, which demonstrates normal chitin binding activity.

Since development of the cerk1-4 phenotype is associated with elevated levels of SA levels upon Bgh inoculation (Petutschnig et al., 2014), infected noce mutants were tested for expression of the SA-responsive gene PR1 in RT-PCR experiments (Figure 23C). PR1 is strongly induced after Bgh inoculation in wild type plants, but the induction is even stronger in cerk1-4 (Petutschnig et al., 2014). In mutants affected in SA synthesis or signalling, PR1 is not induced upon pathogen inoculation (Nawrath \& Métraux, 1999; Zhou et al., 1998). As expected, cerk1-4 plants showed an exaggerated increase of PR1 expression after Bgh infection, while no clear induction was seen in sid2 or pad4 plants. The noce2/7 and noce3/4 mutations could not suppress the increased PR1 induction of 
A
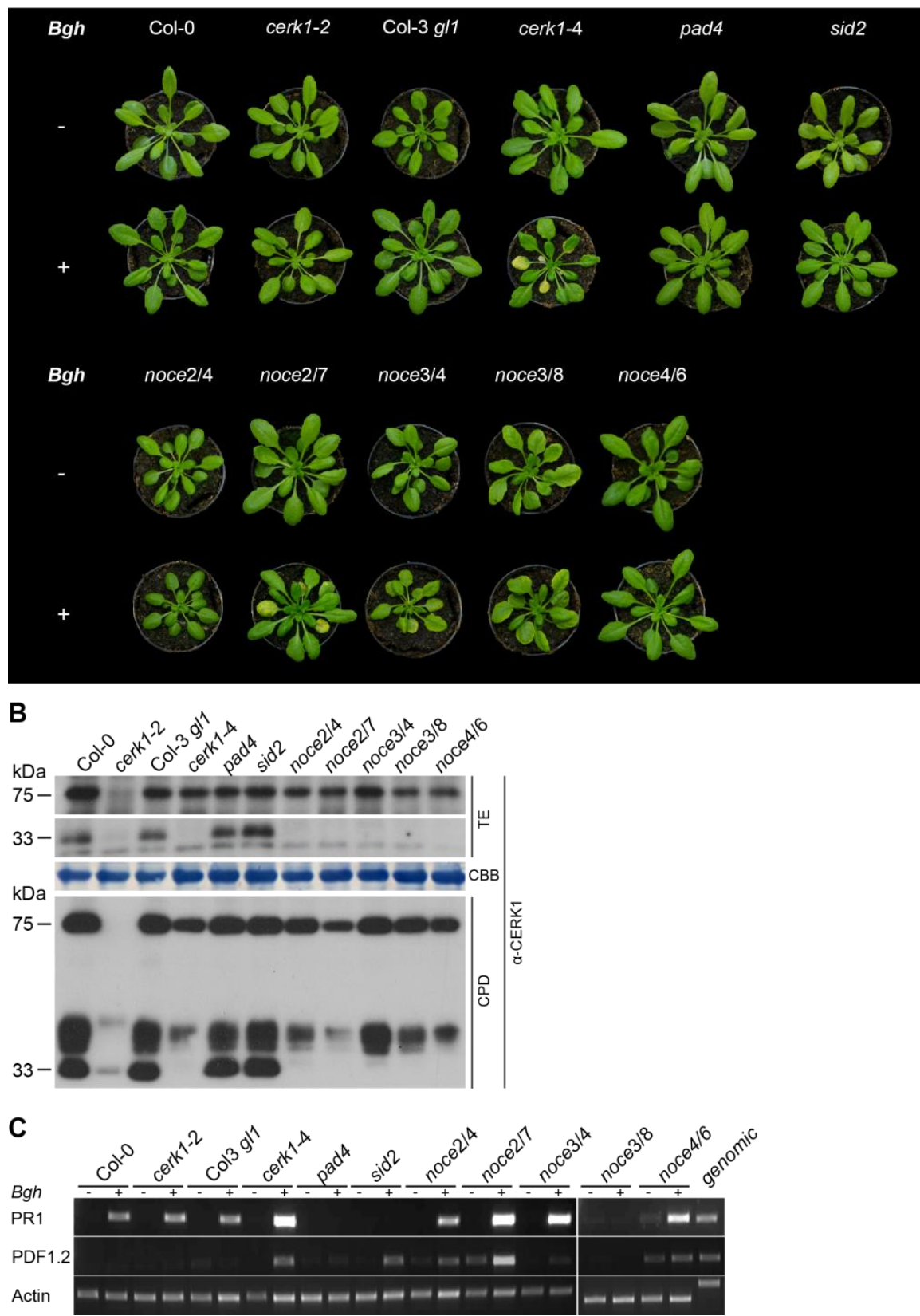

Figure 23. Different noce mutants fully suppress the cerk1-4 phenotype. A) Re-mutagenized cerk1-4 plants derived from an EMS based mutagenesis screen (Marnie Stolze, unpublished) were inoculated with Bgh and the phenotype was assessed seven days after infection. Col-0, cerk1-2, Col-3 gl1, cerk1-4, pad4 and sid2 were used as controls. B) Total protein extracts (TE) were prepared from 6-week-old plants and chitin pull-downs (CPD) were performed using these total extracts. Immunoblot analysis was performed using the specific CERK1 antibody. CBB, Coommasie Brilliant Blue stained membranes (protein loading control) C) PR1 and PDF1.2 expression was analyzed by semi-quantitive RT-PCR. Actin was used as control. Samples were prepared from three whole rosettes per genotype that were either either not inoculated (-) or inoculated with Bgh (+).

cerk1-4, whereas PR1 induction was wild type-like in noce2/4 and noce4/6. PR1 expression in noce3/8 was comparable to the SA signalling mutant pad4 (Glazebrook et al., 1996) and the salicylic acid synthesis mutant sid2 (Wildermuth et al., 2001), pointing to mutations within the SA synthesis or signalling pathways. Suppressor candidates were also assessed for 
expression levels of the ethylene and JA responsive marker gene PDF1.2 (Figure 23C) (Manners et al., 1998). Elevated levels of PDF1.2 expression could be observed for cerk1-4, sid2, noce3/4 and noce3/8. For wild type plants, as well as pad4, noce2/4 and noce4/6 no induction of PDF1.2 expression was measurable.

Mutations in several genes are already known to suppress the cerk1-4 phenotype (Petutschnig et al., 2014). These are SID2, which encodes isochorismate synthase 1 (ICS1) (Wildermuth et al., 2001) a key enzyme in SA biosynthesis, PAD4 and EDS1 two genes encoding lipase-like proteins (Falk et al., 1999; Jirage et al., 1999) involved in SA signaling and the Extra-Large G-Protein XLG2, previously identified in this screen. To investigate if the noce mutants had mutations in any of these proteins, the respective genes were sequenced (Table 11). noce2/4 was wild type for all sequenced genes. As noce2/7 did not suppress the cerk1-4 cell death phenotype, no genes were sequenced. noce4/6 turned out to harbor a mutation within $X L G 2$, where a guanine was substituted by an adenine. This mutation causes a glutamic acid to lysine substitution at position 293 (E293K). As for all other noce mutants, $X L G 2$ turned out to be wild type, the following analyses were carried out with noce4/6.

Table 11. Summary of characteristics of noce mutants including results from sequencing of candidate suppressor genes. nd, not determined.

\begin{tabular}{|l|c|c|c|c|c|}
\hline & noce2/4 & noce2/7 & noce3/4 & noce3/8 & noce4/6 \\
\hline Characteristics & & & & & yes \\
\hline $\begin{array}{l}\text { Suppression of cerk1-4 cell } \\
\text { death }\end{array}$ & yes & no & yes & yes \\
\hline CERK1 pattern like & cerk1-4 & cerk1-4 & cerk1-4 & cerk1-4 & cerk1-4 \\
\hline PR1 induction like & wild type & cerk1-4 & cerk1-4 & sid2/pad4 & wild type \\
\hline $\begin{array}{l}\text { Sequence of candidate } \\
\text { suppressor genes }\end{array}$ & & & & & \\
\hline CERK1 & cerk1-4 & cerk1-4 & cerk1-4 & cerk1-4 & cerk1-4 \\
\hline SID2 & wt & nd & nd & nd & nd \\
\hline PAD4 & wt & nd & nd & nd & nd \\
\hline EDS1 & wt & nd & wt & wt & G->A, \\
\hline XLG2 & & & & nd $293 K)$ \\
\hline
\end{tabular}




\subsubsection{A single amino acid exchange in XLG2 (E293K) suppresses the cerk1-4 phenotype}

To confirm that the amino acid substitution in XLG2 (E293K) is responsible for suppression of the cerk1-4 phenotype, noce4/6 plants were backcrossed to their progenitor cerk 1-4, to induce segregation of the causal mutation (Hartwig et al., 2012). Backcrossed plants of the F2 generation were inoculated with $\mathrm{Bgh}$ and assessed regarding their cell death phenotype. Approximately $1 / 4$ of the plants looked like wild type, indicating that the underlying mutation is recessive. Therefore, cerk1-4 suppressing plants should be homozygous for the causal mutation.
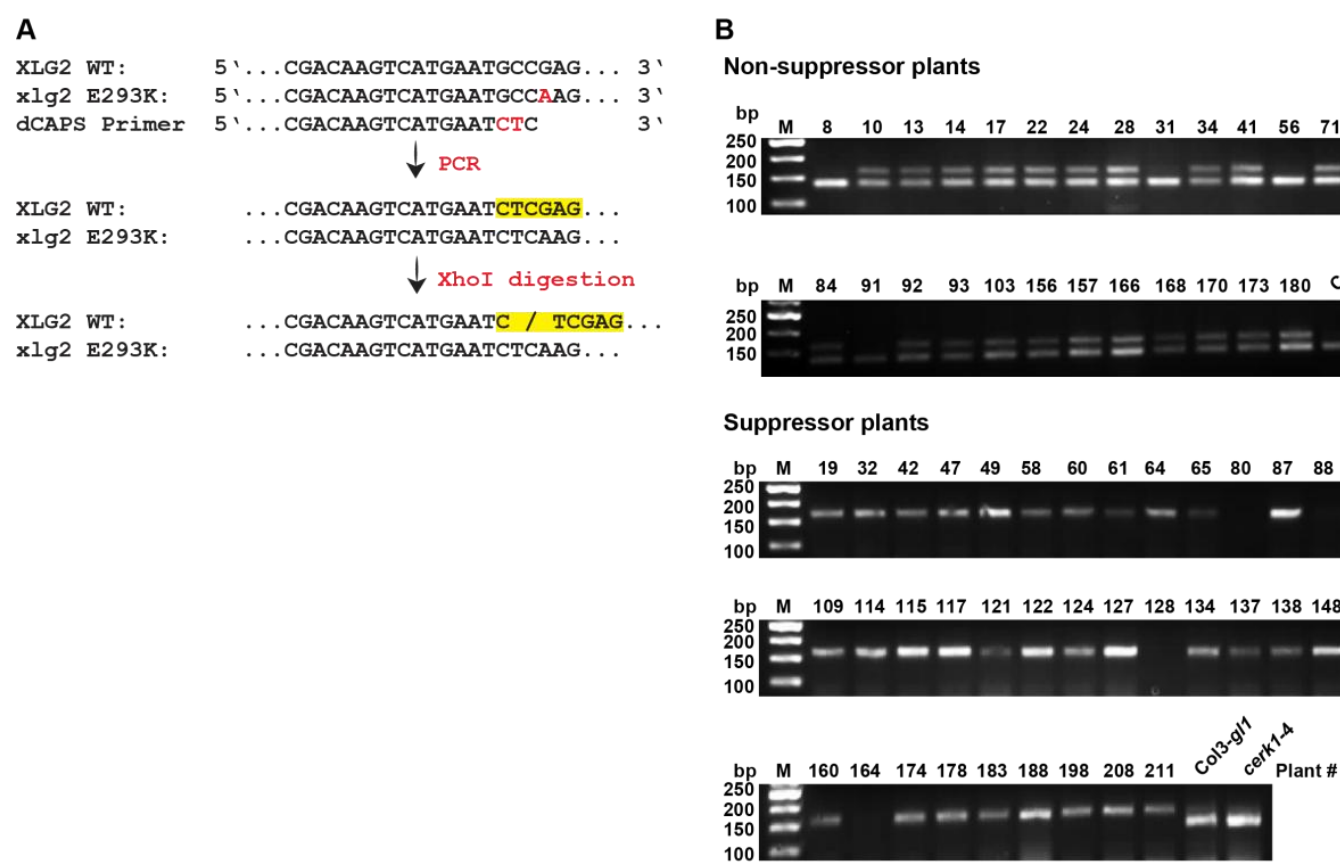

C non-suppressor suppressor

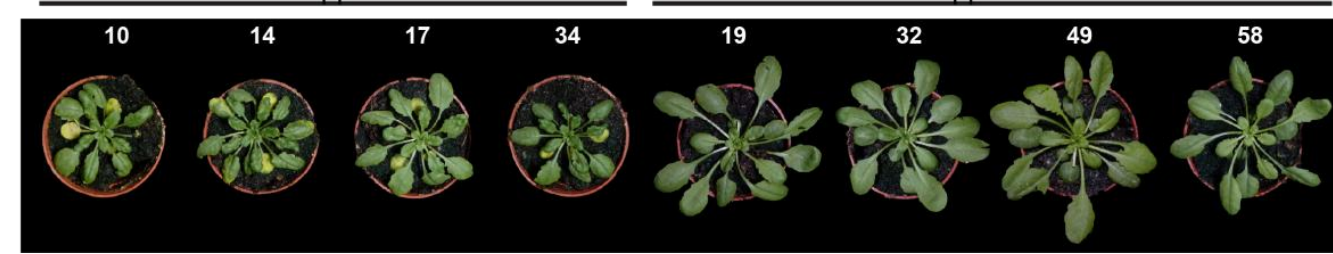

Figure 24. Supression of the cerk1-4 phenotype is genetically linked to the $x / g 2 \mathrm{E} 293 \mathrm{~K}$ (noce4/6) mutation. A) Schematic representation of noce dCAPS marker developed to detect the xlg2 E293K (noce4/6) mutation. The forward dCAPS primer was designed to introduce an Xhol restriction site (yellow) into PCR products derived from the wild type XLG2 allele, but not into PCR fragment derived from the $x \lg 2$ E293K allele. B) 28 non-suppressor and 32 cerk 1-4 suppressor plants were analyzed with the dCAPS marker described in A). Restriction digestion was analyzed by agarose gel electrophoresis. Upper panel, non-suppressor plants were either heterozygous (169bp fragment + 137bp fragment) for xlg2 E293K or homozygous for the XLG2 wild type allele (only 137bp fragment). Lower panel, plants suppressing the cerk1-4 phenotype were all homozygous for xlg2 E293K showing only a 169bp fragment. C) Example pictures of cerk1-4 suppressing and non-suppressing plants. Plant numbering corresponds to numbering in agarose gel images. 
A derived cleaved amplified polymorphic sequence (dCAPS) marker was designed to detect the noce $4 / 6$ mutation by PCR and subsequent restriction digestion. Primers were designed to introduce an Xhol cleavage site into PCR products derived from the wild type XLG2 sequence (Figure 24A). After Xhol digestion of the PCR product, an uncleaved $169 \mathrm{bp}$ product should be detected for the mutant (E293K) XLG2 allele, while a cleaved $137 \mathrm{bp}$ fragment should be observed with the wild type XLG2 allele. From the backcrossed F2 population, 41 suppressor and 28 non-suppressor plants were thus analyzed to investigate the linkage between the suppressor phenotype and the noce4/6 mutation. All nonsuppressing plants were either heterozygous for the xlg2 E293K mutation or homozygous for the XLG2 wild type allele (Figure 24B).

Plants suppressing the cerk1-4 phenotype were all homozygous for the $x \lg 2$ E293K mutation, as only the non-cleaved 169bp fragment could be detected. This result indicates that the $x \lg 2$ E293K mutation is highly linked with cerk1-4 phenotype suppression, making it a very likely candidate for the causal suppressor mutation.Genotyping revealed that all cerk1-4 suppressing plants derived from noce4/6 backcrosses were homozygous for $x$ lg2 E293K. To confirm that $x \lg 2 \mathrm{E} 293 \mathrm{~K}$ is indeed the causal mutation for suppression of the cerk 1-4 phenotype, noce4/6 plants were transformed with a genomic fragment containing the wild type XLG2 gene including the XLG2 promoter. The resulting transformants were tested for restoration of the cerk1-4 phenotype. Transformed plants were inoculated with Bgh and the phenotype was assessed seven days after infection.

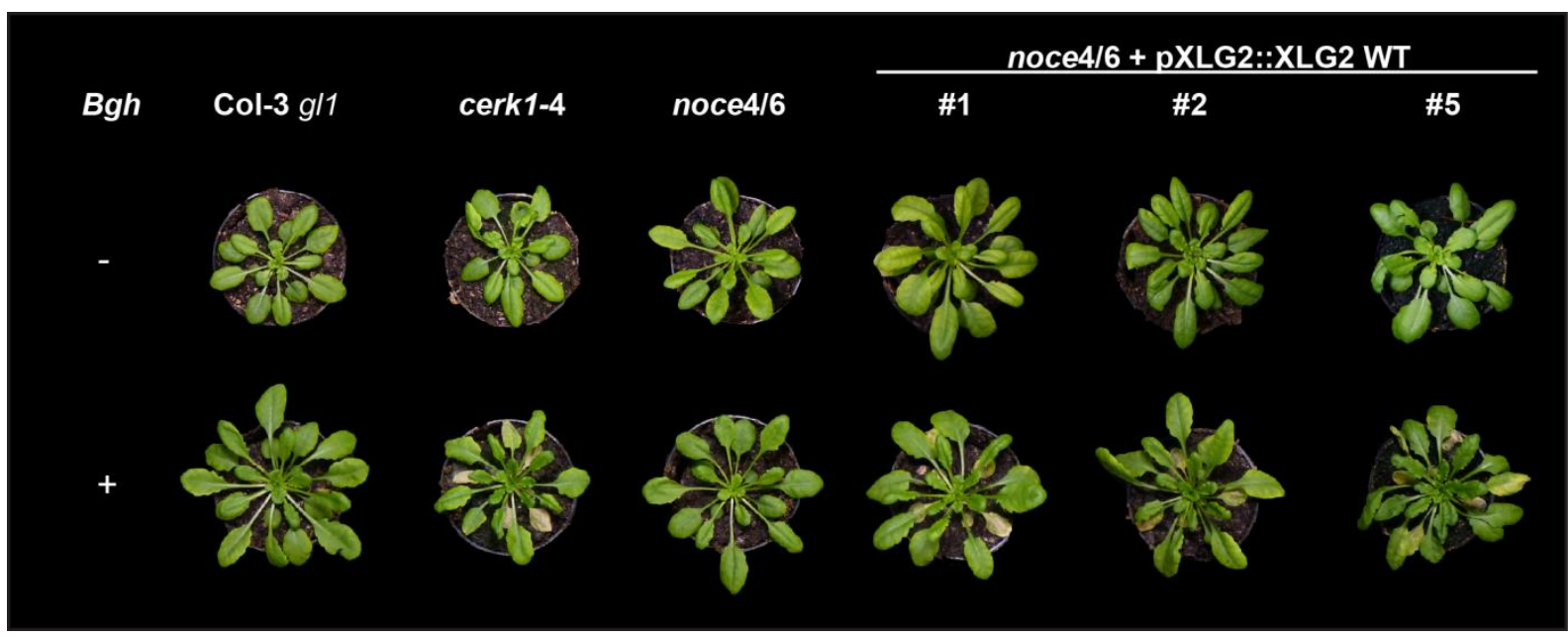

Figure 25. Expression of a genomic wild type XLG2 fragment can restore the cerk1-4 phenotype in nole6-1 plants. noce $4 / 6$ plants were transformed with a genomic fragment derived from wild type plants containing the XLG2 gene including its promoter. Positive transformants, as well as Col-3 gl1, cerk 1-4 and nole6-1 controls were inoculated with Bgh. Pictures of non-inoculated (-) and inoculated (+) plants were taken seven days after infection. 
Expression of wild type XLG2 could restore the cerk1-4 phenotype in all tested lines thereby delivering the last piece of evidence for $x / g 2$ E293K being the causal mutation of noce4/6 (Figure 25). Since the nole1-1 mutant also harbours a mutation within XLG2, noce4/6 was renamed to nole1-2 cerk1-4.

E293 (which is mutated to $\mathrm{K}$ in nole1-2 plants) is located to the N-terminal part of XLG2 in a highly conserved part C-terminal to the CxxC-motifs. Like the $\mathrm{CxxC}$ motifs, this glutamic acid is highly conserved in XLG proteins from mosses to flowering plants (Figure 26). 


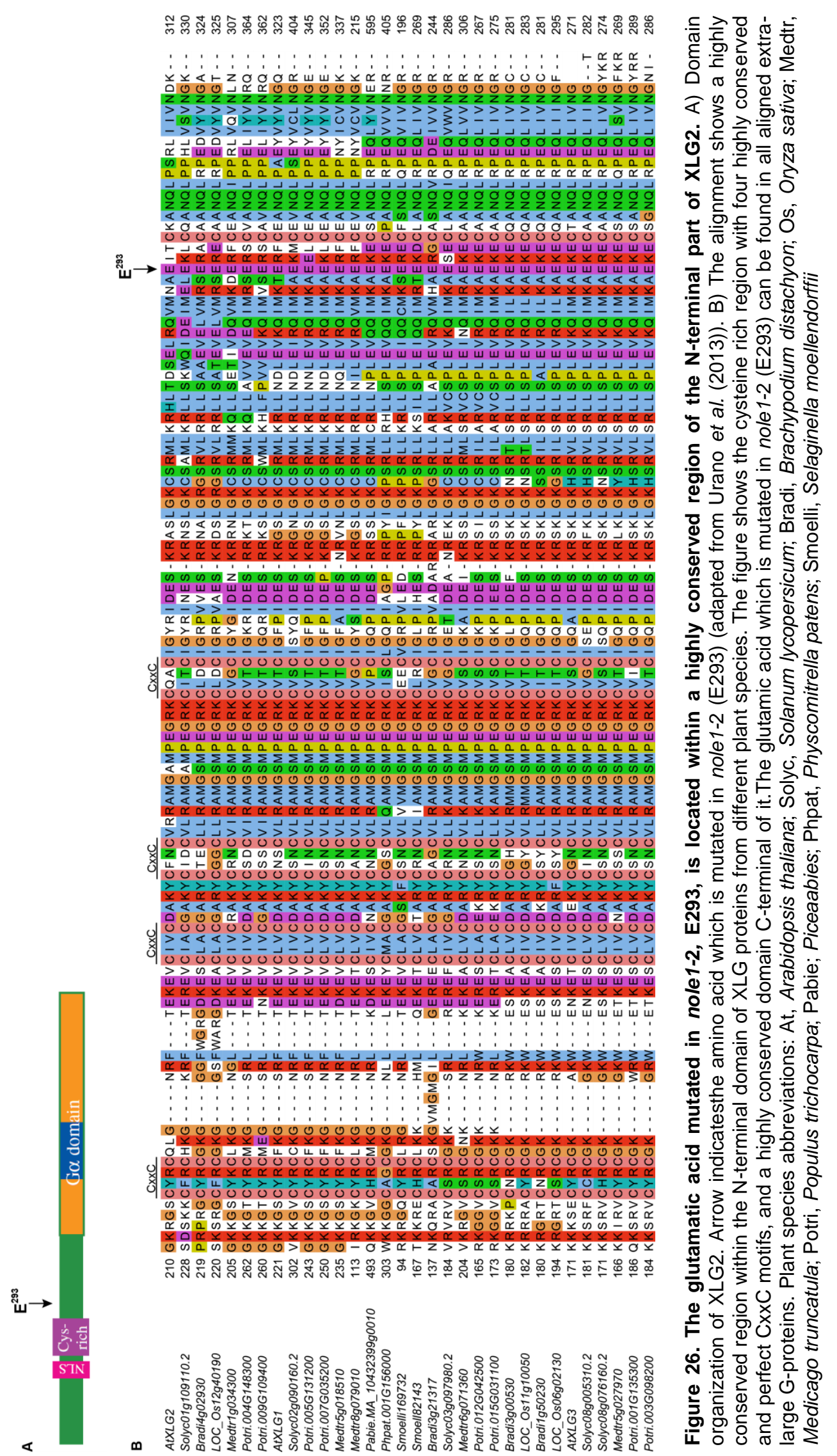




\subsubsection{Localization studies with XLG2-GFP fusion protein}

\subsubsection{XLG2-GFP and $x$ Ig2-E293K-GFP are located to the nucleus and cell periphery in $N$. benthamiana}

Previous studies reported localization of XLG2 to the nucleus, cytoplasm and plasma membrane when heterologously expressed in Nicotiana benthamiana (Chakravorty et al., 2015; Maruta et al., 2015) or to the nucleus and plasma membrane in stably transformed Arabidopsis thaliana plants (Chakravorty et al., 2015; Maruta et al., 2015). However, in these studies XLG2 expression was under control of the strong 35S or UBIQUITIN10 promoters and the reported localization patterns might be influenced by overexpression.

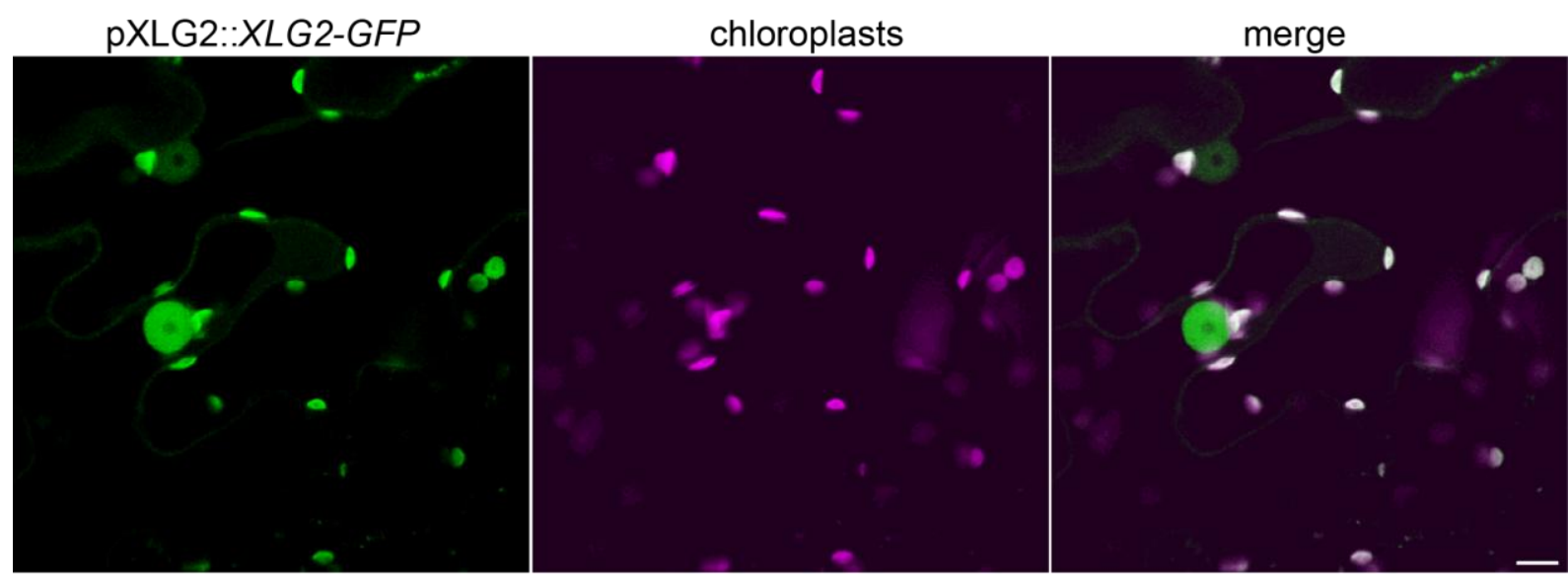

pXLG2::xlg2 E293K-GFP

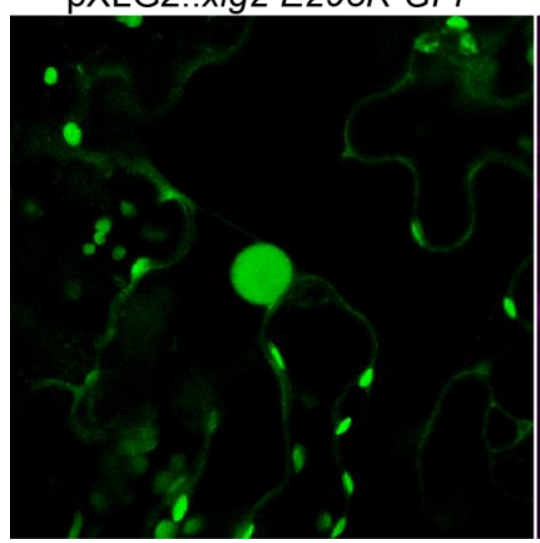

chloroplasts

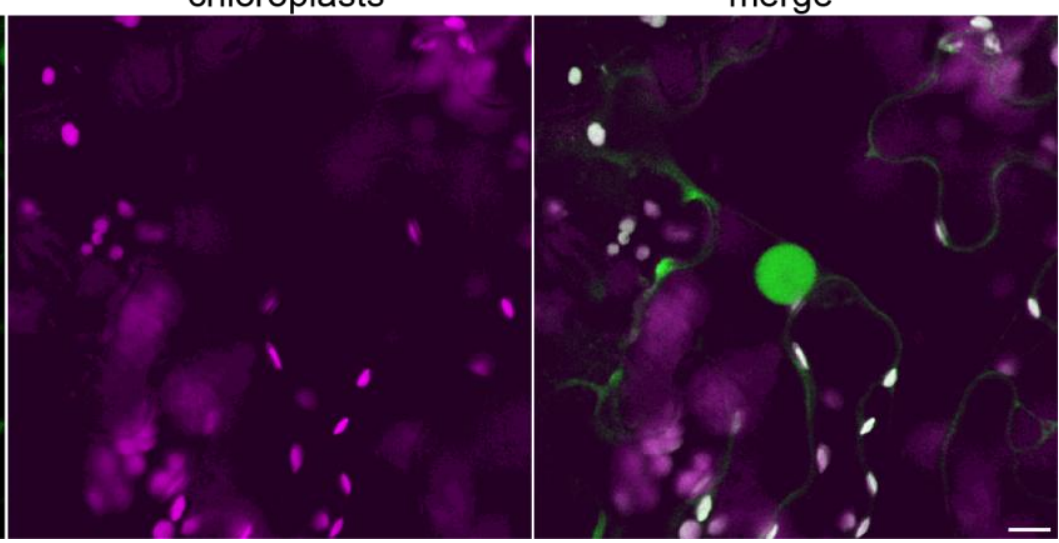

Figure 27. XLG2-GFP and $x I g 2$ E293K-GFP are located to the nucleus and the cell periphery in $N$. benthamiana. Agrobacteria either carrying a plasmid expressing XLG2-GFP or xlg2 E293K-GFP under control of the native XLG2 promoter were infiltrated into $N$. benthamiana. Confocal laser scanning microscopy (CLSM) was carried out two days after infiltration. Size bar indicates $10 \mu \mathrm{m}$. 
To re-assess the subcellular localization of XLG2 and to investigate the localization of $x \lg 2$ E293K, C-terminal GFP fusions under control of the endogeneous XLG2 promoter were generated in the pGWB604 vector. Transient expression of XLG-GFP constructs in Nicotiana benthamiana confirmed localization of XLG2 to the nucleus but not the nucleolus. Also, weak localization of XLG-GFP to the cell periphery was seen (Figure 27). The same localization pattern was observed for xlg2 E293K-GFP (Figure 27).

\subsubsection{XLG2-GFP localizes to the cell periphery in unchallenged Arabidopsis plants and accumulates in the nucleus upon stress}

The XLG2-GFP fusion construct was transformed into Arabidopsis thaliana plants. The resulting transformants were used to study the subcellular localization of XLG2 when stably expressed in Arabidopsis. Expression levels of XLG2-GFP in leaves of Arabidopsis Col-3 gl1 plants were very low (Figure $28 \mathrm{~A}$, upper panel) and no signal could be detected for $x \lg 2$ E293K-GFP expressing lines (data not shown). Nevertheless, a signal at the cell periphery was detectable for XLG2-GFP. Surprisingly, no signal in nuclei could be observed. Thus, the localization of XLG2-GFP upon PAMP treatment was investigated. Leaf discs were vacuum infiltrated with either chitin or $\mathrm{H}_{2} \mathrm{O}$ as control, to test for any localization changes (Figure $28 \mathrm{~A}$, lower panels). Short incubation times did not cause any discernible alterations in XLG2-GFP localization (data not shown). An anti-GFP immunoblot revelead a signal at $130 \mathrm{kDa}$ corresponding to full length fusion protein for XLG2-GFP and $x \lg 2$ E293K-GFP expressing plants (Figure 28B). No difference between wild type XLG2-GFP and xlg2 E293K-GFP concerning the band pattern was observable. However, after incubation for 16 hours in either $\mathrm{H}_{2} \mathrm{O}$ or chitin, the overall signal for XLG2-GFP appeared to be increased and a clear GFPsignal in nuclei became visible. These results suggest that in unstimulated plants, XLG2 is localized only to the cell periphery, whereas upon exposure to stress, XLG2 also accumulates in the nucleus. The fact that water infiltration also caused this change in localization indicates that XLG2 responds either to mechanical stimuli or unspecifically to any stress. 
A

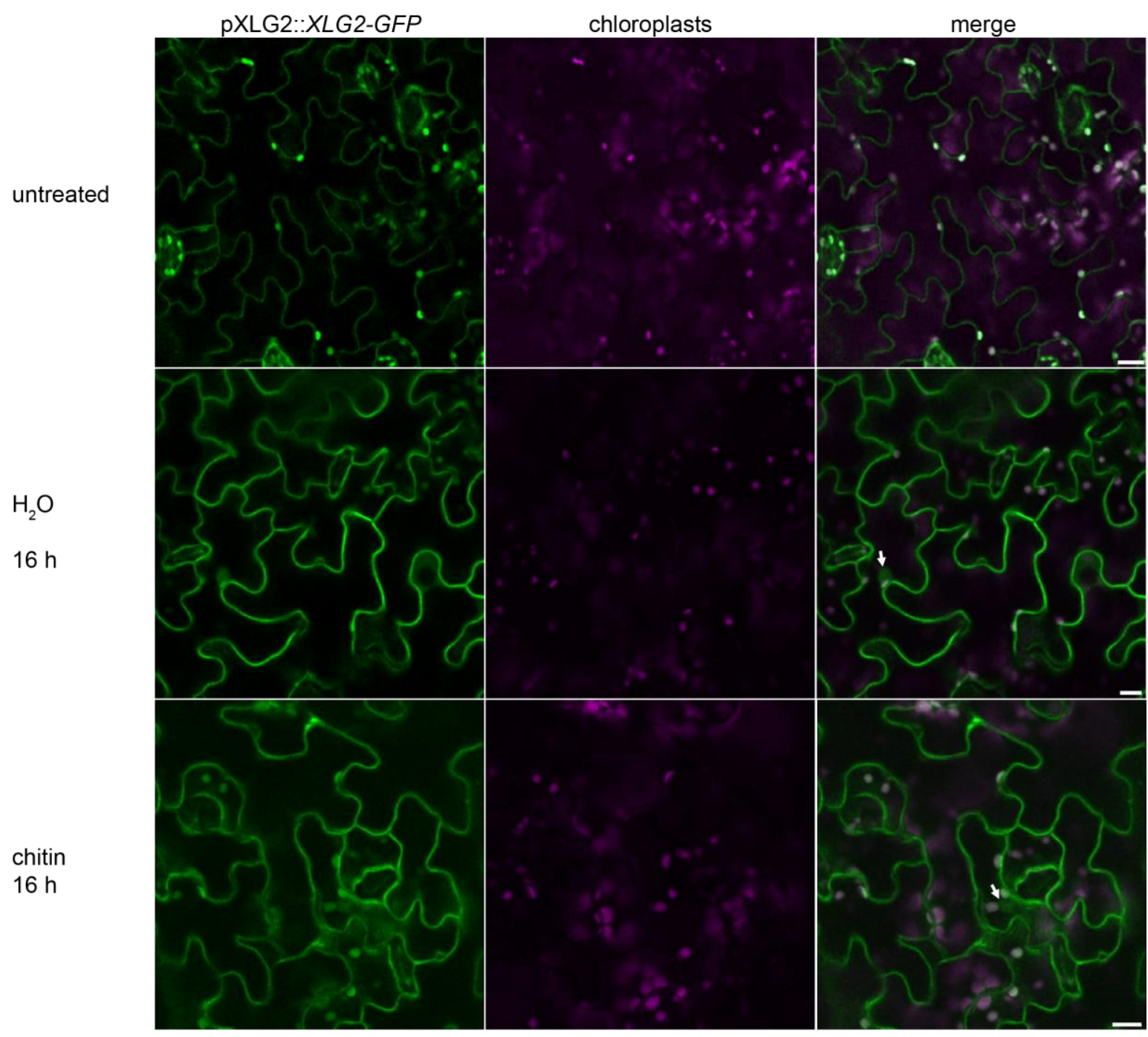

B

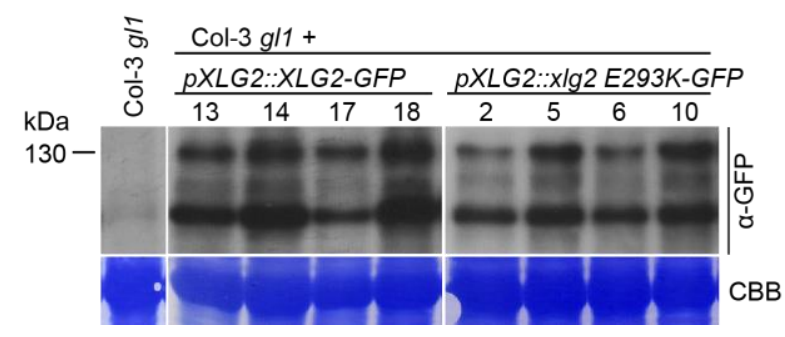

Figure 28. XLG2-GFP localization is stimulus dependent. A) Localization of XLG2 was investigated in leaf discs of Col-3 g/1 plants stably expressing XLG2-GFP by confocal laser scanning microscopy. Leaf discs were either untreated or infiltrated with $\mathrm{H}_{2} \mathrm{O}$ or $100 \mu \mathrm{g} \mathrm{ml}^{-1}$ shrimp shell chitin and incubated for $16 \mathrm{~h}$. Pictures show maximum projections of 10 single focus plane images taken $1 \mu \mathrm{m}$ apart. Size bar indicates $10 \mu \mathrm{m}$. B) Anti-GFP immunoblot of four individual transgenic T1 plants either expressing XLG2-GFP or xlg2 E293K-GFP under control of the endogenous XLG2 promoter. Total protein extracts were prepared from leaves. CBB, Coomassie Brilliant blue stained membrane. 


\subsubsection{C-terminal XLG2-GFP fusions are not functional}

The nole1-1 cerk1-4 and nole1-2 cerk1-4 mutants offer the possibility to test XLG2 fusion constructs for functionality. These mutants harbor the cerk1-4 mutation, but do not exhibit the characteristic cerk1-4 phenotype, because they lack functional XLG2 (Chapter 3.2.3). Transformation with a functional XLG2 construct can restore the cerk1-4 phenotype in nole11 cerk1-4 (Elena Petutschnig, unpublished) and nole1-2 cerk1-4 (Figure 25) upon Bgh infection. Therefore, functionality of XLG2-GFP was tested by expression in nole1-1 cerk1-4 and subsequent Bgh infection (Figure 29). nole1-1 cerk1-4 plants expressing XLG2-GFP developed lesions after Bgh infection, but to a much lesser extent than cerk1-4 mutants and more resembled Col-3 g/1 control plants (Figure 29A). This experiment was performed twice with similar results and eleven transgenic plants were tested in total. Immunoblot analysis using a GFP antibody revealed expression of full length XLG2-GFP (130 kDa) in all tested transgenic lines (Figure 29B). Additional signals below the full length signal could be detected for all tested lines and might represent degradation products. Since a specific XLG2 antibody is not available, it cannot be inferred from these blots whether the abundance of XLG2-GFP matches that of the endogenous XLG2 protein. Overall it can be concluded that XLG2-GFP is not functional, either because the tag inhibits XLG2 function, or because protein levels are insufficient. Based on the lack of functionality of XLG2-GFP, studies using this construct should be taken with caution since XLG2-GFP localization might not represent the localization of the endogenous XLG2 protein.

A

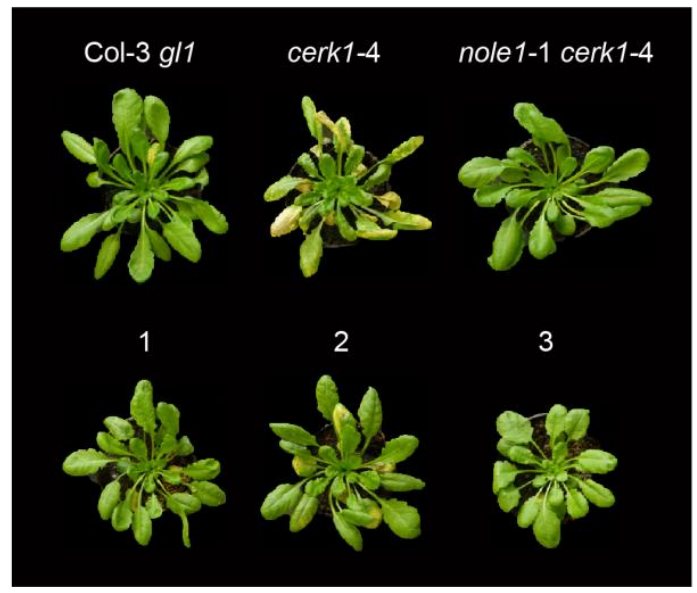

B

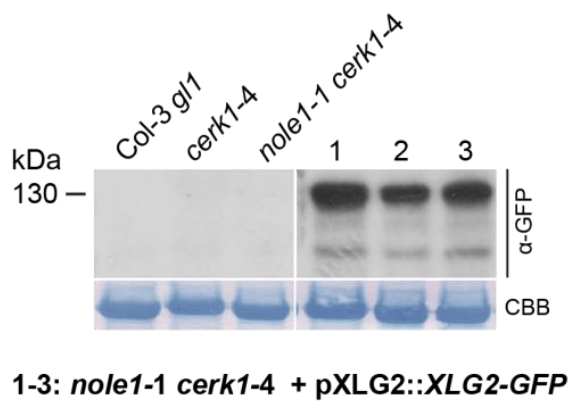

Figure 29. XLG2-GFP is not functional. A) nole1-1 cerk1-4 plants were transformed with constructs containing XLG2-GFP under control of the native XLG2 promoter. Positive transformants were inoculated with Bgh and pictures were taken seven days after infection. Col-3 gl1, cerk1-4 and nole1-1 cerk1-4 were used as controls. B) Total protein extracts prepared from leaves of plants shown in A) were used for immunoblot analysis using a GFP antibody. CBB, Coommassie Brilliant Blue stained membrane (loading control). 
For this reason, no further, more detailed localization studies were carried out with XLG2GFP and related fusion proteins.

\subsubsection{Localization studies with Venus-XLG2}

\subsubsection{Venus-XLG2 localizes to the nucleus, cytoplasm and plasma membrane in Nicotiana benthamiana}

Since XLG2-GFP fusion constructs were shown not to be fully functional, N-terminal fusions of XLG2 with the fluorescence protein Venus (Venus-XLG2) were generated. This construct was used for further analysis of the subcellular localization of XLG2. To allow co-localization studies with marker proteins for different subcellular compartments, Venus-XLG2 was expressed transiently in $N$. benthamiana. These transient expression assays showed localization to the cell periphery, cytoplasm and the nucleus. This localization pattern resembled the localization pattern of C-terminal XLG2-GFP fusions, even though fluorescence intensity of the N-terminal Venus-XLG2 fusion appeared much stronger. Nuclear localization was confirmed by co-infiltration with a nuclear marker construct expressing TagRFP-T fused to Histone2B (Figure 30).
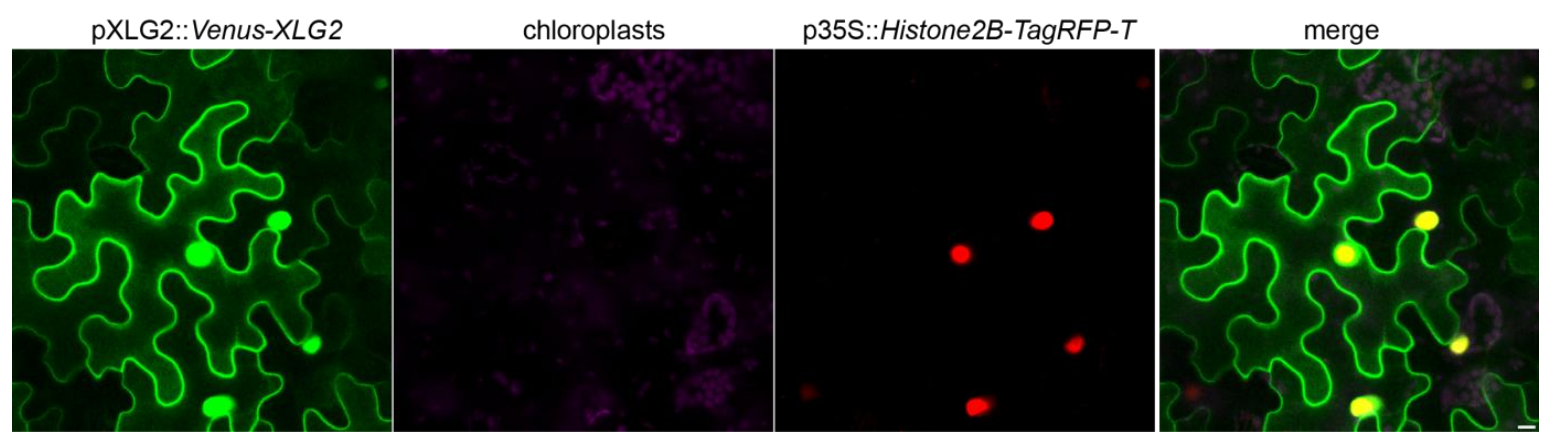

Figure 30. N-terminal XLG2 fusions are localized to the cell periphery and the nucleus. Agrobacteria carrying constructs for pXLG2::Venus-XLG2 and p35S::Histone2B tagged with TagRFP-T were co-infiltrated into $N$. benthamiana leaves. Confocal laser scanning microscopy (CLSM) was carried out two days after infiltration. Images represent a maximum projection of 10 single focal planes recorded $1 \mu \mathrm{m}$ apart. Size bar indicates $10 \mu \mathrm{m}$.

To confirm localization to the plasma membrane, Venus-XLG2 was co-expressed in Nicotiana benthamiana leaves with the LysM-RLK LYK5 fused to the far red fluorescence protein mKate2 (LYK5-mKate2). LYK5 was shown to localise to the plasma membrane (Erwig et al., unpublished) and was therefore considered a suitable plasma membrane marker. Venus-XLG2 co-localized with LYK5-mKate2 and both fusion proteins could be 
found in Hechtian strands after plasmolysis, indicating plasma membrane localization (Figure 31).

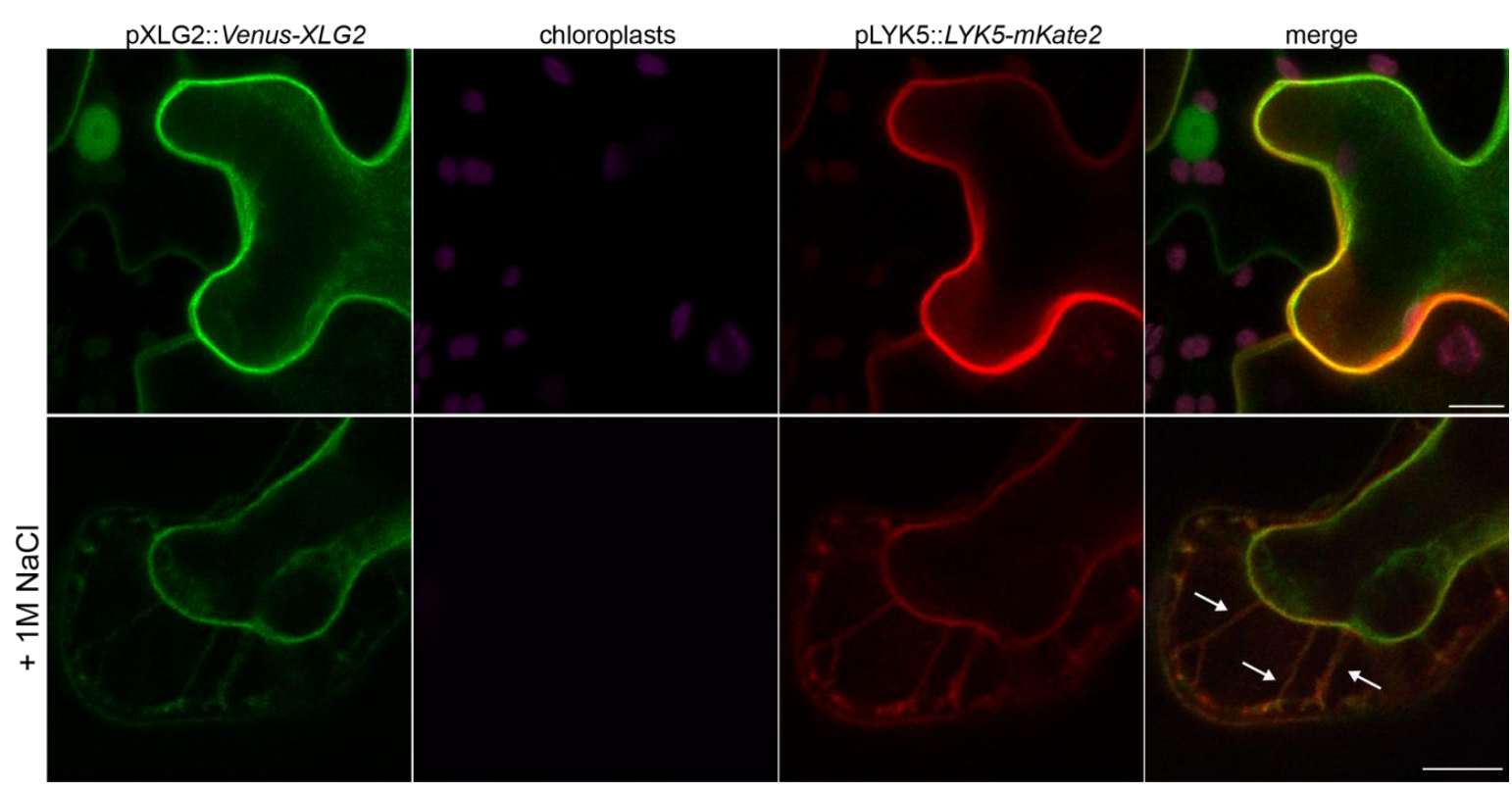

Figure 31. Venus-XLG2 co-localizes with LYK5-mKate at the plasma membrane. Venus-XLG2 and LYK5mKate were co-expressed under control of their respective native promoters in Nicotiana benthamiana. Confocal laser scanning microscopy was perfomed 2 days after infiltration. Upper panel, Venus-XLG2 and LYK5-mKate2 co-localize at the plasma membrane; Lower panel, $1 \mathrm{M} \mathrm{NaCl}$ was used to plasmolyse cells. White arrows indicate Hechtian strands. Size bar indicates $10 \mu \mathrm{m}$.

In order to confirm cytoplasmic localization, XLG2 was co-expressed with free mCherry under control of the 35 S promoter (Figure 32). Venus-XLG2 showed a weak signal for a few cytoplasmic strands, whereas free mCherry strongly labelled cytoplasmic strands throughout the cell. This confirms that Venus-XLG2 is also present in the cytoplasm, but this appears to be only a minor pool compared to XLG2 in the nucleus or the PM.

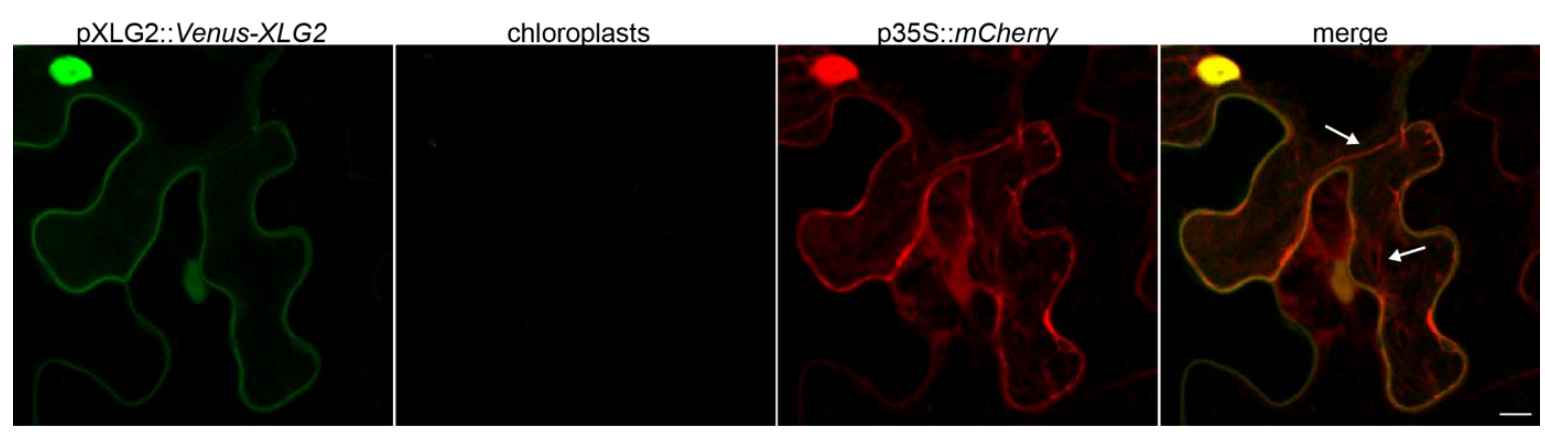

Figure 32. Venus-XLG2 is also found in cytoplasmic strands. Venus-XLG2 expressed under control of its native promoter and mCherry under control of the 35S promoter were co-expressed in Nicotiana benthamiana and confocal laser scanning microscopy was performed two days after infiltration. Arrows indicate cytoplasmic strands. Size bar indicates $10 \mu \mathrm{m}$. 


\subsubsection{N-terminal XLG2 fusions are functional and restore the cerk1-4 phenotype in nole1-1 plants}

Prior to investigating subcellular localization of Venus-XLG2 in transgenic Arabidopsis plants, Venus-XLG2 was tested for functionality. Therefore, nole1-1 cerk1-4 plants were transformed with the Venus-XLG2 construct under control of the native XLG2 promoter and transformants that gave a good signal in confocal microscopy were inoculated with Bgh (Figure 33A).

A

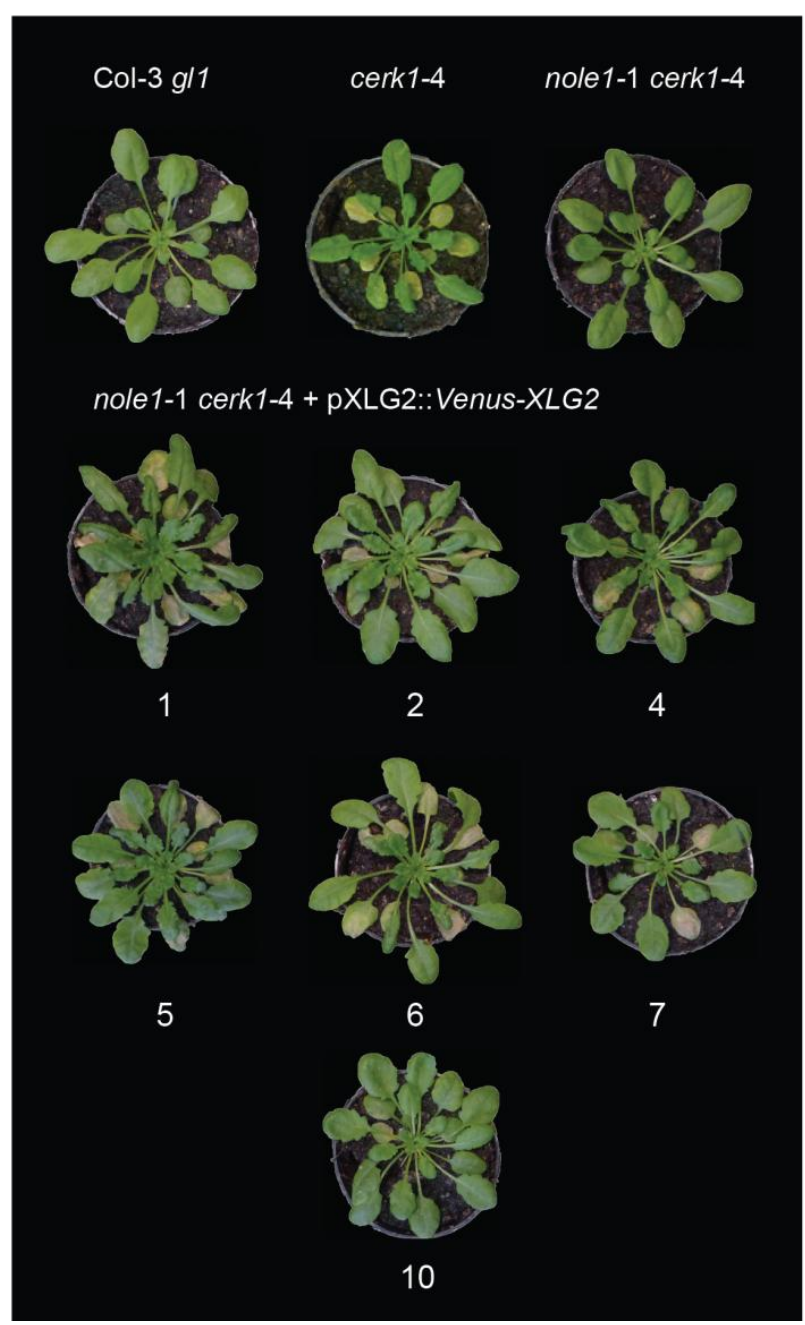

B

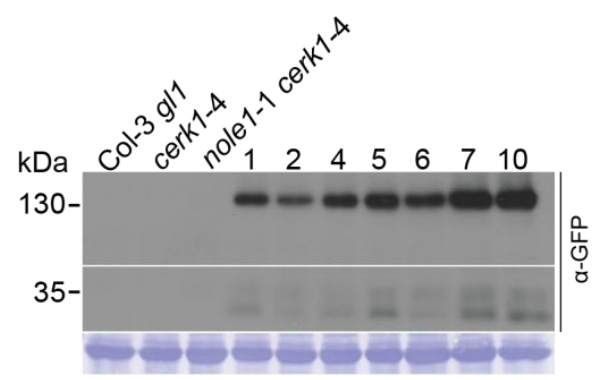

1-7: nole1-1 cerk1-4 + pXLG2::Venus-XLG2

Figure 33. N-terminal XLG2 fusions are functional. A) nole1-1 cerk1-4 plants were transformed with a construct containing Venus-XLG2 under control of the XLG2 promoter. Transformants were checked for fluorescence intensity by confocal laser scanning microscopy (not shown) and strong expressors were chosen for inoculation with Bgh. Col-3 gl1, cerk1-4 and nole1-1 cerk1-4 were used as controls. Pictures were taken seven days after Bgh infection. B) Total protein extracts prepared from leaves of Bgh infected plants shown in A) were used for immunoblot analysis with a GFP antibody. CBB. Commassie Brilliant Blue stained membrane (loading control). 
Transgenic plants developed macroscopically visible lesions comparable to cerk1-4 plants seven days after infection. No lesions were visible in Col-3 gl1 or nole1-1 cerk1-4 mutants. In immunoblot analysis with a GFP antibody, a $130 \mathrm{kDa}$ band corresponding to Venus-XLG2 full length protein could be detected for all transgenic lines (Figure 33B). A weak signal of about $30 \mathrm{kDa}$ was present in all transgenic lines, which might correspond to free Venus. Nevertheless, these results strongly indicate functionality of the N-terminal Venus-XLG2 fusion.

\subsubsection{Venus-XLG2 localises to the cell periphery in unchallenged Arabidopsis plants and accumulates in the nucleus upon stress}

XLG2 localization studies in Nicotiana benthamiana confirmed previous studies (Chakravorty et al., 2015; Maruta et al., 2015) which found XLG2 to be localized to the nucleus, cytoplasm and plasma membrane. In order to investigate the subcellular localization of XLG2 in Arabidopsis thaliana, pXLG2::Venus-XLG2 was transformed into Col-0, agb1-2, Col-3 g/1 and cerk1-4 plants. Confocal laser scanning microscopy revealed localization of XLG2 to the cell periphery in unchallenged Col-0 plants. These results confirm the localization studies conducted with C-terminal GFP fusions in this study and are in contrast to a recent study with stably transformed Arabidopsis plants overexpressing GFP-XLG2 from the 35S promoter (Maruta et al., 2015). To address the question if XLG2 localization might be stimulus dependent, leaves of Col-0 plants expressing Venus-XLG2 were infiltrated with $\mathrm{H}_{2} \mathrm{O}$, chitin or flg22. Analysis by confocal laser scanning microscopy revealed that 3 hours after each of these treatments, the Venus-XLG2 fluorescence signal increased overall and a distinct signal within nuclei appeared. After one day of incubation, the Venus-XLG2 signal intensity was increased further, with pronounced labelling of nuclei. These data suggest that in the wild type background, infiltration stress causes Venus-XLG2 abundance to increase and triggers its accumulation in nuclei. No clear difference in the subcellular behaviour of Venus-XLG2 could be seen between water and PAMP treatment. To investigate if the accumulation of Venus-XLG2 in nuclei is specifically caused by infiltration, leaves of Col-0 plants expressing Venus-XLG2 were analyzed after wounding. Leaf discs were cut out and analyzed either directly by confocal laser scanning microscopy or stored in water for 3 and 24 hours, respectively. Similar to infiltration of $\mathrm{H}_{2} \mathrm{O}$, chitin or flg22, a Venus-XLG2 signal in the nucleus appeared 3 hours after wounding and became more intense after 24 hours Thus it seems likely that different types of abiotic and biotic stress can trigger nuclear accumulation of Venus-XLG2 (Figure 34, Figure 35, Figure 36, Figure 37) 


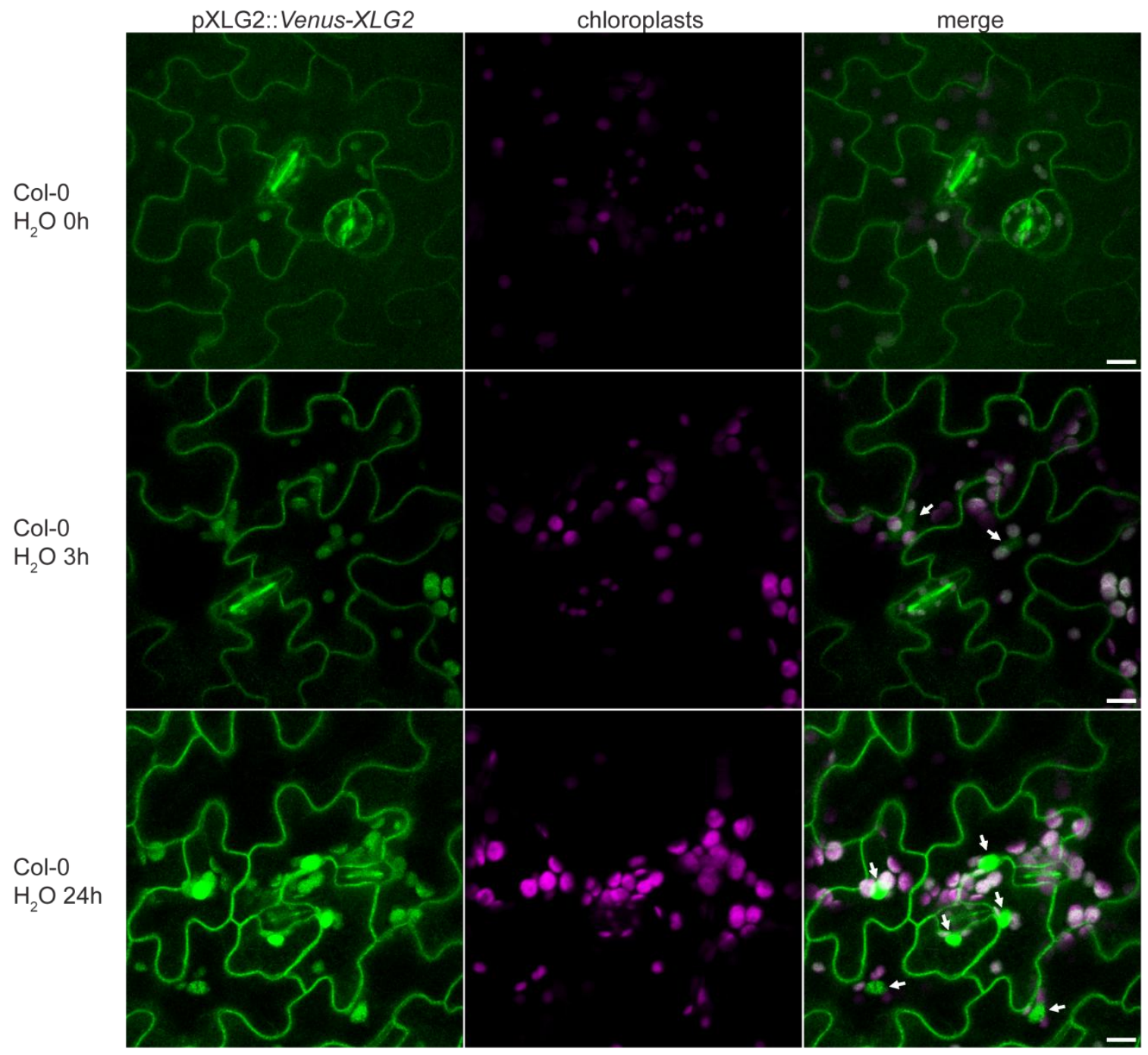

Figure 34. XLG2 is localized to the cell periphery in unchallenged plants and appears in nuclei after $\mathrm{H}_{2} \mathrm{O}$ infiltration in Col-0 plants. Stably transformed Col-0 plants expressing Venus-XLG2 from the XLG2 promoter were analyzed by Confocal laser scanning microscopy. Leaf discs were cut out and vacuum-infiltrated with $\mathrm{H}_{2} \mathrm{O}$ using a syringe. Leaf discs were either used for microscopy directly after infiltration or were incubated in $\mathrm{H}_{2} \mathrm{O}$ for the indicated time points. Images represent maximum projections of 10 single focal plane images taken $1 \mu \mathrm{m}$ apart. White arrows denote nuclei. Size bar indicates $10 \mu \mathrm{m}$. 


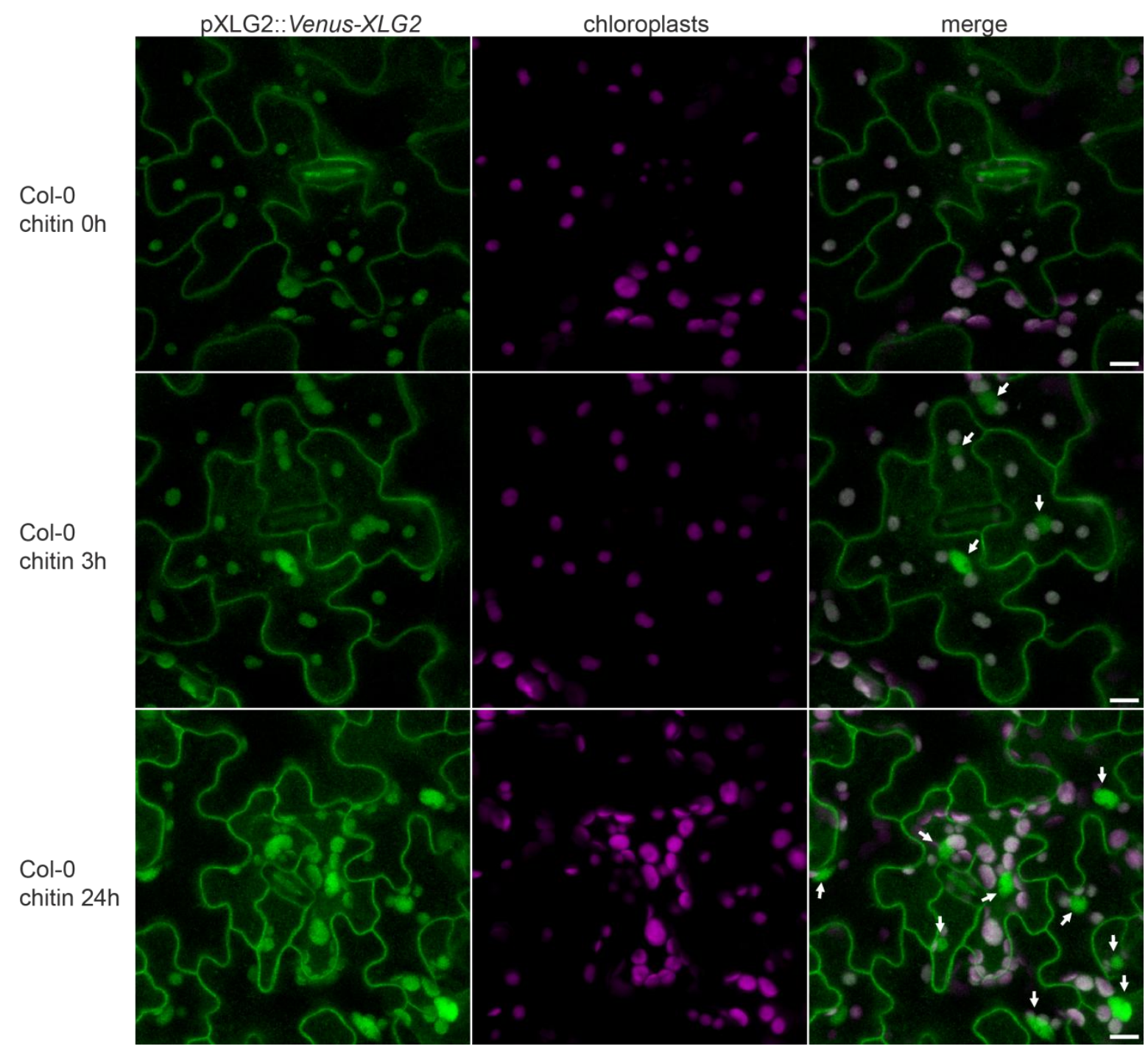

Figure 35. XLG2 is localized to the cell periphery in unchallenged plants and appears in nuclei after chitin infiltration in Col-0 plants. Stably transformed Col-0 plants expressing Venus-XLG2 from the XLG2 promoter were analyzed by Confocal laser scanning microscopy. Leaf discs were cut out and vacuum-infiltrated with 100 $\mathrm{mg} \mathrm{ml}^{-1}$ chitin using a syringe. Leaf discs were either used for microscopy directly after infiltration or were incubated in $100 \mathrm{mg} \mathrm{ml}^{-1}$ chitin solution for the indicated time points. Images represent maximum projections of 10 single focal plane images taken $1 \mu \mathrm{m}$ apart. White arrows denote nuclei. Size bar indicates $10 \mu \mathrm{m}$. 


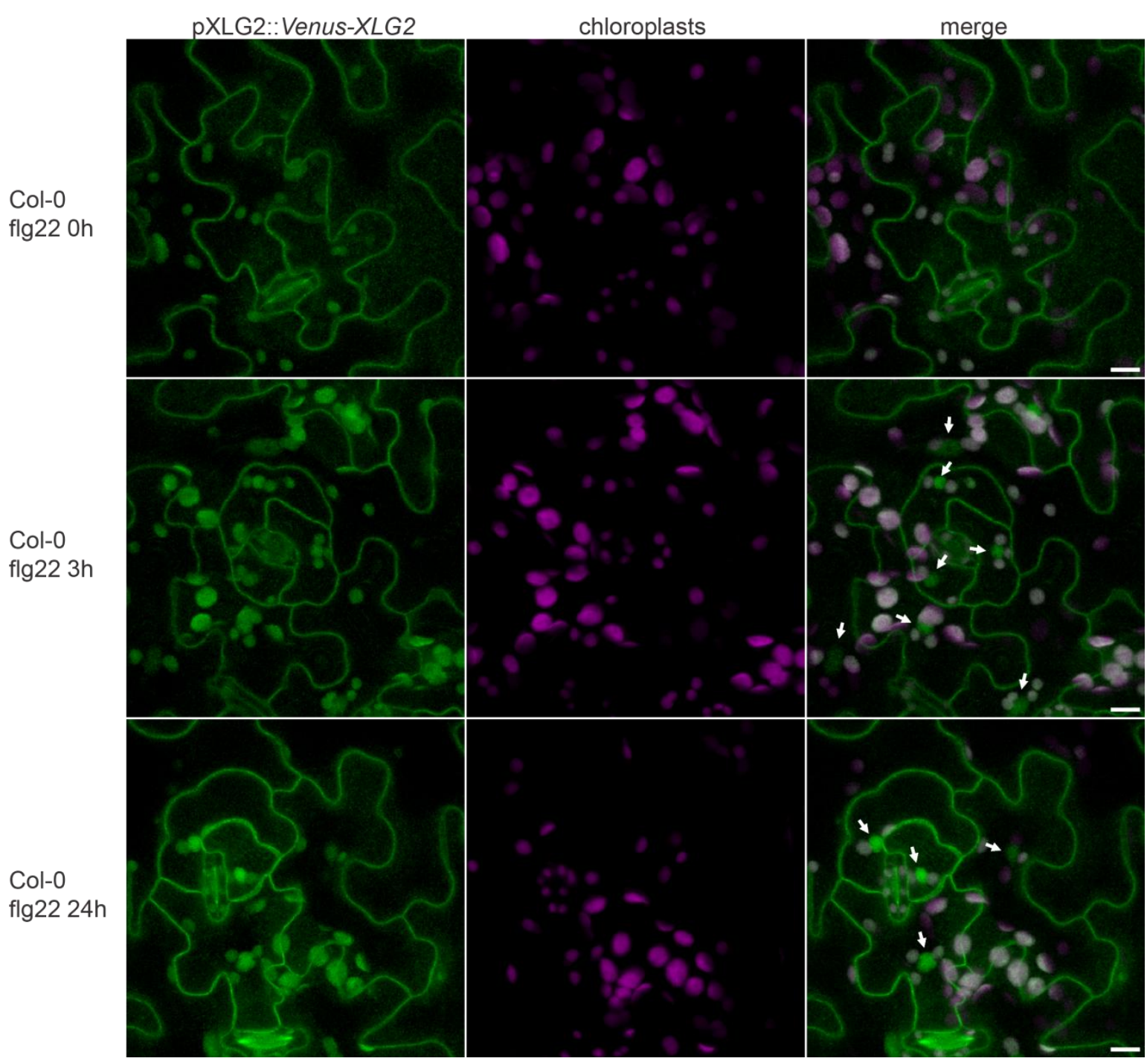

Figure 36. XLG2 is localized to the cell periphery in unchallenged plants and appears in nuclei after flg22 infiltration in Col-0 plants. Stably transformed Col-0 plants expressing Venus-XLG2 from the XLG2 promoter were analyzed by Confocal laser scanning microscopy. Leaf discs were cut out and vacuum-infiltrated with 100nm flg22 using a syringe. Leaf discs were either used for microscopy directly after infiltration or were incubated in $100 \mathrm{~nm}$ flg22 solution for the indicated time points. Images represent maximum projections of 10 single focal plane images taken $1 \mu \mathrm{m}$ apart. White arrows denote nuclei. Size bar indicates $10 \mu \mathrm{m}$. 


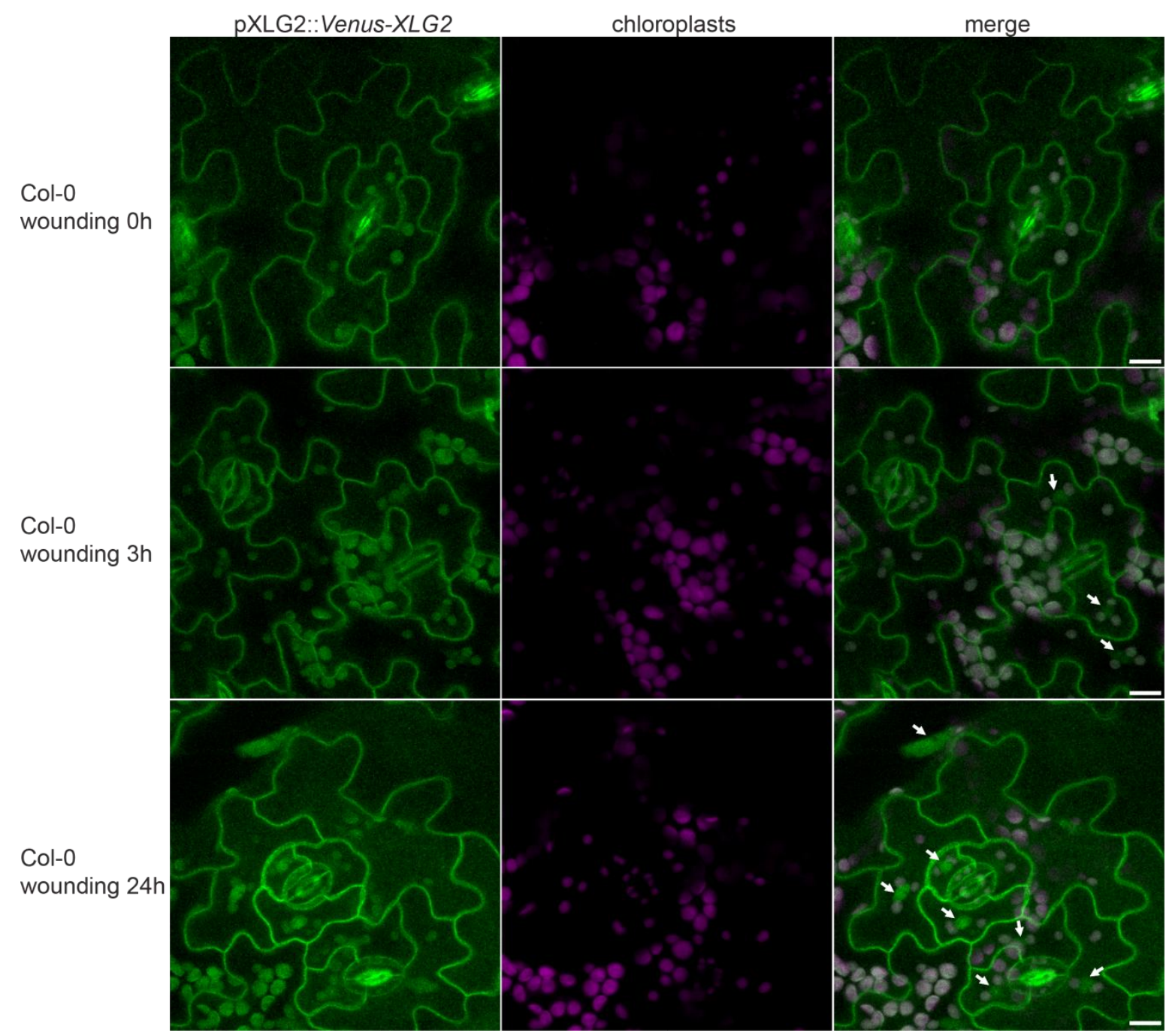

Figure 37. XLG2 is localized to the cell periphery in unchallenged plants and appears in nuclei after wounding in Col-0 plants. Stably transformed Col-0 plants expressing Venus-XLG2 from the XLG2 promoter were analyzed by Confocal laser scanning microscopy. Leaf discs were cut out and directly used for microscopy of were left in water for the indicated time points. Images represent maximum projections of 10 single focal plane images taken $1 \mu \mathrm{m}$ apart. White arrows denote nuclei. Size bar indicates $10 \mu \mathrm{m}$.

Since XLG2 is required for the formation of the cerk1-4 phenotype, the localization of VenusXLG2 was also analyzed in the cerk1-4 mutant and the corresponding wild type control, Col$3 \mathrm{~g} / 1$. The situation was the same as observed in Col-0. Venus-XLG2 localized to the cell periphery in unchallenged plants and showed an increase in overall signal intensity as well as accumulation in the nucleus upon water infiltration (Figure 38, Figure 39). Interestingly, when expressed in agb1-2 plants, Venus-XLG2 was localized to the cell periphery as well as the nucleus even in unchallenged plants. Upon infiltration of water, the signal at the cell periphery did not increase much, but the signal intensity in nuclei became very strong after 3 and 24 hours (Figure 40). The localization of Venus-XLG2 appeared to be shifted towards the nucleus in agb1-2 mutants. 


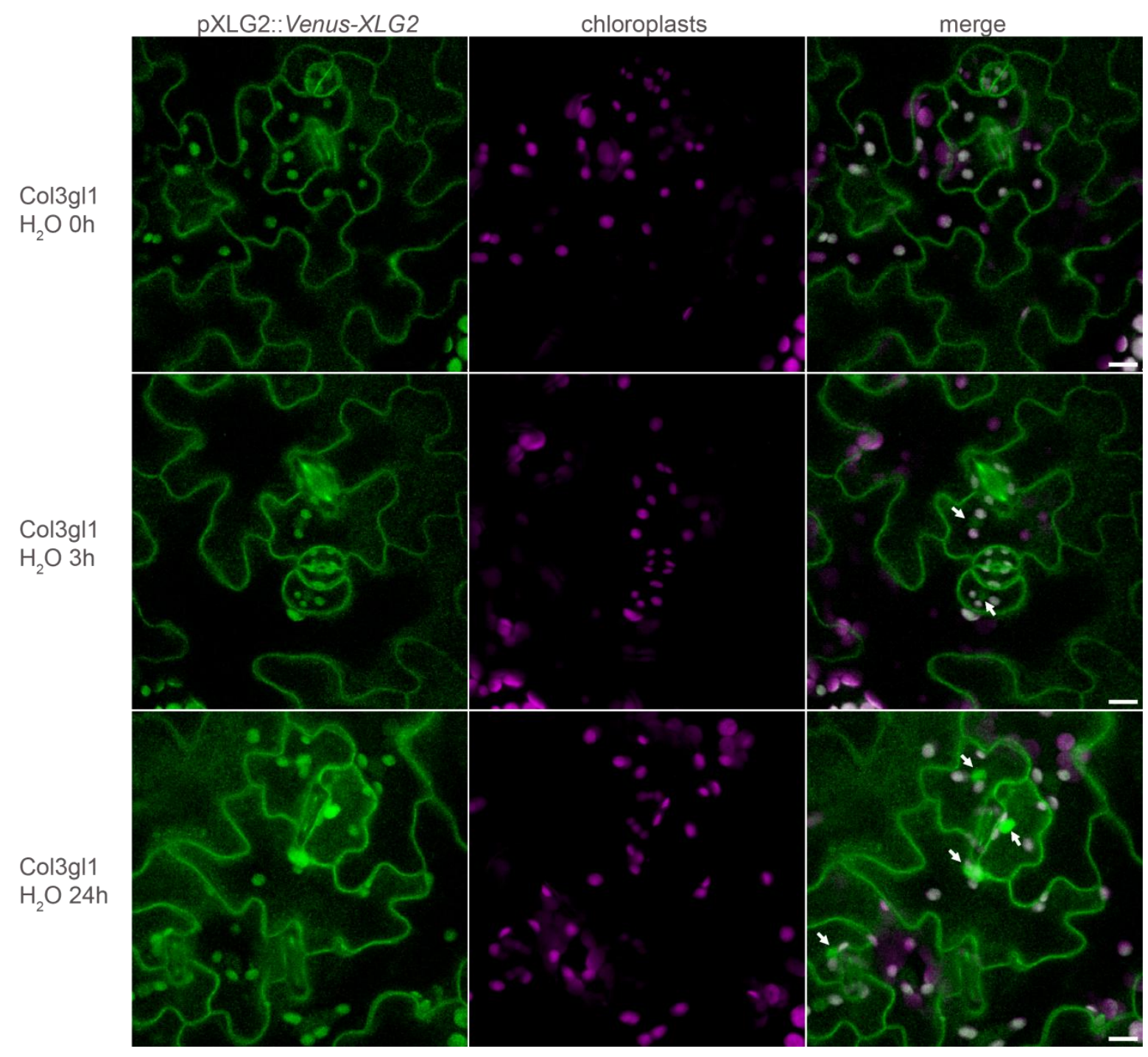

Figure 38. XLG2 is localized to the cell periphery in unchallenged plants and appears in nuclei after $\mathrm{H}_{2} \mathrm{O}$ infiltration in Col-3 gl1 plants. Stably transformed Col-3 gl1 plants expressing Venus-XLG2 from the XLG2 promoter were analyzed by Confocal laser scanning microscopy. Leaf discs were cut out and vacuum-infiltrated with $\mathrm{H}_{2} \mathrm{O}$ using a syringe. Leaf discs were either used for microscopy directly after infiltration or were incubated in $\mathrm{H}_{2} \mathrm{O}$ for the indicated time points. Images represent maximum projections of 10 single focal plane images taken 1 $\mu \mathrm{m}$ apart. White arrows denote nuclei. Size bar indicates $10 \mu \mathrm{m}$. 


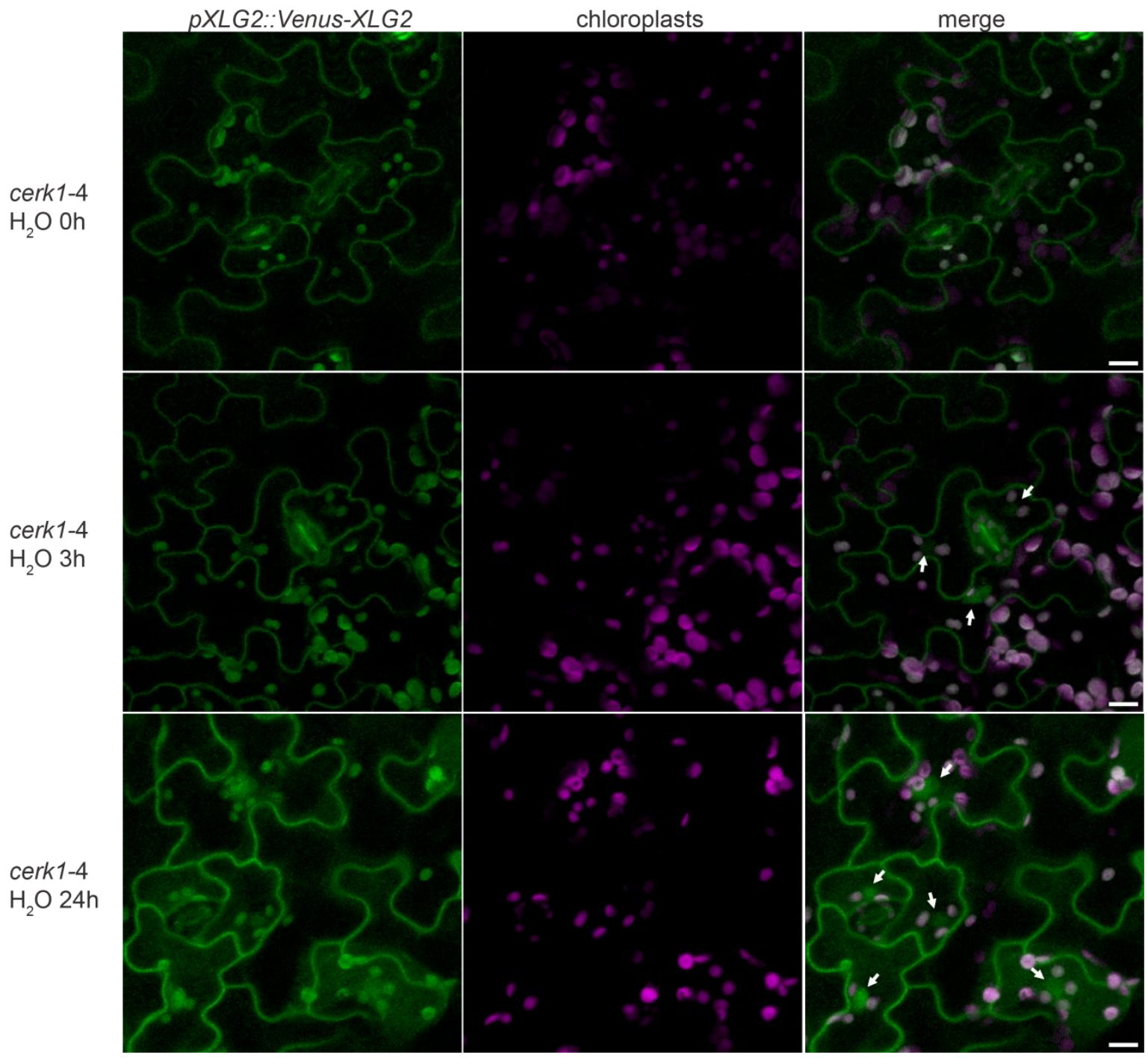

Figure 39. XLG2 is localized to the cell periphery in unchallenged plants and appears in nuclei after $\mathrm{H}_{2} \mathrm{O}$ infiltration in cerk1-4 plants. Stably transformed cerk1-4 plants expressing Venus-XLG2 from the XLG2 promoter were analyzed by Confocal laser scanning microscopy. Leaf discs were cut out and vacuum-infiltrated with $\mathrm{H}_{2} \mathrm{O}$ using a syringe. Leaf discs were either used for microscopy directly after infiltration or were incubated in $\mathrm{H}_{2} \mathrm{O}$ for the indicated time points. Images represent maximum projections of 10 single focal plane images taken 1 $\mu \mathrm{m}$ apart. White arrows denote nuclei. Size bar indicates $10 \mu \mathrm{m}$. 


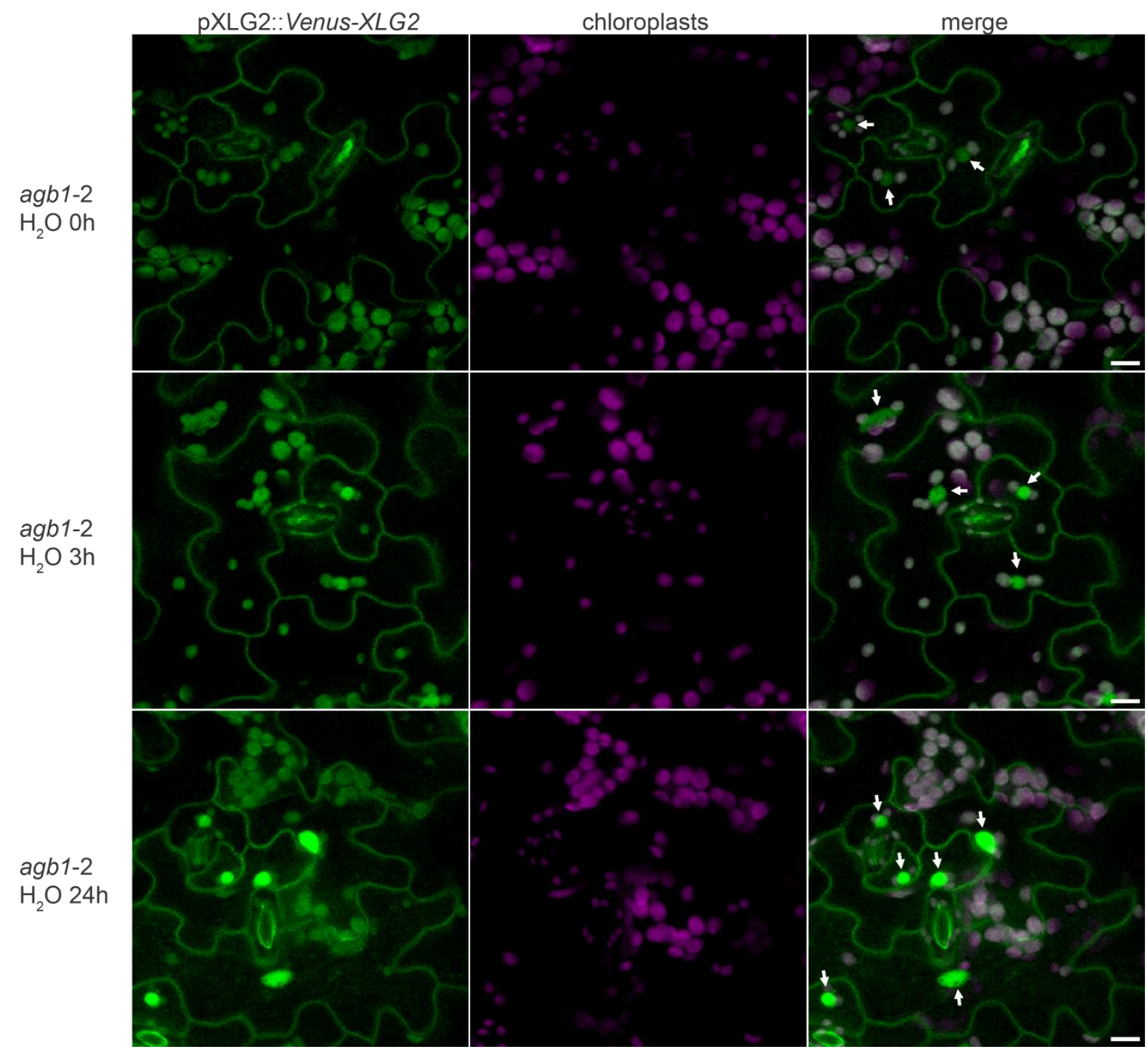

Figure 40. XLG2 is localized to the cell periphery and nucleus in unchallenged and challenged agb1-2 plants. Stably transformed agb1-2 plants expressing Venus-XLG2 from the XLG2 promoter were analyzed by Confocal laser scanning microscopy. Leaf discs were cut out and vacuum-infiltrated with $\mathrm{H}_{2} \mathrm{O}$ using a syringe. Leaf discs were either used for microscopy directly after infiltration or were incubated in $\mathrm{H}_{2} \mathrm{O}$ for the indicated time points. Images represent maximum projections of 10 single focal plane images taken $1 \mu \mathrm{m}$ apart. White arrows denote nuclei. Size bar indicates $10 \mu \mathrm{m}$.

To complement confocal laser scanning microscopy analyses, membrane association of Venus-XLG2 was investigated by immunoblotting. To do so, microsomal fractions were prepared from untreated transgenic plants expressing Venus-XLG2 in the Col-0, agb1-2, Col3 gl1 or cerk1-4 backgrounds. For all genotypes, immunoblot analysis using a GFP antibody revealed the presence of Venus-XLG2 in total extracts and in soluble fractions, but not in microsomal fractions for all genotypes (Figure 41). Since microscopy indicated a plasma membrane localization of Venus-XLG2, the membrane association of Venus-XLG2 might be disrupted by the extraction process. A CERK1 immunoblot was performed using the same samples to validate the identity of the prepared fractions. Full length CERK1 (75 kDa) is 
membrane bound and can only be found in total extracts and microsomal fractions, whereas the CERK1 ectodomain (33 kDa) can be found in total extacts and soluble fractions (Figure 41) (Petutschnig et al., 2014).

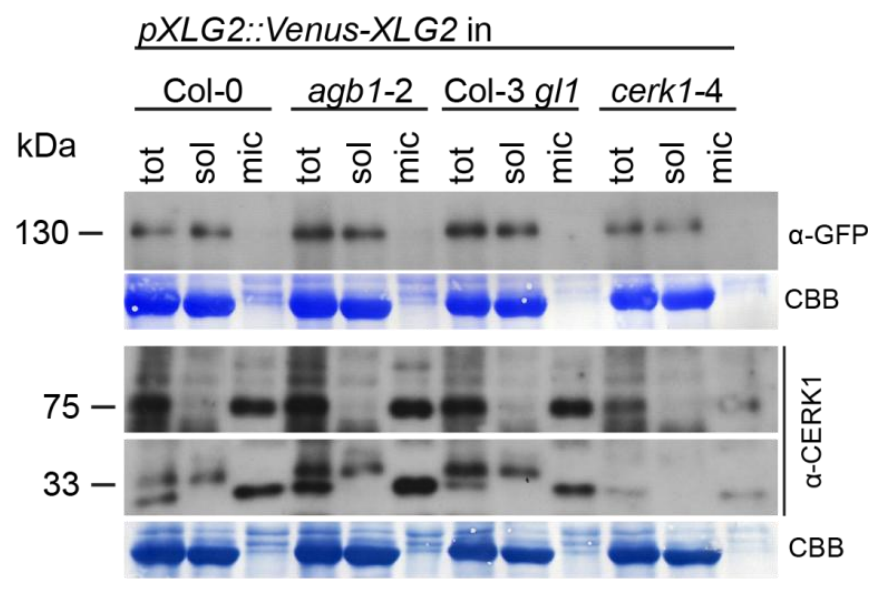

Figure 41. Venus-XLG2 can be found in soluble protein fractions, but not in microsomes. Microsomes were prepared from leaves of transgenic plants expressing Venus-XLG2. Samples were analyzed in immunoblot using a GFP antibody to detect Venus-XLG2 and with a specific CERK1 antibody, to validate microsomal and soluble fractions. Samples which have been used for GFP and CERK1 immunoblot are identical. CBB, Coommassie Brilliant Blue (loading control). Tot, total extracts; sol, soluble; mic, microsomal fraction.

\subsubsection{XLG2 is localized to the nucleus in Bgh attacked and surrounding cells}

The extra-large G-protein XLG2 appears to be a key regulator in cell death execution and is essential for development of the characteristic cerk1-4 phenotype upon Bgh treatment (Marnie Stolze, unpublished, and this study). It was therefore of great interest do study XLG2 localization in Bgh infected plants. Expecially localization of XLG2 in Bgh infected cerk1-4 plants might help deciphering cellular changes that lead to development of the cerk1-4 phenotype.

Transgenic plants expressing pXLG2:: Venus-XLG2 were inoculated with Bgh and analysis by confocal laser scanning microscopy was performed two days after infection (Figure 42). By staining fungal structures with FB28, penetrated cells could easily be detected. Penetrated cells were characterized by an accumulation of Venus-XLG2 fluorescence signal around the penetration site. XLG2 clearly accumulated in the nucleus of cells under Bgh attack. Interestingly, also cells surrounding the penetration site which are not under attack, show localization of XLG2 to the nucleus. This could be observed for Col-0, agb1-2, Col-3 g/1 and cerk1-4 plants. This supports the notion that XLG2 accumulates in nuclei after stress. However, no differences between wild type lines and cerk1-4 could be observed. 


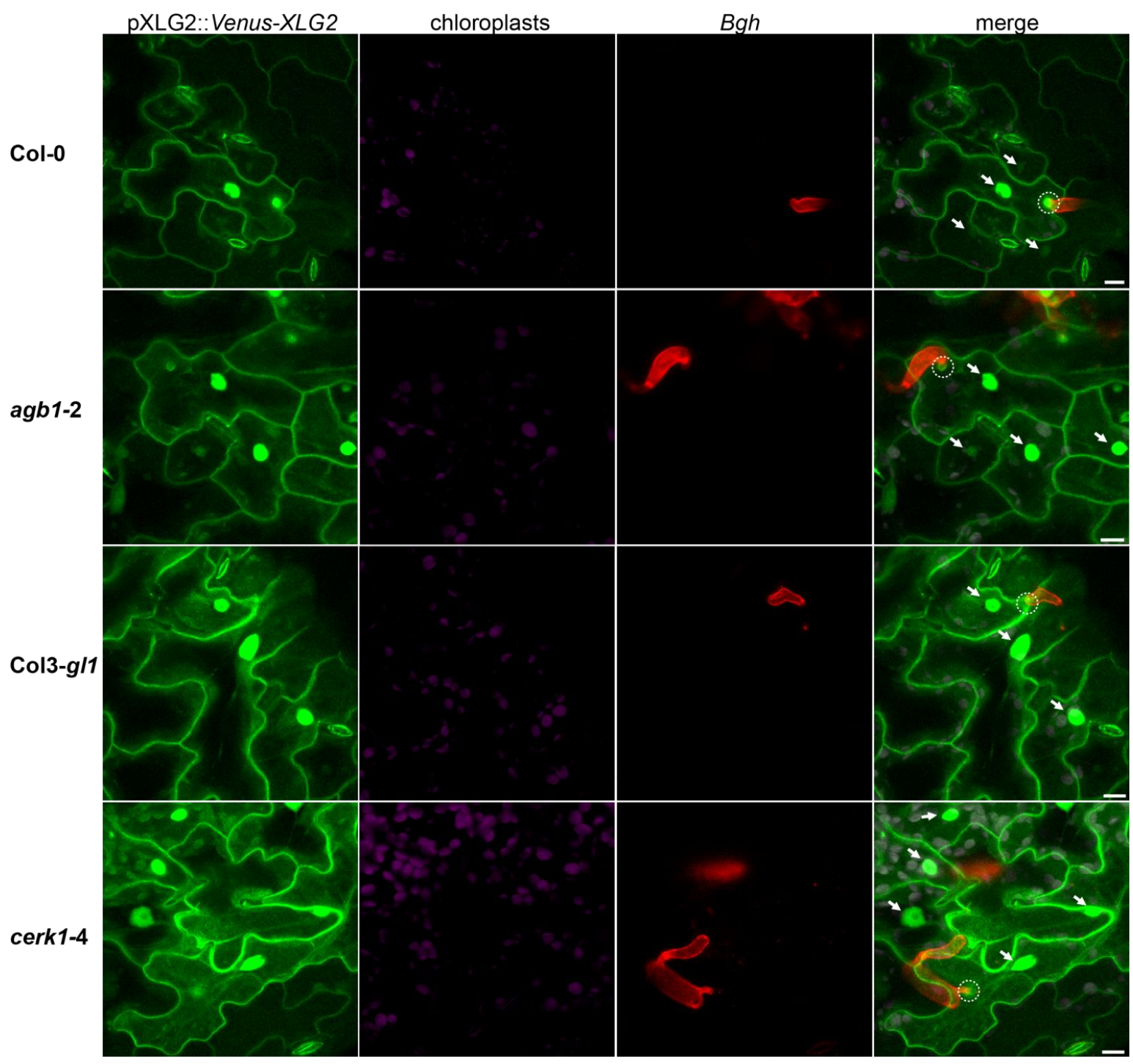

Figure 42. Venus-XLG2 accumulates in nuclei of Bgh-attacked and surrounding cells. Transgenic plants expressing Venus-XLG2 from the XLG2 promoter in Col-0, agb1-2, Col-3 gl1 or cerk1-4 were inoculated with $B g h$. Analysis by confocal laser scanning microscopy was performed two days after infection. Leaf discs were incubated in FB28 for 30 seconds to stain fungal structures. Images represent maximum projections of 10 single focal plane images taken $1 \mu \mathrm{m}$ apart. White arrows denote nuclei. Size bar indicates $10 \mu \mathrm{m}$. 


\section{Discussion}

Ectodomain shedding is a common regulatory mechanism of many membrane-anchored proteins in animals (Hayashida et al., 2010). In plants it has been described only recently for the Arabidopsis receptor-like kinase CERK1 (Petutschnig et al., 2014). A CERK1 mutant (cerk1-4) was isolated which shows altered abundance of the shed ectodomain and enhanced cell death upon pathogen inoculation (Petutschnig et al., 2014). The first part of this study focused on the generation of a non-shedding CERK1 mutant to decipher the function of CERK1 ectodomain shedding and its role in development of the cerk1-4 phenotype.

Extra-large G-proteins (XLGs) are unusual GTPases which can only be found in the plant kingdom (Urano et al., 2013). They play roles in root development, hormone signaling, pathogen resistance and cell death (Ding et al., 2008; Maruta et al., 2015; Pandey et al., 2008; Zhu et al., 2009). A genetic screen to identify components of cerk1-4 cell death execution identified XLG2 as a key regulator (Marnie Stolze, unpublished). The second part of this work focused on identification of a novel XLG2 allele fully suppressing the cerk 1-4 phenotype and the investigation of XLG2 subcellular localization.

\subsection{Analysis of CERK1 ectodomain shedding}

\subsubsection{Prolines within the extracellular stalk of CERK1 modulate the abundance of the CERK1 ectodomain fragment}

In Arabidopsis thaliana Columbia accessions, CERK1 is proteolitically processed to release its ectodomain. cerk1 mutants lacking the soluble ectodomain are characterized by deregulated cell death upon pathogen attack (Petutschnig et al., 2014). Natural variation between Arabidopsis accessions with regard to immune receptor complement is well documented (Gomez-Gomez et al., 1999; Noel et al., 1999; Rose et al., 2004; Zhang et al., 2013).

To investigate if there is also natural variation for CERK1 ectodomain shedding, different Arabidopsis accessions were analyzed with respect to CERK1 ectodomain fragment abundance. All 24 tested accessions showed a signal in immunoblots for the soluble CERK1 ectodomain, but in Mh-1, Rsch-4, Shakdara, Wt-5 and Sorbo, ectodomain levels were reduced compared to Col-0 (Figure 6A). The fact that none of the tested Arabidopsis 
accessions completely lacked the CERK1 ectodomain points to the importance of CERK1 ectodomain shedding.

The reduced CERK1 ectodomain fragment abundance in these five accessions could be due to decreased stability like in the cerk1-4 mutant or it could be the result of decreased shedding. Sequence analysis revealed amino acid changes in the extracellular stalk region of these accessions in comparison to Col-0 (Figure 6B). Especially the proline to alanine substitution in position 221 was regarded as potentially interesting. Prolines are known to disrupt secondary structures (Vanhoof et al., 1995) which can cause structural disorder and may increase protease accessibility (Paetzel et al., 1998). Also, proline-containing motifs play a role in ectodomain shedding of metazoan receptor kinases (Cheng et al., 2003; Thorp et al., 2011; Turk et al., 2001; Yuan et al., 2003). Thus, it seemed possible that the lack of proline 221 caused reduced CERK1 shedding in the five ecotypes with lower ectodomain fragment abundance.

Indeed, $\mathrm{P}^{221}$ was found to be part of several potential EGFR-like cleavage motifs (P/G- $\mathrm{X}_{5-7^{-}}$ $\mathrm{P} / \mathrm{G}$ ) within the extracellular stalk (Figure $8 \mathrm{~A}$ ). This motif is required for ectodomain shedding of EGFR family RTKs in animals (Cheng et al., 2003; Yuan et al., 2003). EGFRs can be shed by ADAMs (Rio et al., 2000) which are not present in plants (Seals \& Courtneidge, 2003). However, the related class of MMP proteases do occur in plants (Maidment et al., 1999) and have been reported to recognize similar motifs to ADAMs (Caescu et al., 2009; Turk et al., 2001).

The amino acid directly $\mathrm{N}$-terminal of $\mathrm{P}^{221}$ is also a proline $\left(\mathrm{P}^{220}\right)$. It is therefore conceivable that the two adjacent prolines at positions 220 and 221 might play redundant roles in CERK1 ectodomain shedding. This would also be an explanation for the fact that the CERK1 ectodomain fragment abundance is reduced in the ecotypes lacking $\mathrm{P}^{221}$, but the fragment is not completely gone. In an attempt to generate a non-shedding CERK1 mutant, both prolines were mutated to alanine (cerk1 cvg1). Alanine is a helix-forming amino acid (Rohl et al., 1999) promoting a secondary structure that possibly interferes with protease accessibility. When this construct was expressed in Arabidopsis plants, the cerk1 cvg1 protein indeed showed lower levels of soluble ectodomain fragment, which is consistent with the idea of prolines being modulators of CERK1 ectodomain shedding. However, the cleaved CERK1 ectodomain was still detectable in cerk1 cvg1, which argues against $P^{220}$ and $P^{221}$ redundantly mediating ectodomain shedding, unless there is another redundant amino acid. In cerk1 cvg1 there is one remaining proline within the extracellular stalk in position 215 . It cannot be ruled out completely that $\mathrm{P}^{215}$ might contribute to ectodomain shedding and be sufficient for the residual ectodomain fragment observed. However, based on mass spectrometry analyses, the size of the ectodomain fragment and a series of domain swap 
constructs the cleavage site is probably close to the or within the transmembrane domain (see section 4.1 .5 below), which starts at amino acid 233 and is relatively far from $\mathrm{P}^{215}$. Also, a CERK1-FLS2 domain swap construct (FLS2TMex3), in which $\mathrm{P}^{215}, \mathrm{P}^{220}$ and $\mathrm{P}^{221}$ are missing, still showed shed ectodomain. In this construct the extracellular stalk and transmembrane domain of CERK1 were replaced with the stalk and transmembrane domain of FLS2. The stalk of FLS2 also contains two proline residues. It is theoretically possible, that these two prolines (or one of them) mediate cleavage (potentially in addition to other sites see section 4.1.5 below), which would suggest that prolines can promote proteolysis in a wide variety of sequence contexts. The fact that prolines have been reported to be modulators of ectodomain shedding in different types of transmembrane proteins supports this idea. For example, the mutation of a proline within the extracellular stalk of human p75 TNF receptor was shown to prevent protein kinase C-mediated ectodomain shedding (Herman \& Chernajovsky, 1998).

Several cerk1 cvg1 expressing lines showed lower overall CERK1 signal in immunoblots than the Col-0 control. It is normal for transgenic lines to show some variation in transgene expression, thus the lower CERK1 abundance could be attributed to this fact. However, immunoblot experiments with cerk1-4 cvg1 expressing plants (also see below) revealed the full length protein to be unstable. This raises the possibility that the cvg1 mutation alone might have a destabilizing effect on the CERK1 ectodomain and that lower ectodomain abundance is not caused by reduced shedding. This is reminiscent of the cerk 1-4 mutation. When present alone, it destabilizes the shed ectodomain (Petutschnig et al., 2014). When combined with another mutation, cerk $1-5$, which likely also destabilizes the ectodomain, the full length cerk1-4 protein appears to become unstable as well. Similar to cerk1-4 plants, cerk1-5 plants also develop the enhanced cell death phenotype. (Petutschnig et al., 2014). The cerk1-4 and cerk1-5 mutation lie in close vicinity within the second LysM domain and might lead to the formation of a degradation product triggering the cell death phenotype, which is not formed in cerk1 cvg1. When a cerk1-4 cerk1-5 double mutant cerk1 variant is expressed in cerk1-2, no full length protein can be detected in immunoblots and transgenic plants do not develop a cerk1-4 phenotype (Petutschnig and Horlacher, unpublished).

\subsubsection{Reduced abundance of the CERK1 ectodomain cannot suppress the cerk1-4 phenotype}

One topic of this work was the influence of CERK1 ectodomain shedding on development of the cerk1-4 phenotype. Since a non-shedding CERK1 variant could not be generated and 
cerk1 cvg1 showed reduced ectodomain fragment abundance, the cerk1 cvg1 mutation was chosen to be combined with the cerk1-4 mutation. Plants expressing cerk1-4 cvg1 strongly resembled cerk1-4 mutants, indicating that the cvg1 mutation can neither suppress the cerk1-4 enhanced cell death phenotype upon pathogen challenge nor the senescence phenotype (Figure 10A, Figura 11A).

Surprisingly, very little cerk1-4 cvg1 protein was detected in immunoblots, even though the plants developed a very clear cerk1-4-like phenotype. The cleaved cerk1-4 ectodomain is likely to be unstable (Petutschnig et al., 2014). One theory to explain the cerk1-4 cell death phenotype is that a degradation product of the shed ectodomain acts as a DAMP and triggers cell death via an unknown receptor. This could also be the case in cerk1-4 cvg1 plants. Very little full length protein might be left, but sufficient amounts of degradation product(s) might still be formed to trigger the cerk1-4 phenotype.

\subsubsection{CERK1 ectodomain shedding cannot be suppressed by mutating potential protease cleavage motifs}

The prolines acting as possible modulators of CERK1 ectodomain shedding were part of potential EGFR cleavage motifs. Additional putative EGFR cleavage motifs within the CERK1 extracellular stalk containing glycines could be found (Figure 8A). Furthermore, sequences with similarities to cleavage motifs of rhomboid proteases were identified within the CERK1 transmembrane domain. Most rhomboid proteases were shown to depend on the presence of helix-relaxing amino acids in the outermost third of their substrate transmembrane domain (N-terminal part of type I transmembrane proteins) (Urban, 2006; Urban \& Freeman, 2003). Also, the presence of small amino acids in this region promotes rhomboid cleavage (Urban \& Freeman, 2003). For example, replacing a glycine with phenylalanine in the outer part of the transmembrane domain could successfully suppress cleavage by Drosophila Rhomboid-1 (Urban \& Freeman, 2003). cerk1 cvg2 and cerk1 cvg3 were designed to harbor amino acid substitutions of helix-relaxing glycines within the $\mathrm{N}$-terminal part of the transmembrane domain and at the same time target putative EGFR cleavage motifs that overlapped with the CERK1 extracellular stalk and transmembrane domain (Figure 8B). Both CERK1 variants exhibited slightly enhanced ectodomain abundance when expressed in Arabidopsis. Thus cerk1 cvg2 and cvg3 mutations certainly did not suppress ectodomain shedding. EGFRs are shed by MMPs and ADAMs (Carey et al., 2005; Rio et al., 2000), the latter of which do not occur in plants (Seals \& Courtneidge, 2003). Other, yet unknown proteases may compensate 
for the lack of ADAMs in plants. These proteases might rely on amino acid sequences completely different from ADAMs.

Apart from EGFR cleavage motifs, cerk1 cvg3 harbored mutations aiming at inhibiting cleavage by rhomboid proteases. For this purpose, the helix-relaxing amino acid glycine was replaced by phenylalanine. The preference of rhomboid protease cleavage towards such helix-relaxing amino acids seems to be rather strict (Urban, 2006; Urban \& Freeman, 2003). This is further supported by ATRBL2, an Arabidopsis rhomboid homologue, which was shown to exhibit a cleavage motif preference similar to its Drosophila counterpart Rho-1 (Kanaoka et al., 2005). Taking this into consideration along with the fact that extracellular and cytoplasmic domains of substrate do not influence rhomboid activity (Urban \& Freeman, 2003) makes it unlikely for CERK1 to be a rhomboid substrate.

Plant ectodomain shedding might resemble animal ectodomain shedding in the sense that proteins can be subject to proteolytic cleavage by not only one, but a variety of proteases (Hayashida et al., 2010). It might be therefore possible that even though in the generated CERK1 mutants actual cleavage motifs were mutated, cleavage motifs for other proteases still existed or were even created. Furthermore, shedding of the CERK1 ectodomain might not occur at a distinct cleavage site, but at a fixed distance from the transmembrane domain, which was also suggested for APP (Sisodia, 1992).

In immunoblots after chitin pull-down, CERK1 often shows multiple bands at around $40 \mathrm{kDa}$ whose exact identity and function is unknown (Figure $8 \mathrm{C}$ ). These multiple bands could potentially be precursors of the cleaved CERK1 ectodomain. In contrast to the CERK1 ectodomain fragment, these bands are membrane-associated and their size suggests that in addition to the ecto- and transmembrane domain they also harbor parts of the intracellular domain. Interestingly, the intracellular juxtamembrane domain of CERK1 harbors potential EGFR cleavage motifs, similar to the extracellular domain (Figure 9A). Such motifs were also found in the intracellular juxtamembrane domains of several rice RLKs (Ding et al., 2009) and phosphorylation of sites flanked by the cleavage motifs was reported to inhibit cleavage of the rice RLK XA21 (Xu et al., 2006). By deleting potential corresponding motifs in CERK1, cerk1 clx aimed at repressing the generation of the $40 \mathrm{kDa}$ fragment group. However, cerk1 clx was neither successful in inhibiting the generation of $40 \mathrm{kDa}$ signals nor did it inhibit generation of the soluble CERK1 ectodomain derivative (Figure 9C). In cerk1 clx immunoblots it seemed like the highest of the multiple bands around $40 \mathrm{kDa}$ was shifted upwards. This could indicate that the cleavage site for generation of this particular $40 \mathrm{kDa}$ fragment was shifted to the C-terminus. However, at present it is not known if the multiple bands around $40 \mathrm{kDa}$ arise from cleavage at multiple, adjacent sites. Alternatively CERK1 might be cleaved in only one position and the different apparent molecular weights might be 
caused by protein modifications such as phosphorylation or differential patterns of glycosylation.

\subsubsection{Reduction of extracellular stalk length cannot suppress CERK1 ectodomain shedding}

Results of mutational analysis of possible CERK1 cleavage motifs revealed that other factors than the sole amino acid sequence might be critical for CERK1 ectodomain shedding. Ectodomain shedding of the transmembrane proteins L-selectin (Migaki et al., 1995), the interleukin 6-receptor (Baran et al., 2013) and the p75 neurotrophin receptor (Weskamp et al., 2004) were reported to depend on the length of their extracellular stalk. Based on these studies CERK1 extracellular stalk deletion constructs were generated (Figure 12A). Shortening the CERK1 extracellular stalk by five amino acids could not repress ectodomain shedding. While for L-selectin deletion of five amino acids was sufficient for inhibition of ectodomain shedding (Migaki et al., 1995), an extracellular stalk deletion of 15 amino acids was required with the p75 TNF receptor (Weskamp et al., 2004). The 15 amino acid deletion left only two amino acids of the extracellular stalk and could successfully repress p75 TNF proteolytic cleavage. It was speculated that long deletions place the ectodomain in close vicinity to the plasma membrane thereby abolishing protease accessibility. Consequently, a CERK1 variant with a deletion of 16 amino acids within the CERK1 extracellular stalk was generated (cerk1 del2). However, when the respective construct was stably expressed in Arabidopsis, none of the transformants contained any cerk1 del2 protein. Long stalk deletions might interfere with proper membrane insertion of CERK1 resulting in protein degradation. Sterical hindrance between ectodomain and plasma membrane or transmembrane domain might also be a reason for cerk1 del2 degradation. Nevertheless, a series of successive deletions of 6 to 15 amino acids might result in a CERK1 variant where the ectodomain is close enough to the plasma membrane to inhibit shedding but does not interfere with protein stability. It would be interesting to address this issue in future experiments.

\subsubsection{The CERK1 extracellular stalk and transmembrane domain are not critical for ectodomain shedding}

In order to narrow down which parts of CERK1 are required for ectodomain shedding, a series CERK1-FLS2 chimeras were generated (Figure 13A). In cerk1 fls2tm, the 
transmembrane domain (TM) of CERK1 was replaced with the TM of FLS2. In cerk1 fls2tmex3, both the TM and extracellular stalk were replaced with the FLS2 counterparts. cerk1 fls2tmex1 and fls2tmex2 variants contained the FLS2 transmembrane domain and a composite extracellular stalk with elements from CERK1 as well as FLS2. None of these domain swaps could suppress ectodomain shedding of CERK1 in Nicotiana benthamiana. The CERK1-FLS2 chimera cerk1 fls2tm and cerk1 fls2tmex1 were also stably transformed into Arabidopsis thaliana where the corresponding transgenic proteins still showed ectodomain shedding.

The fact that the cleaved CERK1 ectodomain is soluble (Petutschnig et al., 2014) implicates that cleavage occurs within the extracellular stalk or transmembrane domain. The cerk1 fls2tmex variant contained the complete FLS2 transmembrane domain and extracellular stalk and still underwent ectodomain shedding. Thus, the cleavage must have occurred within the FLS2 sequences and CERK1 ectodomain shedding obviously does neither depend on the CERK1 transmembrane domain nor on the CERK1 extracellular stalk. Consequently, the FLS2 sequences which were introduced into CERK1 must meet the structural and/or sequence criteria for ectodomain shedding. This suggests that FLS2 might also be subject to ectodomain shedding. Peptides corresponding to the extracellular domains of several LRRRLKs could be found in the supernatants of cell cultures (see section 4.1.6) further supporting the possibility of FLS2 being subject to ectodomain shedding.

The chimeras cerk1 fls2tmex1 and cerk1 fls2tmex3 have longer extracellular stalks than CERK1 and accordingly showed a bigger signal for the full length receptor than wild type CERK1 (Figure 13B). Interestingly, the cerk1 fls2tmex1 and cerk1 fls2tmex3 ectodomain fragments differed markedly in size. The shed cerk1 fl2tmex1 ectodomain was discernibly bigger than in the wild type, which was expected. However, it appeared as a double band. In contrast, the size of cerk1 fls2tmex 3 ectodomain fragment was comparable to the shed ectodomain of wild type CERK1. This implies an N-terminal shift of the cleavage site in cerk1 fls2tmex3. The fact that the cerk1 fl2tmex1 ectodomain fragment appeared as a double band suggests that this new cleavage site might also be present in cerk 1 fls2tmex 3 , likely in addition to a more C-terminal site. Additionally, mutation or deletion of a shared KS motif found in all CERK1 FLS2 chimeric constructs did not abolish ectodomain shedding (Figure 15B). All in all, the data indicate that ectodomain shedding is not dependent on a specific sequence or motif within the TM or extracellular stalk.

The three LysM domains of CERK1 might be of importance for ectodomain shedding. Ectodomain shedding of the angiotensin converting enzyme (ACE) was reported to depend on an N-terminal (distal) part of its ectodomain (Sadhukhan et al., 1998). ACE and CD4 are transmembrane proteins, of which ACE is subject to ectodomain shedding and CD4 is not. 
Chimeras of the distal ACE ectodomain with the extracellular stalk and transmembrane domain of CD4 were shed within the CD4 sequence. Combining the distal ectdomain of CD4 with the juxtamembrane and transmembrane domain of ACE did not lead to ectodomain shedding (Sadhukhan et al., 1998). The extracellular domain of CERK1 or one of its three LysM domains might be critical for interaction with a protease which is involved in proteolytic cleavage of the CERK1 ectodomain, whereas the amino acid sequence of the extracellular stalk and transmembrane domain appear to be of minor importance.

\subsubsection{The extracellular domain of many RLKs is proteolytically processed}

The analysis of Arabidopsis cell culture supernatants and apoplastic wash fluids from leaves by mass spectrometry revealed the presence of peptides corresponding to the extracellular domains of numerous receptor-like kinases (Figure 16). The exon structure of many of those RLKs excludes the possibility of the extracellular domain being generated by alternative splicing. This suggests that many RLKs in addition to CERK1 may undergo ectodomain shedding. LRR-RLKs were the biggest group of RLKs found in the cell culture supernatants and apoplastic wash fluids. Based on the fact that LRR-RLKs are the largest family of RLKs in Arabidopsis (Shiu \& Bleecker, 2001), this could be expected. Even though FLS2 is not among the identified LRR-RLKs, its ectodomain domain might also be released. This might explain why the CERK1-FLS2 chimeras were still subject to ectodomain shedding. Interestingly, some types of RLKs appeared to be enriched in the cell culture supernatant and apoplastic wash fluid samples. Arabidopsis contains four LRR-RLKs of the TMK family (Dai et al., 2013), of which three were detected in this study. The remaining one (TMK2) is only expressed in reproductive organs (Dai et al., 2013) and thus was probably not present in the samples investigated. TMKs contain two extracellular LRR-domains that are linked by a hinge domain (Liu et al., 2013b). The peptides identified mapped to the entire ectodomains of the TMKs, indicating that they are subject to ectodomain shedding and not cleavage between extracellular subdomains (Figure 17A). The exon structure precludes alternative splicing as the source of soluble TMK forms, thus it is highly likely that the entire TMK family undergoes ectodomain shedding. Interestingly, TMK1 was found as a putative interactor of CERK1 in a yeast two hybrid screen (Lipka, unpublished). CERK1 and LYK5 were also detected in this study, confirming previous results (Petutschnig et al., 2014). It is tempting to speculate that TMKs and LysM-RLKs interact and might undergo ectodomain shedding together.

Also, many RLKs were found that contain malectin-like domains in their extracellular domains. The Malectin-LRR-RLK SYMRK is required for symbiosis in Lotus japonicus. 
SYMRK releases its malectin-like domain and this process depends on the presence of a GDPC motif (Antolín-Llovera et al., 2014). In the supernatant of cell cultures three MalectinLRR-RLKs could be found. Like SYMRK, they also harbor a GDPC motif within their extracellular domain (Figure 17B). Only peptides N-terminal to this GDPC motif were found indicating that the malectin-like domain is released in a process similar to SYMRK. However, as cleavage via the GDPC motif does not occur in close vicinity to the transmembrane domain, this process is not referred to as ectodomain shedding (Antolín-Llovera et al., 2014). Malectin cleavage of SYMRK enhances its interaction with the LysM-RLK NFR5 (AntolínLlovera et al., 2014). Some Arabidopsis Malectin-LRR-RLKs might also interact with LysMRLKs such as CERK1 and the proteolytic processing might modulate the interaction.

Comparable to cell culture supernatants, numerous peptides corresponding to the extracellular domains of RLKs including Malectin-LRR-RLKs were found in apoplastic wash fluids (Figure 20). In contrast to cell culture supernatants, single peptides C-terminal to the characteristic Malectin-LRR-RLK GDPC motif were found. Moreover, also few peptides corresponding to intracellular domains could be identified. These peptides probably derive from wounded plant tissue which is a consequence of the preparation method.

Table 12. RLKs identified in cell wall proteome studies. RLKs marked with an asterisk were also found in cell culture supernatants and/or apoplastic wash fluids.

\begin{tabular}{|c|c|c|}
\hline Material & Identified RLKs & Reference \\
\hline $\begin{array}{l}\text { Cell suspension } \\
\text { cultures }\end{array}$ & $\begin{array}{l}(\mathrm{LRR}-\mathrm{RLK})-\text { AT3G08680 } \\
(\mathrm{LRR}-\mathrm{RLK})-\text { AT3G02880* } \\
(\mathrm{LRR}-\mathrm{RLK})-\text { AT2G01210 } \\
(\mathrm{LRR}-\mathrm{RLK})-\text { AT2G01820 - TMK3* } \\
(\mathrm{LRR}-\mathrm{RLK})-\text { AT3G51740 } \\
(\mathrm{LRR}-\mathrm{RLK})-\text { AT5G16590 - LRR1* } \\
(\mathrm{LRR}-\mathrm{RLK})-\text { AT2G16250 }\end{array}$ & Bayer et al. (2006) \\
\hline Etiolated hypocotyls & $\begin{array}{l}(\mathrm{LRR}-\mathrm{RLK}) \text { - AT3G02880* } \\
(\mathrm{LRR}-\mathrm{RLK})-\mathrm{AT} 5 \mathrm{G} 16590 \text { - LRR1* }\end{array}$ & Zhang et al. (2011) \\
\hline Etiolated hypocotyls & $($ LRR - RLK) - AT2G29000 & Feiz et al. (2006) \\
\hline Roots & $\begin{array}{l}(\text { LRR - RLK) - AT3G02880* } \\
(\text { LRR - RLK) - AT3G17840 - RLK902* } \\
(\text { LRR - RLK) - AT3G28450 } \\
\text { (LRR - RLK) - AT5G37450 } \\
\text { (Malectin - LRR - RLK) - AT2G14510 } \\
\text { (Malectin - LRR - RLK) - AT1G51850* } \\
\text { (Malectin - LRR - RLK) - AT1G51890 } \\
\text { (Malectin - LRR - RLK) - AT2G28990 } \\
\text { (Malectin - LRR - RLK) - AT5G59680* }\end{array}$ & Nguyen-Kim et al. (2016) \\
\hline
\end{tabular}


RLKs could also be identified in studies analyzing the cell wall proteome. These RLKs belong to the group of LRR-RLKs and Malectin-LRR-RLKs, some of which could also be found in the present study (Table 12). However, the degree of contamination of the cell wall preparations and to which part of the RLKs the identified peptides match is not known. Nevertheless, these results add further evidence to the hypothesis that proteolytic processing of extracellular domains is a more widespread phenomenon in Arabidopsis than previously known.

\subsubsection{Possible function of CERK1 ectodomain shedding}

The function of ectodomain shedding in many animal RTKs is to reduce the amount of functional receptors on the cellular surface upon ligand binding (Chen \& Hung, 2015). Proteolytic cleavage of the extracellular domain is often followed by intramembrane proteolysis to release the intracellular domain which can be transported to the nucleus. For example, the intracellular domain of erbB4/Her-4 translocates into the nucleus after being released from the plasma membrane by $\mathrm{Y}$-secretase cleavage (Jones, 2008). In the nucleus it acts as a transcriptional co-activator and is involved in regulation of growth and differentiation of breast epithelium cells. Since CERK1 ectodomain shedding is chitinindependent, it is likely not involved in chitin signaling into the cell (Petutschnig et al., 2014). Moreover, confocal microscopy of plants expressing CERK1-GFP fusions could not detect a signal within the nucleus (Erwig et al., unpublished; Petutschnig et al., 2014). Therefore, the function of CERK1 ectodomain shedding is probably different from erbB4/Her-4 ectodomain shedding. CERK1 is thought to form a chitin induced complex with the LysM-RLK LYK5 (Cao et al., 2014). Proteolytic cleavage of the CERK1 ectodomain might be a prerequisite for separation of the receptor complex components. In this scenario CERK1 would remain at the plasma membrane, while LYK5 is removed from the plasma membrane via endocytosis (Erwig et al., unpublished).

CERK1 ectodomain shedding was shown to be upregulated upon pathogen attack (Petutschnig et al., 2014). Thus it seems conceivable that the released ectodomain binds chitin fragments within the extracellular space to prevent excessive receptor activation. The CERK1 ectodomain might also function as extracellular decoy. Pathogens secrete a variety of effectors in the plant apoplast (Jashni et al., 2015). These effectors include proteases which might then target the CERK1 ectodomain instead of the full length plasma membrane bound receptor. Development of the cerk1-4 phenotype was hypothesized to be triggered by degradation product(s) of the cerk1-4 ectodomain (Petutschnig et al., 2014) which could 
activate DAMP signaling. In analogy to this, degradation of the wild type decoy CERK1 ectodomain by pathogenic effector proteases might also lead to the generation of degradation products which initiate DAMP signaling.

\subsubsection{Conclusion}

The findings of the present study could not reveal the sequence determinants or structurally relevant elements for CERK1 ectodomain shedding. Different approaches to generate nonshedding CERK1 mutants failed. This prevented investigation of the function of CERK1 ectodomain shedding and its involvement in generation of the cerk1-4 phenotype. A nonshedding CERK1 would be required to investigate these topics.

The underlying mechanism and responsible proteases of CERK1 ectodomain shedding remain unclear. Mutation of potential protease cleavage motifs, deletion and domain swap mutants point to a rather relaxed sequence specificity of the responsible protease or participation of several proteases in this process. CERK1 FLS2 chimeras further raise the possibility of the three LysM domains to be the critical for ectodomain shedding and the amino acid sequence to be of secondary importance. The amount of ectodomain could be modulated by modifications within the CERK1 extracellular stalk. Prolines within the extracellular stalk were found to be possibly important for structural integrity of the ectodomain. Reducing the abundance of CERK1 ectodomain by mutating these prolines could not suppress the cerk1-4 phenotype.

Mass spectrometry analysis of cell culture supernatants revealed the presence of peptides corresponding to the extracellular domains of numerous RLKs suggesting that not only CERK1 but several RLKs are subject to ectodomain shedding.

\subsubsection{Outlook}

This study could not reveal the mechanism and function of CERK1 ectodomain shedding. To decipher the function of CERK1 ectodomain shedding, a non-shedding CERK1 variant will be required. In this work, deletions of five amino acids within the extracellular stalk did not suppress CERK1 ectodomain shedding, while deletions of 16 amino acids led to structural instability of the protein. Intermediate deletion mutants might be successful in inhibiting ectodomain shedding. To test if the CERK1 LysM domains are critical for CERK1 ectdomain shedding, the CERK1 ectodomain could be replaced by the ectodomain of another RLK (e.g. 
FLS2) and tested for ectodomain shedding. However, this would require an antibody for the respective ectodomain.

An alternative approach would be identification of the shedding protease. In animals, receptor kinases are shed by MMPs and ADAMs (Chen \& Hung, 2015), the latter of which are not present in plants (Seals \& Courtneidge, 2003). Preliminary studies with multiple Arabidopsis MMP mutants suggest that CERK1 ectodomain shedding is not MMP-dependent (Stolze, unpublished). Rhomboids could act as sheddases on CERK1. However, mutation of a putative rhomboid motif argues against this. Also rhomboids are a large family of proteases in Arabidopsis, making a reverse genetics approach not feasible. In animals, many proteins are cleaved by $\mathrm{Y}$-secretase after ectodomain shedding. A recent study revealed the presence of a putative $\mathrm{Y}$-secretase complex in Arabidopsis (Smolarkiewicz et al., 2014). All components of the complex were shown to be expressed in leaves. T-DNA knockout mutants of components of the $Y$-secretase complex could be investigated. The fate of the C-terminal CERK1 fragment in these mutants would be of particular interest and could be investigated using C-terminally tagged CERK1 constructs. Moreover, expression of cerk1-4 would reveal if the development of the cerk1-4 phenotype is dependent on $\mathrm{y}$-secretase processing.

In plants, research on proteolytic processing of plasma membrane localized receptors is only in its infancies and much work will be required in the future to elucidate the underlying mechanisms and, importantly, the functional implications.

\subsection{Analysis of nole1-2 and XLG2 subcellular localization}

\subsubsection{XLG2 is a key regulator of cerk1-4 cell death execution}

A cerk1-4 suppressing mutant was identified in the present study. The causal mutation was mapped to the N-terminal part of XLG2, where a glutamic acid (E) was replaced by a lysine $(K)$ in a highly conserved region (Figure 26). Based on immunoblot analysis of xlg2 E293K expressing plants suppression of the cerk1-4 phenotype is probably not caused by reduced protein stability. However, the function of XLG2 may be disturbed by replacement of negatively charged glutamic acid with positively charged lysine. Recently, xlg2 and agb1 single, as well as agg1 agg2 double mutants were reported to suppress the cell death phenotype of a BIR1 mutant (bir1-1) (Liu et al., 2013a; Maruta et al., 2015). These results suggest that XLG2 together with Gyß-dimers can act in receptor-like kinase mediated cell death regulation. $x \lg 2 \mathrm{E} 293 \mathrm{~K}$ might be disturbed in perceiving or transducing signals within these pathways. However, findings from our laboratory (Elena Petutschnig, unpublished) 
showed that agb1 single and agg1 agg2 double mutants cannot fully suppress the cerk1-4 phenotype. This indicates that XLG2 acts independently from Gßy-dimers in cerk1-4 mediated cell death and that CERK1 and BIR1 mediate different cell death pathways. Furthermore, these results exclude the possibility that cerk1-4 suppression in nole1-2 mutants is caused by disturbed interaction with AGB1.

The N-terminal domain of XLG2 harbors a region of regularly spaced cysteines (Figure 26B). (Ding et al., 2008), whose function is unclear. These cysteines resemble zinc-finger domains which are implicated in protein-DNA interactions (Leon \& Roth, 2000) suggesting that XLG2 might act as transcriptional regulator. As the nole1-2 mutation is in close vicinity to the cysteine rich domain, it might disturb XLG2 DNA binding. This is further supported by the fact that XLG2 is localized to the nucleus upon stimulus (Chapter 3.2.5.2).

Although a function as direct transcriptional regulator has to be confirmed, XLG2 was already shown to exhibit functions within the nucleus, where it was shown to promote the activation of the DNA binding protein RELATED TO VERNALIZATION 1 (RTV1) (Heo et al., 2012). Apart from DNA binding, regularly spaced cysteines can also be involved in formation of disulphide bridges. One of the key regulators of SA signaling, NON-EXPRESSOR OF PR1 (NPR1), was shown to form intermolecular disulphide bridges which result in oligomer formation (Mou et al., 2003). Salicylic acid (SA) induced cellular redox changes lead to reduction of intermolecular disulphide bridges and NPR1 monomer formation. NPR1 monomers then accumulate in the nucleus and activate expression of PR1.

\subsubsection{XLG2 localization is stimulus dependent}

Previous studies on XLG2 localization were performed using the strong 35S or UBIQUITIN10 promoter (Chakravorty et al., 2015; Ding et al., 2008; Maruta et al., 2015). In the present study, XLG2 localization was re-assessed using fluorescently labeled XLG2 under control of the endogenous XLG2 promoter. In a first approach, the C-terminus of XLG2 was chosen for fusion of GFP. Expression of XLG2 constructs in the nole1-1 cerk1-4 or nole1-2 cerk1-4 background provides the possibility to assess functionality of XLG2 constructs. Only functional constructs can restore the cerk1-4 phenotype in these mutant backgrounds. Expression of XLG2-GFP in nole1-1 cerk1-4 could not restore the cerk1-4 phenotype and revealed this construct not to be functional (Figure 29). Previous studies encountered problems with protein accumulation even when expressing XLG2-GFP under control of the $35 \mathrm{~S}$ promoter (Zhu et al., 2009). However, as a signal in immunoblot and confocal microscopy could be detected (Figure 28) compromised protein stability may not be the 
reason for missing functionality in the present study. On the contrary, a scenario is more likely in which other factors are responsible for functional insufficiency. In this context, it is important to note that one amino acid substitution within the GTPase domain

of XLG2 was sufficient to abolish in vitro GTP binding capacity and to block interaction with downstream targets (xlg2 T476N, falsely denoted as T475N) (Heo et al., 2012). Thus, fusion of GFP to the C-terminus might cause GTP binding problems similar to the $x / g 2 \mathrm{~T} 476 \mathrm{~N}$ mutant and therefore might not be functional. As the C-terminus of XLG2 was found not to be suitable for fluorescent tag fusions, an N-terminal XLG2 fusion with the fluorescent protein Venus was generated. Venus-XLG2 restored the cerk1-4 phenotype in nole1-1 cerk1-4 and was therefore considered functional. Studies using this construct in Arabidopsis thaliana showed localization to the cell periphery in Col-0, Col-3 gl1 and cerk1-4. Considering previous studies, which reported nuclear localization for XLG2, this was surprising (Maruta et al., 2015). After infiltration of $\mathrm{H}_{2} \mathrm{O}$ however, nucleus localization became visible after three hours in all genotypes (Figure 34, Figure 38, Figure 39). The same held true for chitin and flg22 infiltration, as well as wounding in Col-0 plants (Figure 35, Figure 36, Figure 37). As XLGs were found to be involved in responses to osmotic stress, hormones and pathogens (Ding et al., 2008; Maruta et al., 2015; Zhu et al., 2009) it seems conceivable that XLG2 changes its localization pattern, when stress and/or defense responses are activated. Overexpression of XLG2 might be the cause for the results of previous studies, which reported XLG2 to be localized to the plasma membrane and nucleus even in untreated cells (Maruta et al., 2015). As overexpression of XLG2 leads to the accumulation of abnormal defense related transcripts (Zhu et al., 2009), it might also induce cellular defense responses which lead to XLG2 translocation into the nucleus.

In contrast to the canonical $\alpha$-subunit GPA1, XLG2 does not possess a motif or domain for plasma membrane targeting (Adjobo-Hermans et al., 2006; Urano et al., 2013). It probably relies on interaction with other proteins, such as the Gßy-dimer, for plasma membrane tethering. The amount of interaction partners in XLG2 overexpressing lines might not be sufficient to sequester all XLG2 molecules to the plasma membrane. Unbound XLG2 proteins are then localized to the nucleus. In the opposite case, overexpression of G $\beta$ Ydimers in Nicotiana benthamiana sequestered XLG3 to the plasma membrane, which can be normally found in nuclei and the plasma membrane (Chakravorty et al., 2015).

In agb1 mutant plants, XLG2 was localized to the cell periphery and the nucleus even in unchallenged plants (Figure 40). Nuclear localization of XLG2 might be caused by a lack of interaction partners at the plasma membrane. However, the question remains how XLG2 is tethered to the membrane in agb1 mutants. XLG2 was shown to interact with AGB1, but interaction with $A G G 1$ and AGG2 remains controversial (Chakravorty et al., 2015; Maruta et 
al., 2015; Zhu et al., 2009). XLG2 might indeed be capable to directly interact with Gysubunits or other proteins involved in G-protein signaling like AtRGS1. However, it is not known whether XLG2 is constitutively GTP bound like the canonical $\alpha$-subunit GPA1 (Johnston et al., 2007). It might therefore rely on activation by a yet unidentified GPCR which might be, at least partially, responsible for plasma membrane localization of XLG2.

To confirm plasma membrane localization of XLG2, microsomal fractions of untreated Venus-XLG2 expressing lines in the Col-0, agb1-2, Col-3 gl1 and cerk1-4 background were prepared (Figure 41). Immunoblot analysis using a CERK1 antibody confirmed integrity of the prepared fractions, as full length CERK1 was only detectable in total and microsomal fractions, while the CERK1 ectodomain was present in total and soluble fractions. Anti-GFP immunoblot revealed the presence of Venus-XLG2 in total and soluble fractions, but not in microsomal fractions for all genotypes. This was surprising, as plasma membrane localization of XLG2 could be confirmed by heterologous expression in Nicotiana benthamiana (Figure 31) and was reported in previous studies (Maruta et al., 2015). However, as XLG2 is no integral transmembrane protein and probably only localized to the plasma membrane via protein-protein interaction, microsomal fractionation might be too harsh to retain XLG2 in microsomal fractions. Microsomal fractionation involves ultracentrifugation steps that might cause dissociation of XLG2 from its interaction partner. This is probably the reason, why Venus-XLG2 can only be found in total and soluble, but not in microsomal fractions.

Co-localization studies using Venus-XLG2 and plasma membrane, cytosolic and nuclear marker, respectively, in Nicotiana benthamiana were performed in this study. In contrast to XLG2 localization in Arabidopsis, XLG2 localization studies in $N$. benthamiana confirmed previous studies (Figure 30, Figure 31, Figure 32) (Chakravorty et al., 2015; Maruta et al., 2015). However, under the already mentioned circumstances that XLG2 does not have any motif or domain for plasma membrane localization, it has to interact with other proteins like $\mathrm{G} \beta Y$ dimers. Components from Arabidopsis thaliana which are responsible for XLG2 membrane tethering are absent from $N$. benthamiana indicating that XLG2 interacts with $N$. benthamiana proteins for membrane localization. However, Agrobacterium infiltration into leaves of $N$. benthamiana might, comparable to $\mathrm{H}_{2} \mathrm{O}$, chitin or flg22 infiltration in Arabidopsis, induce defense responses. Induction of defense responses does then, similar to Arabidopsis, lead to translocation of XLG2 to the nucleus. 


\subsubsection{XLG2 localization in Bgh-infected cerk1-4 plants does not differ from wild type plants}

The mechanism how XLG2 is involved in execution of cell death in cerk1-4 plants upon Bgh infection is unknown. In wild type plants, cell death upon Bgh infection is restricted to single cells, whereas in cerk1-4, a deregulated cell death response leads to cell death of surrounding tissue (Petutschnig et al., 2014). It was therefore of great interest to investigate the role of XLG2 in this deregulated cell death response. Two days after inoculation, VenusXLG2 was localized to the nucleus in cells which were under fungal attack (Figure 42). Furthermore, cells surrounding those attack sites also accumulated XLG2 in the nucleus. This could be observed for all tested genotypes with no obvious differences. The expected scenario of deregulated cell death in cerk1-4 included massive nuclear accumulation of XLG2 in attacked cells which then spreads throughout the tissue. However, nuclear XLG2 accumulation in cerk1-4 was not stronger than in wild type plants. Therefore, the cerk1-4 phenotype is probably not caused by upregulation and accumulation of XLG2 within the nucleus. Previous studies overexpressing either untagged or tagged XLG2 did not report cell death phenotypes, suggesting that overexpression of XLG2 alone is not sufficient to confer cell death phenotype (Heo et al., 2012; Maruta et al., 2015). As already mentioned, XLG2 was shown to function as an indirect transcriptional regulator (Heo et al., 2012) and might also function as direct transcriptional regulator. In cerk1-4 plants, Bgh attacked cells might translocate XLG2 into the nucleus, where it constitutively activates target genes. Since the cerk1-4 phenotype is characterized by high levels of SA (Petutschnig et al., 2014), XLG2 might be involved in activation of genes involved in SA synthesis or signaling. This notion is further supported by the fact that upon bacterial infection, induction of the SA-responsive gene PR1 in xlg2 mutants is significantly reduced (Zhu et al., 2009).

\subsubsection{Conclusion}

A novel mutant fully suppressing the cerk1-4 phenotype was identified. The underlying mutation was mapped to the N-terminal part of the extra-large G-protein XLG2 where a glutamic acid was replaced by lysine. This glutamic acid is highly conserved from mosses to flowering plants. The investigation of the subcellular localization of XLG2 was contradictory to previous studies. XLG2 localization in untreated plants could be observed at the cell periphery, while upon stimulus, XLG2 was localized to the nucleus. In knockout plants of the Arabidopsis G-protein $\beta$-subunit (AGB1), XLG2 was localized to the nucleus already in 
unstimulated cells. Further investigation of Bgh inoculated plants revealed no difference between cerk1-4 and wild type plants.

\subsubsection{Outlook}

The present study identified XLG2 to be a key regulator of cell death downstream of CERK1. A mutation within the N-terminal part of XLG2 could fully suppress the cell death phenotype of cerk1-4. In order to get further insights into the mechanism of cerk1-4 suppression by nole1-2, the function of the N-terminal part of XLG2 has to be elucidated. To test if cysteine rich region of XLG2 is able to bind DNA, electrophoretic mobility shift assays (EMSA) could be performed. If no non-specific DNA binding can be observed, XLG2 target genes could be identified by chromatin immunoprecipitation with subsequent sequencing (ChIP-Seq). Mutational analysis of the regularly spaced cysteines would then provide information whether this region is critical for DNA binding. Expression of these mutants in nole1-1 cerk1-4 or nole1-2 cerk1-4 would reveal if XLG2 DNA binding is critical for development of the cerk1-4 phenotype. The question whether the XLG2 cysteine-rich region forms disulphide bridges and exhibits differences to $x \lg 2 \mathrm{E} 293 \mathrm{~K}$ could be answered with methods to display the redox status of the examined protein (Rudyk \& Eaton, 2014). Reduced thiol groups are blocked and remaining oxidized thiol groups are reduced and labeled. Labels of relatively large size induce band shifts in immunoblots and can be used to investigate differences in redox levels. It would further be interesting to know if nuclear localization of XLG2 is a prerequisite for development of the cerk1-4 phenotype. Therefore, the noncanonical NLS of XLG2 (KKRAKIACAVF) (Chakravorty et al., 2015) could be mutated to exclude nuclear localization. In this context, the addition of a second NLS could shift XLG2 localization completely to the nucleus and might answer the question if localization to both, cytoplasmic and plasma membrane is critical for cerk1-4 phenotype development. It would be further interesting to perform pathogen assays with nole 1-2 plants, to see if they exhibit enhanced susceptibility to bacterial and necrotrophic fungal pathogens comparable to xlg2 mutants.

In order to microscopically validate the localization of XLG2 in Arabidopsis thaliana, it will be essential to generate transgenic lines co-expressing Venus-XLG2 together with marker constructs for plasma membrane, nuclear and cytosolic localization.

In contrast to microsomal preparation, nuclear fractionation should be suitable to confirm nuclear localization of XLG2. Comparison of infiltrated versus uninfiltrated tissue could confirm that XLG2 nuclear localization is stimulus dependent.

The expression of Venus-XLG2 in single Gy-subunit mutants and in G $\beta y$ higher order 
mutants could reveal which G-protein components are involved in XLG2 localization.

To correlate XLG2 localization with cellular SA levels in treated and untreated cells, transgenic Venus-XLG2 lines should be crossed with SA reporter lines of the Colorful system developed in our laboratory (Hassan Ghareeb, unpublished). They consist of a fluorescence protein which is expressed under control of hormone responsive promoters. These are combined with a plasma membrane marker and a normalizer and allow quantification of hormonal levels.

Taken together, the mechanism of cell death execution mediated by XLG2 is unknown. The nole1-1 cerk1-4 and nole1-2 cerk1-4 mutants offer the unique possibility, to decipher the functions of XLG2 on a molecular level and will provide further insights into XLG2 mediated cell death execution. 


\section{References}

Adam Z. (2013) Emerging roles for diverse intramembrane proteases in plant biology. Biochimica et biophysica acta, 1828, 2933-2936.

Adjobo-Hermans M.J.W., Goedhart J., Gadella T.W.J. (2006) Plant G protein heterotrimers require dual lipidation motifs of Galpha and Ggamma and do not dissociate upon activation. Journal of cell science, 119, 5087-5097.

Antolín-Llovera M., Ried M.K., Binder A., Parniske M. (2012) Receptor kinase signaling pathways in plant-microbe interactions. Annual review of phytopathology, 50, 451-473.

Antolín-Llovera M., Ried M.K., Parniske M. (2014) Cleavage of the SYMBIOSIS RECEPTOR-LIKE KINASE ectodomain promotes complex formation with Nod factor receptor 5. Current biology CB, 24, 422-427.

Ao Y., Li Z., Feng D., Xiong F., Liu J., Li J.-F., Wang M., Wang J., Liu B., Wang H.-B. (2014) OsCERK1 and OsRLCK176 play important roles in peptidoglycan and chitin signaling in rice innate immunity. The Plant journal for cell and molecular biology, 80, 1072-1084.

Arribas J., Borroto A. (2002) Protein Ectodomain Shedding. Chem. Rev., 102, 4627-4638.

Aster J.C., Pear W.S., Blacklow S.C. (2008) Notch signaling in leukemia. Annual review of pathology, 3, 587-613.

Axtell M.J., Staskawicz B.J. (2003) Initiation of RPS2-Specified Disease Resistance in Arabidopsis Is Coupled to the AvrRpt2-Directed Elimination of RIN4. Cell, 112, 369-377.

Baran P., Nitz R., Grötzinger J., Scheller J., Garbers C. (2013) Minimal interleukin 6 (IL-6) receptor stalk composition for IL-6 receptor shedding and IL-6 classic signaling. The Journal of biological chemistry, 288, 14756-14768.

Bayer E.M., Bottrill A.R., Walshaw J., Vigouroux M., Naldrett M.J., Thomas C.L., Maule A.J. (2006) Arabidopsis cell wall proteome defined using multidimensional protein identification technology. Proteomics, 6, 301-311.

Birnboim H.C., Doly J. (1979) A rapid alkaline extraction procedure for screening recombinant plasmid DNA. Nucleic acids research, 7, 1513-1523.

Blobel C.P. (2005) ADAMs: key components in EGFR signalling and development. Nature reviews. Molecular cell biology, 6, 32-43.

Boller T., Felix G. (2009) A renaissance of elicitors: perception of microbe-associated molecular patterns and danger signals by pattern-recognition receptors. Annual review of plant biology, 60, 379-406.

Bozkulak E.C., Weinmaster G. (2009) Selective use of ADAM10 and ADAM17 in activation of Notch1 signaling. Molecular and cellular biology, 29, 5679-5695. 
Brachmann C.B., Davies A., Cost G.J., Caputo E., Li J., Hieter P., Boeke J.D. (1998) Designer deletion strains derived from Saccharomyces cerevisiae S288C: a useful set of strains and plasmids for PCR-mediated gene disruption and other applications. Yeast (Chichester, England), 14, 115-132.

Bradford M.M. (1976) A rapid and sensitive method for the quantitation of microgram quantities of protein utilizing the principle of protein-dye binding. Analytical Biochemistry, 72, 248-254.

Buist I., Bredeweg S.W., van Mechelen W., Lemmink, Koen A P M, Pepping G.-J., Diercks R.L. (2008) No effect of a graded training program on the number of running-related injuries in novice runners: a randomized controlled trial. The American journal of sports medicine, 36, 33-39.

Cacas J.-L., Furt F., Le Guédard M., Schmitter J.-M., Buré C., Gerbeau-Pissot P., Moreau P., Bessoule J.-J., Simon-Plas F., Mongrand S. (2012) Lipids of plant membrane rafts. Progress in lipid research, 51, 272-299.

Caescu C.I., Jeschke G.R., Turk B.E. (2009) Active-site determinants of substrate recognition by the metalloproteinases TACE and ADAM10. The Biochemical journal, 424, 79-88.

Cao Y., Liang Y., Tanaka K., Nguyen C.T., Jedrzejczak R.P., Joachimiak A., Stacey G. (2014) The kinase LYK5 is a major chitin receptor in Arabidopsis and forms a chitininduced complex with related kinase CERK1. eLife, 3.

Carey K.D., Dugger D.L., Schwall R.H., Sliwkowski M.X. (2005) ErbB2/Her2 ectodomain shedding is regulated by a membrane-associated metalloprotease. Cancer Res, 65, 871.

Carpenter G., Liao H.-J. (2009) Trafficking of receptor tyrosine kinases to the nucleus. Experimental cell research, 315, 1556-1566.

Chakravorty D., Gookin T.E., Milner M., Yu Y., Assmann S.M. (2015) Extra-Large G proteins (XLGs) expand the repertoire of subunits in Arabidopsis heterotrimeric G protein signaling. Plant Physiol., pp.00251.2015.

Chakravorty D., Trusov Y., Zhang W., Acharya B.R., Sheahan M.B., McCurdy D.W., Assmann S.M., Botella J.R. (2011) An atypical heterotrimeric G-protein Y-subunit is involved in guard cell $\mathrm{K}^{+}$-channel regulation and morphological development in Arabidopsis thaliana. The Plant journal for cell and molecular biology, 67, 840-851.

Chen J.-G., Gao Y., Jones A.M. (2006) Differential Roles of Arabidopsis Heterotrimeric GProtein Subunits in Modulating Cell Division in Roots. Plant Physiol., 141, 887-897. Chen J.-G., Willard F.S., Huang J., Liang J., Chasse S.A., Jones A.M., Siderovski D.P. (2003) A seven-transmembrane RGS protein that modulates plant cell proliferation. Science (New York, N.Y.), 301, 1728-1731. 
Chen M.-K., Hung M.-C. (2015) Proteolytic cleavage, trafficking, and functions of nuclear receptor tyrosine kinases. The FEBS journal, 282, 3693-3721.

Cheng Q.-C., Tikhomirov O., Zhou W., Carpenter G. (2003) Ectodomain cleavage of ErbB-4: characterization of the cleavage site and $\mathrm{m} 80$ fragment. The Journal of biological chemistry, 278, 38421-38427.

Cheng Y.T., Germain H., Wiermer M., Bi D., Xu F., Garcia A.V., Wirthmueller L., Despres C., Parker J.E., Zhang Y., Li X. (2009) Nuclear Pore Complex Component MOS7/Nup88 Is Required for Innate Immunity and Nuclear Accumulation of Defense Regulators in Arabidopsis. THE PLANT CELL ONLINE, 21, 2503-2516.

Chillakuri C.R., Sheppard D., Lea S.M., Handford P.A. (2012) Notch receptor-ligand binding and activation: insights from molecular studies. Seminars in cell \& developmental biology, 23, 421-428.

Chinchilla D., Bauer Z., Regenass M., Boller T., Felix G. (2006) The Arabidopsis receptor kinase FLS2 binds flg22 and determines the specificity of flagellin perception. The Plant cell, 18, 465-476.

Chinchilla D., Zipfel C., Robatzek S., Kemmerling B., Nürnberger T., Jones J.D.G., Felix G., Boller T. (2007) A flagellin-induced complex of the receptor FLS2 and BAK1 initiates plant defence. Nature, 448, 497-500.

Chow F.L., Fernandez-Patron C. (2007) Many membrane proteins undergo ectodomain shedding by proteolytic cleavage. Does one sheddase do the job on all of these proteins? IUBMB life, 59, 44-47.

Christianson T.W., Sikorski R.S., Dante M., Shero J.H., Hieter P. (1992) Multifunctional yeast high-copy-number shuttle vectors. Gene, 110, 119-122.

Clough S.J., Bent A.F. (1998) Floral dip: a simplified method for Agrobacterium-mediated transformation of Arabidopsis thaliana. The Plant journal for cell and molecular biology, 16, 735-743.

Colot H.V., Park G., Turner G.E., Ringelberg C., Crew C.M., Litvinkova L., Weiss R.L., Borkovich K.A., Dunlap J.C. (2006) A high-throughput gene knockout procedure for Neurospora reveals functions for multiple transcription factors. Proceedings of the National Academy of Sciences of the United States of America, 103, 10352-10357.

Dai N., Wang W., Patterson S.E., Bleecker A.B. (2013) The TMK subfamily of receptor-like kinases in Arabidopsis display an essential role in growth and a reduced sensitivity to auxin. PloS one, 8, e60990.

Dangl J.L., Horvath D.M., Staskawicz B.J. (2013) Pivoting the plant immune system from dissection to deployment. Science (New York, N.Y.), 341, 746-751. 
David J.M., Rajasekaran A.K. (2012) Dishonorable discharge: the oncogenic roles of cleaved E-cadherin fragments. Cancer research, 72, 2917-2923.

Dawkins E., Small D.H. (2014) Insights into the physiological function of the $\beta$-amyloid precursor protein: beyond Alzheimer's disease. Journal of neurochemistry, 129, 756-769.

Dewdney J., Reuber T.L., Wildermuth M.C., Devoto A., Cui J., Stutius L.M., Drummond E.P., Ausubel F.M. (2000) Three unique mutants of Arabidopsis identify eds loci required for limiting growth of a biotrophic fungal pathogen. Plant J, 24, 205-218.

Ding L., Pandey S., Assmann S.M. (2008) Arabidopsis extra-large G proteins (XLGs) regulate root morphogenesis. The Plant journal for cell and molecular biology, 53, 248263.

Ding X., Richter T., Chen M., Fujii H., Seo Y.S., Xie M., Zheng X., Kanrar S., Stevenson R.A., Dardick C., Li Y., Jiang H., Zhang Y., Yu F., Bartley L.E., Chern M., Bart R., Chen X., Zhu L., Farmerie W.G., Gribskov M., Zhu J.-K., Fromm M.E., Ronald P.C., Song W.-Y. (2009) A Rice Kinase-Protein Interaction Map. Plant Physiol., 149, 1478-1492.

Dodds P.N., Rathjen J.P. (2010) Plant immunity: towards an integrated view of plantpathogen interactions. Nature reviews. Genetics, 11, 539-548.

Eckardt N.A. (2008) Chitin signaling in plants: insights into the perception of fungal pathogens and rhizobacterial symbionts. The Plant cell, 20, 241-243.

Elenius K., Corfas G., Paul S., Choi C.J., Rio C., Plowman G.D., Klagsbrun M. (1997) A Novel Juxtamembrane Domain Isoform of HER4/ErbB4: ISOFORM-SPECIFIC TISSUE DISTRIBUTION AND DIFFERENTIAL PROCESSING IN RESPONSE TO PHORBOL ESTER. Journal of Biological Chemistry, 272, 26761-26768.

Erwig J., Ghareeb H., Kopischke M., Hacke R., Matei A., Petutschnig E.-K., Lipka V. (unpublished) Chitin-induced and CERK1 phosphorylation-dependent endocytosis of Arabidopsis LYK5.

Falk A., Feys B.J., Frost L.N., Jones J.D.G., Daniels M.J., Parker J.E. (1999) EDS1, an essential component of $\mathrm{R}$ gene-mediated disease resistance in Arabidopsis has homology to eukaryotic lipases. Proceedings of the National Academy of Sciences of the United States of America, 96, 3292-3297.

Faulkner C., Petutschnig E., Benitez-Alfonso Y., Beck M., Robatzek S., Lipka V., Maule A.J. (2013) LYM2-dependent chitin perception limits molecular flux via plasmodesmata. Proceedings of the National Academy of Sciences of the United States of America, 110, 9166-9170.

Faull R.J., Stanley J.M., Fraser S., Power D.A., Leavesley D.I. (2001) HB-EGF is produced in the peritoneal cavity and enhances mesothelial cell adhesion and migration. Kidney international, 59, 614-624. 
Feiz L., Irshad M., Pont-Lezica R.F., Canut H., Jamet E. (2006) Evaluation of cell wall preparations for proteomics: a new procedure for purifying cell walls from Arabidopsis hypocotyls. Plant methods, 2, 10.

Feng X.-H., Derynck R. (2005) Specificity and versatility in tgf-beta signaling through Smads. Annual review of cell and developmental biology, 21, 659-693.

Freeman M. (2009) Rhomboids: 7 years of a new protease family. Seminars in cell \& developmental biology, 20, 231-239.

Gajria D., Chandarlapaty S. (2011) HER2-amplified breast cancer: mechanisms of trastuzumab resistance and novel targeted therapies. Expert review of anticancer therapy, 11, 263-275.

Ganten D., Birchmeier W., Epplen J.T., Genser K., Gossen M., Kersten B., Lehrach H., Nolte C., Oschkinat H., Ruckpaul K., Ruiz P. (Eds) (2006) Encyclopedic Reference of Genomics and Proteomics in Molecular Medicine. Springer-Verlag, Berlin, Heidelberg.

Gao M., Wang X., Wang D., Xu F., Ding X., Zhang Z., Bi D., Cheng Y.T., Chen S., Li X., Zhang Y. (2009) Regulation of cell death and innate immunity by two receptor-like kinases in Arabidopsis. Cell host \& microbe, 6, 34-44.

Garvey K.J., Saedi M.S., Ito J. (1986) Nucleotide sequence of Bacillus phage phi 29 genes 14 and 15: homology of gene 15 with other phage lysozymes. Nucleic acids research, 14, 10001-10008.

Gimenez-lbanez S., Ntoukakis V., Rathjen J.P. (2009) The LysM receptor kinase CERK1 mediates bacterial perception in Arabidopsis. Plant signaling \& behavior, 4, 539-541.

Glazebrook J., Rogers E.E., Ausubel F.M. (1996) Isolation of Arabidopsis Mutants With Enhanced Disease Susceptibility by Direct Screening. Genetics, 143, 973-982.

Golldack D., Popova O.V., Dietz K.-J. (2002) Mutation of the matrix metalloproteinase At2MMP inhibits growth and causes late flowering and early senescence in Arabidopsis. The Journal of biological chemistry, 277, 5541-5547.

Gomez-Gomez L., Felix G., Boller T. (1999) A single locus determines sensitivity to bacterial flagellin in Arabidopsis thaliana. The Plant journal for cell and molecular biology, 18, 277284.

Gómez-Gómez L., Boller T. (2000) FLS2. Molecular Cell, 5, 1003-1011.

Guruharsha K.G., Kankel M.W., Artavanis-Tsakonas S. (2012) The Notch signalling system: recent insights into the complexity of a conserved pathway. Nature reviews. Genetics, 13 , 654-666.

Gust A.A. (2015) Peptidoglycan Perception in Plants. PLoS pathogens, 11, e1005275. 
Gust A.A., Willmann R., Desaki Y., Grabherr H.M., Nürnberger T. (2012) Plant LysM proteins: modules mediating symbiosis and immunity. Trends in plant science, 17, 495502.

Haass C., Hung A.Y., Schlossmacher M.G., Teplow D.B., Selkoe D.J. (1993) beta-Amyloid peptide and a 3-kDa fragment are derived by distinct cellular mechanisms. The Journal of biological chemistry, 268, 3021-3024.

Haass C., Kaether C., Thinakaran G., Sisodia S. (2012) Trafficking and proteolytic processing of APP. Cold Spring Harbor perspectives in medicine, 2, a006270.

Hann D.R., Rathjen J.P. (2007) Early events in the pathogenicity of Pseudomonas syringae on Nicotiana benthamiana. The Plant journal for cell and molecular biology, 49, 607-618.

Hartwig B., James G.V., Konrad K., Schneeberger K., Turck F. (2012) Fast isogenic mapping-by-sequencing of ethyl methanesulfonate-induced mutant bulks. Plant physiology, 160, 591-600.

Hayafune M., Berisio R., Marchetti R., Silipo A., Kayama M., Desaki Y., Arima S., Squeglia F., Ruggiero A., Tokuyasu K., Molinaro A., Kaku H., Shibuya N. (2014) Chitin-induced activation of immune signaling by the rice receptor CEBiP relies on a unique sandwichtype dimerization. Proceedings of the National Academy of Sciences of the United States of America, 111, E404-13.

Hayashida K., Bartlett A.H., Chen Y., Park P.W. (2010) Molecular and cellular mechanisms of ectodomain shedding. Anatomical record (Hoboken, N.J. 2007), 293, 925-937.

He K., Gou X., Yuan T., Lin H., Asami T., Yoshida S., Russell S.D., Li J. (2007) BAK1 and BKK1 regulate brassinosteroid-dependent growth and brassinosteroid-independent celldeath pathways. Current biology $C B, 17,1109-1115$.

Heese A., Hann D.R., Gimenez-Ibanez S., Jones A.M.E., He K., Li J., Schroeder J.I., Peck S.C., Rathjen J.P. (2007) The receptor-like kinase SERK3/BAK1 is a central regulator of innate immunity in plants. Proceedings of the National Academy of Sciences of the United States of America, 104, 12217-12222.

Hellens R.P., Edwards E.A., Leyland N.R., Bean S., Mullineaux P.M. (2000) pGreen: a versatile and flexible binary Ti vector for Agrobacterium-mediated plant transformation. Plant Mol Biol, 42, 819-832.

Heo J.B., Sung S., Assmann S.M. (2012) Ca2+-dependent GTPase, extra-large G protein 2 (XLG2), promotes activation of DNA-binding protein related to vernalization 1 (RTV1), leading to activation of floral integrator genes and early flowering in Arabidopsis. The Journal of biological chemistry, 287, 8242-8253.

Herman C., Chernajovsky Y. (1998) Mutation of Proline 211 Reduces Shedding of the Human p75 TNF Receptor. J Immunol, 160, 2478-2487. 
Higashiyama S., Nanba D., Nakayama H., Inoue H., Fukuda S. (2011) Ectodomain shedding and remnant peptide signalling of EGFRs and their ligands. Journal of biochemistry, 150, 15-22.

Hok S., Danchin E.G.J., Allasia V., Panabières F., Attard A., Keller H. (2011) An Arabidopsis (malectin-like) leucine-rich repeat receptor-like kinase contributes to downy mildew disease. Plant, cell \& environment, 34, 1944-1957.

Hollmén M., Liu P., Kurppa K., Wildiers H., Reinvall I., Vandorpe T., Smeets A., Deraedt K., Vahlberg T., Joensuu H., Leahy D.J., Schöffski P., Elenius K. (2012) Proteolytic Processing of ErbB4 in Breast Cancer. PloS one, 7.

Hollmén M., Määttä J.A., Bald L., Sliwkowski M.X., Elenius K. (2009) Suppression of breast cancer cell growth by a monoclonal antibody targeting cleavable ErbB4 isoforms.

Oncogene, 28, 1309-1319.

Hubbard S.R., Miller W.T. (2007) Receptor tyrosine kinases: mechanisms of activation and signaling. Current opinion in cell biology, 19, 117-123.

Hueck C.J. (1998) Type III protein secretion systems in bacterial pathogens of animals and plants. Microbiology and molecular biology reviews MMBR, 62, 379-433.

Humphry M., Bednarek P., Kemmerling B., Koh S., Stein M., Göbel U., Stüber K., PislewskaBednarek M., Loraine A., Schulze-Lefert P., Somerville S., Panstruga R. (2010) A regulon conserved in monocot and dicot plants defines a functional module in antifungal plant immunity. Proceedings of the National Academy of Sciences of the United States of America, 107, 21896-21901.

lizasa E., Mitsutomi M., Nagano Y. (2010) Direct binding of a plant LysM receptor-like kinase, LysM RLK1/CERK1, to chitin in vitro. The Journal of biological chemistry, 285, 29963004.

Jashni M.K., Mehrabi R., Collemare J., Mesarich C.H., de Wit, Pierre J G M (2015) The battle in the apoplast: further insights into the roles of proteases and their inhibitors in plantpathogen interactions. Frontiers in plant science, 6, 584.

Jirage D., Tootle T.L., Reuber T.L., Frost L.N., Feys B.J., Parker J.E., Ausubel F.M., Glazebrook J. (1999) Arabidopsis thaliana PAD4 encodes a lipase-like gene that is important for salicylic acid signaling. Proceedings of the National Academy of Sciences, 96, 13583-13588.

Johnston C.A., Taylor J.P., Gao Y., Kimple A.J., Grigston J.C., Chen J.-G., Siderovski D.P., Jones A.M., Willard F.S. (2007) GTPase acceleration as the rate-limiting step in Arabidopsis G protein-coupled sugar signaling. Proceedings of the National Academy of Sciences of the United States of America, 104, 17317-17322. 
Jones A.M., Assmann S.M. (2004) Plants: the latest model system for G-protein research. EMBO reports, 5, 572-578.

Jones F.E. (2008) HER4 Intracellular Domain (4ICD) Activity in the Developing Mammary

Gland and Breast Cancer. Journal of mammary gland biology and neoplasia, 13, 247258.

Jones J.D.G., Dangl J.L. (2006) The plant immune system. Nature, 444, 323-329.

Joo J.H., Wang S., Chen J.G., Jones A.M., Fedoroff N.V. (2005) Different Signaling and Cell

Death Roles of Heterotrimeric G Protein $\alpha$ and $\beta$ Subunits in the Arabidopsis Oxidative

Stress Response to Ozone. Plant Cell, 17, 957-970.

Josso N., Di Clemente N. (1997) Serine/threonine kinase receptors and ligands. Current

Opinion in Genetics \& Development, 7, 371-377.

Kadota Y., Sklenar J., Derbyshire P., Stransfeld L., Asai S., Ntoukakis V., Jones J.D.,

Shirasu K., Menke F., Jones A., Zipfel C. (2014) Direct regulation of the NADPH oxidase

RBOHD by the PRR-associated kinase BIK1 during plant immunity. Molecular Cell, 54, 43-55.

Kaku H., Nishizawa Y., Ishii-Minami N., Akimoto-Tomiyama C., Dohmae N., Takio K., Minami E., Shibuya N. (2006) Plant cells recognize chitin fragments for defense signaling through a plasma membrane receptor. Proceedings of the National Academy of Sciences of the United States of America, 103, 11086-11091.

Kaku H., Shibuya N. (2011) [Chitin receptor for plant innate immunity]. Seikagaku. The Journal of Japanese Biochemical Society, 83, 31-36.

Kanaoka M.M., Urban S., Freeman M., Okada K. (2005) An Arabidopsis Rhomboid homolog is an intramembrane protease in plants. FEBS Letters, 579, 5723-5728.

Kearse M., Moir R., Wilson A., Stones-Havas S., Cheung M., Sturrock S., Buxton S., Cooper A., Markowitz S., Duran C., Thierer T., Ashton B., Meintjes P., Drummond A. (2012) Geneious Basic: an integrated and extendable desktop software platform for the organization and analysis of sequence data. Bioinformatics (Oxford, England), 28, 16471649.

Kemmerling B., Schwedt A., Rodriguez P., Mazzotta S., Frank M., Qamar S.A., Mengiste T., Betsuyaku S., Parker J.E., Müssig C., Thomma, Bart P H J, Albrecht C., Vries S.C. de, Hirt H., Nürnberger T. (2007) The BRI1-associated kinase 1, BAK1, has a brassinolideindependent role in plant cell-death control. Current biology $C B, 17,1116-1122$.

Khokha R., Murthy A., Weiss A. (2013) Metalloproteinases and their natural inhibitors in inflammation and immunity. Nature reviews. Immunology, 13, 649-665.

Klopffleisch K., Phan N., Augustin K., Bayne R.S., Booker K.S., Botella J.R., Carpita N.C., Carr T., Chen J.-G., Cooke T.R., Frick-Cheng A., Friedman E.J., Fulk B., Hahn M.G., 
Jiang K., Jorda L., Kruppe L., Liu C., Lorek J., McCann M.C., Molina A., Moriyama E.N., Mukhtar M.S., Mudgil Y., Pattathil S., Schwarz J., Seta S., Tan M., Temp U., Trusov Y., Urano D., Welter B., Yang J., Panstruga R., Uhrig J.F., Jones A.M. (2011) Arabidopsis Gprotein interactome reveals connections to cell wall carbohydrates and morphogenesis. Molecular systems biology, 7, 532.

Kmiec-Wisniewska B., Krumpe K., Urantowka A., Sakamoto W., Pratje E., Janska H. (2008) Plant mitochondrial rhomboid, AtRBL12, has different substrate specificity from its yeast counterpart. Plant molecular biology, 68, 159-171.

Koncz C., Schell J. (1986) The promoter of TL-DNA gene 5 controls the tissue-specific expression of chimaeric genes carried by a novel type of Agrobacterium binary vector. Molec Gen Genet, 204, 383-396.

König S., Feussner K., Schwarz M., Kaever A., Iven T., Landesfeind M., Ternes P., Karlovsky P., Lipka V., Feussner I. (2012) Arabidopsis mutants of sphingolipid fatty acid a-hydroxylases accumulate ceramides and salicylates. The New phytologist, 196, 10861097.

Koonin E.V., Makarova K.S., Rogozin I.B., Davidovic L., Letellier M.-C., Pellegrini L. (2003) Koonin et al 2003. Genome Biol, 4, R19.

Kopan R., Ilagan M.X.G. (2004) Gamma-secretase: proteasome of the membrane? Nature reviews. Molecular cell biology, 5, 499-504.

Kopan R., Ilagan M.X.G. (2009) The canonical Notch signaling pathway: unfolding the activation mechanism. Cell, 137, 216-233.

Kouzai Y., Mochizuki S., Nakajima K., Desaki Y., Hayafune M., Miyazaki H., Yokotani N., Ozawa K., Minami E., Kaku H., Shibuya N., Nishizawa Y. (2014a) Targeted gene disruption of OsCERK1 reveals its indispensable role in chitin perception and involvement in the peptidoglycan response and immunity in rice. Molecular plant-microbe interactions MPMI, 27, 975-982.

Kouzai Y., Nakajima K., Hayafune M., Ozawa K., Kaku H., Shibuya N., Minami E., Nishizawa Y. (2014b) CEBiP is the major chitin oligomer-binding protein in rice and plays a main role in the perception of chitin oligomers: Plant Molecular Biology. Plant Mol Biol, 84, 519528.

Kullander K., Klein R. (2002) Mechanisms and functions of Eph and ephrin signalling. Nature reviews. Molecular cell biology, 3, 475-486.

Kunze G., Zipfel C., Robatzek S., Niehaus K., Boller T., Felix G. (2004) The N terminus of bacterial elongation factor Tu elicits innate immunity in Arabidopsis plants. The Plant cell, 16, 3496-3507. 
Lal M., Caplan M. (2011) Regulated intramembrane proteolysis: signaling pathways and biological functions. Physiology (Bethesda, Md.), 26, 34-44.

Lee S., Rojas C.M., Ishiga Y., Pandey S., Mysore K.S. (2013a) Arabidopsis heterotrimeric Gproteins play a critical role in host and nonhost resistance against Pseudomonas syringae pathogens. PloS one, 8, e82445.

Lee S.-W., Han S.-W., Sririyanum M., Park C.-J., Seo Y.-S., Ronald P.C. (2009) A type Isecreted, sulfated peptide triggers XA21-mediated innate immunity. Science (New York, N.Y.), 326, 850-853.

Lee S.-W., Han S.-W., Sririyanum M., Park C.-J., Seo Y.-S., Ronald P.C. (2013b) Retraction. A type I-secreted, sulfated peptide triggers XA21-mediated innate immunity. Science (New York, N.Y.), 342, 191.

Lee Y.-R., Assmann S. (1999) Arabidopsis thaliana 'extra-large GTP-binding protein' (AtXLG1): a new class of G-protein: Plant Molecular Biology. Plant Mol Biol, 40, 55-64.

Lefebvre B., Furt F., Hartmann M.-A., Michaelson L.V., Carde J.-P., Sargueil-Boiron F., Rossignol M., Napier J.A., Cullimore J., Bessoule J.-J., Mongrand S. (2007) Characterization of lipid rafts from Medicago truncatula root plasma membranes: a proteomic study reveals the presence of a raft-associated redox system. Plant physiology, 144, 402-418.

Leon O., Roth M. (2000) Zinc fingers: DNA binding and protein-protein interactions. Biol. Res., 33.

Li D., Zhang H., Song Q., Wang L., Liu S., Hong Y., Huang L., Song F. (2015) Tomato SI3MMP, a member of the Matrix metalloproteinase family, is required for disease resistance against Botrytis cinerea and Pseudomonas syringae pv. tomato DC3000. BMC plant biology, 15, 143.

Li J., Wen J., Lease K.A., Doke J.T., Tax F.E., Walker J.C. (2002) BAK1, an Arabidopsis LRR Receptor-like Protein Kinase, Interacts with BRI1 and Modulates Brassinosteroid Signaling. Cell, 110, 213-222.

Lichtenthaler S.F., Haass C., Steiner H. (2011) Regulated intramembrane proteolysis-lessons from amyloid precursor protein processing. Journal of neurochemistry, 117, 779 796.

Liebrand T.W.H., van den Burg, Harrold A, Joosten, Matthieu H A J (2014) Two for all: receptor-associated kinases SOBIR1 and BAK1. Trends in plant science, 19, 123-132.

Lin K.-T., Sloniowski S., Ethell D.W., Ethell I.M. (2008) Ephrin-B2-induced cleavage of EphB2 receptor is mediated by matrix metalloproteinases to trigger cell repulsion. The Journal of biological chemistry, 283, 28969-28979. 
Lipka V., Dittgen J., Bednarek P., Bhat R., Wiermer M., Stein M., Landtag J., Brandt W., Rosahl S., Scheel D., Llorente F., Molina A., Parker J., Somerville S., Schulze-Lefert P. (2005) Pre- and postinvasion defenses both contribute to nonhost resistance in Arabidopsis. Science (New York, N.Y.), 310, 1180-1183.

Litterst C., Georgakopoulos A., Shioi J., Ghersi E., Wisniewski T., Wang R., Ludwig A., Robakis N.K. (2007) Ligand binding and calcium influx induce distinct ectodomain/gamma-secretase-processing pathways of EphB2 receptor. The Journal of biological chemistry, 282, 16155-16163.

Liu B., Li J.-F., Ao Y., Qu J., Li Z., Su J., Zhang Y., Liu J., Feng D., Qi K., He Y., Wang J., Wang H.-B. (2012a) Lysin motif-containing proteins LYP4 and LYP6 play dual roles in peptidoglycan and chitin perception in rice innate immunity. The Plant cell, 24, 34063419.

Liu C., Xu P., Lamouille S., Xu J., Derynck R. (2009) TACE-mediated ectodomain shedding of the type I TGF- $\beta$ receptor downregulates TGF- $\beta$ signaling. Molecular Cell, 35, 26-36.

Liu J., Ding P., Sun T., Nitta Y., Dong O., Huang X., Yang W., Li X., Botella J.R., Zhang Y. (2013a) Heterotrimeric $G$ proteins serve as a converging point in plant defense signaling activated by multiple receptor-like kinases. Plant physiology, 161, 2146-2158.

Liu J., Elmore J.M., Lin Z.-J.D., Coaker G. (2011) A receptor-like cytoplasmic kinase phosphorylates the host target RIN4, leading to the activation of a plant innate immune receptor. Cell host \& microbe, 9, 137-146.

Liu P., Hu Z., Zhou B., Liu S., Chai J. (2013b) Crystal structure of an LRR protein with two solenoids. Cell research, 23, 303-305.

Liu P.C., Liu X., Li Y., Covington M., Wynn R., Huber R., Hillman M., Yang G., Ellis D., Marando C., Katiyar K., Bradley J., Abremski K., Stow M., Rupar M., Zhuo J., Li Y.-L., Lin Q., Burns D., Xu M., Zhang C., Qian D.-Q., He C., Sharief V., Weng L., Agrios C., Shi E., Metcalf B., Newton R., Friedman S., Yao W., Scherle P.A., Hollis G., Burn T.C. (2006) Identification of ADAM10 as a major source of HER2 ectodomain sheddase activity in HER2 overexpressing breast cancer cells. Cancer Biology \& Therapy, 5, 657-664.

Liu T., Liu Z., Song C., Hu Y., Han Z., She J., Fan F., Wang J., Jin C., Chang J., Zhou J.-M., Chai J. (2012b) Chitin-induced dimerization activates a plant immune receptor. Science (New York, N.Y.), 336, 1160-1164.

Llorente F., Alonso-Blanco C., Sanchez-Rodriguez C., Jorda L., Molina A. (2005) ERECTA receptor-like kinase and heterotrimeric $G$ protein from Arabidopsis are required for resistance to the necrotrophic fungus Plectosphaerella cucumerina. The Plant journal for cell and molecular biology, 43, 165-180. 
Lo Presti L., Lanver D., Schweizer G., Tanaka S., Liang L., Tollot M., Zuccaro A., Reissmann S., Kahmann R. (2015) Fungal effectors and plant susceptibility. Annual review of plant biology, 66, 513-545.

Lovering A.L., Safadi S.S., Strynadka N.C.J. (2012) Structural perspective of peptidoglycan biosynthesis and assembly. Annual review of biochemistry, 81, 451-478.

Lu D., Wu S., Gao X., Zhang Y., Shan L., He P. (2010) A receptor-like cytoplasmic kinase, BIK1, associates with a flagellin receptor complex to initiate plant innate immunity. Proceedings of the National Academy of Sciences of the United States of America, 107, 496-501.

Macho A.P., Zipfel C. (2014) Plant PRRs and the activation of innate immune signaling. Molecular Cell, 54, 263-272.

Maidment J.M., Moore D., Murphy G.P., Murphy G., Clark I.M. (1999) Matrix Metalloproteinase Homologues from Arabidopsis thaliana: EXPRESSION AND ACTIVITY. Journal of Biological Chemistry, 274, 34706-34710.

Manners J.M., Penninckx I.A., Vermaere K., Kazan K., Brown R.L., Morgan A., Maclean D.J., Curtis M.D., Cammue B.P., Broekaert W.F. (1998) The promoter of the plant defensin gene PDF1.2 from Arabidopsis is systemically activated by fungal pathogens and responds to methyl jasmonate but not to salicylic acid. Plant molecular biology, 38, 10711080.

Maruta N., Trusov Y., Brenya E., Parekh U., Botella J.R. (2015) Membrane-localized extralarge $\mathrm{G}$ proteins and $\mathrm{Gbg}$ of the heterotrimeric $\mathrm{G}$ proteins form functional complexes engaged in plant immunity in Arabidopsis. Plant physiology, 167, 1004-1016.

Migaki G.I., Kahn J., Kishimoto T.K. (1995) Mutational analysis of the membrane-proximal cleavage site of L-selectin: relaxed sequence specificity surrounding the cleavage site. The Journal of experimental medicine, 182, 549-557.

Miya A., Albert P., Shinya T., Desaki Y., Ichimura K., Shirasu K., Narusaka Y., Kawakami N., Kaku H., Shibuya N. (2007) CERK1, a LysM receptor kinase, is essential for chitin elicitor signaling in Arabidopsis. Proceedings of the National Academy of Sciences of the United States of America, 104, 19613-19618.

Morel J., Claverol S., Mongrand S., Furt F., Fromentin J., Bessoule J.-J., Blein J.-P., SimonPlas F. (2006) Proteomics of plant detergent-resistant membranes. Molecular \& cellular proteomics MCP, 5, 1396-1411.

Mou Z., Fan W., Dong X. (2003) Inducers of plant systemic acquired resistance regulate NPR1 function through redox changes. Cell, 113, 935-944. 
Mullis K., Faloona F., Scharf S., Saiki R., Horn G., Erlich H. (1986) Specific enzymatic amplification of DNA in vitro: the polymerase chain reaction. Cold Spring Harbor symposia on quantitative biology, $51 \mathrm{Pt} \mathrm{1,} \mathrm{263-273.}$

Murphy M.P., LeVine H. (2010) Alzheimer's disease and the amyloid-beta peptide. Journal of Alzheimer's disease JAD, 19, 311-323.

Muzzarelli R.A.A. (1977) Chitin. Pergamon Pr, Oxford: 309 pp.

Nakamura S., Mano S., Tanaka Y., Ohnishi M., Nakamori C., Araki M., Niwa T., Nishimura M., Kaminaka H., Nakagawa T., Sato Y., Ishiguro S. (2010) Gateway binary vectors with the bialaphos resistance gene, bar, as a selection marker for plant transformation. Bioscience, biotechnology, and biochemistry, 74, 1315-1319.

Nawrath C., Métraux J.-P. (1999) Salicylic Acid Induction-Deficient Mutants of Arabidopsis Express PR-2 and PR-5 and Accumulate High Levels of Camalexin after Pathogen Inoculation. Plant Cell, 11, 1393-1404.

Newman M.-A., Sundelin T., Nielsen J.T., Erbs G. (2013) MAMP (microbe-associated molecular pattern) triggered immunity in plants. Frontiers in plant science, 4, 139.

Nguyen-Kim H., San Clemente H., Balliau T., Zivy M., Dunand C., Albenne C., Jamet E. (2016) Arabidopsis thaliana root cell wall proteomics: Increasing the proteome coverage using a combinatorial peptide ligand library and description of unexpected Hyp in peroxidase amino acid sequences. Proteomics, 16, 491-503.

Ni C.Y., Murphy M.P., Golde T.E., Carpenter G. (2001) gamma -Secretase cleavage and nuclear localization of ErbB-4 receptor tyrosine kinase. Science (New York, N.Y.), 294, 2179-2181.

Nitta Y., Ding P., Zhang Y. (2015) Heterotrimeric G proteins in plant defense against pathogens and ABA signaling. Environmental and Experimental Botany, 114, 153-158. Noe V., Fingleton B., Jacobs K., Crawford H.C., Vermeulen S., Steelant W., Bruyneel E., Matrisian L.M., Mareel M. (2001) Release of an invasion promoter E-cadherin fragment by matrilysin and stromelysin-1. Journal of cell science, 114, 111-118.

Noel L., Moores T.L., van Der Biezen, E A, Parniske M., Daniels M.J., Parker J.E., Jones J.D. (1999) Pronounced intraspecific haplotype divergence at the RPP5 complex disease resistance locus of Arabidopsis. The Plant cell, 11, 2099-2112.

Nürnberger T., Lipka V. (2005) Non-host resistance in plants: new insights into an old phenomenon. Molecular plant pathology, 6, 335-345.

Paetzel M., Dalbey R.E., Strynadka N.C. (1998) Crystal structure of a bacterial signal peptidase in complex with a beta-lactam inhibitor. Nature, 396, 186-190. 
Pandey S., Monshausen G.B., Ding L., Assmann S.M. (2008) Regulation of root-wave response by extra large and conventional $\mathrm{G}$ proteins in Arabidopsis thaliana. The Plant journal for cell and molecular biology, 55, 311-322.

Park C.-J., Bart R., Chern M., Canlas P.E., Bai W., Ronald P.C. (2010) Overexpression of the endoplasmic reticulum chaperone BiP3 regulates XA21-mediated innate immunity in rice. PloS one, 5, e9262.

Park C.-J., Ronald P.C. (2012) Cleavage and nuclear localization of the rice XA21 immune receptor. Nature Communications, 3, 920.

Paulick M.G., Bertozzi C.R. (2008) The glycosylphosphatidylinositol anchor: a complex membrane-anchoring structure for proteins. Biochemistry, 47, 6991-7000.

Petutschnig E.K., Jones, Alexandra M E, Serazetdinova L., Lipka U., Lipka V. (2010) The lysin motif receptor-like kinase (LysM-RLK) CERK1 is a major chitin-binding protein in Arabidopsis thaliana and subject to chitin-induced phosphorylation. The Journal of biological chemistry, 285, 28902-28911.

Petutschnig E.K., Stolze M., Lipka U., Kopischke M., Horlacher J., Valerius O., Rozhon W., Gust A.A., Kemmerling B., Poppenberger B., Braus G.H., Nürnberger T., Lipka V. (2014) A novel Arabidopsis CHITIN ELICITOR RECEPTOR KINASE 1 (CERK1) mutant with enhanced pathogen-induced cell death and altered receptor processing. The New phytologist, 204, 955-967.

Piepkorn M., Pittelkow M.R., Cook P.W. (1998) Autocrine regulation of keratinocytes: the emerging role of heparin-binding, epidermal growth factor-related growth factors. The Journal of investigative dermatology, 111, 715-721.

Postina R., Schroeder A., Dewachter I., Bohl J., Schmitt U., Kojro E., Prinzen C., Endres K., Hiemke C., Blessing M., Flamez P., Dequenne A., Godaux E., van Leuven F., Fahrenholz F. (2004) A disintegrin-metalloproteinase prevents amyloid plaque formation and hippocampal defects in an Alzheimer disease mouse model. J. Clin. Invest., 113, 14561464.

Pruitt R.N., Schwessinger B., Joe A., Thomas N., Liu F., Albert M., Robinson M.R., Chan L.J.G., Luu D.D., Chen H., Bahar O., Daudi A., Vleesschauwer D. de, Caddell D., Zhang W., Zhao X., Li X., Heazlewood J.L., Ruan D., Majumder D., Chern M., Kalbacher H., Midha S., Patil P.B., Sonti R.V., Petzold C.J., Liu C.C., Brodbelt J.S., Felix G., Ronald P.C. (2015) The rice immune receptor XA21 recognizes a tyrosine-sulfated protein from a Gram-negative bacterium. Science Advances, 1, e1500245-e1500245.

Raffler N.A., Rivera-Nieves J., Ley K. (2005) L-selectin in inflammation, infection and immunity. Drug Discovery Today: Therapeutic Strategies, 2, 213-220. 
Rappsilber J., Mann M., Ishihama Y. (2007) Protocol for micro-purification, enrichment, prefractionation and storage of peptides for proteomics using StageTips. Nat Protoc, 2 , 1896-1906.

Rio C. (2000) Tumor Necrosis Factor-alpha -converting Enzyme Is Required for Cleavage of erbB4/HER4. Journal of Biological Chemistry, 275, 10379-10387.

Rio C., Buxbaum J.D., Peschon J.J., Corfas G. (2000) Tumor necrosis factor-alphaconverting enzyme is required for cleavage of erbB4/HER4. The Journal of biological chemistry, 275, 10379-10387.

Robatzek S., Bittel P., Chinchilla D., Kochner P., Felix G., Shiu S.-H., Boller T. (2007) Molecular identification and characterization of the tomato flagellin receptor LeFLS2, an orthologue of Arabidopsis FLS2 exhibiting characteristically different perception specificities. Plant molecular biology, 64, 539-547.

Rohl C.A., Fiori W., Baldwin R.L. (1999) Alanine is helix-stabilizing in both templatenucleated and standard peptide helices. Proceedings of the National Academy of Sciences of the United States of America, 96, 3682-3687.

Rose L.E., Bittner-Eddy P.D., Langley C.H., Holub E.B., Michelmore R.W., Beynon J.L. (2004) The maintenance of extreme amino acid diversity at the disease resistance gene, RPP13, in Arabidopsis thaliana. Genetics, 166, 1517-1527.

Ross E.M., Wilkie T.M. (2000) GTPase-activating proteins for heterotrimeric G proteins: regulators of $\mathrm{G}$ protein signaling (RGS) and RGS-like proteins. Annual review of biochemistry, 69, 795-827.

Rotz R.C. von, Kohli B.M., Bosset J., Meier M., Suzuki T., Nitsch R.M., Konietzko U. (2004) The APP intracellular domain forms nuclear multiprotein complexes and regulates the transcription of its own precursor. Journal of cell science, 117, 4435-4448.

Roux M., Schwessinger B., Albrecht C., Chinchilla D., Jones A., Holton N., Malinovsky F.G., Tör M., Vries S.d., Zipfel C. (2011) The Arabidopsis Leucine-Rich Repeat Receptor-Like Kinases BAK1/SERK3 and BKK1/SERK4 Are Required for Innate Immunity to Hemibiotrophic and Biotrophic Pathogens. Plant Cell, 23, 2440-2455.

Rudyk O., Eaton P. (2014) Biochemical methods for monitoring protein thiol redox states in biological systems. Redox biology, 2, 803-813.

Rutledge B.J., Zhang K., Bier E., Jan Y.N., Perrimon N. (1992) The Drosophila spitz gene encodes a putative EGF-like growth factor involved in dorsal-ventral axis formation and neurogenesis. Genes \& development, 6, 1503-1517.

Rzeniewicz K., Newe A., Rey Gallardo A., Davies J., Holt M.R., Patel A., Charras G.T., Stramer B., Molenaar C., Tedder T.F., Parsons M., Ivetic A. (2015) L-selectin shedding is activated specifically within transmigrating pseudopods of monocytes to regulate cell 
polarity in vitro. Proceedings of the National Academy of Sciences of the United States of America, 112, E1461-70.

Sadhukhan R., Sen G.C., Ramchandran R., Sen I. (1998) The distal ectodomain of angiotensin-converting enzyme regulates its cleavage-secretion from the cell surface. Proceedings of the National Academy of Sciences of the United States of America, 95, 138-143.

Saftig P., Reiss K. (2011) The "A Disintegrin And Metalloproteases" ADAM10 and ADAM17: novel drug targets with therapeutic potential? European journal of cell biology, 90, 527535.

Schlessinger J. (2000) Cell Signaling by Receptor Tyrosine Kinases. Cell, 103, 211-225.

Schulze B., Mentzel T., Jehle A.K., Mueller K., Beeler S., Boller T., Felix G., Chinchilla D. (2010) Rapid heteromerization and phosphorylation of ligand-activated plant transmembrane receptors and their associated kinase BAK1. The Journal of biological chemistry, 285, 9444-9451.

Schwessinger B., Roux M., Kadota Y., Ntoukakis V., Sklenar J., Jones A., Zipfel C. (2011) Phosphorylation-dependent differential regulation of plant growth, cell death, and innate immunity by the regulatory receptor-like kinase BAK1. PLoS genetics, 7, e1002046.

Seals D.F., Courtneidge S.A. (2003) The ADAMs family of metalloproteases: multidomain proteins with multiple functions. Genes \& development, 17, 7-30.

Selkoe D.J. (2001) Alzheimer's disease: genes, proteins, and therapy. Physiological Reviews, 81, 741-766.

Seubert P., Oltersdorf T., Lee M.G., Barbour R., Blomquist C., Davis D.L., Bryant K., Fritz L.C., Galasko D., Thal L.J. (1993) Secretion of beta-amyloid precursor protein cleaved at the amino terminus of the beta-amyloid peptide. Nature, 361, 260-263.

Shimizu T., Nakano T., Takamizawa D., Desaki Y., Ishii-Minami N., Nishizawa Y., Minami E., Okada K., Yamane H., Kaku H., Shibuya N. (2010) Two LysM receptor molecules, CEBiP and OsCERK1, cooperatively regulate chitin elicitor signaling in rice. The Plant journal for cell and molecular biology, 64, 204-214.

Shinya T., Motoyama N., Ikeda A., Wada M., Kamiya K., Hayafune M., Kaku H., Shibuya N. (2012) Functional characterization of CEBiP and CERK1 homologs in arabidopsis and rice reveals the presence of different chitin receptor systems in plants. Plant \& cell physiology, 53, 1696-1706.

Shinya T., Nakagawa T., Kaku H., Shibuya N. (2015) Chitin-mediated plant-fungal interactions: catching, hiding and handshaking. Current opinion in plant biology, 26, 6471. 
Shinya T., Yamaguchi K., Desaki Y., Yamada K., Narisawa T., Kobayashi Y., Maeda K., Suzuki M., Tanimoto T., Takeda J., Nakashima M., Funama R., Narusaka M., Narusaka Y., Kaku H., Kawasaki T., Shibuya N. (2014) Selective regulation of the chitin-induced defense response by the Arabidopsis receptor-like cytoplasmic kinase PBL27. The Plant journal for cell and molecular biology, 79, 56-66.

Shiu S.H., Bleecker A.B. (2001) Receptor-like kinases from Arabidopsis form a monophyletic gene family related to animal receptor kinases. Proceedings of the National Academy of Sciences of the United States of America, 98, 10763-10768.

Siegel P.M., Massagué J. (2003) Cytostatic and apoptotic actions of TGF-beta in homeostasis and cancer. Nature reviews. Cancer, 3, 807-821.

Singh A.B., Harris R.C. (2005) Autocrine, paracrine and juxtacrine signaling by EGFR ligands. Cellular signalling, 17, 1183-1193.

Singh A.B., Tsukada T., Zent R., Harris R.C. (2004) Membrane-associated HB-EGF modulates HGF-induced cellular responses in MDCK cells. Journal of cell science, 117, 1365-1379.

Sisodia S.S. (1992) Beta-amyloid precursor protein cleavage by a membrane-bound protease. Proceedings of the National Academy of Sciences of the United States of America, 89, 6075-6079.

Smalley D.M., Ley K. (2005) L-selectin: Mechanisms and physiological significance of ectodomain cleavage. J Cellular Mol Med, 9, 255-266.

Smolarkiewicz M., Skrzypczak T., Michalak M., Leśniewicz K., Walker J.R., Ingram G., Wojtaszek P. (2014) Gamma-secretase subunits associate in intracellular membrane compartments in Arabidopsis thaliana. Journal of experimental botany, 65, 3015-3027.

Song W.-Y., Wang G.-L., Chen L.-L., Kim H.-S., Pi L.-Y., Holsten T., Gardner J., Wang B., Zhai W.-X., Zhu L.-H., Fauquet C., Ronald P. (1995) A Receptor Kinase-Like Protein Encoded by the Rice Disease Resistance Gene, Xa21. Science, 270, 1804-1806.

Spoel S.H., Dong X. (2012) How do plants achieve immunity? Defence without specialized immune cells. Nature reviews. Immunology, 12, 89-100.

Stahl E.A., Dwyer G., Mauricio R., Kreitman M., Bergelson J. (1999) Dynamics of disease resistance polymorphism at the Rpm1 locus of Arabidopsis. Nature, 400, 667-671.

Stracke S., Kistner C., Yoshida S., Mulder L., Sato S., Kaneko T., Tabata S., Sandal N., Stougaard J., Szczyglowski K., Parniske M. (2002) A plant receptor-like kinase required for both bacterial and fungal symbiosis. Nature, 417, 959-962.

Takai R., Isogai A., Takayama S., Che F.-S. (2008) Analysis of flagellin perception mediated by flg22 receptor OsFLS2 in rice. Molecular plant-microbe interactions MPMI, 21, 16351642. 
Tanz S.K., Castleden I., Hooper C.M., Vacher M., Small I., Millar H.A. (2013) SUBA3: a database for integrating experimentation and prediction to define the SUBcellular location of proteins in Arabidopsis. Nucleic acids research, 41, D1185-91.

Tax F., Kemmerling B. (Eds) (2012) Receptor-like Kinases in Plants: From Development to Defense, 2012nd edn. Signaling and Communication in Plants, 13. Springer, Berlin.

Temple B.R.S., Jones A.M. (2007) The plant heterotrimeric G-protein complex. Annual review of plant biology, 58, 249-266.

Ternes P., Feussner K., Werner S., Lerche J., Iven T., Heilmann I., Riezman H., Feussner I. (2011) Disruption of the ceramide synthase LOH1 causes spontaneous cell death in Arabidopsis thaliana. The New phytologist, 192, 841-854.

Thompson E.P., Smith S.G.L., Glover B.J. An Arabidopsis rhomboid protease has roles in the chloroplast and in flower development. J. Exp. Bot., ers012.

Thompson E.P., Smith S.G.L., Glover B.J. (2012) An Arabidopsis rhomboid protease has roles in the chloroplast and in flower development. Journal of experimental botany, 63, 3559-3570.

Thorp E., Vaisar T., Subramanian M., Mautner L., Blobel C., Tabas I. (2011) Shedding of the Mer Tyrosine Kinase Receptor Is Mediated by ADAM17 Protein through a Pathway Involving Reactive Oxygen Species, Protein Kinase Cס, and p38 Mitogen-activated Protein Kinase (MAPK)*. The Journal of biological chemistry, 286, 33335-33344.

Thung L., Trusov Y., Chakravorty D., Botella J.R. (2012) Gy1+Gy2+Gy3=Gß: the search for heterotrimeric G-protein y subunits in Arabidopsis is over. Journal of plant physiology, 169, 542-545.

Torres M.A., Morales J., Sánchez-Rodríguez C., Molina A., Dangl J.L. (2013) Functional interplay between Arabidopsis NADPH oxidases and heterotrimeric G protein. Molecular plant-microbe interactions MPMI, 26, 686-694.

Trdá L., Boutrot F., Claverie J., Brulé D., Dorey S., Poinssot B. (2015) Perception of pathogenic or beneficial bacteria and their evasion of host immunity: pattern recognition receptors in the frontline. Frontiers in plant science, 6, 219.

Trusov Y., Rookes J.E., Chakravorty D., Armour D., Schenk P.M., Botella J.R. (2006) Heterotrimeric G Proteins Facilitate Arabidopsis Resistance to Necrotrophic Pathogens and Are Involved in Jasmonate Signaling1. Plant physiology, 140, 210-220.

Trusov Y., Rookes J.E., Tilbrook K., Chakravorty D., Mason M.G., Anderson D., Chen J.-G., Jones A.M., Botella J.R. (2007) Heterotrimeric G Protein y Subunits Provide Functional Selectivity in Gßy Dimer Signaling in ArabidopsisOA. The Plant cell, 19, 1235-1250.

Turk B.E., Huang L.L., Piro E.T., Cantley L.C. (2001) Determination of protease cleavage site motifs using mixture-based oriented peptide libraries. Nature biotechnology, 19, 661-667. 
Ullah H., Chen J.-G., Temple B., Boyes D.C., Alonso J.M., Davis K.R., Ecker J.R., Jones A.M. (2003) The $\beta$-Subunit of the Arabidopsis G Protein Negatively Regulates AuxinInduced Cell Division and Affects Multiple Developmental Processes. Plant Cell, 15, 393409.

Urano D., Chen J.-G., Botella J.R., Jones A.M. (2013) Heterotrimeric G protein signalling in the plant kingdom. Open biology, 3, 120186.

Urano D., Jones A.M. (2014) Heterotrimeric G protein-coupled signaling in plants. Annual review of plant biology, 65, 365-384.

Urano D., Jones J.C., Wang H., Matthews M., Bradford W., Bennetzen J.L., Jones A.M. (2012a) G protein activation without a GEF in the plant kingdom. PLoS genetics, 8 , e1002756.

Urano D., Phan N., Jones J.C., Yang J., Huang J., Grigston J., Taylor J.P., Jones A.M. (2012b) Endocytosis of the seven-transmembrane RGS1 protein activates G-proteincoupled signalling in Arabidopsis. Nature cell biology, 14, 1079-1088.

Urban S. (2006) Rhomboid proteins: conserved membrane proteases with divergent biological functions. Genes \& development, 20, 3054-3068.

Urban S., Freeman M. (2003) Substrate Specificity of Rhomboid Intramembrane Proteases Is Governed by Helix-Breaking Residues in the Substrate Transmembrane Domain. Molecular Cell, 11, 1425-1434.

Urban S., Lee J.R., Freeman M. (2001) Drosophila Rhomboid-1 Defines a Family of Putative Intramembrane Serine Proteases. Cell, 107, 173-182.

van der Hoorn R.A., Kamoun S. (2008) From Guard to Decoy: a new model for perception of plant pathogen effectors. The Plant cell, 20, 2009-2017.

van Roy F., Berx G. (2008) The cell-cell adhesion molecule E-cadherin. Cellular and molecular life sciences CMLS, 65, 3756-3788.

Vanhoof G., Goossens F., Meester I.D., Hendriks D., Scharpé S. (1995) Proline motifs in peptides and their biological processing. FASEB J, 9, 736-744.

Wakatsuki S., Kurisaki T., Sehara-Fujisawa A. (2004) Lipid rafts identified as locations of ectodomain shedding mediated by Meltrin beta/ADAM19. Journal of neurochemistry, 89, 119-123.

Walcheck B., Alexander S.R., St Hill C.A., Matala E. (2003) ADAM-17-independent shedding of L-selectin. Journal of Leukocyte Biology, 74, 389-394.

Wan J., Tanaka K., Zhang X.-C., Son G.H., Brechenmacher L., Nguyen, Tran Hong Nha, Stacey G. (2012) LYK4, a lysin motif receptor-like kinase, is important for chitin signaling and plant innate immunity in Arabidopsis. Plant physiology, 160, 396-406. 
Wan J., Zhang X.-C., Stacey G. (2008) Chitin signaling and plant disease resistance. Plant signaling \& behavior, 3, 831-833.

Wang Z.Y., Seto H., Fujioka S., Yoshida S., Chory J. (2001) BRI1 is a critical component of a plasma-membrane receptor for plant steroids. Nature, 410, 380-383.

Weigel D., Mott R. (2009) The 1001 genomes project for Arabidopsis thaliana. Genome biology, 10, 107.

Weiss A., Attisano L. (2013) The TGFbeta superfamily signaling pathway. Wiley interdisciplinary reviews. Developmental biology, 2, 47-63.

Weskamp G., Schlondorff J., Lum L., Becherer J.D., Kim T.-W., Saftig P., Hartmann D., Murphy G., Blobel C.P. (2004) Evidence for a critical role of the tumor necrosis factor alpha convertase (TACE) in ectodomain shedding of the p75 neurotrophin receptor (p75NTR). The Journal of biological chemistry, 279, 4241-4249.

Wessel D., Flügge U.I. (1984) A method for the quantitative recovery of protein in dilute solution in the presence of detergents and lipids. Analytical Biochemistry, 138, 141-143.

Wildermuth M.C., Dewdney J., Wu G., Ausubel F.M. (2001) Isochorismate synthase is required to synthesize salicylic acid for plant defence. Nature, 414, 562-565.

Willmann R., Lajunen H.M., Erbs G., Newman M.-A., Kolb D., Tsuda K., Katagiri F., Fliegmann J., Bono J.-J., Cullimore J.V., Jehle A.K., Götz F., Kulik A., Molinaro A., Lipka V., Gust A.A., Nürnberger T. (2011) Arabidopsis lysin-motif proteins LYM1 LYM3 CERK1 mediate bacterial peptidoglycan sensing and immunity to bacterial infection. Proceedings of the National Academy of Sciences of the United States of America, 108, 19824-19829.

Winter D., Vinegar B., Nahal H., Ammar R., Wilson G.V., Provart N.J. (2007) An "Electronic Fluorescent Pictograph" Browser for Exploring and Analyzing Large-Scale Biological Data Sets. PLOS ONE, 2, e718.

Wolfenstetter S., Chakravorty D., Kula R., Urano D., Trusov Y., Sheahan M.B., McCurdy D.W., Assmann S.M., Jones A.M., Botella J.R. (2015) Evidence for an unusual transmembrane configuration of AGG3, a class C Gy subunit of Arabidopsis. The Plant journal for cell and molecular biology, 81, 388-398.

Xu W.-H., Wang Y.-S., Liu G.-Z., Chen X., Tinjuangjun P., Pi L.-Y., Song W.-Y. (2006) The autophosphorylated Ser686, Thr688, and Ser689 residues in the intracellular juxtamembrane domain of XA21 are implicated in stability control of rice receptor-like kinase. The Plant journal for cell and molecular biology, 45, 740-751.

Yamazaki S., Iwamoto R., Saeki K., Asakura M., Takashima S., Yamazaki A., Kimura R., Mizushima H., Moribe H., Higashiyama S., Endoh M., Kaneda Y., Takagi S., Itami S., Takeda N., Yamada G., Mekada E. (2003) Mice with defects in HB-EGF ectodomain 
shedding show severe developmental abnormalities. The Journal of cell biology, 163 , 469-475.

Yuan C.-X., Lasut A.L., Wynn R., Neff N.T., Hollis G.F., Ramaker M.L., Rupar M.J., Liu P., Meade R. (2003) Purification of Her-2 extracellular domain and identification of its cleavage site. Protein expression and purification, 29, 217-222.

Zhang J., Li W., Xiang T., Liu Z., Laluk K., Ding X., Zou Y., Gao M., Zhang X., Chen S., Mengiste T., Zhang Y., Zhou J.-M. (2010) Receptor-like cytoplasmic kinases integrate signaling from multiple plant immune receptors and are targeted by a Pseudomonas syringae effector. Cell host \& microbe, 7, 290-301.

Zhang W., Fraiture M., Kolb D., Loffelhardt B., Desaki Y., Boutrot F.F.G., Tor M., Zipfel C., Gust A.A., Brunner F. (2013) Arabidopsis receptor-like protein30 and receptor-like kinase suppressor of BIR1-1/EVERSHED mediate innate immunity to necrotrophic fungi. The Plant cell, 25, 4227-4241.

Zhang Y., Giboulot A., Zivy M., Valot B., Jamet E., Albenne C. (2011) Combining various strategies to increase the coverage of the plant cell wall glycoproteome. Phytochemistry, 72, 1109-1123.

Zhou N., Tootle T.L., Tsui F., Klessig D.F., Glazebrook J. (1998) PAD4 Functions Upstream from Salicylic Acid to Control Defense Responses in Arabidopsis. Plant Cell, 10, 10211030.

Zhou W., Carpenter G. (2000) Heregulin-dependent trafficking and cleavage of ErbB-4. The Journal of biological chemistry, 275, 34737-34743.

Zhu H., Li G.-J., Ding L., Cui X., Berg H., Assmann S.M., Xia Y. (2009) Arabidopsis extra large G-protein 2 (XLG2) interacts with the Gbeta subunit of heterotrimeric $\mathrm{G}$ protein and functions in disease resistance. Molecular plant, 2, 513-525.

Ziegler Y. (2015) The Role Of The Putative Receptor-Like Cytoplasmic Kinase CLR1 In Chitin Signalling. PhD Thesis, Göttingen.

Zimina E.P., Bruckner-Tuderman L., Franzke C.-W. (2005) Shedding of collagen XVII ectodomain depends on plasma membrane microenvironment. The Journal of biological chemistry, 280, 34019-34024.

Zipfel C. (2014) Plant pattern-recognition receptors. Trends in immunology, 35, 345-351.

Zipfel C., Kunze G., Chinchilla D., Caniard A., Jones J.D.G., Boller T., Felix G. (2006) Perception of the bacterial PAMP EF-Tu by the receptor EFR restricts Agrobacteriummediated transformation. Cell, 125, 749-760.

Zipfel C., Robatzek S., Navarro L., Oakeley E.J., Jones J.D.G., Felix G., Boller T. (2004) Bacterial disease resistance in Arabidopsis through flagellin perception. Nature, 428, 764-767. 


\section{Supplemental material}

\begin{tabular}{|c|c|c|c|c|c|c|c|c|c|c|c|}
\hline$\underset{\Xi}{\mathbf{\Xi}}$ & 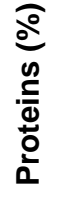 & 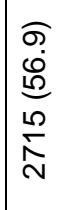 & 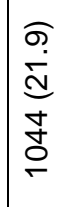 & $\begin{array}{l}\tilde{L} \\
\stackrel{1}{\rho} \\
0 \\
\stackrel{0}{\rho}\end{array}$ & 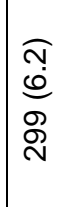 & $\begin{array}{l}\sigma \\
\stackrel{\sigma}{0} \\
\stackrel{\sigma}{\sigma}\end{array}$ & 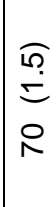 & $\begin{array}{l}\widehat{10} \\
\stackrel{0}{N} \\
\text { N }\end{array}$ & 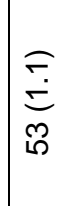 & $\begin{array}{l}\widehat{1} \\
0 \\
\mathcal{N} \\
\mathcal{N}\end{array}$ & 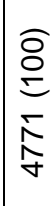 \\
\hline ڤ్ & 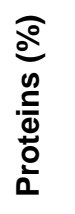 & $\begin{array}{l}\widehat{\sigma} \\
\dot{N} \\
\stackrel{\infty}{\infty} \\
\stackrel{\infty}{\sim}\end{array}$ & 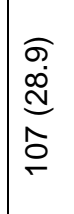 & $\begin{array}{l}\widehat{1} \\
0 \\
0 \\
10 \\
0\end{array}$ & 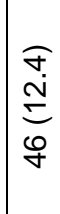 & $\begin{array}{l}\widehat{\omega} \\
\stackrel{\omega}{ } \\
\stackrel{\omega}{N}\end{array}$ & $\begin{array}{l}\widehat{\mathfrak{T}} \\
\mathfrak{d} \\
\stackrel{0}{\underline{O}}\end{array}$ & $\frac{\sigma}{\sigma}$ & 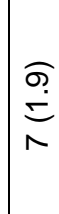 & $\underset{0}{\sigma}$ & 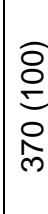 \\
\hline $\begin{array}{l}\mathscr{0} \\
0 \\
0\end{array}$ & 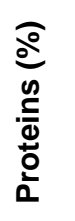 & 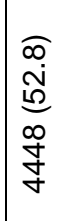 & 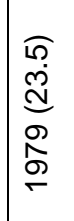 & 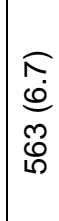 & 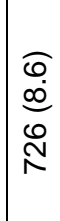 & 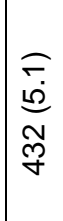 & 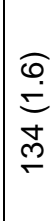 & $\begin{array}{l}\hat{\pi} \\
\hat{e} \\
\tilde{r}\end{array}$ & 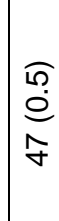 & $\begin{array}{l}10 \\
0 \\
0 \\
0 \\
0\end{array}$ & 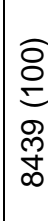 \\
\hline ஸొ & $\begin{array}{l}\widehat{o} \\
\stackrel{0}{0} \\
. \frac{c}{0} \\
\overline{0} \\
\frac{0}{0}\end{array}$ & 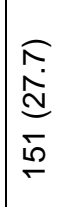 & $\begin{array}{l}\widehat{\alpha} \\
0 \\
0 \\
0 \\
o \infty \\
0 \\
0\end{array}$ & $\begin{array}{l}\widehat{\alpha} \\
\stackrel{0}{0} \\
\stackrel{0}{0} \\
\text { on }\end{array}$ & 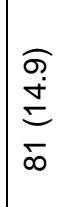 & $\begin{array}{l}\widehat{\infty} \\
\infty \\
\infty \\
\dot{\varphi}\end{array}$ & $\begin{array}{l}\widehat{\infty} \\
\stackrel{0}{\mathfrak{i}} \\
\underline{L}\end{array}$ & $\frac{\pi}{\tilde{C}}$ & $\begin{array}{l}\widetilde{T} \\
\widetilde{\sigma} \\
\sigma\end{array}$ & 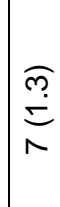 & 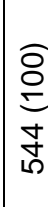 \\
\hline $\begin{array}{l}\text { N } \\
\text { D }\end{array}$ & $\begin{array}{l}\widehat{o} \\
\stackrel{0}{0} \\
\frac{0}{0} \\
\frac{0}{0} \\
\frac{0}{2}\end{array}$ & $\begin{array}{l}0 \\
0 \\
0 \\
0 \\
\infty \\
0 \\
0 \\
e\end{array}$ & 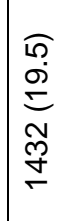 & $\begin{array}{l}\widehat{I} \\
\stackrel{0}{0} \\
\stackrel{0}{C} \\
\text { N } \\
N\end{array}$ & $\begin{array}{l}\widehat{\alpha} \\
\dot{\theta} \\
\hat{\sigma} \\
\hat{g}\end{array}$ & 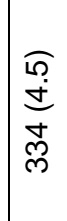 & $\begin{array}{l}\hat{f} \\
\hat{\theta} \\
\tilde{N} \\
\hat{\sigma}\end{array}$ & $\begin{array}{l}\widehat{\kappa} \\
\vdots \\
\infty \\
\infty \\
\dot{v}\end{array}$ & $\begin{array}{l}\widehat{\sigma} \\
\dot{0} \\
\tilde{\theta}\end{array}$ & $\mid \begin{array}{l}\widehat{T} \\
0 \\
0 \\
0 \\
0\end{array}$ & 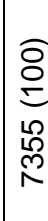 \\
\hline ळొ & $\begin{array}{l}\widehat{o} \\
\stackrel{0}{0} \\
\frac{0}{0} \\
\frac{0}{0} \\
\frac{0}{0}\end{array}$ & 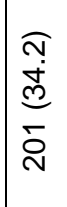 & 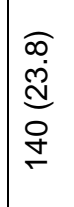 & 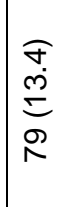 & 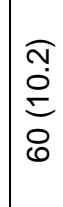 & $\begin{array}{l}\widehat{\check{N}} \\
\stackrel{N}{Y}\end{array}$ & $\begin{array}{l}\widehat{D} \\
\dot{J} \\
\stackrel{D}{N}\end{array}$ & $\begin{array}{l}\widehat{\sigma} \\
\stackrel{\Gamma}{=} \\
=\end{array}$ & $\mid \begin{array}{l}\widehat{\alpha} \\
\stackrel{\infty}{\epsilon} \\
\text { Oㅁ }\end{array}$ & $\begin{array}{l}\mathfrak{T} \\
\mathfrak{N} \\
\underline{0}\end{array}$ & 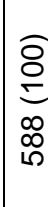 \\
\hline$\delta_{0}^{5}$ & $\begin{array}{l}\widehat{o} \\
\stackrel{0}{0} \\
\frac{0}{0} \\
\frac{0}{0} \\
\frac{0}{0}\end{array}$ & 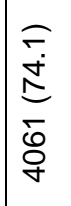 & $\begin{array}{l}\widehat{1} \\
\infty \\
0 \\
\hat{o} \\
y\end{array}$ & $\begin{array}{l}\widehat{\rho} \\
\infty \\
\hat{\infty} \\
\hat{b}\end{array}$ & $\begin{array}{l}\widehat{a} \\
\stackrel{d}{d} \\
\stackrel{\rho}{\circ}\end{array}$ & 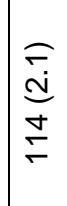 & $\mid \begin{array}{l}\tilde{r} \\
\tilde{\rho} \\
\tilde{N} \\
\tilde{N}\end{array}$ & $\begin{array}{l}\frac{1}{10} \\
\frac{0}{0} \\
\infty\end{array}$ & $\begin{array}{c}\widehat{T} \\
\mathfrak{e} \\
o\end{array}$ & $\begin{array}{l}\widehat{\Omega} \\
0 \\
0 \\
\text { m }\end{array}$ & 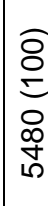 \\
\hline ळొ & 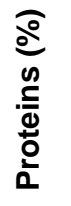 & \begin{tabular}{l}
$\widehat{\sigma}$ \\
$\dot{\theta}$ \\
\multirow{\theta}{*}{} \\
$\underline{\theta}$
\end{tabular} & 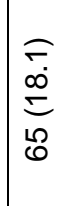 & 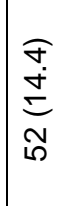 & $\begin{array}{l}\widehat{\rho} \\
\infty \\
\infty \\
\stackrel{\infty}{\infty}\end{array}$ & $\begin{array}{l}\widehat{\infty} \\
\text { ம் } \\
\text { o }\end{array}$ & $\begin{array}{l}\widehat{\sigma} \\
\dot{0} \\
\stackrel{D}{N}\end{array}$ & $\begin{array}{l}\widehat{\infty} \\
\stackrel{e}{m} \\
m\end{array}$ & $\begin{array}{l}\widehat{\alpha} \\
\dot{e} \\
m\end{array}$ & $\begin{array}{c}\widehat{\sigma} \\
\stackrel{e}{0} \\
-\end{array}$ & 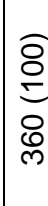 \\
\hline 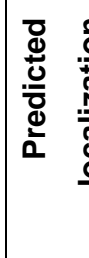 & 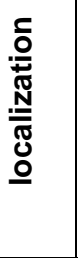 & 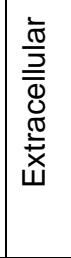 & $\begin{array}{l}\bar{\delta} \\
0 \\
0 \\
\text { ôd } \\
0\end{array}$ & $\sum_{0}$ & $\begin{array}{l}\frac{\text { 음 }}{\tilde{y}} \\
\frac{\widetilde{\sigma}}{\alpha} \\
\end{array}$ & 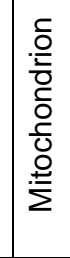 & $\begin{array}{l}\frac{0}{0} \\
0 \\
0 \\
\frac{0}{7}\end{array}$ & 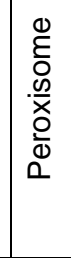 & 舀 & $\frac{\frac{\omega}{0}}{\frac{\omega}{0}}$ & $\mid \begin{array}{l}\bar{\sigma} \\
\stackrel{\sigma}{\circ}\end{array}$ \\
\hline
\end{tabular}




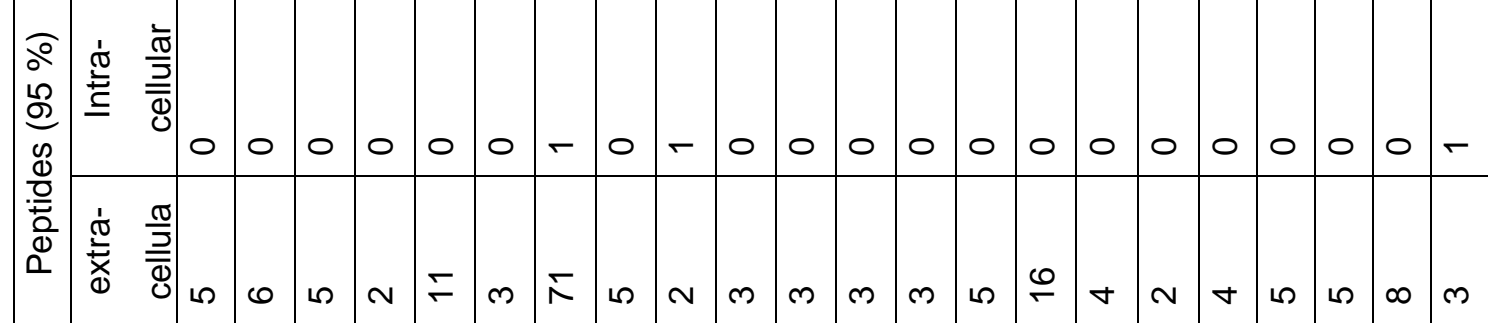

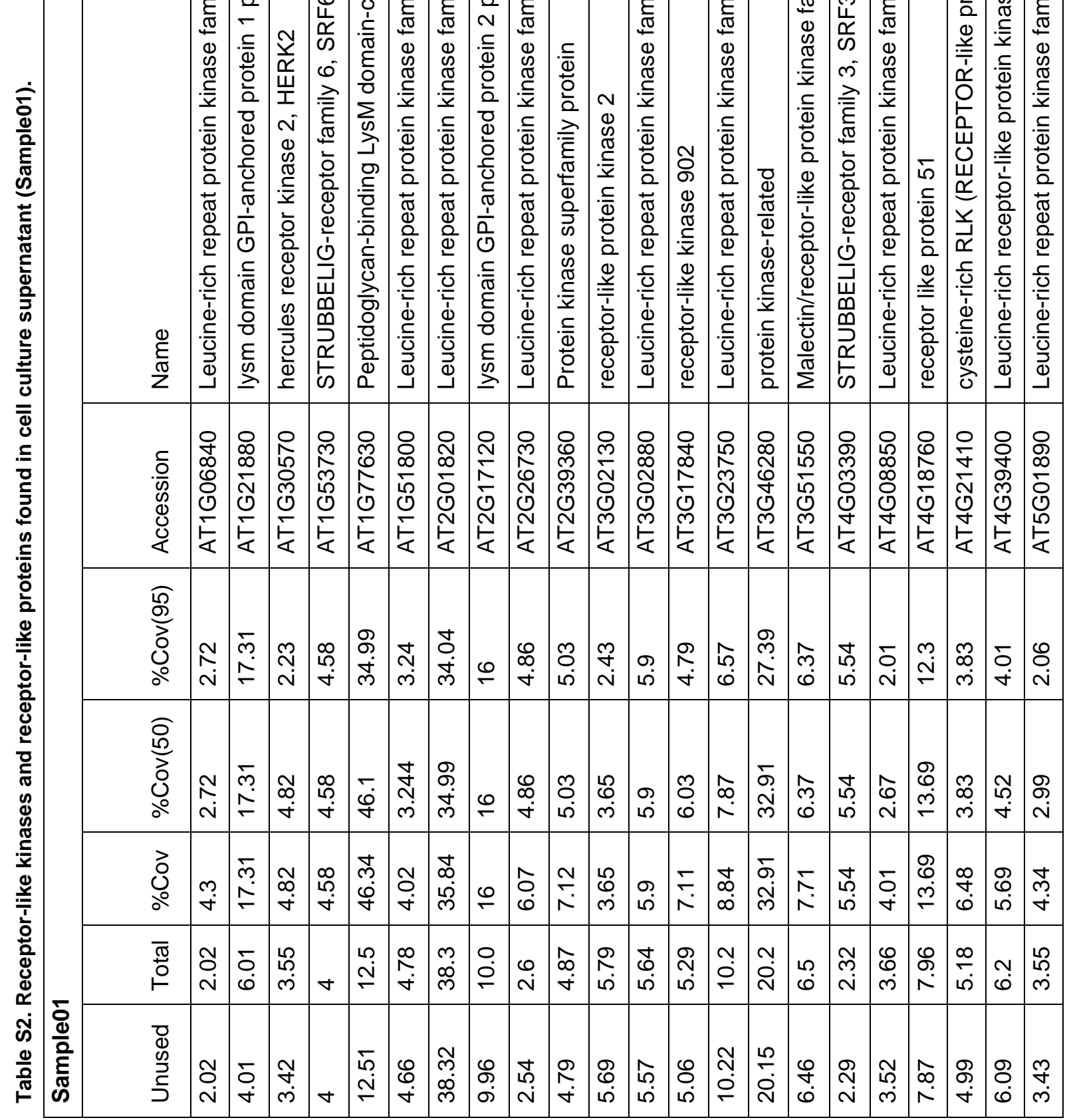




(2)

$\stackrel{8}{\infty}$

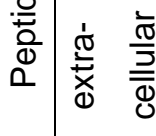

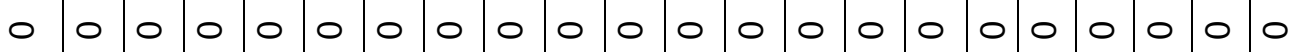

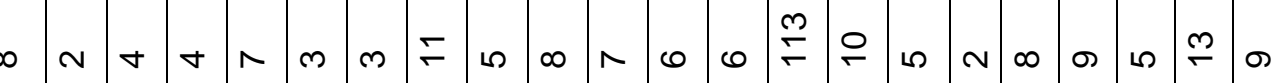

\begin{tabular}{|c|c|c|c|c|c|c|c|c|c|c|c|c|c|c|c|c|c|c|c|c|c|c|}
\hline \multicolumn{2}{|c|}{ 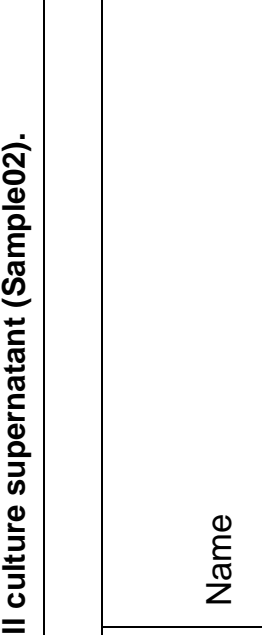 } & 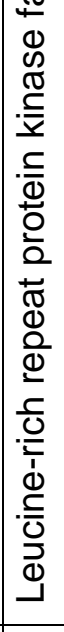 & 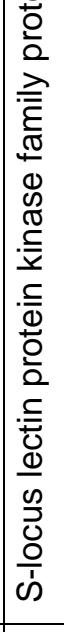 & 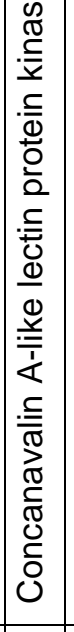 & 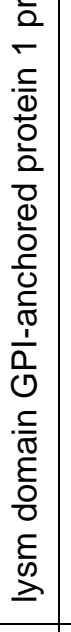 & 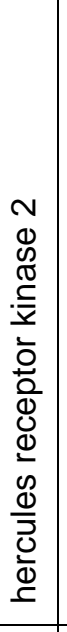 & 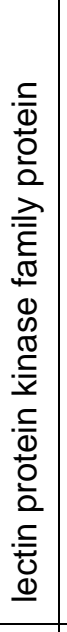 & 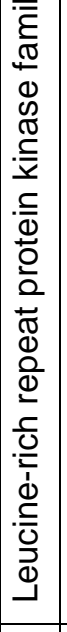 & 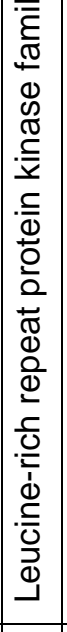 & 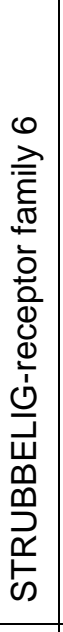 & 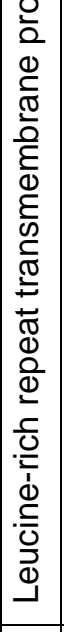 & 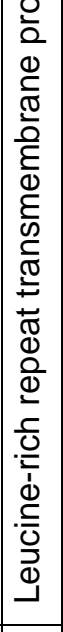 & 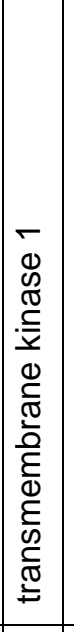 & 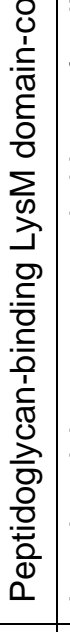 & 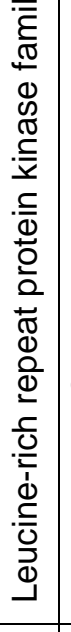 & 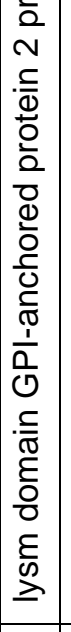 & 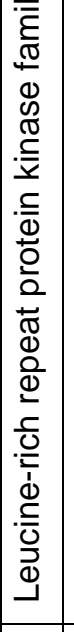 & 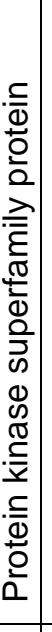 & 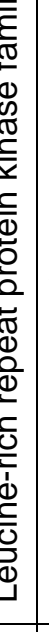 & 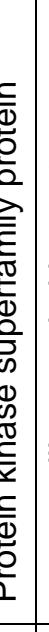 & 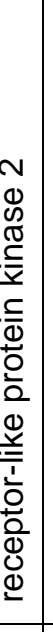 & 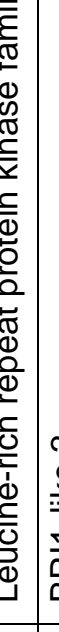 \\
\hline & 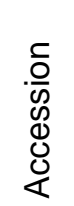 & 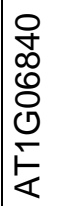 & 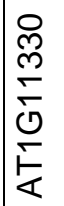 & 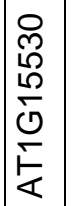 & 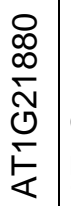 & 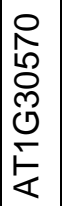 & 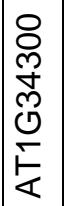 & 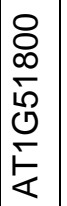 & 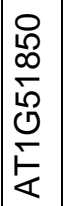 & 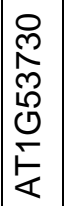 & 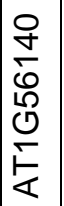 & 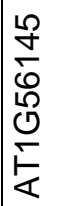 & 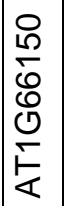 & 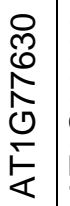 & 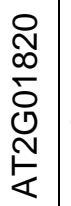 & 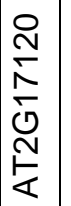 & 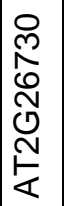 & 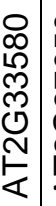 & 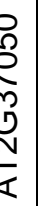 & 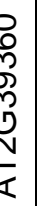 & & 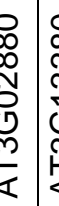 \\
\hline & 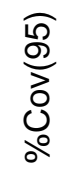 & $\frac{\infty}{\infty}$ & 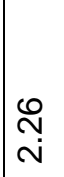 & $\ddot{\theta}$ & 苗 & $\begin{array}{l}0 \\
\infty \\
\infty\end{array}$ & \begin{tabular}{|l|}
$\stackrel{0}{O}$ \\
$\dot{\forall}$
\end{tabular} & f) & 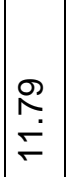 & \begin{tabular}{l}
$\mathcal{y}$ \\
\multirow{2}{\infty}{} \\
\end{tabular} & 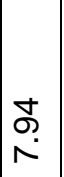 & $\begin{array}{l}0 \\
0 \\
\end{array}$ & $\mid \begin{array}{l}m \\
\dot{\sigma}\end{array}$ & 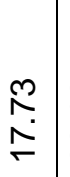 & $\begin{array}{l}\mathscr{M} \\
\mathscr{m}\end{array}$ & స & 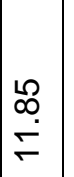 & $\begin{array}{l}\mathscr{S} \\
\stackrel{9}{-} \\
\end{array}$ & गे. & s. & & : \\
\hline & 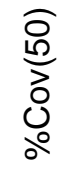 & $\begin{array}{l}\bar{\sigma} \\
\infty\end{array}$ & $\begin{array}{l}\bar{N} \\
\end{array}$ & $\begin{array}{l}\dot{\theta} \\
\dot{0}\end{array}$ & $\begin{array}{l}\tilde{N} \\
\stackrel{N}{\sim} \\
\stackrel{n}{-}\end{array}$ & \begin{tabular}{|l|}
0 \\
$\infty$ \\
$\infty$
\end{tabular} & 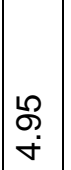 & $\begin{array}{l}\text { f } \\
\dot{m}\end{array}$ & $\frac{9}{\stackrel{R}{r}}$ & 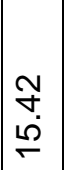 & $\mid \begin{array}{c}0 \\
\varnothing \\
\infty\end{array}$ & Oִ & $\begin{array}{l}\mathcal{O} \\
\stackrel{0}{\sim} \\
\end{array}$ & $\begin{array}{l}\text { ले } \\
\text { ळె } \\
\end{array}$ & $\begin{array}{l}\dot{J} \\
\dot{m} \\
\dot{m}\end{array}$ & N & 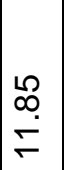 & 号 & న़े & 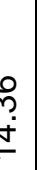 & مُ & 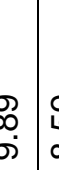 \\
\hline & $\begin{array}{l}\text { ठे } \\
\text { o. } \\
\text { o. }\end{array}$ & $\begin{array}{l}9 \\
0 \\
0\end{array}$ & ্ָণ & $\mid$\begin{tabular}{l|} 
\\
0 \\
0
\end{tabular} & $\begin{array}{l}\tilde{N} \\
\stackrel{N}{\sim} \\
\end{array}$ & $\begin{array}{l}0 \\
\infty\end{array}$ & $\mid \begin{array}{l}0 \\
0 \\
10\end{array}$ & 告 & $\underset{\Gamma}{\bar{\Gamma}}$ & 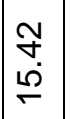 & $\begin{array}{c}\bar{T} \\
\infty \\
\infty\end{array}$ & 主 & 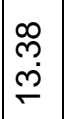 & $\begin{array}{l}\stackrel{\circ}{m} \\
\stackrel{\circ}{\circ}\end{array}$ & $\begin{array}{l}\infty \\
0 \\
\dot{\infty} \\
\text { ले }\end{array}$ & న & $\mid \begin{array}{l}\llcorner \\
\infty \\
\stackrel{+}{T} \\
\end{array}$ & $\begin{array}{l}\mathscr{Q} \\
\stackrel{\leftrightarrow}{-}\end{array}$ & to & 总 & ל. & ') \\
\hline & $\begin{array}{l}\bar{\pi} \\
\end{array}$ & $\stackrel{\nabla}{\check{\tau}}$ & $\nabla$ & $\mid \begin{array}{l}\left|\begin{array}{l}0 \\
0 \\
0\end{array}\right| \\
\end{array}$ & \begin{tabular}{|l|} 
\\
0 \\
$\mathscr{\sigma}$ \\
\end{tabular} & $\begin{array}{l}0 \\
0 \\
0\end{array}$ & $\left|\begin{array}{l}0 \\
0 \\
0\end{array}\right|$ & $\mid \begin{array}{l}\infty \\
\omega \\
\omega\end{array}$ & $\stackrel{\bar{m}}{\stackrel{m}{\sigma}}$ & $\mid \begin{array}{l}0 \\
\text { N. } \\
\end{array}$ & \begin{tabular}{|l|}
0 \\
$\stackrel{0}{+}$ \\
\end{tabular} & $\begin{array}{l}\infty \\
\stackrel{0}{\circ}\end{array}$ & $\stackrel{\infty}{\mp}$ & $\begin{array}{l}12 \\
\infty \\
\infty\end{array}$ & $\frac{9}{\square}$ & $\begin{array}{l}\stackrel{N}{\omega} \\
\stackrel{n}{\sim}\end{array}$ & 0 & $\sim$ & v & ¿. & $\begin{array}{l}y \\
y \\
\infty^{\circ}\end{array}$ & E. \\
\hline $\begin{array}{l}\overline{\text { 을 }} \\
\frac{5}{\sqrt{0}} \\
\text { ஸे }\end{array}$ & 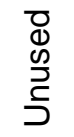 & \begin{tabular}{l}
\multirow{Y}{*}{} \\
$\stackrel{0}{\circ}$
\end{tabular} & $\forall$ & $\mid \begin{array}{c}\infty \\
\infty \\
0 \\
0\end{array}$ & $\begin{array}{l}J \\
\stackrel{\sim}{N}\end{array}$ & ô. & $\begin{array}{l}0 \\
0 \\
0\end{array}$ & $\hat{~}$ & ó & $\stackrel{N}{\stackrel{N}{N}}$ & 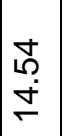 & $\begin{array}{l}\infty \\
0 \\
0 \\
\omega\end{array}$ & $\frac{m}{\square}$ & $\begin{array}{l}\infty \\
\stackrel{\infty}{\infty} \\
\end{array}$ & $\begin{array}{l}\text { D़ } \\
\text { हn }\end{array}$ & $\begin{array}{l}\stackrel{N}{\omega} \\
\stackrel{n}{-}\end{array}$ & 0 & & & & $\begin{array}{l}\stackrel{d}{a} \\
\infty \\
\infty\end{array}$ & דू \\
\hline
\end{tabular}




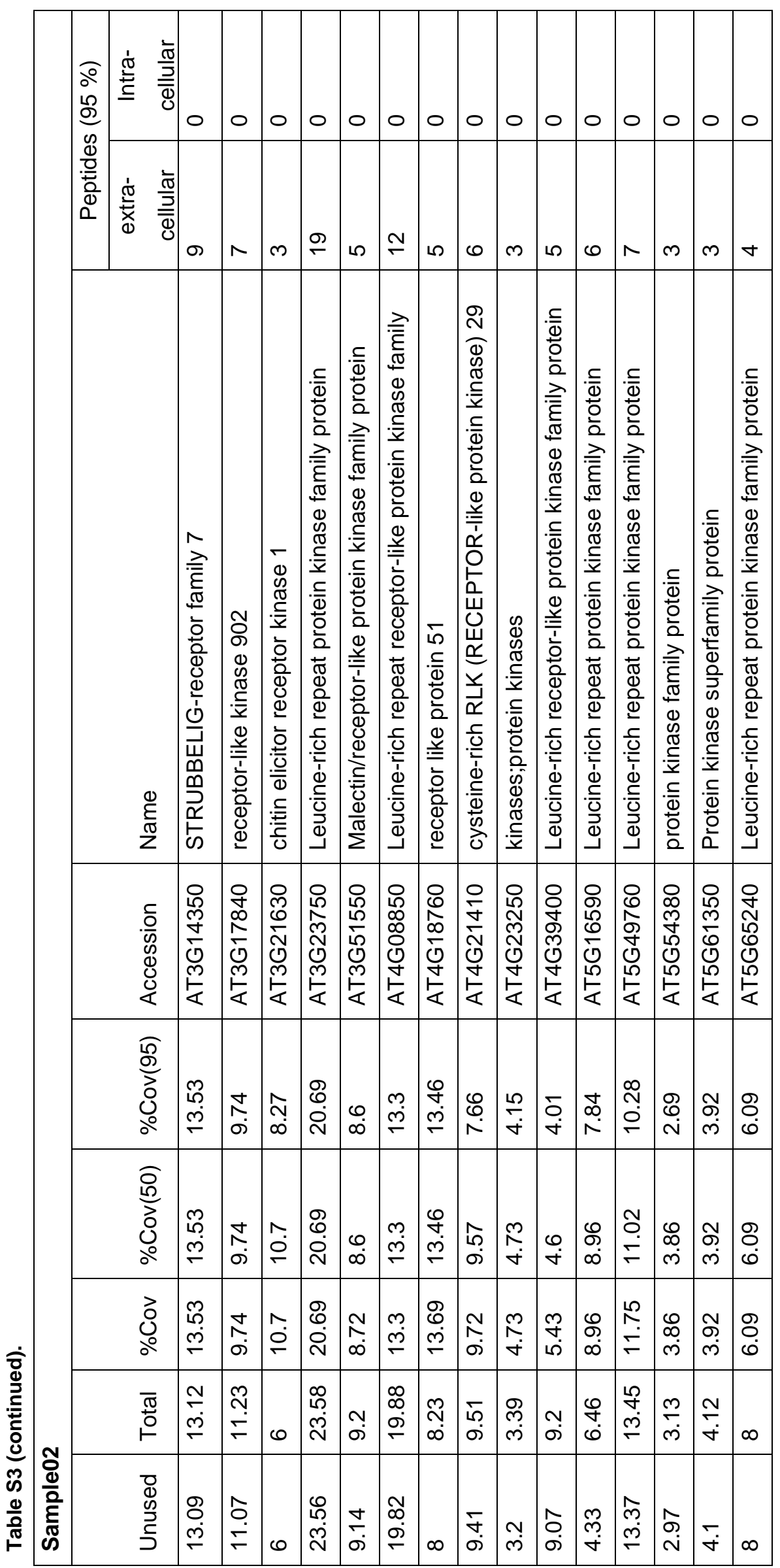




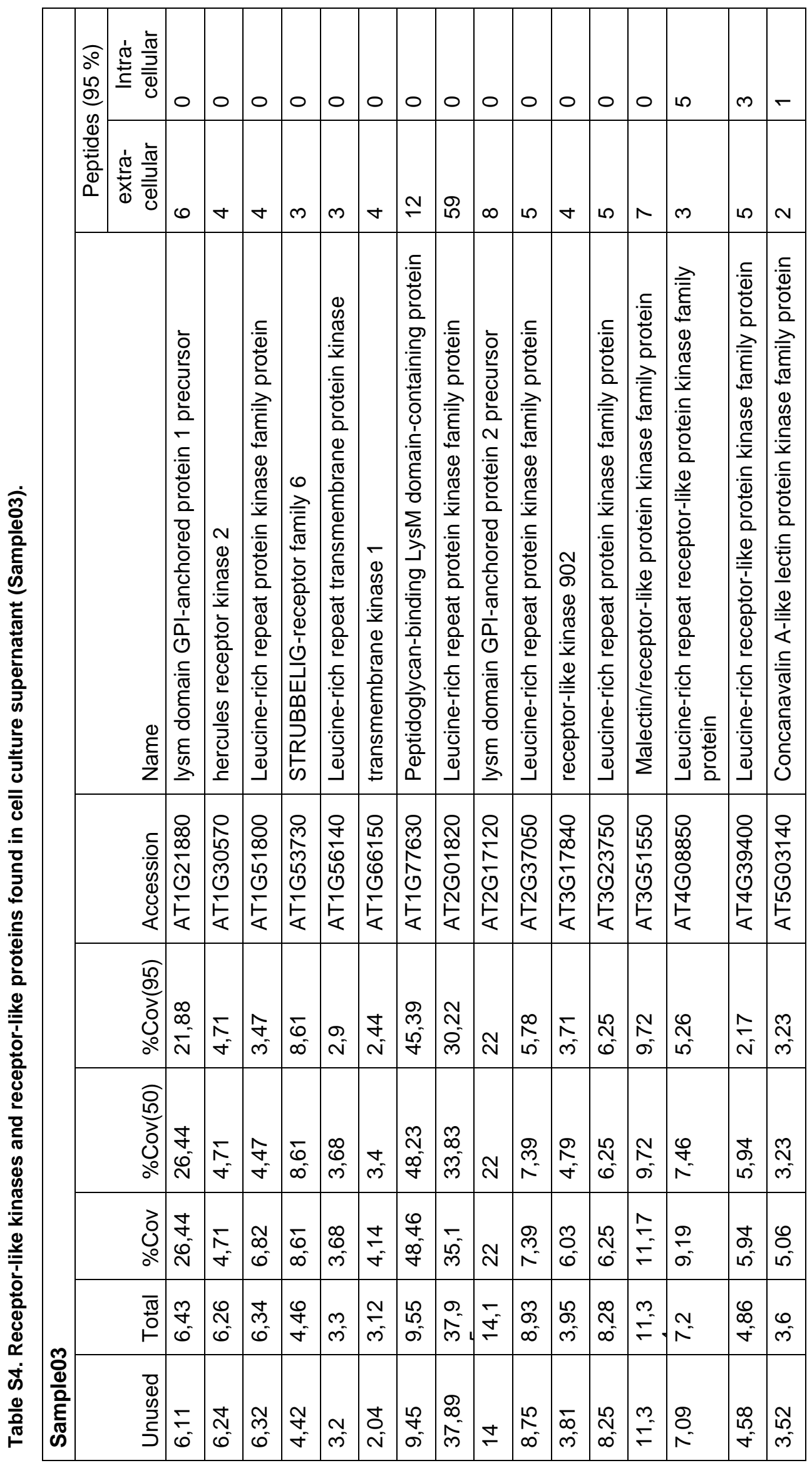







(Cys-rich RLK) - AT4G21410 - CRK29

(LRR - RLK) - AT1G53730 - SRF

(LRR - RLK) - AT2G01820 - TMK3

(LRR - RLK) - AT2G26730

(LRR - RLK) - AT3G02130 - RPK2, TOAD2, CLI

(LRR - RLK) - AT3G02880

(LRR - RLK) - AT3G17840 - RLK902

(LRR - RLK) - AT3G23750 - TMK4

(LRR - RLK) - AT4G08850

(LRR - RLK) - AT5G01890

(LRR - RLK) - AT1G06840

(LRR - RLK) - AT4G03390 - SRF3

(LRR- RLK) - AT4G39400 - BRI1

(LRR - RLP) - RLP51

(LysM - RLP) - AT1G21880 - LYM1

(LysM - RLP) - AT2G17120 - LYM2

(LySM - RLP) - AT1G77630 - LYM3

(Malectin - LRR - RLK) - AT1G51800 - IOS1

(Malectin - RLK) - AT1G30570 - HERK2

(Malectin - RLK) - AT2G39360

(Malectin - RLK) - AT3G51550 - FERONIA

AT3G46280

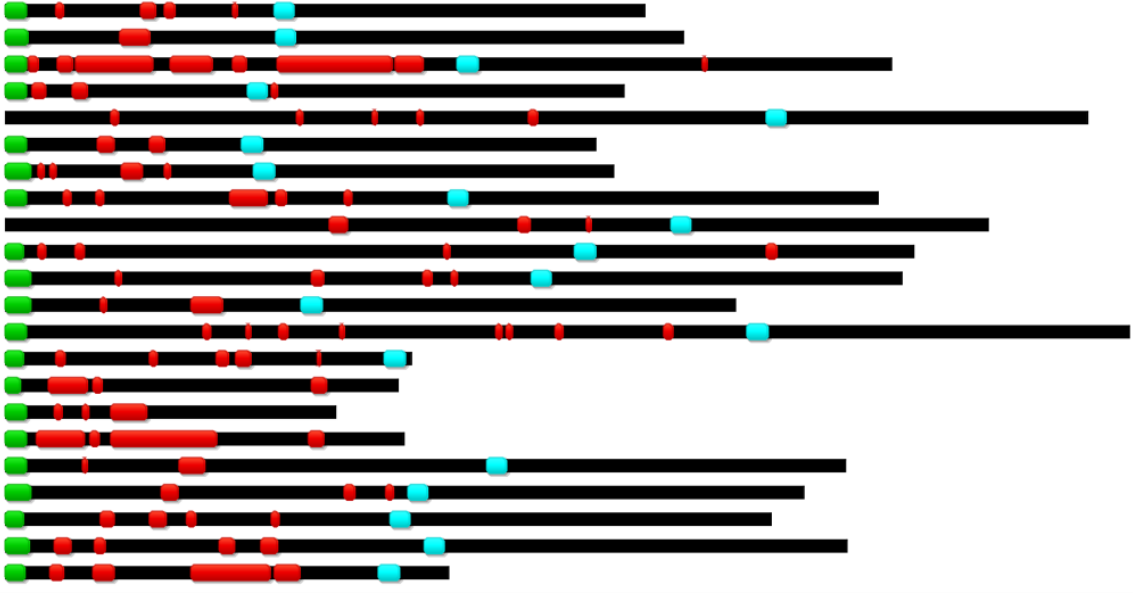

Figure S1. Receptor-like kinases and receptor-like proteins found in Col-0 cell culture supernatants of Sample01. Identified peptides were mapped to the amino acid sequence of the respective receptor-like kinase or receptor-like protein and peptide coverage is shown in red. Predicted signal peptides are given in green and transmembrane domain in light blue.

(LECTIN - RLK) - AT5G03140 - LECRK-VIII.2

(LRR - RLK) - AT1G53730 - SRF6

(LRR - RLK) - AT1G66150 - TMK

(LRR - RLK) - AT2G01820 - TMK3

(LRR - RLK) - AT3G23750 - TMK4

(LRR - RLK) - AT4G08850

(LRR - RLK) - AT4G39400

(LRR - RLK) - AT5G53890

(LRR- RLK) - AT3G17840-RLK902

(LysM - RLP) - AT1G21880 - LYM

(LySM-RLP)-AT2

(Malectin - LRR - RLK) - AT1G51800 - IOS

(Malectin - RLK) - AT1G30570 - HERK2

(Malectin - RLK) - AT1G56140

(Malectin - RLK) - AT2G37050

(Malectin - RLK) - At3G51550 - FERONIA

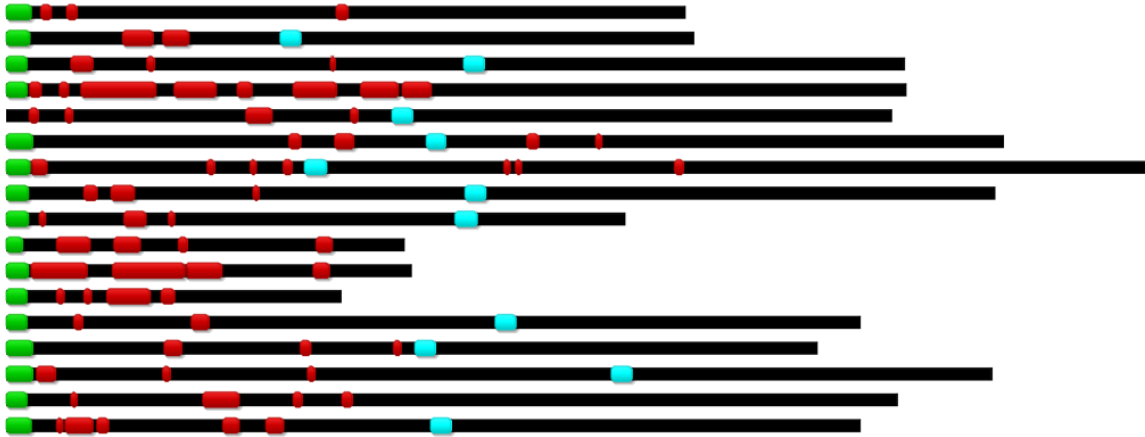

Figure S2. Receptor-like kinases and receptor-like proteins found in Col-0 cell culture supernatants of Sample03. Identified peptides were mapped to the amino acid sequence of the respective receptor-like kinase or receptor-like protein and peptide coverage is shown in red. Predicted signal peptides are given in green and transmembrane domain in light blue.

(LRR - RLK) - AT2G01820 - TMK3

(LRR - RLK) - AT4G08850

(LRR - RLK) - AT4G39400 - BRI1

(LYSM - RLP) - AT1G77630 - LYM3

(LYSM - RLP) - AT2G17120 - LYM2

(LYSM - RLP) - AT1G21880 - LYM

(Malectin - LRR - RLK) - AT1G51800 - IOS

(Malectin - RLK) - AT3G51550 - FERONIA

AT1G49730

AT3G19300

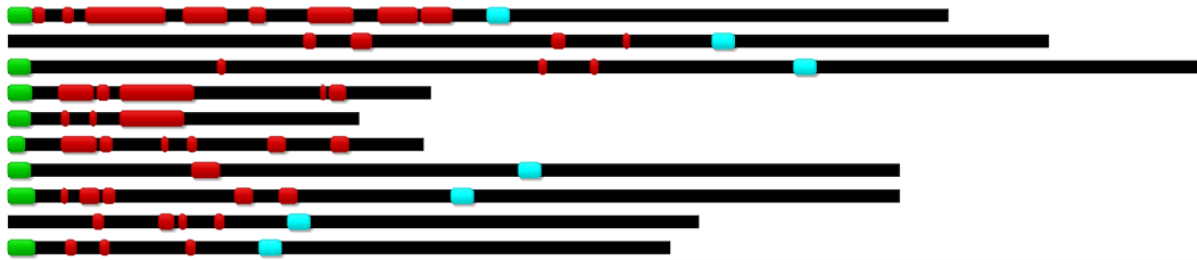

Figure S3. Receptor-like kinases and receptor-like proteins found in Col-0 cell culture supernatants of Sample04. Identified peptides were mapped to the amino acid sequence of the respective receptor-like kinase or receptor-like protein and peptide coverage is shown in red. Predicted signal peptides are given in green and transmembrane domain in light blue. 
Supplemental file 1: 01 . Sample01_localization.xlsx Localization prediction of proteins identified in Sample01.

Supplemental file 2: 02 . Sample02_localization.xlsx Localization prediction of proteins identified in Sample02.

Supplemental file 3: 03. Sample03_localization.xlsx Localization prediction of proteins identified in Sample03.

Supplemental file 4: 04. Sample04_localization.xlsx Localization prediction of proteins identified in Sample04.

Supplemental file 5: 05. Sample01_TAIR10_repGeneModel.group Raw data of Sample01.

Supplemental file 6: 06. Sample01_TAIR10_repGeneModel_FDR.xIsx Raw data of Sample01.

Supplemental file 7: 07. Sample02_TAIR10_repGeneModel.group Raw data of Sample02.

Supplemental file 8: 08. Sample02_TAIR10_repGeneModel_FDR.xlsx Raw data of Sample02.

Supplemental file 9: 09. Sample03_TAIR10_repGeneModel.group Raw data of Sample03.

Supplemental file 10: 10. Sample03_TAIR10_repGeneModel_FDR.xIsx Raw data of Sample03.

Supplemental file 11: 11. Sample04_TAIR10_repGeneModel.group Raw data of Sample04.

Supplemental file 12: 12. Sample04_TAIR10_repGeneModel_FDR.xIsx Raw data of Sample04. 


\section{List of tables}

Table 1. Arabidopsis accessions used in this study. .................................. 26

Table 2. Mutant Arabidopsis lines used in this study.................................... 27

Table 3. Transgenic Arabidopsis lines used in thisstudy. .............................. 28

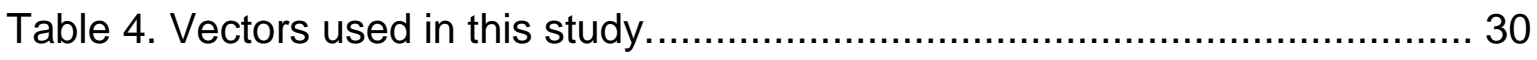

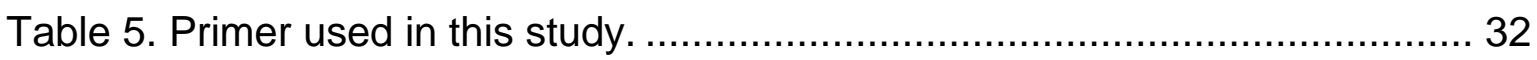

Table 6. Buffers used in this study. .................................................. 38

Table 7. Antibodies used in this study................................................... 42

Table 8. Settings for fluorophore detection.......................................... 57

Table 9. Predicted localization of proteins from cell culture supernatants........... 78

Table 10. Predicted localization of proteins from apoplastic wash fluids. ............. 82

Table 11. Summary of characteristics of noce mutants including results from sequencing of candidate suppressor genes.................................88

Table 12. RLKs identified in cell wall proteome studies................................. 118 


\section{List of figures}

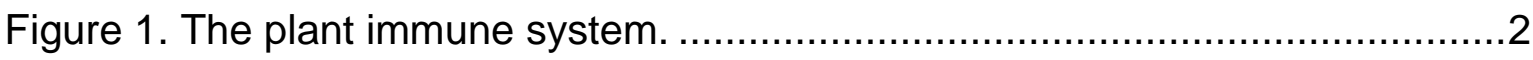

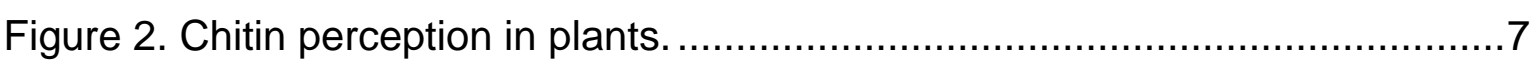

Figure 3. Cycle of heterotrimeric G-protein activation in animals and in

Arabidopsis.................................................................... 10

Figure 4. Ectodomain shedding and RIP of integral membrane proteins. ............17

Figure 5. Proteolytic processing of amyloid precursor protein. ..........................19

Figure 6. CERK1 ectodomain shedding is reduced in some Arabidopsis accessions

Figure 7. Wt-5 ectodomain shedding is also reduced in cerk1-2.

Figure 8. CERK1 cleavage motif mutants could not fully suppress CERK1 ectodomain shedding.

Figure 9. Deletion of potential intracellular cleavage motifs could not suppress CERK1 ectodomain shedding.

Figure 10. The cvg1 mutation cannot suppress the Bgh-induced cerk1-4 phenotype.

Figure 11. The cvg1 mutation cannot suppress the cerk1-4 senescence phenotype.

Figure 12. Deletion within the extracellular stalk did not suppress CERK1 ectodomain shedding.

Figure 13. Replacement of the CERK1 extracellular stalk and transmembrane domain could not suppress CERK1 ectodomain shedding.

Figure 14. CERK1 and FLS2 extracellular stalk share a lysine-serine motif. .76

Figure 15. The KS motif within the FLS2 and CERK1 extracellular stalk is most likely not a cleavage motif. .77

Figure 16. Receptor-like kinases found in Col-0 cell culture supernatants. 79

Figure 17. Detailed analysis of TMK1-3 and Malectin-LRR-RLKs.

Figure 18. Receptor like proteins found in Col-0 cell culture supernatant. .81

Figure 19. Only soluble ectodomain can be found in cell culture supernatants.....82

Figure 20. Receptor-like kinases found in apoplastic wash fluids of Col-3 g/1 leaves. .83

Figure 21. Receptor-like proteins found in Col-3 g/1 apoplastic wash fluids. .84 
Figure 22. Sphingolipid mutants show enhanced CERK1 ectodomain shedding. . 85

Figure 23. Different noce mutants fully suppress the cerk1-4 phenotype. .86

Figure 24. Supression of the cerk1-4 phenotype is genetically linked to the $x \lg 2$ E293K (noce4/6) mutation.

Figure 25. Expression of a genomic wild type XLG2 fragment can restore the cerk 1-4 phenotype in nole6-1 plants.

Figure 26. The glutamatic acid mutated in nole1-2, E293, is located within a highly conserved region of the N-terminal part of XLG2.

Figure 27. XLG2-GFP and xlg2 E293K-GFP are located to the nucleus and the cell periphery in $N$. benthamiana.

Figure 28. XLG2-GFP localization is stimulus dependent. .................................95

Figure 29. XLG2-GFP is not functional. .96

Figure 30. N-terminal XLG2 fusions are localized to the cell periphery and the nucleus.

Figure 31. Venus-XLG2 co-localizes with LYK5-mKate at the plasma membrane.

Figure 32. Venus-XLG2 is also found in cytoplasmic strands. 98

Figure 33. N-terminal XLG2 fusions are functional. .99

Figure 34. XLG2 is localized to the cell periphery in unchallenged plants and appears in nuclei after $\mathrm{H}_{2} \mathrm{O}$ infiltration in Col-0 plants.

Figure 35. XLG2 is localized to the cell periphery in unchallenged plants and appears in nuclei after chitin infiltration in Col-0 plants

Figure 36. XLG2 is localized to the cell periphery in unchallenged plants and appears in nuclei after flg22 infiltration in Col-0 plants.

Figure 37. XLG2 is localized to the cell periphery in unchallenged plants and appears in nuclei after wounding in Col-0 plants.

Figure 38. XLG2 is localized to the cell periphery in unchallenged plants and appears in nuclei after $\mathrm{H}_{2} \mathrm{O}$ infiltration in Col-3 g/1 plants 105

Figure 39. XLG2 is localized to the cell periphery in unchallenged plants and appears in nuclei after $\mathrm{H}_{2} \mathrm{O}$ infiltration in cerk 1-4 plants. 106

Figure 40. XLG2 is localized to the cell periphery and nucleus in unchallenged and challenged agb1-2 plants. 
Figure 41. Venus-XLG2 can be found in soluble protein fractions, but not in microsomes. 108

Figure 42. Venus-XLG2 accumulates in nuclei of Bgh-attacked and surrounding cells. 109 


\section{List of supplemental tables}

Table S1. Predicted localization of proteins from cell culture supernatants

Table S2. Receptor-like kinases and receptor-like proteins found in cell culture supernatant (Sample01) 150

Table S3. Receptor-like kinases and receptor-like proteins found in cell culture supernatant (Sample02)

Table S4. Receptor-like kinases and receptor-like proteins found in cell culture supernatant (Sample03)

Table S5. Receptor-like kinases and receptor-like proteins found in cell culture supernatant (Sample04) 


\section{List of supplemental figures}

Figure S1. Receptor-like kinases and receptor-like proteins found in Col-0 cell culture supernatants of Sample01 155

Figure S2. Receptor-like kinases and receptor-like proteins found in Col-0 cell culture supernatants of Sample03 155

Figure S3. Receptor-like kinases and receptor-like proteins found in Col-0 cell culture supernatants of Sample04 155 


\section{Danksagung}

Nach fast 4 Jahren gibt es doch einige Leute, bei denen ich mich für die Unterstützung bei der Fertigstellung dieser Arbeit bedanken möchte.

Bei Prof. Dr. Volker Lipka möchte ich für die Überlassung des Themas und die Möglichkeit diese Arbeit in seinem Labor anzufertigen, bedanken. Jede Phase dieser Arbeit wurde von inm intensiv und professionell begleitet. Die Freiheiten vor allem beim Thema des Ectodomain sheddings habe ich sehr genossen. Neben der professionellen Unterstützung waren es auch die Gespräche über Themen abseits vom Laborleben, die für eine posititve Grundstimmung innerhalb der Arbeitsgruppe gesorgt haben:

Großer Dank gebührt Dr. Elena Petutschnig möchte ich für die Betreuung während der Anfertigung dieser Arbeit bedanken. Ihre Hilfe im täglichen Laboralltag, ständige Dikussionsbereitschaft, auch bei teilweise abstrusen Ideen und die damit verbundene konstruktive Kritik haben maßgeblich zum Gelingen dieser Arbeit beigetragen. Danke vor allem auch für die zuletzt zahlreichen Stunden am Schreibtisch um diese Arbeit auf Herz und Nieren zu überprüfen.

Danke an PD. Dr. Thomas Teichmann für die Übernahme des Korreferats, sowie Hilfe bei kleinen und großen Problemen des Laboralltags.

Prof. Dr. Ivo Feußner, Dr. Martin Fulda, Prof. Dr. Gatz und Prof Dr. Andrea Polle bedanke ich mich für die Bereitschaft zusammen mit meinem Betreuungsausschuss meine Prüfungskommission zu bilden.

Vielen Dank an Dr. Andrzej Majcherczyk für die massenspektrometrischen Analysen und die Hilfe bei der Interpretation und Auswertung der daraus resultierenden Daten.

Bei Kathi, Ludmilla und Sabine möchte ich mich für die Hilfe im Labor bedanken. DNA und vor allem RNA waren manchmal einfach nicht meine Freunde. Danke auch für die Herstellung von Puffern, das Aufräumen von Laborbänken und nicht zu vergessen die Übernahme des Spüldienstes, wenn der mal wieder vergessen wurde.

Den Gärtnern Feli, Susanne und Herrn Wedemeyer danke ich für das Stopfen von Töpfen 
und Siebearbeiten, die das Laborleben um einiges vereinfacht haben. Feli danke ich darüber hinaus für die zahlreichen Äpfel vom heimischen Apfelbaum.

Danke an alle aktuellen und ehemaligen Mitglieder der Arbeitsgruppe, für Grillaktionen, Geburtstagskuchen und vieles mehr. Großen Dank an Hassen, der einem jeder Zeit mit Rat und Tat bei Mikroskopieproblemen zur Seite stand. Marcel, danke für die Verwaltung der Kaffeekasse und das regelmäßige Auffüllen des Kaffeevorrats. Auch bei Anja möchte ich mich für die Überwindung so einiger bürokratischer Hürden bedanken.

Danke auch an alle aktuellen und ehemaligen „Mitstreiter“ Marnie, Charlotte, Yvonne, Karin, Jan, Merlin, Johanna, Dimitri und Sabine. Ohne Martin und Zubi wäre der Freitag niemals eine so gute Einleitung des Wochenendes gewesen. Danke.

Bei Sebastian möchte ich mich für die Übernahme des Korreferats eines Sky-Abos bedanken. Das waren 2 gute Jahre, leider gingen sie viel zu schnell vorbei. Bei Matthias möchte ich mich darüber hinaus für das von ihm geschriebene Programm zur Auswertung der Massenspektrometrie Daten bedanken. Ohne dies wäre die Fertigstellung dieser Arbeit im Jahr 2016 nicht möglich gewesen.

Bei den Jungs in und um Osnabrück möchte ich mich für die Urlaube, zahlreichen Feiern und die Verfügbarkeit von Sofas zum Übernachten bedanken.

Ein großer Dank geht natürlich auch an meine Familie. Ohne die großartige Unterstützung der letzten Jahre wäre diese Arbeit niemals zustande gekommen. 


\section{Curriculum vitae}

\section{Personal information}

Name: Christopher Meusel

Adress: $\quad$ Planckstr. 10, 37073 Göttingen

Date of birth: $\quad 05.12 .1985$

Place of birth: Ankum

\section{Education}

05/2012 - present

Georg-August-University of Göttingen

Schwann-Schleiden Centre, Plant Cell Biology

$\mathrm{PhD}$

Title of PhD thesis: Analysis of CERK1 ectodomain shedding and the role of extra-large g-protein 2 (XLG2) in cerk1-4 cell death execution

10/2009-03/2012 Philipps-University of Marburg

Course of study: Molecular and Cellular Biology

Degree: Master of Science (grade: 1.5)

10/2006 - 09/2009 Leibniz-University of Hanover

Course of study: Biology

Degree: Bachelor of Science (grade: 2.3)

08/1996 - 07/2005 Integrierte Gesamtschule Fürstenau

Qualification for university entrance: A levels/

Abitur (grade: 1.7)

\section{Research experience}

$09 / 2010-01 / 2011$

Department of Biochemistry and Molecular Biology

Universidad de Valencia (UV), Spain

Internship in the group of Dr. Ismael Mingarro

\section{Additional skills}

Languages:

German (native language)

Englisch (fluent)

IT skills:

MS-Office: Word, Excel, PowerPoint

Photoshop, Illustrator

Geneious, Clone manager 
Conferences

07/2014

XVI International Congress on Molecular Plant

Microbe Interactions, Rhodos (Greece)

Poster: Ectodomain shedding - A general post-

translational modification of plant PRRs?

03/2013

Gemeinsame Jahrestagung der DPG-Arbeitkreise

Mykologie und Wirt-Parasit-Beziehungen, Göttingen

(Germany)

Talk: Analysis of CERK1 ectodomain shedding 